\title{
IMMUNOLOGY, IMAGING AND TREATMENT OF ADVANCED PENILE CARCINOMA
}

SARAH ROSANNE OTTENHOF

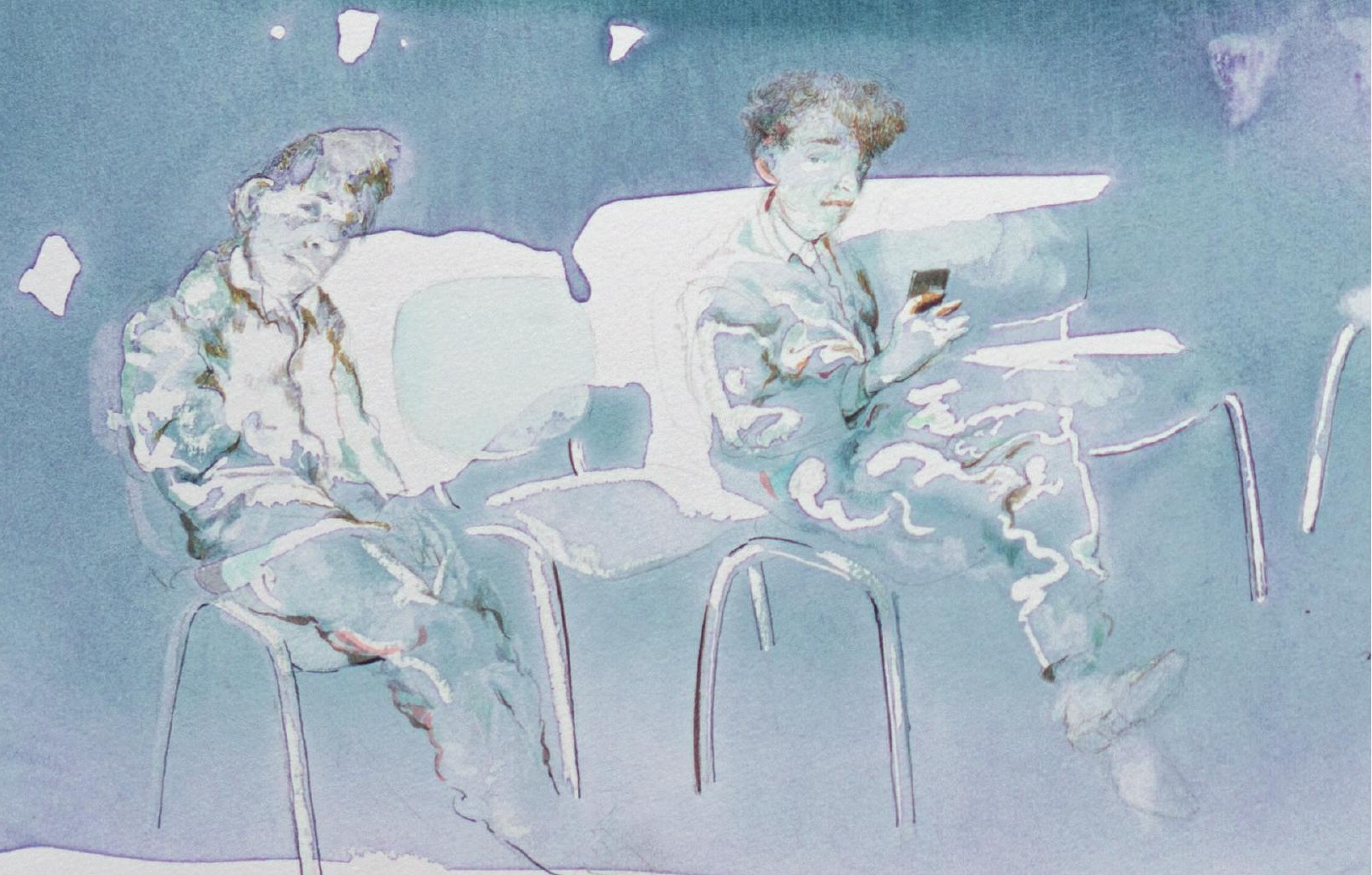


IMMUNOLOGY, IMAGING AND TREATMENT OF ADVANCED PENILE CARCINOMA

Sarah Rosanne Ottenhof 
Colofon

Cover art

Cover photography

Lay out and printing

ISBN

Online
John ten Berge | www.wieisjohn.com | instagram: @wieisjohn Bosse Kemper | www.happykemper.com

Proefschrift-AIO.nl

978-94-93184-96-1

www.NARCIS.nl | doi.org/10.33540/755

The work described in this thesis was performed at the Netherlands Cancer Institute, Amsterdam, the Netherlands

The research was funded by Stichting Lucendi Foundation

Printing of this thesis was funded by the Netherlands Cancer Institute. 


\title{
IMMUNOLOGY, IMAGING AND TREATMENT OF ADVANCED PENILE CARCINOMA
}

\author{
Immunologie, beeldvorming en behandeling van gevorderd \\ peniscarcinoom \\ (met een samenvatting in het Nederlands)
}

\author{
Proefschrift \\ ter verkrijging van de graad van doctor aan de \\ Universiteit Utrecht \\ op gezag van de \\ rector magnificus, prof.dr. H.R.B.M. Kummeling, \\ ingevolge het besluit van het college voor promoties \\ in het openbaar te verdedigen op \\ donderdag 8 juli 2021 des ochtends te 10.15 uur \\ door
}

\section{Sarah Rosanne Ottenhof}

geboren op 8 juli 1988

te Wageningen 
Promotor:

Prof. dr. S. Horenblas

Copromotor:

Dr. E.S. Jordanova 


\section{INDEX}

Ik zie, ik zie.. - Vincent van der Noort

Chapter 1 General introduction

Chapter 2 Expression of Programmed Death Ligand 1 (PD-L1) in penile cancer is of prognostic value and associated with HPV status

Chapter 3 The prognostic value of immune factors in the tumor microenvironment of penile squamous cell carcinoma

Chapter $4 \quad$ Advancement in staging and imaging for penile 75 carcinoma

Chapter 5 The role of PET/CT imaging in penile cancer staging

Chapter 6 F-18 fluorodeoxyglucose positron emission tomography with computed tomography has high diagnostic value for pelvic and distant staging in patients with high-risk penile carcinoma

Chapter 7 Surgical and oncological outcomes in patients after vascularised flap reconstruction for locoregionally advanced penile cancer

Chapter $8 \quad$ Chemoradiotherapy as primary treatment of locoregionally advanced penile cancer

Chapter 9 General Discussion

Chapter 10 Summary \& concluding remarks

Chapter 11 Appendices

List of abbreviations

Review committee

List of coauthors

List of publications \& presentations

About the author

Dankwoord 


\section{IK ZIE, IK ZIE..}

\section{Column gepubliceerd in: Wetenschap in Beeld, 2016 www.wibnet.nl}

Vincent van der Noort - Wiskundige en kankeronderzoeker

Elke dinsdagmiddag komt een vlotte jonge vrouw mijn kamer binnen om met mijn collega te overleggen over het afhakken, invriezen en in plakjes snijden van menselijke penissen. De vraag is welke (daardoor verkregen) informatie voorspellend is voor de overleving van peniskankerpatiënten. Ik werp wel eens een steelse blik op de staafdiagrammen op het computerscherm van mijn collega. Onder de factoren die op een langere overleving wijzen steekt er één met kop en schouders bovenuit: de aanwezigheid van HPV (Humaan Papillomavirus).

Betekent dit dat we massaal de condooms aan de wilgen moeten hangen en het veelbesproken vaccinatieprogramma voor meisjes moeten opschorten? Natuurlijk niet. Dit ogenschijnlijk gunstige effect van HPV is niet de verdienste van het virus. In een (figuurlijke) doorsnee van alle Nederlandse mannen leven mannen met HPV gemiddeld juist korter. Maar de mannen in het onderzoek hebben allemaal kanker, anders waren ze nooit in onze database terecht gekomen. Bij velen is HPV de oorzaak van de ziekte, maar de mannen die zonder HPV toch kanker hebben, hebben vaak een veel agressievere variant. Achteraf logisch, maar toch is er altijd die ene seconde waarin je denkt een Wereldschokkende Ontdekking te hebben gedaan.

Dit is een voorbeeld van selectiebias, een altijd op de loer liggende denkfout. In mijn geval duurde de verwarring niet lang, maar dat is niet altijd het geval.

In de Eerste Wereldoorlog werden van het front teruggekeerde vliegtuigen met staalplaten versterkt op de plekken waar kogelgaten zaten. Pas vele dode piloten later opperde iemand dat juist de plekken waar ze niet geraakt waren versterkt moesten worden. Dáár zaten waarschijnlijk de kogels in de vliegtuigen die niet terugkeerden.

Waarom is deze denkfout toch zo hardnekkig? Omdat je jezelf er steeds aan moet herinneren dat de groepen die je niet ziet (mannen zonder peniscarcinoom, neergeschoten vliegtuigen) echt bestaan. Dat klinkt makkelijk. Maar denk aan het spelletje 'ik zie, ik zie wat jij niet ziet' en de ander begint als een gek dingen op te noemen die hij wel ziet. Mensen zijn onverbeterlijk. 



$$
1
$$


Chapter 1

Introduction and Outline 


\section{INTRODUCTION AND OUTLINE}

In part adapted from Textbook of Penile Cancer ${ }^{1}$, chapters Epidemiology of penile cancer, Etiology of penile cancer, Management of Lymph Nodes, and Follow-Up of Patients with Penile Cancer.

Penile cancer is a rare malignancy and a potentially mutilating disease for men. The majority of tumours are squamous cell carcinomas (SCC) arising from the glans or inner prepuce. ${ }^{2}$ It may appear as a wound-like lesion that does not heal, but in case of a narrow foreskin can be obscured. The patient may notice thickening of the skin or a foul-smelling discharge.

Roughly, for penile cancers two distinct pathogenic pathways are identified. ${ }^{3,4}$ The first is related to high risk human papilloma virus (hrHPV) infection, the second is related to chronic irritation and inflammation, for example due to lichen sclerosus (LS) and phimosis.

Penile cancer usually shows a typically step-wise lymphogenic spread prior to hematogenic dissemination. The primary draining lymph nodes are almost invariably located within the inguinal region. Thereafter, dissemination usually continues to the pelvic nodes and/or distant sites. At initial presentation, distant metastases are present in only 1-2\% of the patients and are virtually always associated with clinically evident lymph node metastases.

Most patients present with no metastases and have a good prognosis. But presence of lymph node metastases is the single most important prognostic factor, as with stepwise spread of metastatic disease into lymph nodes and then the distant organs, the long term prognosis is considerably reduced. ${ }^{5-7}$ The cornerstone of treatment is surgery, but for extensive lymph node metastases multimodality treatment is indicated, and for palliation mostly non-surgical options are used.

\section{Epidemiology}

In Western Europe and the United States the age adjusted incidence of penile cancer is 0.7-2.1 per 100,000, accounting for approximately $0.2 \%$ of all male malignancies in Western countries. ${ }^{8-10}$ Penile cancer incidence varies widely and can account for over $10 \%$ of malignant disease in men in certain regions across the world, with the highest incidence reported in Romania and Brazil (>6/100.000) and the lowest in Israel (0.1/100.000). ${ }^{11-13}$ 
The substantial worldwide variation in penile cancer incidences is most likely due to the differences in socio-economic conditions and cultural practices such as circumcision. Penile cancer is rarely seen in populations who routinely practice circumcision during the neonatal or childhood period. ${ }^{14-17}$

\section{Aetiology and risk factors}

About 25-50\% of penile cancers are linked to oncogenic (high risk) types of the human papilloma virus (hrHPV) which appears to be a favourable prognostic factor. $4,18,19$

Furthermore, genital lichen sclerosus (LS) in men is a chronic inflammatory condition which can result in the development of a phimosis. LS is associated with up to $30 \%$ of penile carcinomas. Other factors associated with an increased risk of penile carcinoma are tobacco use, non-circumcision and HIV infection.

\section{HPV}

In systematic reviews, 40-51\% of penile cancers are hrHPV-associated, with HPV-16 being the predominant viral subtype. ${ }^{17,20,21}$ The majority of cancers is squamous cell carcinoma (SCC) of the usual histological subtype. Similar to vulvar and head and neck carcinomas, SCC of the basaloid and warty subtype display the strongest association with hrHPV (ranging from 66 to 100\%) and their etiological relationship with hrHPV infection is most plausible. ${ }^{22,23}$

HPV can be transmitted via sexual contact, but also non-sexually. ${ }^{24}$ A persistent infection with hrHPV can be the start of malignant transformation, although in uterine cervical infections only $<5 \%$ of persistent infections lead to a malignancy. Overexpression of the viral oncogenes E6 and E7 leads to deregulation of cell cycle controlling pathways, as E6 and E7 bind to and inactivate p53 and Rb. This leads to more genomic instability, more (epi)genetic changes and ultimately, to malignant transformation. ${ }^{25}$

\section{Lichen Sclerosus}

HPV-negative tumours are thought to arise from a background of chronic inflammation and/or irritation, such as Lichen Sclerosus (LS). The exact etiopathology of LS is unknown, but genetic factors, autoimmune mechanisms and irritative (urine) or infective influences have been postulated as being causal. ${ }^{26}$ LS is characterized by chronic inflammation and atrophy and clinical evaluation shows areas of pale atrophic and sclerotic plaques (patches). Its course is progressive and plaques may fuse and become sclerotic, sometimes 


\section{Chapter 1}

resulting in meatal stenosis, circumcoronal adhesions and significant phimosis. ${ }^{27}$ Observational studies show that LS is frequently present in peritumoral tissue thus establishing a rationale that LS plays a role in the development of penile carcinoma. Scarce evidence suggest a transformation rate of $2-10 \%$. $^{28-30}$

A complicating factor in describing a (potential) relationship is the lack of evidence showing histologically proven LS incidence numbers in the healthy population. Moreover, the eventual development of phimosis might partially explain the relationship between LS and penile cancer. Interestingly Bunker et al. described no cases of malignant transformation in 329 male genital LS patients, suggesting that an adequate recognition and treatment averts development of invasive carcinoma. ${ }^{31}$

An Austrian study found histopathological evidence for LS in $74 \%$ of tissue samples and Lichen Planus (LP) in 26\% of HPV-, together with a dense T-cell dominant lymphocytic infiltrate in almost 50\%. LP, likewise, is an inflammatory condition with an unknown aetiology. The authors suggest an enhanced tolerance in the tumour micro-environment (TME) by T-cells that mediate both chronic inflammatory diseases. ${ }^{32}$

\section{Non-circumcision}

Non-circumcision is the most important risk factor for penile cancer. The positive effect of circumcision is explained in view of both pathways. First, by preventing conditions such as poor penile hygiene, smegma retention, and phimosis, which have been reported as risk factors for penile cancer. ${ }^{14,17,33}$ Phimosis invariably leads to retention of the normally desquamated epidermal cells and urinary products (smegma) resulting in the development of an environment where chronic irritation and bacterial infection cause inflammation of the prepuce and the glans. When performing statistical analyses after exclusion of phimosis as a risk factor, the presence of a foreskin did not increase the risk of penile cancer. ${ }^{33,34}$ Although carcinogenesis has been attributed to chronic inflammation due to the irritating effects of smegma, to date no carcinogenic agent has been identified and isolated within smegma itself nor has the carcinogenic effect of smegma been proven. ${ }^{35-37}$

Secondly, circumcision is believed to reduce the risk of HPV-infection by removal of the inner prepuce which acts as a receptive site of infection by the human papilloma virus. ${ }^{38}$ The practice of circumcision as a preventive measure still remains controversial with its benefits, complication risks and ethical aspects. ${ }^{39,40}$ 


\section{Tobacco use}

Smoking shows a dose-dependent association with penile cancer. The use of tobacco in any form is a risk factor for penile cancer and has been described in several studies. ${ }^{14,33,41}$ Maden et al. found an increased risk of penile cancer in current cigarette smokers which was further related to the number of pack-years. The risk of penile cancer among men who smoked at diagnosis was 2.8 times that of men who never smoked. ${ }^{14}$ Similarly chewing tobacco is a significant risk factor for penile cancer and a combination of cigarette smoking and chewing tobacco carries an even higher risk. ${ }^{42}$

Although the association has been repeatedly observed, the exact role that smoking plays in the development of this disease is still not known. Tobacco may act either through one of its metabolites or may act directly after systemic absorption which can alter the patient's immune response. ${ }^{42}$

\section{Socioeconomic status}

Among other malignancies, penile cancer showed a significant association with area poverty in a large population based study in the United States. ${ }^{43}$ Scandinavian studies found associations between higher stages of penile cancer and low educational level or low disposable income, and between living in poor socioeconomic circumstances and poor prognosis. The same accounts for unmarried or single-living men. ${ }^{44,45}$

\section{Other risk factors}

The risk of penile cancer in men with a history of genital warts due to low-risk HPV infection, has been reported as 8.2 times that of men who have no history of warts. ${ }^{46}$ Similarly there is an eightfold increased risk of penile cancer in patients with HIV. ${ }^{47}$ The increased risk of penile cancer amongst men infected with HIV may be related to the higher incidence of HPV among men with HIV and a lower ability to clear HPV. ${ }^{47,48}$ Poblet et al., have suggested that HIV-1 could synergize with HPV, resulting in progression of premalignant penile lesions into invasive cancer. ${ }^{49}$ Circumcision reduces the risk of HIV transmission by reduction of the susceptible area and allowing a period of eukeratinisation. ${ }^{50}$

Like phimosis, poor hygiene is thought to contribute to chronic irritation, smegma retention and carcinogenesis. Factors leading to poor hygiene such as selfneglect, obesity and a buried penis are also possible risk factors. ${ }^{51,52}$ 
Patients with psoriasis undergoing treatment with psoralen-UV-A photochemotherapy are also at an increased risk of penile cancer. ${ }^{53,54}$ Maden et al., found that a history of small tears or small abrasions to the penis was associated with a risk of 3.9 relative to men without such a history. ${ }^{14}$

\section{Immune surveillance}

Our immune system protects us from infection with bacteria and viruses, but also from cancer cells. This system, where mutated or infected cells are recognized and killed, is called immune surveillance. Cancer patients suffer from tumours that have escaped these surveillance mechanisms.

Malignant cells use a plethora of mechanisms to escape the immune system. These mechanisms include: expression of co-inhibitory factors, expression of nonclassical human leukocyte antigens (HLA), downregulated expression of classical HLA, release of cytokines that inhibit T-cell response directly or indirectly, and many others.

Normally, all nucleated cells express peptides (antigens) presented on their cell surface by the HLA complex. In this way, T-cells can recognise the body cells as "self/normal" or "foreign/abnormal" and in case of the latter, generate a T-cell response. Recognition is avoided by downregulation of classical HLA, or expression of non-classical HLA. ${ }^{55,56}$

Checkpoint molecules can provide an inhibitory signal to the T-cell when these ligands bind to the complementary T-cell receptor. Well known examples of co-inhibitory checkpoint molecules are PD-L1, its binding PD-1 and CTLA-4, immunotherapy has been approved blocking these molecules. ${ }^{57}$

Myeloid cells (including macrophages and dendritic cells) are a heterogeneous cell population with an at least equally heterogeneous spectrum of functions in the tumour microenvironment. Populations of myeloid cells have been associated with promoting tumour growth, tumour spread, angiogenesis, therapy resistance and immune inhibition. At the same time, myeloid cells can aid tumour rejection. A lot of these immune escape mechanisms are yet poorly understood. ${ }^{58,59}$

\section{Staging and imaging}

The presence of nodal involvement is the single most important prognostic factor in penile cancer. ${ }^{5,7,60-65}$ As the currently available non-invasive staging modalities have a low sensitivity in detecting the regional lymph node status (i.e. missing micrometastatic disease), the optimal management of clinically node-negative 
(cNO) patients has been the subject of debate. Approximately 10-20\% of these cNO patients have occult metastasis. Therefore, invasive staging methods (dynamic sentinel node biopsy, modified lymphadenectomy or radical inguinal lymphadenectomy) can be used in those patients considered to be at risk for occult metastases, so called "risk-adapted approach". 66 While close surveillance may lead to unintentional delay because of outgrowth of occult metastases, elective as well as risk-adapted inguinal lymphadenectomy is considered unnecessary in 80-90\% of such cases, because of the absence of metastases. ${ }^{67,68}$ Furthermore, Iymphadenectomy is associated with a high morbidity rate. Up to $35-70 \%$ of patients have short- or long-term complications. ${ }^{69-72}$

The different staging and imaging modalities for penile cancer will be further described in chapter $\mathbf{4}$ and $\mathbf{5}$ of this thesis.

\section{Tumor Node Metastasis (TNM)}

In 2017, the Union for International Cancer Control (UICC) TNM staging system was updated. The presence of two inguinal nodes was considered $\mathrm{pN} 1$ in the $8^{\text {th }}$ edition, where it was pN2 in the $7^{\text {th }}$, pN3 remained unchanged as well as clinical staging (Table 1). ${ }^{73}$ In this thesis, the $7^{\text {th }}$ edition is used in most chapters, as the included patients were staged before 2017 . In chapter 8 , the $8^{\text {th }}$ edition is used, and patients that were included during the first years, were re-staged according to the last edition.

Table 1: TNM Clinical classification and staging

\section{T - Primary Tumour}

\begin{tabular}{|c|c|c|}
\hline & 7th edition 2009 & Changes is the 8th edition, 2017 \\
\hline TX & Primary tumour cannot be assessed & \\
\hline TO & No evidence of primary tumour & \\
\hline Tis & Carcinoma in situ & \\
\hline Ta & Non-invasive verrucous carcinoma & \\
\hline T1 & Tumour invades subepithelial connective tissue & \\
\hline T1a & $\begin{array}{l}\text { Tumour invades subepithelial connective tissue } \\
\text { without lymphovascular invasion and is not } \\
\text { poorly differentiated }\end{array}$ & \\
\hline T1b & $\begin{array}{l}\text { Tumour invades subepithelial connective tissue } \\
\text { with lymphovascular invasion or is poorly } \\
\text { differentiated }\end{array}$ & \\
\hline T2 & $\begin{array}{l}\text { Tumour invades corpus spongiosum/corpora } \\
\text { cavernosa }\end{array}$ & $\begin{array}{l}\text { Tumour invades corpus spongiosum with } \\
\text { or without invasion of the urethra }\end{array}$ \\
\hline T3 & Tumour invades urethra & $\begin{array}{l}\text { Tumour invades corpus cavernosum with } \\
\text { or without invasion of the urethra }\end{array}$ \\
\hline T4 & Tumour invades other adjacent structures & \\
\hline
\end{tabular}




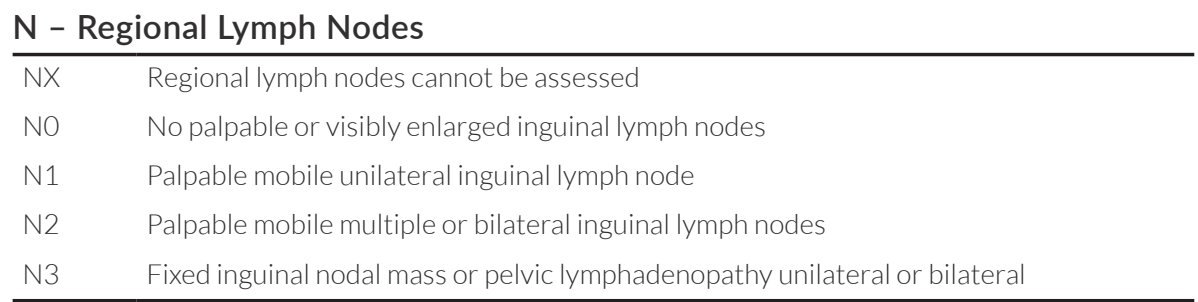

\section{$\mathrm{pN}$ - Regional lymph nodes, pathological staging}

\begin{tabular}{|c|c|c|}
\hline $\mathrm{pNX}$ & $\begin{array}{l}\text { Regional lymph nodes cannot be } \\
\text { assessed }\end{array}$ & \\
\hline pNO & $\begin{array}{l}\text { No palpable or visibly enlarged } \\
\text { inguinal lymph nodes }\end{array}$ & \\
\hline pN1 & Single intranodal metastasis & Metastasis in one or two inguinal lymph nodes \\
\hline pN2 & $\begin{array}{l}\text { Metastases in multiple or bilateral } \\
\text { lymph nodes }\end{array}$ & $\begin{array}{l}\text { Metastasis in more than two unilateral inguinal } \\
\text { nodes or bilateral inguinal lymph nodes }\end{array}$ \\
\hline pN3 & $\begin{array}{l}\text { Metastasis in pelvic lymph node(s), } \\
\text { unilateral or bilateral or extranodal } \\
\text { extension of regional lymph node } \\
\text { metastasis }\end{array}$ & \\
\hline
\end{tabular}

\section{M - Distant Metastasis}

\begin{tabular}{ll}
\hline M0 & No distant metastasis \\
M1 & Distant metastasis \\
\hline
\end{tabular}

\section{Stage}

\begin{tabular}{lccc}
\hline Stage O & Tis & NO & MO \\
Stage I & Ta & NO & MO \\
Stage IIA & T1a & NO & MO \\
Stage IIB & T1b,T2 & NO & MO \\
Stage IIIA & T3 & NO & MO \\
Stage IIIB & T1, T2, T3 & N2 & MO \\
Stage IV & T1, T2,T3 & Any N & MO \\
& T4 & N3 & MO \\
& Any T & Any N & MO \\
& Any $T$ &
\end{tabular}

\section{Treatment and survival}

\section{Primary tumour}

Penile tumours can be treated in various ways although most tumours are treated with surgical removal. For superficial tumours, low risk, or penile intraepithelial 
neoplasia (PeIN), laser ablation can be used, usually in combination with biopsies for histopathologic evaluation. During the years, the use of penile sparing surgery (wide local excision, partial or total glansectomy or partial penectomy) has increased. The risk of recurrence is a little higher after penile sparing surgery, but this does not compromise survival and seemingly quality of life is better.74,75

Large tumours can be challenging to manage, as surgical removal may require a skin flap reconstruction for wound closure and/or urinary diversion. ${ }^{76}$ With ingrowth in adjacent organs such as scrotum, prostate, or pubic bone the prognosis is poor. Whether these patients should be treated with curative or palliative intent is often difficult to decide and should be discussed individually in multidisciplinary tumour boards. Combining surgery with induction treatment with chemotherapy and/or radiation may be useful to achieve radicality of resection.

\section{Lymph nodes}

Patients with non-palpable lymph nodes undergo minimally invasive staging. Standard procedure in the Netherlands Cancer Institute is ultrasound examination with fine-needle aspiration cytology of suspicious lymph nodes and a dynamic sentinel node biopsy procedure in clinically node negative patients. If either one shows metastatic cells, a completion inguinal lymph node dissection is scheduled.

Patients with palpable inguinal nodal disease, require at least pathologic evaluation of the enlarged lymph nodes. Often, an inguinal lymphadenectomy is immediately performed when the patient is deemed operable. In clinically dubious cases, an ultrasound and sentinel node procedure can be considered as the sentinel node procedure includes thorough palpation of the groin and removal of palpably suspicious nodes.

In patients with clinically suspicious groins, the therapeutic value of regional Iymphadenectomy justifies the complications associated with this procedure. Surgery remains the cornerstone of therapy in patients with metastatic disease, with cure in approximately $80 \%$ of patients with one or two involved inguinal nodes without extranodal extension (ENE).7,60-64 When the inguinal region contains two or more tumour-positive lymph nodes or ENE, an ipsilateral prophylactic pelvic lymph node dissection is advised because of a substantial risk of metastasis. ${ }^{77}$ Cross-over metastasis to the contralateral pelvic lymph nodes has not been reported. When pelvic lymph nodes appear metastatic on imaging, a pelvic lymph node dissection is performed. 


\section{Locoregionally advanced disease and palliative treatment}

With large and bulky metastases in the groin or pelvic metastases, surgery alone is not sufficient and guidelines advise multimodal treatment. ${ }^{77}$ The most applied combination so far is neoadjuvant or adjuvant chemotherapy with adequate lymphadenectomy for responders. Yet, even with chemotherapy, survival rates are unsatisfactory (1-year overall survival (OS) approx. 50\%) and toxicity is high (grade 3-4 events in up to $65 \%$ of patients). ${ }^{78-82}$ Whether concurrent chemoradiotherapy is an alternative for neoadjuvant chemotherapy, is not yet clear. The optimal role of radiation therapy has been debated in penile cancer due to a lack of robust data. ${ }^{83,84}$ Further studies are warranted to optimize the combination and sequence of local and systemic therapies in patients with advanced regional disease.

After involvement of the pelvic lymph nodes, penile cancer spreads to the paraaortic lymph nodes and further to other organs (lung, bone, etc.) and is then considered incurable. Systemic therapy often contains taxane or platinum. Palliation can entail resection of large, painful or ulcerating masses, as spread to distant organs without involvement of lower echelons is very rare (although possible in case of basaloid histology). Also, radiotherapy is an option for symptomatic local or metastatic lesions.

\section{Thesis objective}

This thesis aimed to be a starting point of improvement of advanced penile cancer care. Especially in these cases, cure can be hard to obtain and a need is felt for more and better treatment options. Firstly, with Science Magazine calling immunotherapy out as the "Breakthrough of the Year" in 2013, we wanted to assess whether penile cancer bears targets for immunotherapy.

Secondly, we focussed on different imaging modalities, investigating room for improvement. Patients with pelvic metastases do not fare well with surgery alone. Moreover, pelvic metastases are mostly detected upon surgical resection and multimodal treatment is indicated. Early detection enables early start of multimodal treatment strategies that hopefully will lead to higher cure rates. Conventional imaging (CT, MRI) have a sensitivity of only $40 \%$ but FDG-PET/ CT showed excellent test performances albeit only in small series. We aimed to evaluate FDG-PET/CT ability to detect advanced stages of disease adequately.

Lastly, this research aimed to evaluate therapeutic strategies. Due to the rarity of the disease, and in particular advanced stages, large clinical trials comparing multimodal treatments are almost absent. Patients undergoing large 
surgical interventions do not always seem to fare well. A trial with neoadjuvant chemotherapy in our centre had somewhat disappointing results. By setting up a retrospective cohort of patients requiring flap-reconstruction we wanted to quantify challenges in this rare patient category. By setting up a prospective chemoradiation trial, we aimed to evaluate chemoradiotherapy as a treatment alternative for locoregionally advanced penile cancer.

\section{Outline of thesis}

In chapter 2 we investigated expression of the PD-L1 checkpoint molecule in primary penile tumours. In chapter $\mathbf{3}$ more of the TME was analysed together with PD-L1 expression: T-cell markers, myeloid markers, HPV status and HLA expression were also included. As clinical outcomes we used presence of lymph node metastases at diagnosis and disease specific survival.

The chapters 4 and 5 review staging and imaging of penile cancer, with the use of PET/CT scan in particular. Chapter 6 describes a retrospective cohort where PET/CT was used for staging and evaluated its ability to accurately detect pelvic metastatic lymph nodes and distant metastases before invasive lymph node staging is done.

Chapter $\mathbf{7}$ is a two-centre evaluation of large surgical procedures using a vascularized muscular flap for reconstruction of the primary or inguinal resection site. Due to the rarity of the locoregionally advanced stages and the procedure only fifteen patients were included.

A multimodality treatment alternative for locoregionally advanced cancer is presented in chapter $\mathbf{8}$. It is a preliminary script of a prospective study looking at curative combined chemotherapy and radiation therapy for advanced penile cancer. Chapter 9 provides a general discussion of this thesis, chapter 10 provides a summary in English and Dutch. 


\section{REFERENCES}

1. Muneer A and Horenblas S eds: Textbook of Penile Cancer. Second edi. London: Springer-Verlag; 2016.

2. de Sousa IDB, Vidal FCB, Branco Vidal JPC, et al: Prevalence of human papillomavirus in penile malignant tumors: viral genotyping and clinical aspects. BMC Urol. 2015; 15: 13.

3. Mentrikoski MJ, Stelow EB, Culp S, et al: Histologic and immunohistochemical assessment of penile carcinomas in a North American population. Am. J. Surg. Pathol. 2014; 38: 1340-1348.

4. Chaux A and Cubilla AL: The role of human papillomavirus infection in the pathogenesis of penile squamous cell carcinomas. Semin. Diagn. Pathol. 2012; 29: 67-71.

5. Djajadiningrat RS, Graafland NM, van Werkhoven E, et al: Contemporary management of regional nodes in penile cancer-improvement of survival? J. Urol. 2014; 191: 68-73.

6. Kirrander P, Sherif A, Friedrich B, et al: Swedish National Penile Cancer Register: incidence, tumour characteristics, management and survival. BJU Int. 2016; 117: 28792.

7. Ornellas AA, Kinchin EW, Nóbrega BLB, et al: Surgical treatment of invasive squamous cell carcinoma of the penis: Brazilian National Cancer Institute long-term experience. J. Surg. Oncol. 2008; 97: 487-95.

8. Jakobsen JK, Krarup KP, Kirrander P, et al: Penile cancer in Scandinavia: Current practice and future perspectives. Scand. J. Urol. 2016; 50: 90-92.

9. Barnholtz-Sloan JS, Maldonado JL, Pow-sang J, et al: Incidence trends in primary malignant penile cancer. Urol. Oncol. 2007; 25: 361-367.

10. Arya M, Li R, Pegler K, et al: Long-term trends in incidence, survival and mortality of primary penile cancer in England. Cancer Causes Control 2013; 24: 2169-2176.

11. Coelho RWP, Pinho JD, Moreno JS, et al: Penile cancer in Maranhão, Northeast Brazil: the highest incidence globally? BMC Urol. 2018; 18: 50.

12. Montes Cardona CE and García-Perdomo HA: Incidence of penile cancer worldwide: systematic review and meta-analysis. Rev. Panam. Salud Publica 2017; 41: e117.

13. Shavit O, Roura E, Barchana M, et al: Burden of human papillomavirus infection and related diseases in Israel. Vaccine 2013; 31 Suppl 8: I32-41.

14. Maden C, Sherman KJ, Beckmann AM, et al: History of circumcision, medical conditions, and sexual activity and risk of penile cancer. J. Natl. Cancer Inst. 1993; 85: 19-24.

15. Moses S, Bailey RC and Ronald AR: Male circumcision: assessment of health benefits and risks. Sex. Transm. Infect. 1998; 74: 368-373.

16. Schoen EJ, Oehrli M, Colby C d, et al: The highly protective effect of newborn circumcision against invasive penile cancer. Pediatrics 2000; 105: E36.

17. Dillner J, von Krogh G, Horenblas S, et al: Etiology of squamous cell carcinoma of the penis. Scand. J. Urol. Nephrol. Suppl. 2000: 189-193.

18. Djajadiningrat RS, Jordanova ES, Kroon BK, et al: Human papillomavirus prevalence in invasive penile cancer and association with clinical outcome. J. Urol. 2015; 193 : 526-31. 
19. Alemany L, Cubilla A, Halec G, et al: Role of Human Papillomavirus in Penile Carcinomas Worldwide. Eur. Urol. 2015; 69: 953-961.

20. Olesen TB, Sand FL, Rasmussen CL, et al: Prevalence of human papillomavirus DNA and p16(INK4a) in penile cancer and penile intraepithelial neoplasia: a systematic review and meta-analysis. Lancet. Oncol. 2019; 20: 145-158.

21. de Martel C, Plummer M, Vignat J, et al: Worldwide burden of cancer attributable to HPV by site, country and HPV type. Int. J. cancer 2017; 141: 664-670.

22. Backes DM, Kurman RJ, Pimenta JM, et al: Systematic review of human papillomavirus prevalence in invasive penile cancer. Cancer Causes Control 2009; 20: $449-457$.

23. Cubilla AL, Velazques EF, Reuter VE, et al: Warty (condylomatous) squamous cell carcinoma of the penis: a report of 11 cases and proposed classification of "verruciform" penile tumors. Am. J. Surg. Pathol. 2000; 24: 505-512.

24. Petca A, Borislavschi A, Zvanca ME, et al: Non-sexual HPV transmission and role of vaccination for a better future (Review). Exp. Ther. Med. 2020; 20: 186.

25. Snijders PJF, Steenbergen RDM, Heideman DAM, et al: HPV-mediated cervical carcinogenesis: concepts and clinical implications. J. Pathol. 2006; 208: 152-64.

26. Bunker CB and Shim TN: Male genital lichen sclerosus. Indian J. Dermatol. 2015; 60: 111-117.

27. Velazquez EF and Cubilla AL: Lichen sclerosus in 68 patients with squamous cell carcinoma of the penis: frequent atypias and correlation with special carcinoma variants suggests a precancerous role. Am. J. Surg. Pathol. 2003; 27: 1448-1453.

28. Nasca MR, Innocenzi D and Micali G: Penile cancer among patients with genital lichen sclerosus. J. Am. Acad. Dermatol. 1999; 41: 911-914.

29. Barbagli G, Palminteri E, Mirri F, et al: Penile carcinoma in patients with genital lichen sclerosus: a multicenter survey. J. Urol. 2006; 175: 1359-1363.

30. Micali G, Nasca MR and Innocenzi D: Lichen sclerosus of the glans is significantly associated with penile carcinoma. Sex. Transm. Infect. 2001; 77: 226.

31. Edmonds EVJ, Hunt S, Hawkins D, et al: Clinical parameters in male genital lichen sclerosus: a case series of 329 patients. J. Eur. Acad. Dermatol. Venereol. 2012; 26: 730-737.

32. Mannweiler S, Sygulla S, Beham-Schmid C, et al: Penile carcinogenesis in a lowincidence area: a clinicopathologic and molecular analysis of 115 invasive carcinomas with special emphasis on chronic inflammatory skin diseases. Am. J. Surg. Pathol. 2011; 35: 998-1006.

33. Daling JR, Madeleine MM, Johnson LG, et al: Penile cancer: importance of circumcision, human papillomavirus and smoking in in situ and invasive disease. Int. J. Cancer 2005; 116: 606-616.

34. Tsen HF, Morgenstern H, Mack T, et al: Risk factors for penile cancer: results of a population-based case-control study in Los Angeles County (United States). Cancer Causes Control 2001; 12: 267-277.

35. Reddy DG and Baruah IK: Carcinogenic action of human smegma. Arch. Pathol. 1963; 75: 414-420. 
36. Misra S, Chaturvedi A and Misra NC: Penile carcinoma: a challenge for the developing world. Lancet. Oncol. 2004; 5: 240-247.

37. Van Howe RS and Hodges FM: The carcinogenicity of smegma: debunking a myth. J. Eur. Acad. Dermatol. Venereol. 2006; 20: 1046-54.

38. Hernandez BY, Wilkens LR, Zhu X, et al: Circumcision and human papillomavirus infection in men: a site-specific comparison. J. Infect. Dis. 2008; 197: 787-794.

39. Van Howe RS: Is neonatal circumcision clinically beneficial? Argument against. Nat. Clin. Pract. Urol. 2009; 6: 74-75.

40. Morris BJ: Why circumcision is a biomedical imperative for the 21 (st) century. Bioessays 2007; 29: 1147-58.

41. Hellberg D, Valentin J, Eklund T, et al: Penile cancer: is there an epidemiological role for smoking and sexual behaviour? Br. Med. J. (Clin. Res. Ed). 1987; 295: 1306-1308.

42. Harish $\mathrm{K}$ and Ravi R: The role of tobacco in penile carcinoma. Br. J. Urol. 1995; 75: 375-377.

43. Boscoe FP, Johnson CJ, Sherman RL, et al: The relationship between area poverty rate and site-specific cancer incidence in the United States. Cancer 2014; 120: 2191-2198.

44. Baekhøj Kortsen D, Predbjørn Krarup K and Jakobsen JK: DaPeCa-9 - cohabitation and socio-economic conditions predict penile cancer-specific survival in a national clinical study from Denmark. Scand. J. Urol. 2021: 1?5.

45. Torbrand C, Wigertz A, Drevin L, et al: Socioeconomic factors and penile cancer risk and mortality; a population-based study. BJU Int. 2017; 119: 254-260.

46. Blomberg M, Friis S, Munk C, et al: Genital warts and risk of cancer: a Danish study of nearly 50000 patients with genital warts. J. Infect. Dis. 2012; 205: 1544-1553.

47. Engels EA, Pfeiffer RM, Goedert JJ, et al: Trends in cancer risk among people with AIDS in the United States 1980-2002. AIDS 2006; 20: 1645-1654.

48. Moscicki A-B, Schiffman M, Burchell A, et al: Updating the natural history of human papillomavirus and anogenital cancers. Vaccine 2012; 30 Suppl 5: F24-33.

49. Poblet E, Alfaro L, Fernander-Segoviano P, et al: Human papillomavirus-associated penile squamous cell carcinoma in HIV-positive patients. Am. J. Surg. Pathol. 1999; 23: 1119-1123.

50. Chin-Hong P V: Cutting human papillomavirus infection in men. J. Infect. Dis. 2008; 197: 781-783.

51. Abdulla A, Daya D, Pinthus J, et al: Buried penis: An unrecognized risk factor in the development of invasive penile cancer. Can. Urol. Assoc. J. 2012; 6: E199-202.

52. Barnes KT, McDowell BD, Button A, et al: Obesity is associated with increased risk of invasive penile cancer. BMC Urol. 2016; 16: 42.

53. Archier E, Devaux S, Castela E, et al: Carcinogenic risks of psoralen UV-A therapy and narrowband UV-B therapy in chronic plaque psoriasis: a systematic literature review. J. Eur. Acad. Dermatol. Venereol. 2012; 26 Suppl 3: 22-31.

54. Stern RS: Genital tumors among men with psoriasis exposed to psoralens and ultraviolet A radiation (PUVA) and ultraviolet B radiation. The Photochemotherapy Follow-up Study. N. Engl. J. Med. 1990; 322: 1093-1097.

55. Garcia-Lora A, Algarra I and Garrido F: MHC class I antigens, immune surveillance, and tumor immune escape. J. Cell. Physiol. 2003; 195: 346-55. 
56. Garrido F: MHC/HLA Class I Loss in Cancer Cells. Adv. Exp. Med. Biol. 2019; 1151: 15-78.

57. Darvin P, Toor SM, Sasidharan Nair V, et al: Immune checkpoint inhibitors: recent progress and potential biomarkers. Exp. Mol. Med. 2018; 50: 1-11.

58. Schmid MC and Varner JA: Myeloid cells in the tumor microenvironment: modulation of tumor angiogenesis and tumor inflammation. J. Oncol. 2010; 2010: 201026.

59. Neophytou CM, Pierides C, Christodoulou M-I, et al: The Role of Tumor-Associated Myeloid Cells in Modulating Cancer Therapy. Front. Oncol. 2020; 10: 899.

60. Horenblas S and van Tinteren H: Squamous cell carcinoma of the penis. IV. Prognostic factors of survival: analysis of tumor, nodes and metastasis classification system. J. Urol. 1994; 151: 1239-43.

61. Lont AP, Kroon BK, Gallee MPW, et al: Pelvic lymph node dissection for penile carcinoma: extent of inguinal lymph node involvement as an indicator for pelvic lymph node involvement and survival. J. Urol. 2007; 177: 947-52; discussion 952.

62. Sánchez-Ortiz RF and Pettaway CA: The role of lymphadenectomy in penile cancer. Urol. Oncol. 2004; 22: 236-44; discussion 244-5.

63. Pandey D, Mahajan V and Kannan RR: Prognostic factors in node-positive carcinoma of the penis. J. Surg. Oncol. 2006; 93: 133-8.

64. Sun M, Djajadiningrat RS, Alnajjar HM, et al: Development and external validation of a prognostic tool for prediction of cancer-specific mortality after complete locoregional pathological staging for squamous cell carcinoma of the penis. BJU Int. 2015; 116: 734-43.

65. Srinivas V, Morse MJ, Herr HW, et al: Penile cancer: relation of extent of nodal metastasis to survival. J. Urol. 1987; 137: 880-2.

66. Solsona E, Algaba F, Horenblas S, et al: EAU Guidelines on Penile Cancer. Eur. Urol. 2004; 46: 1-8.

67. Hegarty PK, Kayes O, Freeman A, et al: A prospective study of 100 cases of penile cancer managed according to European Association of Urology guidelines. BJU Int. 2006; 98: 526-31.

68. Ercole CE, Pow-Sang JM and Spiess PE: Update in the surgical principles and therapeutic outcomes of inguinal lymph node dissection for penile cancer. Urol. Oncol. 2013; 31: 505-516.

69. Ravi R: Morbidity following groin dissection for penile carcinoma. Br. J. Urol. 1993; 72: 941-5.

70. Ornellas AA, Seixas AL and de Moraes JR: Analyses of 200 lymphadenectomies in patients with penile carcinoma. J. Urol. 1991; 146: 330-2.

71. Bevan-Thomas R, Slaton JW and Pettaway CA: Contemporary morbidity from lymphadenectomy for penile squamous cell carcinoma: the M.D. Anderson Cancer Center Experience. J. Urol. 2002; 167: 1638-42.

72. Stuiver MM, Djajadiningrat RS, Graafland NM, et al: Early wound complications after inguinal lymphadenectomy in penile cancer: a historical cohort study and riskfactor analysis. Eur. Urol. 2013; 64: 486-492.

73. Brierley JD, Gospodarowicz MK and Wittekind C eds: TNM Classification for Malignant Tumours, 8th Edition. 8th ed. Wiley-Blackwell; 2016. 
74. Djajadiningrat RS, van Werkhoven E, Meinhardt W, et al: Penile Sparing Surgery for Penile Cancer-Does it Affect Survival? J. Urol. 2014; 192: 120-126.

75. Sosnowski R, Wolski JK, Kulpa M, et al: Assessment of quality of life in patients surgically treated for penile cancer: Impact of aggressiveness in surgery. Eur. J. Oncol. Nurs. Off. J. Eur. Oncol. Nurs. Soc. 2017; 31: 1-5.

76. Shukla CJ, Shabbir M, Feneley MR, et al: Palliation of male genital cancers. Clin. Oncol. 2010; 22: 747-754.

77. Hakenberg OW (chair), Compérat E, Minhas S, et al: EAU Guidelines on Penile Cancer. 2020. Available at: http://uroweb.org/guideline/penile-cancer/, accessed December 12, 2020.

78. Djajadiningrat RS, Bergman AM, van Werkhoven E, et al: Neoadjuvant taxanebased combination chemotherapy in patients with advanced penile cancer. Clin. Genitourin. Cancer 2015; 13: 44-49.

79. Necchi A, Pond GRGR, Raggi D, et al: Clinical Outcomes of Perioperative Chemotherapy in Patients With Locally Advanced Penile Squamous-Cell Carcinoma: Results of a Multicenter Analysis. Clin. Genitourin. Cancer 2017; 15.

80. Pagliaro LC, Williams DL, Daliani D, et al: Neoadjuvant paclitaxel, ifosfamide, and cisplatin chemotherapy for metastatic penile cancer: a phase II study. J. Clin. Oncol. 2010; 28: 3851-3857.

81. Hakenberg OW, Nippgen JBW, Froehner M, et al: Cisplatin, methotrexate and bleomycin for treating advanced penile carcinoma. BJU Int. 2006; 98: 1225-1227.

82. Nicholson S, Hall E, Harland SJ, et al: Phase II trial of docetaxel, cisplatin and 5FU chemotherapy in locally advanced and metastatic penis cancer (CRUK/09/001). Br. J. Cancer 2013; 109: 2554-2559.

83. Hakenberg OW, Compérat E, Minhas S, et al: EAU Guidelines on Penile Cancer. 2020. Available at: https://uroweb.org/guideline/penile-cancer/, accessed August 22, 2020.

84. Flaig TW, Spiess PE, Agarwal N, et al: NCCN Clinical Practice Guidelines in Oncology - Penile Cancer. Version 1.2021. 2021. 


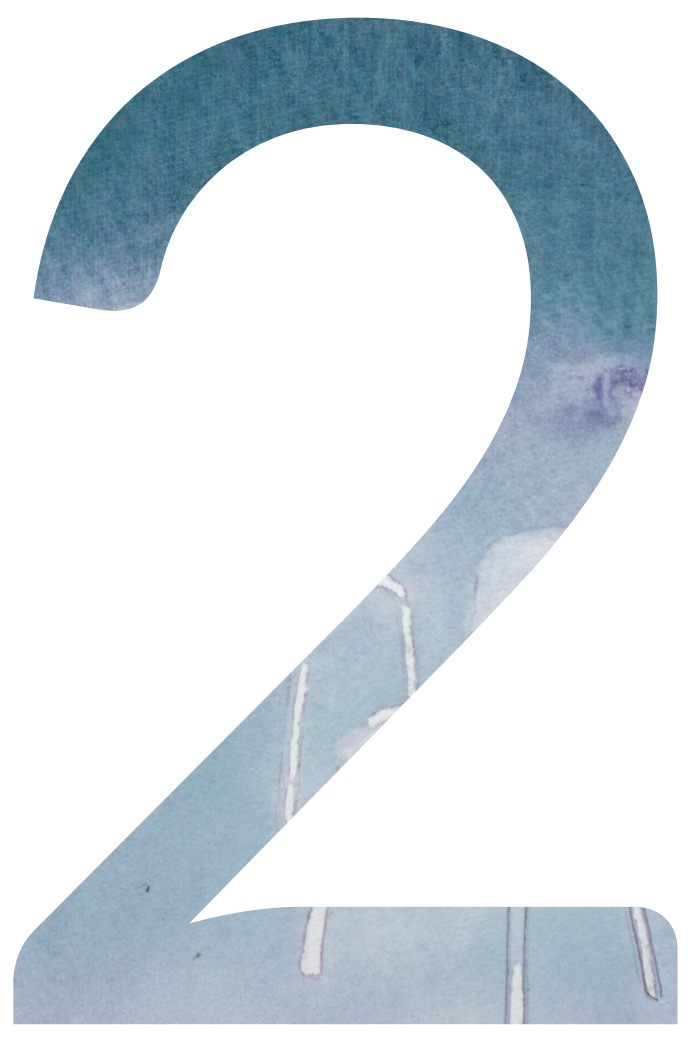


Chapter 2

Expression of programmed death ligand 1 (PD-L1) in penile cancer is of prognostic value and associated with HPV status

Sarah R. Ottenhof, Rosa S. Djajadiningrat, Jeroen de Jong, Helene H. Thygesen, Simon Horenblas, Ekaterina S. Jordanova 


\section{ABSTRACT}

Purpose: PD-L1 (Programmed Death Ligand 1) inhibits T-cell function and prevents tumor eradication. This is facilitated by PD-L1 positive tumor cells and PD-L1 positive immune cells, and can be prevented by anti-PD-1 (Programmed Death 1)/PD-L1 immunotherapy. In advanced penile cancer there is a need for new therapeutic strategies. We investigated PD-L1 expression in penile cancers and compared PD-L1 expression with disease-specific survival, Iymph-node metastases at diagnosis, and high-risk human papilloma virus (hrHPV) status in a large patient cohort.

Materials \& Methods: A total of 213 primary tumors were immunohistochemically stained for PD-L1 and scored for tumor (percentage), stroma (binary) and PD-L1+ tumor infiltrating macrophages (TIM). Additionally, PD-L1+ tumors were scored for expression pattern, that is diffuse or predominantly present at the tumorstroma margin.

Results: Staining was successful in 200 tumors, of which 75\% were hrHPV $^{-}$. Median follow-up was 62 months. Of 200 tumors, 96 (48\%) were PD-L1+ (scored $1 \%$ or greater), of which 59 (62\%) had a marginal expression pattern and 79 (82\%) were $\mathrm{hrHPV}^{-}(\mathrm{p}=$ 0.03). Compared to PD-L1- tumors, the PD-L1 expression patterns each had different prognostic values, in the whole cohort as well as in the hrHPV ${ }^{-}$subgroup. On multivariable analyses, a marginal expression pattern was associated with absence of lymph-node metastases (OR 0.4), while diffuse expression was associated with poor survival (HR 2.58). These results were more prominent in the hrHPV- subgroup (OR 0.25,HR 3.92).

Conclusions: PD-L1 was expressed in 48\% of penile carcinomas and mainly in $\mathrm{HPV}^{-}$tumors. The pattern of expression was a prognostic factor as marginal expression was associated with absence of lymph-node metastases, and a diffuse expression was associated with poor survival. 


\section{INTRODUCTION}

Penile cancer is a rare but potentially lethal disease with an age adjusted incidence of 0.6-2.1 per 100.000 in Western countries..$^{1,2}$ Involvement of regional Iymph nodes is the most important prognostic factor as five year survival decreases from greater than $90 \%$ to approximately 50\% when lymph node metastases are present. ${ }^{3}$ Current treatment options for the latter patient group are not always curative and treatment for locally inoperable tumors or distant metastases is almost invariably palliative, indicating the imperative need for new therapeutic options. In various other malignancies, new therapies effectively target tumor interactions with the host immune system. ${ }^{4,5}$

Malignant cells suppress and escape the immune response in various ways, leading to an immunotolerant state in the tumor microenvironment. ${ }^{6}$ One of the immunotolerance enhancing checkpoints is the Programmed Death 1 (PD1)/ Programmed Death Ligand 1 (PD-L1) axis. PD-1 is a cell receptor on $T$ Iymphocytes. When PD-L1 binds to PD-1, T cells receive an inhibitory signal. ${ }^{7}$ PDL1 is expressed by tumor cells as well as by immune cells such as macrophages and T cells. ${ }^{8}$ Ample expression of PD-L1 has been found in squamous cell carcinomas. ${ }^{8-10 i n c l u d i n g ~ d y s r e g u l a t i o n ~ o f ~ i m m u n e ~ c h e c k p o i n t s ~ s u c h ~ a s ~ t h e ~ P D-~}$ 1:PD-L1 pathway. We investigated the expression of programmed cell deathligand 1 (PD-L1 New therapies block the PD-1/PD-L1 checkpoint, preventing immunotolerance. ${ }^{8,11}$ Recently, the first study on PD-L1 expression in penile squamous cell carcinomas showed PD-L1 expression in 62.2\% of primary tumors, which correlated with regional lymph node metastases and poor survival. ${ }^{12}$ locallyadvanced and/or metastatic penile squamous cell carcinoma (SqCC This provides a rationale for anti-PD-1/PD-L1 immunotherapy in patients with penile cancer. However, that study was performed on a limited cohort of 37 patients.

In the current study, we report PD-L1 expression in a large and clinically welldefined cohort 213 patients with penile carcinoma. In addition, we analyzed PDL1 expression in the context of high risk human papilloma virus (hrHPV) status, lymph node involvement and disease specific survival (DSS). 


\section{MATERIALS AND METHODS}

\section{Patients}

Patients surgically treated for primary penile carcinoma between 2000 and 2009 at the Netherlands Cancer Institute were selected for analysis if they did not receive radiation or chemotherapy prior to surgery, did not receive primary treatment elsewhere and had invasive cancer, excluding carcinoma in situ. ${ }^{13,14}$ The use of clinical material was approved by the institutional translational research board. Clinical data on all patients, including TNM classification (2009 modification) and follow-up, were available from a prospectively maintained institutional database. Histopathological data, including HPV status, Iymphovascular invasion (LVI) and grade of differentiation, were available from previous studies. ${ }^{13}$

\section{Staining \& scoring}

From 213 primary tumors, 3 um whole mount sections of formalin-fixed, paraffinembedded tissue were immunohistochemically stained for PD-L1 using a BenchMark Ultra autostainer. Paraffin sections were heated at $75^{\circ} \mathrm{C}$ for 28 minutes and deparaffinized in the instrument with EZ prep Solution (Ventana Medical Systems, Tucson, Arizona). Heat induced antigen retrieval was performed using Cell Conditioning 1 (CC1, Ventana Medical Systems) for 64 minutes at $95^{\circ} \mathrm{C}$. PD-L1 was detected using a rabbit monoclonal antibody (clone E1L3N, Cell Signaling Technology ${ }^{\circledR}$, 1:200 dilution, for 1 hour at room temperature). Bound antibody was detected using the OptiView DAB Detection Kit (Ventana Medical Systems). Slides were counterstained with hematoxylin.

Staining was scored manually for tumor cells, stroma and tumor associated immune cells. Tumor positivity was scored by two of us (ESJ, SRO) as the percent of positive tumor cells, considering $1 \%$ or greater as a tumor positive for PDL1. This cutoff level was based on published data showing successful anti-PD-1 therapy in patients with low PD-L1 expression. ${ }^{4}$ Cytoplasmic staining was ignored because it may represent intracellular stores of PD-L1 and only membranous $\mathrm{PD}-\mathrm{L} 1$ is thought to be functional. ${ }^{15}$ Problematic cases were discussed with an experienced pathologist ( $\mathrm{J} \mathrm{d} J$ ). Additional tumor scoring was done for notable PDL1 expression patterns, including diffuse - throughout the tumor and marginal - predominantly at the tumor-stroma margin. Immune cells in stroma were then scored binary (negative/positive). Tumor infiltrating macrophage-like cells, referred to as TIMs, were identified by size, shape and position (large and round with dendrites and in tumor fields). PD-L $1^{+}$TIMs were also scored binary (absent/ present). PD- $\mathrm{L} 1^{+}$myeloid immune cells arranged as a cordon sanitaire around 
the tumor, were identified by similar criteria as for TIMs and scored separately (absent/present).

In cases with PD-L1+ CD163 (a marker of tumor associated macrophages) on consecutive slides using similar preparation of $3 \mu \mathrm{m}$ sections, antibody clone MRQ-26 (Cell Marque ${ }^{\mathrm{TM}}$ ) with the ready to use dispenser for 32 minutes at $37^{\circ} \mathrm{C}$ and the ultraView DAB Detection Kit (Ventana Medical Systems). Slides were counterstained with hematoxylin II and bluing reagent (Ventana Medical Systems).

\section{Analysis}

PD-L1 expression was compared to hrHPV-status, lymph node status and

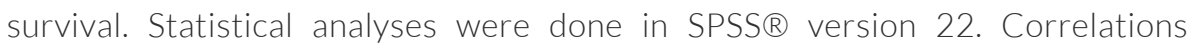
between categorical variables were tested with the 2 -sided chi-square test, and correlations with continuous variables were tested with the Spearman correlation test. Hazard ratios (HRs) and multivariable survival analysis were done using Cox regression models, odds ratios (ORs) on multivariable analysis were estimated by logistic regression. Disease specific survival (DSS) was calculated using KaplanMeier estimates, with the log rank test used for comparisons. Two-sided $p<0.05$ was considered statistically significant.

\section{RESULTS}

\section{Expression}

PD-L1-staining was successful in 200 of 213 tumors (Figure 1). A total of 11 sections were uninterpretable due to unreliable staining caused by tissue fixation variability, excess parakeratosis, or lack of tumor cells in the section.

Supplementary Table 1 compares clinicopathological parameters between PD$\mathrm{L}^{+}{ }^{+}$and $\mathrm{PD}-\mathrm{L} 1^{-}$cases at a cutoff of $1 \%$. We tested multiple commonly used cutoff values including 1\%, 5\%,10\% and 50\%.8 At the 1\% cutoff PD-L1 was positive in 96 tumors (48\%) while 28\%, 24\%, and 7\% of cases was scored as 5\% or greater, $10 \%$ or greater, and $50 \%$ or greater, respectively. PD-L1 positivity significantly correlated with the grade of differentiation at all cutoff values (each $p<0.01$, supplementary Table 1). Correlations with hrHPV and lymph nodes are described below. No other significant correlations were found.

Of 96 positive tumors 59 (61\%) had a distinctive marginal expression pattern, predominantly at the tumor-stroma interface (Figure 1c). 
TIM scoring was possible in 194 tumors with TIMs present in 27.8\% (Figure 2a).A PD-L1+ cordon or border was present in $15.7 \%$ of tumors (Figure 2c). The myeloid origin of PD-L1 $1^{+}$TIMs and cordons was confirmed by CD163 staining on consecutive slides (Figure $\mathbf{2} \mathbf{b}$ and $\mathbf{d}$ ).

Stroma scoring was possible in 198 tumors. Stroma positivity was seen in 150 tumors (75.8\%), which strongly correlated with tumor positivity, cordon-positivity and the presence of PD-L1+ TIMs (each $p<0.01$ ). Only 38 samples (17.8\%) had no PD-L1 at all.

\section{HrHPV status}

HPV data on this patient cohort, which were previously published, showed a significant survival benefit in hrHPV ${ }^{+}$patients. ${ }^{13}$ In short, samples were classified hrHPV- or hrHPV+ using a GP5+/6+ polymerase chain reaction and subsequently genotyped by bead based array on the Luminex ${ }^{\circledR}$ platform. ${ }^{13}$

Of the 200 tumors successfully stained for PD-L1 75.2\% were hrHPV-. The hrHPV negative cases were significantly more often positive for PD-L1 expression on tumor cells ( $p=0.03$ see Table). This association was not significant at other PDL1 cutoff values. hrHPV status did not correlate with other PD-L1 parameters or Iymph node status (supplementary Table 2, and see Table).

\section{Lymph node status}

Of 66 patients (31\%) with tumor positive lymph nodes 6 (9\%) had no successful PD-L1 staining, 31 (47\%) showed PD-L1+ status, and 21 (32\%) were scored as $5 \%$ or greater. Of 147 patients (69\%) without lymph node metastases 7 (5\%) had no successful PD-L1 staining, 44\% were PD- L $1^{+}$and $23 \%$ were scored $5 \%$ or greater. Of all of the different PD-L1-parameters scored only the PD-L1 tumor cell expression pattern was significantly associated with lymph node status at staging with more lymph node metastases present in cases with diffuse PD-L1 expression ( $p<0.01$, supplementary Table 2 ).

On multivariable analysis of relevant clinical parameters the grade of differentiation, LVI and pattern of PD-L1 expression remained significant prognostic factors for lymph node metastasis (supplementary Table 2). These parameters were included in receiver operating characteristic (ROC) curves to calculate the concordance-index (area under the curve, which is a measure of the proportion of concordantly predicted outcomes). Adding the pattern of PD-L1 expression to this model improved the concordance-index 4\% from 77.8 to 81.8 . 



Figure 1. Representative examples of PD-L1 expression show no PD-L1 expression in tumor cells ( $a$ ), and different PD-L1 expression patterns, including diffuse expression (b) and expression predominantly at tumor-stroma margin (c). Reduced from x20.
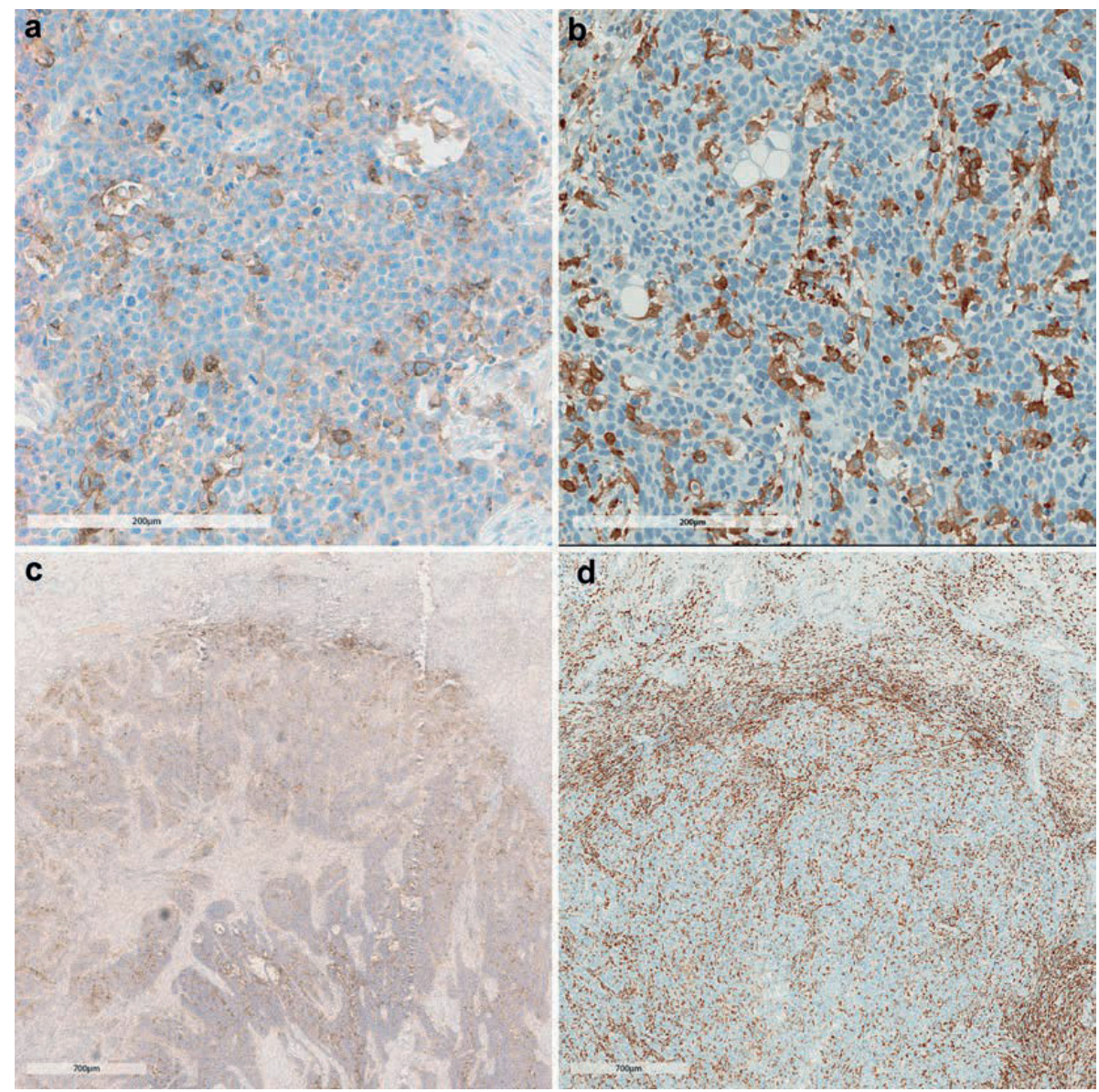

Figure 2. Identification of PD-L1 positive TIMs (a) and PD-L1 positive cordon (c) compared to CD163 staining of same tumor areas ( $b$ and $d$, respectively). Reduced from $\times 20$ ( $a$ and $b$ ) and $\times 3$ ( $c$ and $d)$. 


\section{Disease Specific Survival}

Median follow-up in the current cohort was 62 months. PD-L1 expression of the tumor (positive vs. negative) was not a prognostic factor for DSS at all tested cutoff values (at 1\%, 5\%,10\% and 50\% log rank $p=0.16,0.87,0.81$ and 0.80, respectively). However, among PD-L $1^{+}$tumors a diffuse expression pattern of PDL1 was associated with a poorer DSS than for tumors with a marginal expression pattern (HR 4.38, 95\% Cl 1.54 - 12.43, p < 0.01) especially in HPV- cases (HR 6.29, $95 \% \mathrm{Cl}$ 2.03-19.52, p < 0.01, figure 3). Univariable survival analysis revealed no prognostic value for the presence of PD-L1+ TIMs, PD-L1+ stroma or a PD-L1+ cordon (supplementary Table 3 ).

Multivariable survival analyses were performed (supplementary Table 3). All significant prognostic factors on univariable analysis were used, ie lymph node status, tumor size, grade of differentiation, LVI and hrHPV. We left out pT-stage because it partially represents tumor size, supplementary Table 3 . On this analysis PD-L1 expression pattern appeared to be an independent predictor for survival compared to PD-L1- tumors (marginal pattern HR 0.45, $p=0.20$ and diffuse pattern HR 2.58, $p=0.04$ ). When performed in the hrHPV- subgroup, this prognostic value was even more pronounced (marginal expression $0.31, p=0.10$ and diffuse expression HR 3.92, $p=0.01$ ).

When PD-L1+ TIMs were tested against the same clinicopathological variables, no independent prognostic value was found (HR 0.90, $p=0.83$ ) in the whole population or in the hrHPV ${ }^{-}$subgroup (data not shown).

\section{DISCUSSION}

Inhibition of the PD-1/PD-L1 axis is effective against different tumors such as melanoma and non-small cell lung cancer (NSCLC), ${ }^{4,16}$ and promising therapeutic effects have been observed in renal cell and bladder cancer. ${ }^{17,18}$ Recently, PD-1/ PD-L1-checkpoint inhibitors were approved by the United States FDA (Food and Drug Administration) for advanced stages of melanoma and non-small cell lung cancer. However, to our knowledge no studies have been done to evaluate the clinical effect of PD-L1 inhibitors in penile cancers.

In the current study of a large and clinically well-defined penile carcinoma cohort of 213 patients we found that $48 \%$ of the tumors express PD-L1 and that PD-L1 expression was linked to the absence of hrHPV ( $p=0.03)$. When comparing PD- 
L1 positive tumors to PD-L1 negative tumors, a marginal expression-pattern (at the tumor-stroma interface) was independently associated with negative lymph node status (OR 0.4) while diffuse expression was independently associated with poor survival (HR 2.58). The presence of PD-L1+ TIMs or a PD-L1+ cordon had no significant association with survival.

Table 2: PD-L1 expression according to hrHPV status

\begin{tabular}{|c|c|c|c|c|}
\hline Variable & $\begin{array}{c}\text { hrHPV }^{-} \\
\mathrm{N}=158(\%)\end{array}$ & $\begin{array}{c}\text { hrHPV }^{+} \\
\mathrm{N}=52(\%)\end{array}$ & $\begin{array}{c}\text { Total } \\
\mathrm{N}=210(\%)\end{array}$ & P-value* \\
\hline $\begin{array}{l}\text { Tumor cells } \\
\text { PD- } L 1^{+} \\
\text {PD-L1- } \\
\text { Missing }\end{array}$ & $\begin{array}{c}78(49.4) \\
70(44.3) \\
10(6.3)\end{array}$ & $\begin{array}{c}17(32.7) \\
32(61.5) \\
3(5.8)\end{array}$ & $\begin{array}{c}95(45.2) \\
102(48.6) \\
13(6.2)\end{array}$ & 0.03 \\
\hline $\begin{array}{l}\text { Expression pattern } \\
\text { Diffuse } \\
\text { Margin }\end{array}$ & $\begin{array}{l}29(37.2) \\
49(62.8)\end{array}$ & $\begin{array}{c}7(41.2) \\
10(58.8)\end{array}$ & $\begin{array}{l}36(37.9) \\
59(62.1)\end{array}$ & 0.79 \\
\hline $\begin{array}{l}\text { PD-L1+ TIM } \\
\text { Present } \\
\text { Absent } \\
\text { Unknown }\end{array}$ & $\begin{array}{c}44(27.8) \\
99(62.7) \\
15(9.5)\end{array}$ & $\begin{array}{c}10(19.2) \\
38(73.1) \\
4(7.7)\end{array}$ & $\begin{array}{c}54(25.7) \\
137(65.2) \\
19(9.0)\end{array}$ & 0.19 \\
\hline $\begin{array}{l}\text { PD-L1+ cordon } \\
\text { Present } \\
\text { Absent } \\
\text { Unknown }\end{array}$ & $\begin{array}{c}25(15.8) \\
121(76.6) \\
12(7.6)\end{array}$ & $\begin{array}{c}5(9.6) \\
43(82.7) \\
4(7.7)\end{array}$ & $\begin{array}{c}30(14.3) \\
164(78.1) \\
16(7.6)\end{array}$ & 0.27 \\
\hline $\begin{array}{l}\text { Stroma } \\
\text { PD-L1 } 1^{+} \\
\text {PD-L1 } 1^{-} \\
\text {Unknown }\end{array}$ & $\begin{array}{c}114(72.2) \\
32(20.3) \\
12(7.6)\end{array}$ & $\begin{array}{c}34(65.4) \\
15(28.8) \\
3(5.8)\end{array}$ & $\begin{array}{c}148(70.5) \\
47(22.4) \\
15(7.1)\end{array}$ & 0.22 \\
\hline
\end{tabular}

* excluding unknown statuses; Chi $^{2}$ test

a)

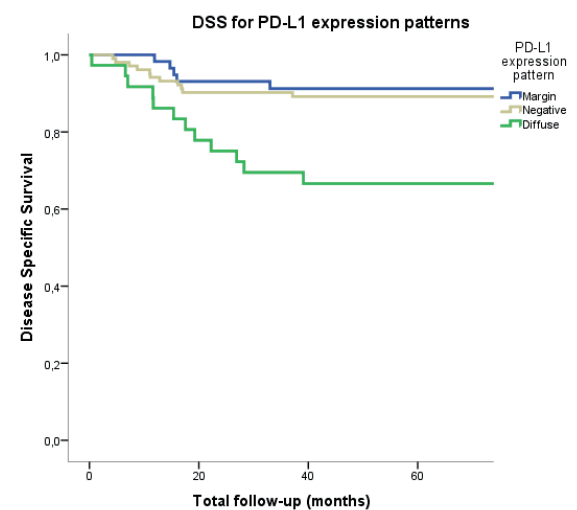

b)

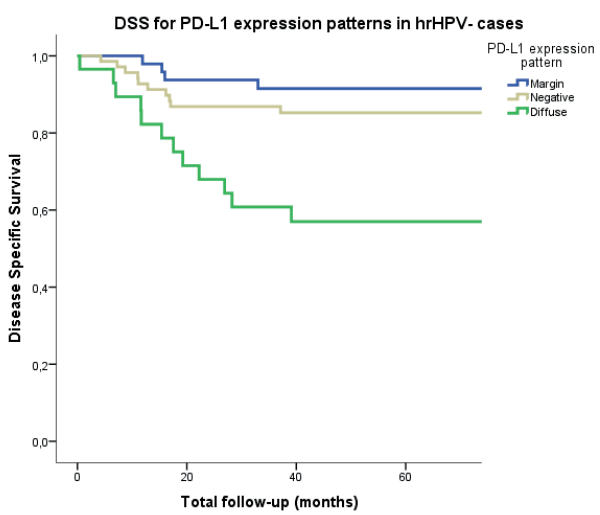

Figure 3. Kaplan-Meier DSS curves reveal diffuse and marginal expression patterns in whole cohort (log rank $\mathrm{p}<0.01$ ) (a) and in hrHPV negative subgroup (log rank $\mathrm{p}<0.01$ ) (b). 
The relatively good prognosis of the cases with a marginal PD-L1 expressionpattern was also seen in cervical cancer. ${ }^{19}$ Because PD-L1 can be up-regulated in response to IFN-y (interferon gamma), we hypothesize that marginal expression is present as a response to the IFN- $\gamma$ released from activated lymphocytes in the stroma. 6,15,20 In contrast, diffuse expression may be indicative of genetic aberrations leading to PD-L1 expression, as found in melanoma, and cervix and vulva cancer. ${ }^{21,22}$ This suggests that marginal positivity reflects an active immune response with corresponding good prognosis and diffuse positivity represent a more genetically altered/poorly differentiated group.

Recently, Udager et al. reported frequent PD-L1 expression in penile cancer. ${ }^{12}$ PD-L1 expression on tumor cells was associated with poor survival and positive lymph node status, although the pattern of expression was not considered. In addition, a strong correlation between PD-L1 expression in primary tumors and metastases was reported. We believe that the PD-L1 positive cases described in the latter study were mainly cases with diffuse expression, which is strengthened by the significant correlation observed with poor differentiation. The differences between the results described by Udager et al. and those in our study may be due to different scoring methods as well as to the small sample size and the even smaller HPV- subgroups included in their analysis. In addition, the cohort in our study included relatively more tumors of the usual histological subtype (84\% compared to $54 \%) .{ }^{12}$

Expression of PD-L1 has been studied in different cancers, with most investigators using a $1 \%$ or $5 \%$ cutoff for positivity. 8,23 The $48 \%$ incidence of tumor PDL1 expression in our cohort is higher than in bladder cancer but lower than or comparable to percents reported in melanoma and NSCLC. ${ }^{8}$ The prognostic significance of PD-L1 expression on tumor cells seems to differ per tumor type since a worse prognosis in renal cell cancer, ${ }^{24}$ gliomas ${ }^{25}$ and NSCLC, ${ }^{26}$ and a better prognosis in melanoma ${ }^{27}$ have been reported. Based on the prognostic value of the marginal and diffuse PD-L1 expression that we observed, we suggest that future studies evaluating the prognostic value of PD-L1 should consider the different expression patterns, especially as we have also observed these differences in cervical cancer. ${ }^{19}$ However, substantial response rates to anti-PD-L1 therapy have been reported even in PD-L1 ${ }^{-}$tumors. ${ }^{4}$ This warrants further investigation on the usefulness of PD-L1 expression as a biomarker in various tumor types.

In bladder cancer PD-L1+ infiltrating immune cells were present in $27 \%$ of tumors, which is a low incidence compared to our cohort. ${ }^{25}$ It was suggested that 
PD-L1 expression on infiltrating immune cells is more predictive of response to immunotherapy than expression on tumor cells. ${ }^{11,18,28}$ In addition, poor prognosis has also been associated with PD-L1+ immune-cells. ${ }^{28,29}$ In contrast to results in a recent study of cervical carcinoma, we found no significant prognostic value for $\mathrm{PD}-\mathrm{L} 1^{+} \mathrm{TIMs}$ or a PD-L1+ cordon in the whole cohort or in the HPV negative and positive subgroups. ${ }^{19}$

Some limitations of the current study should be noted. The use of PD-L1 as a prognostic or predictive biomarker is complicated by technical and biological issues. ${ }^{8}$ Differences in the choice of antibody, the scoring method, the cutoff value and whether cytoplasmic staining is considered, all result in different outcomes. ${ }^{8,23}$ In addition, the identification of staining patterns and using 1\% as a cutoff for positivity was arbitrary. However, the clone used in this study has been validated in several studies and the patterns identified were clearly distinguishable. ${ }^{15,30}$ In the current series we applied CD163 staining on sequential slides to identify the PD-L1+ $1^{+}$IMs, and PD-L1+ macrophages in the cordon and in the stromal compartment. In future studies, multicolor immunohistochemical analysis will allow for the identification of different PD- $L 1^{+}$subsets in a single slide. ${ }^{19}$ Further, in the current study, we did not analyze PD-L1 expression in Iymph node metastases, which may be different from expression levels and patterns in the primary tumor. Therefore, our results do not suggest an effect of immunotherapy on lymph node metastases. Future studies should address this issue. PD-L1 expression had a distinct prognostic value in this study. Although no clinical efficacy of checkpoint immunotherapy can be guaranteed, we believe that these results support the rationale of PD-1/PD-L1 checkpoint immunotherapy effectiveness patients with penile cancer.

\section{Conclusions}

This study shows that PD-L1 was expressed in almost half of the penile cancers and mostly in hrHPV ${ }^{-}$tumors. The pattern of PD-L1 expression was a prognostic factor as patients with strong PD-L1 expression at the tumorstroma interface showed a lower incidence of positive lymph nodes at pathological staging compared to those with PD-L1 negative findings, while a diffuse expression pattern was associated with poor disease specific survival. In the future, it would be interesting to unravel the biological background of the mechanisms leading to these different patterns of PD-L1 expression. Our results support immunotherapy trials targeting the PD-1/PD-L1-checkpoint axis in patients penile cancer. 
Chapter 2

\section{Acknowledgements}

NKI-AVL Core Facility Molecular Pathology and Biobanking (CFMPB) provided the Netherlands Cancer Institute - Antoni van Leeuwenhoek with biobank material, staining and technical support. 


\section{REFERENCES}

1. Kirrander P, Sherif A, Friedrich B, et al: Swedish National Penile Cancer Register: incidence, tumour characteristics, management and survival. BJU Int. 2016; 117: 287-92.

2. Barnholtz-Sloan JS, Maldonado JL, Pow-sang J, et al: Incidence trends in primary malignant penile cancer. Urol. Oncol. 2007; 25: 361-367.

3. Moses KA, Winer A, Sfakianos JP, et al: Contemporary management of penile cancer: greater than 15 year MSKCC experience. Can. J. Urol. 2014; 21: 7201-7206.

4. Carbognin L, Pilotto S, Milella M, et al: Differential Activity of Nivolumab, Pembrolizumab and MPDL3280A according to the Tumor Expression of Programmed Death-Ligand-1 (PD-L1): Sensitivity Analysis of Trials in Melanoma, Lung and Genitourinary Cancers. PLoS One 2015; 10: e0130142.

5. Borghaei H, Paz-Ares L, Horn L, et al: Nivolumab versus Docetaxel in Advanced Nonsquamous Non-Small-Cell Lung Cancer. N. Engl. J. Med. 2015; 373: 1627-1639.

6. Schreiber RD, Old LJ and Smyth MJ: Cancer immunoediting: integrating immunity's roles in cancer suppression and promotion. Science 2011; 331: 1565-1570.

7. Zou W, Wolchok JD and Chen L: PD-L1 (B7-H1) and PD-1 pathway blockade for cancer therapy: Mechanisms, response biomarkers, and combinations. Sci. Transl. Med. 2016; 8: 328rv4.

8. Patel SP and Kurzrock R: PD-L1 Expression as a Predictive Biomarker in Cancer Immunotherapy. Mol. Cancer Ther. 2015; 14: 847-856.

9. Kim HS, Lee JY, Lim SH, et al: Association Between PD-L1 and HPV Status and the Prognostic Value of PD-L1 in Oropharyngeal Squamous Cell Carcinoma. Cancer Res. Treat. 2015; 117: 165-70.

10. Mezache L, Paniccia B, Nyinawabera A, et al: Enhanced expression of PD L1 in cervical intraepithelial neoplasia and cervical cancers. Mod. Pathol. 2015; 28: 1594-1602.

11. Teng MWL, Ngiow SF, Ribas A, et al: Classifying Cancers Based on T-cell Infiltration and PD-L1. Cancer Res. 2015; 75: 2139-2145.

12. Udager AM, Liu T-Y, Skala SL, et al: Frequent PD-L1 expression in primary and metastatic penile squamous cell carcinoma: potential opportunities for immunotherapeutic approaches. Ann. Oncol. Off. J. Eur. Soc. Med. Oncol. 2016; 27: 1706-12.

13. Djajadiningrat RS, Jordanova ES, Kroon BK, et al: Human papillomavirus prevalence in invasive penile cancer and association with clinical outcome. J. Urol. 2015; 193: 526-31.

14. Djajadiningrat RS, Horenblas S, Heideman DAM, et al: Classic and nonclassic HLA class I expression in penile cancer and relation to HPV status and clinical outcome. J. Urol. 2015; 193: 1245-1251.

15. Taube JM, Anders RA, Young GD, et al: Colocalization of inflammatory response with B7-h1 expression in human melanocytic lesions supports an adaptive resistance mechanism of immune escape. Sci. Transl. Med. 2012; 4: 127ra37.

16. Weber JS, D'Angelo SP, Minor D, et al: Nivolumab versus chemotherapy in patients with advanced melanoma who progressed after anti-CTLA-4 treatment (CheckMate 037): A randomised, controlled, open-label, phase 3 trial. Lancet Oncol. 2015; 16: 375-384.

17. Motzer RJ, Rini BI, McDermott DF, et al: Nivolumab for Metastatic Renal Cell Carcinoma: Results of a Randomized Phase II Trial. J. Clin. Oncol. 2015; 33: 14301437. 
18. Powles T, Eder JP, Fine GD, et al: MPDL3280A (anti-PD-L1) treatment leads to clinical activity in metastatic bladder cancer. Nature 2014; 515: 558-562.

19. Heeren AM, Punt S, Bleeker MC, et al: Prognostic effect of different PD-L1 expression patterns in squamous cell carcinoma and adenocarcinoma of the cervix. Mod. Pathol. an Off. J. United States Can. Acad. Pathol. Inc. 2016; 29: 753-63.

20. Kryczek I, Wei S, Gong W, et al: Cutting edge: IFN-gamma enables APC to promote memory Th17 and abate Th1 cell development. J. Immunol. 2008; 181: 5842-5846.

21. Taube JM, Young GD, McMiller TL, et al: Differential Expression of ImmuneRegulatory Genes Associated with PD-L1 Display in Melanoma: Implications for PD-1 Pathway Blockade. Clin. Cancer Res. 2015; 21: 3969-3976.

22. Howitt BE, Sun HH, Roemer MGM, et al: Genetic Basis for PD-L1 Expression in Squamous Cell Carcinomas of the Cervix and Vulva. JAMA Oncol. 2016; 2: 518-522.

23. Ilie M, Hofman $V$, Dietel $M$, et al: Assessment of the PD-L1 status by immunohistochemistry: challenges and perspectives for therapeutic strategies in lung cancer patients. Virchows Arch. 2016; 268: 511-25.

24. Safaei HR, Rostamzadeh $A$, Rahmani $O$, et al: Prognostic investigations of B7-H1 and B7-H4 expression levels as independent predictor markers of renal cell carcinoma. Tumour Biol. 2015; 37: 7583-7.

25. Zeng J, Zhang X-K, Chen H-D, et al: Expression of programmed cell death-ligand 1 and its correlation with clinical outcomes in gliomas. Oncotarget 2016; 7: 8944-55.

26. Wang A, Wang HY, Liu Y, et al: The prognostic value of PD-L1 expression for non-small cell lung cancer patients: a meta-analysis. Eur. J. Surg. Oncol. 2015; 41: 450-456.

27. Gadiot J, Hooijkaas AI, Kaiser ADM, et al: Overall survival and PD-L1 expression in metastasized malignant melanoma. Cancer 2011; 117: 2192-2201.

28. Sun S, Fei X, Mao Y, et al: PD-1(+) immune cell infiltration inversely correlates with survival of operable breast cancer patients. Cancer Immunol. Immunother. 2014; 63: 395-406.

29. Gatalica Z, Snyder C, Maney T, et al: Programmed cell death 1 (PD-1) and its ligand (PD-L1) in common cancers and their correlation with molecular cancer type. Cancer Epidemiol. Biomarkers Prev. 2014; 23: 2965-2970.

30. Mahoney KM, Sun H, Liao X, et al: PD-L1 Antibodies to Its Cytoplasmic Domain Most Clearly Delineate Cell Membranes in Immunohistochemical Staining of Tumor Cells. Cancer Immunol. Res. 2015; 3: 1308-1315. 
Supplementary table 1: Clinicopathological characteristics

\begin{tabular}{|c|c|c|c|c|c|}
\hline Characteristic & & $\begin{array}{c}\text { PD-L1 } \geq 1 \% \\
N=96(\%)\end{array}$ & $\begin{array}{l}\text { PD-L1 <1\% } \\
\mathrm{N}=104(\%)\end{array}$ & $\begin{array}{c}\text { Total } \\
\mathrm{N}=200(\%)\end{array}$ & P-value* \\
\hline pT-stage & $\begin{array}{l}\text { T1a } \\
\text { T1b } \\
\text { T2 } \\
\text { T3 } \\
\text { T4 }\end{array}$ & $\begin{aligned} 17 & (17.7) \\
5 & (5.2) \\
65 & (67.7) \\
8 & (8.3) \\
1 & (1.0)\end{aligned}$ & $\begin{array}{c}29(27.9) \\
5(4.8) \\
60(57.7) \\
7(6.7) \\
3(2.9)\end{array}$ & $\begin{array}{c}46(23.0) \\
10(5.0) \\
125(62.5) \\
15(7.5) \\
4(2.0)\end{array}$ & 0.40 \\
\hline Grade & $\begin{array}{l}\text { Well } \\
\text { Intermediate } \\
\text { Poorly } \\
\text { Unknown }\end{array}$ & $\begin{array}{l}27(28.1) \\
44(45.8) \\
25(26.0) \\
\quad-\end{array}$ & $\begin{array}{l}48(46.2) \\
43(41.3) \\
12(11.5) \\
1(1.0)\end{array}$ & $\begin{array}{c}75(37.5) \\
87(43.5) \\
37(18.5) \\
1(0.5)\end{array}$ & $<0.01$ \\
\hline $\begin{array}{l}\text { Lymphovascular } \\
\text { invasion }\end{array}$ & $\begin{array}{l}\text { No } \\
\text { Yes } \\
\text { Unknown }\end{array}$ & $\begin{array}{c}83(86.5) \\
12(12.5) \\
1(1.0)\end{array}$ & $\begin{array}{c}85(81.7) \\
18(17.0) \\
1(1.0)\end{array}$ & $\begin{array}{c}168(84.0) \\
30(15.0) \\
2(1.0)\end{array}$ & 0.34 \\
\hline $\begin{array}{l}\text { Histological } \\
\text { subtype }\end{array}$ & $\begin{array}{l}\text { Squamous cell carcinoma } \\
\text { Papillary } \\
\text { Basaloid } \\
\text { Warty } \\
\text { Verrucous } \\
\text { Mixed basaloid-squamous cell } \\
\text { Cuniculatum } \\
\text { Sarcomatoid } \\
\text { Pseudo-hyperplastic } \\
\text { Unknown }\end{array}$ & $\begin{array}{c}82(85.4) \\
4(4.2) \\
2(2.1) \\
2(2.1) \\
- \\
1(1.0) \\
1(1.0) \\
1(1.0) \\
1(1.0) \\
2(2.1)\end{array}$ & $\begin{array}{c}86(82.7) \\
5(4.8) \\
3(2.9) \\
3(2.9) \\
4(3.8) \\
1(1.0) \\
- \\
- \\
- \\
2(1.9)\end{array}$ & $\begin{array}{c}168(84.0) \\
9(4.5) \\
5(2.5) \\
5(2.5) \\
4(2.0) \\
2(1.0) \\
1(0.5) \\
1(0.5) \\
1(0.5) \\
4(2.0)\end{array}$ & 0.51 \\
\hline $\begin{array}{l}\text { Exophytic } \\
\text { growth }\end{array}$ & $\begin{array}{l}\text { No } \\
\text { Yes } \\
\text { Partially } \\
\text { Unknown }\end{array}$ & $\begin{array}{c}63(65.6) \\
22(22.9) \\
6(6.3) \\
5(5.2)\end{array}$ & $\begin{array}{c}63(60.6) \\
29(27.9) \\
5(4.8) \\
7(6.7)\end{array}$ & $\begin{array}{c}126(63.0) \\
51(25.5) \\
11(5.5) \\
12(6.0)\end{array}$ & 0.65 \\
\hline Tumor size & $\begin{array}{l}<3 \mathrm{~cm} \\
\geq 3 \mathrm{~cm} \\
\text { Unknown }\end{array}$ & $\begin{array}{c}44(45.8) \\
50(52.1) \\
2(2.1)\end{array}$ & $\begin{array}{c}48(46.2) \\
56(53.8) \\
-\end{array}$ & $\begin{array}{c}92(46.0) \\
106(53.0) \\
2(1.0)\end{array}$ & 0.93 \\
\hline HPV-status & $\begin{array}{l}\text { Negative } \\
\text { Positive low-risk } \\
\text { Positive high-risk } \\
\text { Positive both } \\
\text { Unknown }\end{array}$ & $\begin{array}{c}78(81.3) \\
- \\
16(16.7) \\
1(1.0) \\
1(1.0)\end{array}$ & $\begin{aligned} 68 & (65.4) \\
2 & (1.9) \\
30 & (28.8) \\
2 & (1.9) \\
2 & (1.9)\end{aligned}$ & $\begin{array}{c}146(73.0) \\
2(1.0) \\
46(23.0) \\
3(1.5) \\
3(1.5)\end{array}$ & $\begin{array}{c}\text { Overall 0.07; } \\
\text { hrHPV 0.03; } \\
\text { IrHPV } 0.37\end{array}$ \\
\hline $\begin{array}{l}\text { Lymph node } \\
\text { positivity }\end{array}$ & $\begin{array}{l}\text { No } \\
\text { Yes }\end{array}$ & $\begin{array}{l}65(67.7) \\
31(32.3)\end{array}$ & $\begin{array}{l}75(72.1) \\
29(27.9)\end{array}$ & $\begin{array}{c}140(70.0) \\
60(30.0)\end{array}$ & 0.50 \\
\hline $\begin{array}{l}\text { Extranodal } \\
\text { extension }\end{array}$ & $\begin{array}{l}\text { No } \\
\text { Yes } \\
\text { Unknown } \\
\text { Negative lymph nodes }\end{array}$ & $\begin{array}{l}16(16.7) \\
12(12.5) \\
3(3.1) \\
65(67.7)\end{array}$ & $\begin{aligned} 22 & (21.2) \\
6 & (5.8) \\
1 & (1.0) \\
75 & (72.1)\end{aligned}$ & $\begin{array}{c}38(19.0) \\
18(9.0) \\
4(2.0) \\
140(70.0)\end{array}$ & $0.09^{* *}$ \\
\hline
\end{tabular}

* excluding unknown statuses; Chi $^{2}$ or Fishers exact test

** excluding patients with negative lymph nodes and unknown extension. 
Supplementary table 2: Univariable and multivariable logistic regression analyses for lymph node status

\begin{tabular}{|c|c|c|c|}
\hline Variable & Tested & OR $(95 \% \mathrm{Cl})$ & P-value \\
\hline \multicolumn{4}{|l|}{ Univariable logistic regression analysis } \\
\hline Tumor size $(\mathrm{cm})$ & Continuous & $1.12(0.998-1.28)$ & 0.09 \\
\hline pT-stage & Overall & & $<0.01$ \\
\hline $1 b$ & Compared to T-stage 1a & $5.00(1.09-22.98)$ & 0.04 \\
\hline 2 & Compared to T-stage $1 \mathrm{a}$ & $3.71(1.47-9.37)$ & $<0.01$ \\
\hline 3 & Compared to T-stage 1a & $7.50(2.05-27.48)$ & $<0.01$ \\
\hline 4 & Compared to T-stage $1 \mathrm{a}$ & $37.50(3.72-377.73)$ & $<0.01$ \\
\hline Grade of differentiation & Overall & & $<0.01$ \\
\hline Grade 2 & Compared to grade 1 & $6.19(2.56-14.93)$ & $<0.01$ \\
\hline Grade 3 & Compared to grade 1 & $15.99(5.81-44.00)$ & $<0.01$ \\
\hline LVI & Present vs. absent & $4.19(1.92-9.16)$ & $<0.01$ \\
\hline HrHPV & Negative vs. positive & $1.29(0.64-2.60)$ & $<0.47$ \\
\hline PD-L1 tumor (\%) & Continuous & $1.01(0.10-1.03)$ & 0.18 \\
\hline PD-L1 tumor & $\geq 1 \%$ vs. $<1 \%$ & $1.23(0.67-2.26)$ & 0.50 \\
\hline PD-L1 pattern & Diffuse vs. margin & $5.13(2.05-12.89)$ & $<0.01$ \\
\hline PD-L1+ stroma & Positive vs. negative & $0.80(0.40-1.61)$ & 0.54 \\
\hline PD-L1+ TIM & Present vs. absent & $1.70(0.87-3.32)$ & 0.12 \\
\hline $\mathrm{PD}-\mathrm{L}^{+}$cordon & Present vs. absent & $1.17(0.51-2.67)$ & 0.70 \\
\hline \multicolumn{4}{|l|}{$\begin{array}{l}\text { Multivariable logistic regression } \\
\text { analysis }\end{array}$} \\
\hline pT-stage & Overall & & 0.28 \\
\hline $1 b$ & Compared to T-stage 1a & $1.39(0.23-8.34)$ & 0.72 \\
\hline 2 & Compared to T-stage $1 \mathrm{a}$ & $1.82(0.58-5.71)$ & 0.30 \\
\hline 3 & Compared to T-stage $1 \mathrm{a}$ & $4.67(0.98-22.36)$ & 0.05 \\
\hline 4 & Compared to T-stage 1a & 7.69 (0.37 - 159.13) & 0.19 \\
\hline Grade of differentiation & Overall & & $<0.01$ \\
\hline Grade 2 & Compared to grade 1 & $4.48(1.61-12.48)$ & $<0.01$ \\
\hline Grade 3 & Compared to grade 1 & $9.97(2.97-33.52)$ & $<0.01$ \\
\hline LVI & Present vs. absent & $2.78(1.04-7.44)$ & 0.04 \\
\hline PD-L1 pattern & Overall & & $<0.01$ \\
\hline Diffuse & Compared to PD-L1- & $2.11(0.83-5.34)$ & 0.12 \\
\hline Margin & Compared to PD-L1- & $0.40(0.16-0.99)$ & 0.05 \\
\hline \multicolumn{4}{|l|}{$\begin{array}{l}\text { Multivariable logistic regression } \\
\text { analysis in only hrHPV- cases }\end{array}$} \\
\hline pT-stage & Overall & & 0.40 \\
\hline $1 b$ & Compared to T-stage 1a & $6.28(0.39-100.10)$ & 0.19 \\
\hline 2 & Compared to T-stage $1 \mathrm{a}$ & $1.40(0.36-5.46)$ & 0.63 \\
\hline 3 & Compared to T-stage $1 \mathrm{a}$ & $4.14(0.63-26.99)$ & 0.14 \\
\hline 4 & Compared to T-stage 1a & $3.73(0.10-143.25)$ & 0.48 \\
\hline Grade of differentiation & Overall & & $<0.01$ \\
\hline Grade 2 & Compared to grade 1 & $9.45(2.85-31.33)$ & $<0.01$ \\
\hline Grade 3 & Compared to grade 1 & $13.59(2.95-62.63)$ & $<0.01$ \\
\hline LVI & Present vs. absent & $5.69(1.56-20.71)$ & $<0.01$ \\
\hline PD-L1 pattern & Overall & & 0.03 \\
\hline Diffuse & Compared to PD-L1- & $1.10(0.34-3.59)$ & 0.87 \\
\hline Margin & Compared to PD-L1- & $0.25(0.08-0.78)$ & 0.02 \\
\hline Multivariable ROC analysis & & C-index $(95 \% \mathrm{Cl})$ & SE \\
\hline T-stage, grade of differentiation and LVI & $\begin{array}{l}\text { Without PD-L1 pattern } \\
\text { With PD-L1 pattern }\end{array}$ & $\begin{array}{l}77.8(71.0-84.5) \\
81.8(75.6-88.0)\end{array}$ & $\begin{array}{l}3.4 \\
3.2\end{array}$ \\
\hline
\end{tabular}

$\mathrm{Cl}$; confidence interval, $\mathrm{ROC}$; receiver operating characteristic, SE; standard error. 
Supplementary table 3: Univariable and multivariable Cox Regression survival analyses

\begin{tabular}{|c|c|c|c|}
\hline Variable & Tested & $\mathrm{HR}(95 \% \mathrm{Cl})$ & P-value \\
\hline \multicolumn{4}{|l|}{ Univariable Cox analysis } \\
\hline Lymph node status & Positive vs. negative & $25.78(7.79-85.30)$ & $<0.01$ \\
\hline Tumor size (cm) & Continuous & $1.20(1.07-1.37)$ & $<0.01$ \\
\hline pT-stage & Compared to T-stage $1 \mathrm{a}$ & & \\
\hline $1 b$ & & $8.95(1.49-53.65)$ & 0.02 \\
\hline 2 & & $2.81(0.64-12.35)$ & 0.17 \\
\hline 3 & & $9.09(1.76-46.84)$ & $<0.01$ \\
\hline 4 & & $49.19(9.46-255.72)$ & $<0.01$ \\
\hline Grade of differentiation & Compared to grade 1 & & \\
\hline Grade 2 & & $2.11(0.75-6.00)$ & 0.16 \\
\hline Grade 3 & & $5.98(2.11-16.97)$ & $<0.01$ \\
\hline LVI & Present vs. absent & $3.25(1.47-7.18)$ & $<0.01$ \\
\hline HrHPV & Negative vs. positive & $4.83(1.15-20.30)$ & 0.03 \\
\hline PD-L1 tumor (\%) & Continuous & $1.00(0.98-1.02)$ & 0.93 \\
\hline PD-L1+ tumor & $\geq 1 \%$ vs. $<1 \%$ & $1.71(0.80-3.65)$ & 0.17 \\
\hline PD-L1 pattern & Diffuse vs. margin & $4.38(1.54-12.43)$ & $<0.01$ \\
\hline Diffuse & Compared to PD-L1- & $3.39(1.49-7.67)$ & $<0.01$ \\
\hline Margin & Compared to PD-L1- & $0.78(0.27-2.25)$ & 0.65 \\
\hline PD-L1+ stroma & Positive vs. negative & $1.36(0.51-3.59)$ & 0.54 \\
\hline PD-L1+ TIM & Present vs. absent & $1.73(0.79-3.81)$ & 0.17 \\
\hline PD-L1+ cordon & Present vs. absent & $0.87(0.30-2.51)$ & 0.79 \\
\hline \multicolumn{4}{|c|}{ Multivariable Cox analysis } \\
\hline Lymph node status & Positive vs. negative & $40.03(9.60-166.88)$ & $<0.01$ \\
\hline Tumor size $(\mathrm{cm})$ & Continuous & $1.30(1.12-1.51)$ & $<0.01$ \\
\hline Grade of differentiation & Compared to grade 1 & & \\
\hline Grade 2 & & $0.33(0.09-1.22)$ & 0.10 \\
\hline Grade 3 & & $1.08(0.30-3.90)$ & 0.91 \\
\hline LVI & Present vs. absent & $1.6(0.62-4.33)$ & 0.32 \\
\hline HrHPV & Negative vs. positive & $11.30(2.37-53.80)$ & $<0.01$ \\
\hline PD-L1 pattern & Compared to PD-L1- & & \\
\hline Diffuse & & $2.58(1.02-6.50)$ & 0.04 \\
\hline Margin & & $0.45(0.13-1.53)$ & 0.20 \\
\hline \multicolumn{4}{|c|}{$\begin{array}{l}\text { Multivariable Cox analysis } \\
\text { in only hrHPV- cases }\end{array}$} \\
\hline Lymph node status & Positive vs. negative & $100.18(18.26-549.69)$ & $<0.01$ \\
\hline Tumor size $(\mathrm{cm})$ & Continuous & $1.42(1.20-1.67)$ & $<0.01$ \\
\hline Grade of differentiation & Compared to grade 1 & & \\
\hline Grade 2 & & $0.20(0.05-0.78)$ & 0.02 \\
\hline Grade 3 & & $0.99(0.28-3.50)$ & 0.99 \\
\hline LVI & Positive vs. negative & $1.87(0.62-5.67)$ & 0.27 \\
\hline PD-L1 pattern & Compared to PD-L1- & & \\
\hline Diffuse & & $3.92(1.46-10.52)$ & 0.01 \\
\hline Margin & & $0.31(0.08-1.25)$ & 0.10 \\
\hline
\end{tabular}




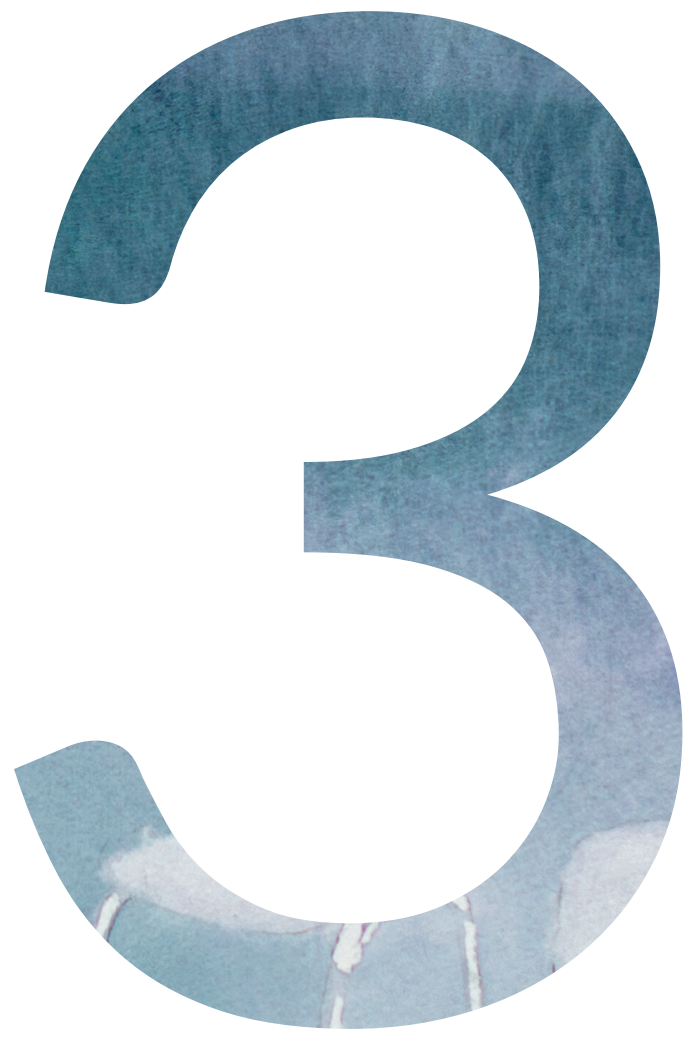


Chapter 3

The prognostic value of

Sarah R. Ottenhof, Rosa S. Djajadiningrat, Helene Hoegsbro Thygesen, Pamela J. Jakobs, Katarzyna Jóźwiak, Anne M. Heeren, Jeroen de Jong, Joyce Sanders, Simon Horenblas, Ekaterina S. Jordanova 


\section{ABSTRACT}

The host's immune system plays a pivotal role in many tumor types, including squamous cell carcinomas (SCCS). We aim to identify immunological prognosticators for lymph node metastases (LNM) and disease specific survival (DSS) in penile SCC. For this retrospective observational cohort study, penile SCC patients $(n=213)$ treated in the Netherlands Cancer Institute, were selected if sufficient formalin-fixed paraffin-embedded tumor material was available. Analysis included previously described high-risk human papilloma virus (hrHPV) status, immunohistochemical scores for classical and non-classical human leukocyte antigen (HLA) class I, programmed death ligand-1 (PD-L1) expression, and novel data on tumor-infiltrating macrophages and cytotoxic an regulatory T-cells. Clinicopathological characteristics and extended follow-up were also included. Regression analyses investigated relationships of the immune parameters with LNM and DSS.

In the total cohort, diffuse PD-L1 tumor-cell expression, CD163+ macrophage infiltration, non-classical HLA class I upregulation, and low stromal CD8 ${ }^{+}$T-cell infiltration were all associated with LNM. In the multivariable model, only tumor PD-L1 expression remained a significant predictor for LNM (odds ratio (OR) 2.8, $p=0.05)$. hrHPV negativity and diffuse PD-L1 tumor-cell expression were significantly associated with poor DSS and remained so upon correction for clinical parameters [hazard ratio (HR) 9.7, $p<0.01$ and HR 2.8, $p=0.03$ ]. The only immune factor with different expression in $\mathrm{HPV}^{+}$and $\mathrm{HPV}^{-}$tumors was PD-L1, with higher PD-L1 expression in the latter ( $p=0.03$ ).

In the HPV - cohort ( $n=158$ ), LNM were associated with diffuse PD-L1 tumor-cell expression, high intratumoral CD163+ macrophage infiltration, and low number of stromal CD8 ${ }^{+}$T-cells. The first two parameters were also linked to DSS. In the multivariable regression model, diffuse PD-L1 expression remained significantly unfavorable for DSS (HR 5.0, $p<0.01)$.

These results emphasize the complexity of the tumor microenvironment in penile cancer and point toward several possible immunotherapy targets. Here described immune factors can aid risk-stratification and should be evaluated in clinical immunotherapy studies to ultimately lead to patient tailored treatment. 


\section{INTRODUCTION}

Penile squamous cell carcinoma (SCC) is a rare disease with an incidence of less than 1/100,000 in Western countries.,2 The prognosis for early stage penile cancer patients is good (5-year survival without lymphogenic spread is $96 \%$ ) but worsens gradually with presence of lymph node metastases (LNM). 2,3 Surgery is the mainstay of penile cancer treatment, for both primary tumors and LNM. Only in advanced stages (e.g., pelvic lymph node involvement or irresectable disease) multimodal treatment is necessary, mostly in the form of neoadjuvant chemotherapy or adjuvant radiation. ${ }^{4}$

In 20-50\% of the patients, penile SCC is induced by a persistent infection with high-risk human papilloma virus (hrHPV). 5,6 Diagnosis, treatment, and follow-up are the same for hrHPV-negative (hrHPV ${ }^{-}$) and hrHPV-positive $\left(\mathrm{hrHPV}^{+}\right)$tumors. ${ }^{4}$ Nevertheless, patients with hrHPV $^{+}$tumors have a better disease-specific survival (DSS) than patients with hrHPV- tumors (5-year DSS of $96 \%$ vs. $82 \%$ respectively).?

The difference in patient outcomes between hrHPV ${ }^{+}$and non-virally induced penile cancer may be partially explained by different immune escape mechanisms. ${ }^{8-14}$ Surely, immunosuppressive and immunostimulating factors in the tumor microenvironment (TME) co-determine the course of disease in many different cancers, but relatively little is known about penile SCC. ${ }^{15,16}$

For example, in head and neck squamous cell carcinomas (HNSCCs) higher levels of tumor-infiltrating immune cells in hrHPV ${ }^{+}$tumors are indicated as pivotal role players in a better response to standard therapy in comparison to hrHPV ${ }^{-}$tumors. ${ }^{17-19}$ This concerns high levels of intratumoral CD8 ${ }^{+}$and CD3 ${ }^{+}$ T-lymphocytes but also antigen presenting cells such as myeloid dendritic cells. ${ }^{18-21}$ CD $^{+}$cytotoxic T-cells are capable of immediate tumor-cell killing and therewith are the effectors of anti-tumor response. ${ }^{21}$ Regulatory T-cells (Tregs) are well known for their detrimental effect on the immune response. ${ }^{10,12,22}$ However, associations of Tregs with clinical outcome remain controversial. High numbers of FoxP3+ Tregs were associated with early stage disease and better overall survival in HNSCC, but with adverse patient outcome in colorectal cancer and non-small-cell lung carcinoma. ${ }^{18,23-25}$ Cytotoxic and Treg subpopulations have both been described as prognostic factors separately, as well as the ratio between the two.15,19,20,26 An increased CD8/FoxP3-ratio at diagnosis has been associated with responsiveness to immunotherapy in renal cancer and 
melanoma. ${ }^{15,27-29}$ Tumor infiltrating macrophages (TIM) are usually macrophages with an immunosuppressive M2-phenotype. ${ }^{30-32}$ These macrophages are marked by CD163, and are associated with T-cell response suppression, migration, and treatment evasion. ${ }^{30,31}$ High CD 163+ macrophage infiltration was associated with high disease stage and LNM in hrHPV ${ }^{+}$cervical cancer, and with poor survival in oral SCC. ${ }^{32,33}$

In penile cancer, various immune escape mechanisms in the TME have been studied (partly by our group). ${ }^{8-14}$ In a multivariable analysis by Vasallo et al., presence of FoxP3-positive Iymphocytes (presumably Tregs) was associated with poor disease free survival. ${ }^{10}$ In addition, a decreased CD8/FoxP3-ratio was associated with tumor progression during follow up. ${ }^{12}$ Human leukocyte antigen (HLA) class I was assessed with immunohistochemical (IHC) staining on a tissue microarray (TMA). A prognostic role was only found for HLA-A expression that was associated with decreased overall survival. ${ }^{9}$ No differences in HLA expression were observed between $\mathrm{HPV}^{-}$and $\mathrm{HPV}^{+}$tumors. Programmed death ligand-1 (PD-L1) expression was assessed in multiple studies, using different antibodies and techniques. ${ }^{10-14} \mathrm{HPV}^{-}$penile cancer cells are more often PD-L $1^{+}$. Tumor cell PD-L1-expression was associated with worse DSS and LNM, especially a diffuse expression of PD-L1 throughout the tumor fields. ${ }^{11,13,14}$

To compare the prognostic value of all these parameters, and to determine which factors have the strongest associations with patient outcomes, different factors from the TME should be evaluated in an integrative analysis. The aim of this study was to gain insight in the TME, and to identify possible associations between TME factors and LNM/DSS in patients with penile cancer.

In this retrospective observational cohort study, we investigated previously determined factors (HPV status, classical and non-classical HLA class I, and PDL1 expression) in combination with novel data on tumor-infiltrating cytotoxic T-cells, Tregs, and M2-polarized macrophages. $7,9,11$

\section{MATERIALS AND METHODS}

\section{Study population and tissue samples}

Between 2001 and 2009, 487 consecutive patients were diagnosed with penile SCC in the Netherlands Cancer Institute, Amsterdam. All were considered for inclusion, according to the following criteria. Exclusion criteria were non-invasive 
carcinoma, neoadjuvant non-surgical treatment, no tumor tissue available in our institutional biobank (mostly because of surgical removal elsewhere or treatment with laser ablation). Inclusion criterion was that sufficient archived tissue needed to be available in our institutional biobank. Sufficient archived formalin-fixed, paraffinembedded (FFPE) material was available from 216 patients. All were staged and surgically treated in a standardized way. ${ }^{34}$ Clinical follow-up data were updated. Patients were usually clinically followed for 5 years, after that, patient status was sometimes available through municipal administration. This study was carried out with approval of the institutional medical ethical committee that considered this study not falling within the scope of the act of research involving human subjects, it was also approved by the translational research board of our institute.

Evaluation of the IHC stainings on $5 \mu \mathrm{m}$ sections was performed by two researchers (RSD and ESJ or SRO and ESJ) and an experienced uropathologist $(\mathrm{JdJ})$. Three patients were excluded because a majority of the parameters could not be analyzed (e.g., no invasive tumor present in sample).

\section{HrHPV-typing}

For protocols of hrHPV-typing, classical HLA, non-classical HLA and PD-L1 IHC analyses, we refer to our previous reports. ${ }^{7,9,11}$ In short, hrHPV-status was determined on 212 tissue samples using GP5 $5^{+} 6^{+}$PCR enzyme-immunoassay for 14 different HPV types. ${ }^{7}$

\section{Immunohistochemistry}

A TMA of 168 samples was immunohistochemically analyzed for HLA class I expression with the following antibodies: HCA2 (HLA-A), HC10 (HLA-B/C; both provided by prof. Neefjes of our institute), anti-beta-2-microglobulin ( $\beta 2 \mathrm{~m}$; DAKO, Denmark), MEM-E/02 (HLA-E; Bio-Rad, USA) and 4H84 (HLA-G; from BD Pharmingen, USA). ${ }^{9}$ PD-L1 was determined on 213 whole-mount sections using the E1L3N clone (Cell Signaling, USA). ${ }^{11}$

Whole-mount sections from 213 FFPE tissue blocks were immunohistochemically stained for CD8 (C8/144B, DAKO, Denmark), FoxP3 (236A/E7, AbCam, England), and CD163 (MRQ-26, Cell Marque, Rocklin, USA) using the Ventana protocol and autostainer with heat induced antigen retrieval. Details of different IHC stainings are summarized in Table S1 in Supplementary Material. 


\section{Immunofluorescent double-staining}

Twelve randomly selected cases (six hrHPV ${ }^{-}$and six hrHPV tumors) were double-stained with primary antibodies CD163 (10D6, NCL-CD163, Novocastra, Germany) and CD68 (514H12, MCA1815, Bio-Rad, UK). Secondary antibodies from Life Technologies, USA were used for detection. The slides were analyzed manually using a fully motorized digital imaging fluorescence microscope (Axiovert-200M, Germany). More details of these stainings can be found in Table

\section{S1 in Supplementary Material.}

\section{Scoring methods}

Human leukocyte antigen-A, HLA-B/C, and $\beta 2 \mathrm{~m}$ expression were scored in a semiquantitative way with the quality control system proposed by de Ruiter et al. using intensity and percentage, resulting in three categories: negative, weak or positive. ${ }^{9,35}$ A combined score of HLA-A, HLA-B/C and $\beta 2 \mathrm{~m}$ grouped tumors into categories of classical HLA class I expression: normal expression (all three positive), complete downregulation (negative $\beta 2 \mathrm{~m}$ or negative HLA-A and HLA$\mathrm{B} / \mathrm{C}$ ), and partial downregulation (other combinations). Although HLA-A was significant in previous multivariable analysis of this cohort, the total score of classical HLA was used for analysis because it had stronger associations with updated variables (comparative data not shown). ${ }^{9}$ HLA-E and HLA-G were scored as absent/upregulated, and a combined score resulted in two groups: tumors into normal expression of non-classical HLA class I (both negative) and upregulation (one or both upregulated).

Only membranous staining of PD-L1 was scored. Percentage of positive cells was noted, cut-off for PD-L1 positivity of tumors was $\geq 1 \%$ of tumor cells. ${ }^{11,12,36,37}$ For $\mathrm{PD}-\mathrm{L} 1^{+}$tumors, the tumor expression-pattern was scored as diffuse (throughout the tumor fields) or margin (predominantly at the tumor-stroma margin. ${ }^{11}$ Immune cells in stroma were scored binary (negative or positive). PD-L1-positive TIMs were identified by size, shape and position (large, round, with dendrites, and in tumor fields) and were scored as present or absent. ${ }^{11}$

For $\mathrm{CD}^{+}$and FoxP3+ ${ }^{+}$-cell infiltration analysis, in each sample three peripheral and three central tumor focus fields were randomly selected in Aperio ImageScope (Leica Biosystems, Solms, Germany) and magnified by 20×. Each image (focus field) contained stroma and tumor fields. The number of positive pixels was determined with the semi-automatic computer program Image-J (NIH, Bethesda, MD, USA; http://rsb.info.nih.gov/ij/). Images were deconvoluted with a plug-in to the color red. By setting a threshold (at 180 for every image), the positive pixels 
were separated from the negative pixels. For every image tumor fields were digitally selected. The size of the total image area, tumor area and stromal area in pixels was noted, together with the number of positive pixels in these areas. The stromal values were calculated by subtracting the tumor area from the whole image area. In each tumor slide, the average number of positive pixels in the six focus fields was used for both CD8 and FoxP3 in tumor area and stromal area. T-cell ratios were calculated by dividing the $\mathrm{CD} 8^{+}$pixels by FoxP3+ pixels.

Semiquantitative analysis of CD163 in tumor and stroma determined low/ high infiltration of CD $163^{+}$cells. The 12 immunofluorescently stained samples (CD163/CD68) were qualitatively analyzed.

\section{Statistical analysis}

High-risk human papilloma virus subgroups were compared with respect to clinicopathological, tumor and stroma characteristics using chi-square test, Fishers' exact test, and t-tests for independent samples. Also, Kaplan-Meier estimated survival curves were plotted for HPV groups (Figure 1). Normality was assessed with Kolmogorov-Smirnov for all continuous parameters. T-cell parameters were transformed to log-scale to meet normality assumption when comparing means (t-test). Pixel counts of CD8 and FoxP3 were divided by 100,000 for statistical analyses so that hazard ratios (HRs) and odds ratios (ORs) represent a substantial change. A constant integer (of 1) was added to stromal CD8 and stroma FoxP3 to prevent division by zero when calculating T-cell ratios. A logistic regression was used to model odds of LNM, and a Cox regression to model DSS from date of diagnosis to death from penile cancer or last follow-up/ death from other cause. Characteristics that were significant or nearly significant in univariable models, were considered for final multivariable models found with a backward stepwise selection approach with models comparison using likelihood-ratio tests and $p>0.10$ as covariate exclusion criterion. All analyses were done using SPSS $B$ version 22 (IBM, Armonk, NY, USA) in collaboration with experienced statisticians ( $\mathrm{HHT}$ and $\mathrm{KJ}$ ). 


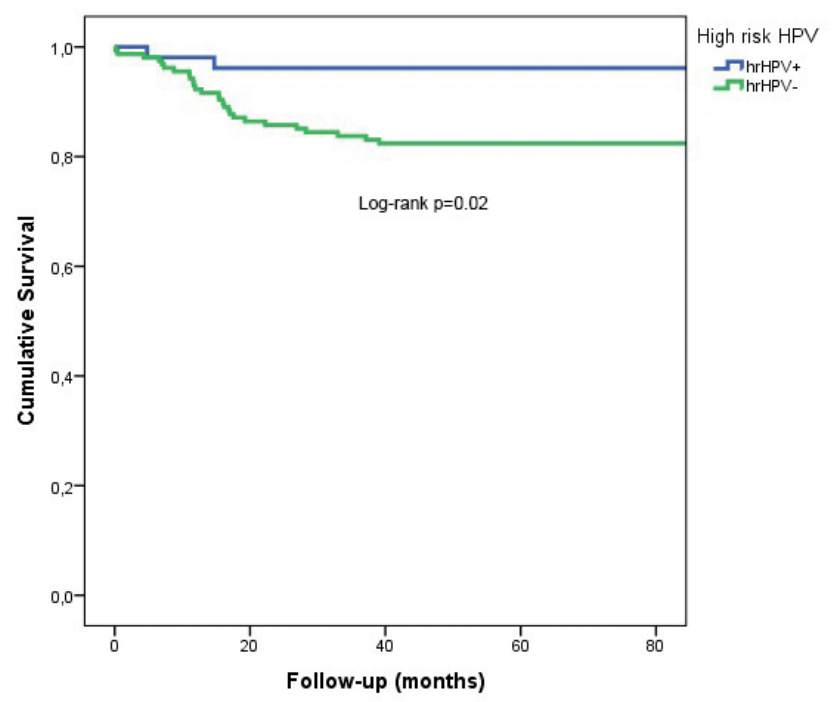

Figure 1. Kaplan-Meier survival plots with log-rank test analysis ofhigh-risk HPV-positive and -negative penile cancer cases.

\begin{tabular}{ccccccl}
\hline Baseline & 12 months & 24 months & 36 months & 48 months & 60 months & \\
\hline 52 & 52 & 49 & 48 & 48 & 45 & hrHPV $^{+}$ \\
158 & 142 & 130 & 142 & 121 & 115 & hrHPV $^{-}$ \\
\hline
\end{tabular}

\section{RESULTS}

\section{Clinicopathological characteristics}

In this cohort ( $n=213)$, 68 patients $(31.9 \%)$ had LNM, and 87 patients $(40.8 \%)$ died during follow-up; 29 patients (13.6\%) died of penile cancer (on average after 14.7 months). Median overall follow-up was 100.7 months (IQR 69.4-119.7). Mean DSS was 166.8 months (median not reached).

Age was normally distributed. Tumor size was not. T-cell parameters (intratumoral and stroma CD8 and FoxP3, and T-cell ratios) were normally distributed after log-scale transformation. Clinicopathological characteristics are summarized in Table 1. When comparing the hrHPV subgroups with respect to these characteristics, we observed a significant difference only in differentiation grade $(p<0.01)$ and death by penile cancer $(p=0.02)$. Most well differentiated tumors were hrHPV ${ }^{-}$(70 vs. 9 in hrHPV ${ }^{+}$). Despite this, DSS was better in hrHPV ${ }^{+}$patients in comparison to $\mathrm{hrHPV}^{-}$patients, with 2 and 27 penile cancer related deaths, 
Table 1: Clinicopathological characteristics.

\begin{tabular}{|c|c|c|c|c|}
\hline Variable & $\mathrm{hrHPV}^{-}, \mathrm{N}=158(\%)$ & $\mathrm{hrHPV}^{+}, \mathrm{N}=52(\%)$ & Total, $N=213(\%)^{a}$ & $p$-Value $b$ \\
\hline Age median (IQR) & $67.6(58.2-74.6)$ & $63.6(54.4-71.6)$ & $65.9(57.3-74.4)$ & 0.38 \\
\hline pT stage & & & & 0.17 \\
\hline pT1 & $42(26.6)$ & $19(36.5)$ & $61(28.6)$ & \\
\hline pT2 & $99(62.7)$ & $28(53.8)$ & $130(61.0)$ & \\
\hline рT3 & $11(7.0)$ & $5(9.6)$ & $16(7.5)$ & \\
\hline pT4 & $6(3.8)$ & - & $6(2.8)$ & \\
\hline Tumor size median (IQR) & $3.0(2.0-4.1)$ & $2.5(1.5-3.9)$ & $3.0(2.0-4.0)$ & 0.09 \\
\hline histological subtype & & & & $0.08 \mathrm{C}$ \\
\hline SCCNOS & $137(87.3)$ & $43(82.7)$ & $180(84.5)$ & \\
\hline Papillary & $8(5.1)$ & $1(1.9)$ & $9(4.2)$ & \\
\hline Verrucous & $5(3.2)$ & - & $5(2.3)$ & \\
\hline Warty & $2(1.3)$ & $3(5.8)$ & $5(2.3)$ & \\
\hline Basaloid & $1(0.6)$ & $4(7.7)$ & $5(2.3)$ & \\
\hline Mixed SCC-basaloid & $1(0.6)$ & $1(1.9)$ & $2(0.9)$ & \\
\hline Sarcomatoid & $1(0.6)$ & - & $1(0.5)$ & \\
\hline Cuniculatum & $1(0.6)$ & - & $1(0.5)$ & \\
\hline Pseudohyperplastic & $1(0.6)$ & - & $1(0.5)$ & \\
\hline Missing & $1(0.6)$ & - & $4(1.9)$ & \\
\hline $\begin{array}{l}\text { grade of differentiation } \\
\text { Well (grade 1) }\end{array}$ & 70 (44.3) & $9(17.3)$ & $80(37.6)$ & $<0.01$ \\
\hline Intermediate (grade 2) & $62(39.2)$ & $31(59.6)$ & $94(44.1)$ & \\
\hline Poor (grade 3) & $26(16.5)$ & $12(23.1)$ & $38(17.8)$ & \\
\hline Missing & - & - & $1(0.5)$ & \\
\hline pn stage & & & & 0.84 \\
\hline $\mathrm{pNO}$ & $107(67.7)$ & $36(69.2)$ & $145(68.1)$ & \\
\hline $\begin{array}{l}\mathrm{pN}+ \\
\text { extranodal growth }\end{array}$ & $51(32.3)$ & $16(30.8)$ & 68 (31.9) & $0.12^{d}$ \\
\hline Present & $19(12.0)$ & $3(5.8)$ & $22(10.3)$ & \\
\hline Absent & $28(17.7)$ & $13(25)$ & $42(19.7)$ & \\
\hline No LNM & $107(67.7)$ & $36(69.2)$ & $145(68.1)$ & \\
\hline Missing & $4(2.5)$ & - & $4(1.9)$ & \\
\hline Death by penile cancer & & & & 0.02 \\
\hline No & $131(82.9)$ & $50(96.2)$ & 184 & \\
\hline Yes & $27(17.1)$ & $2(3.8)$ & & \\
\hline
\end{tabular}

$I Q R$, interquartile range (25th-75th percentile); SCC, squamous cell carcinoma; NOS, not otherwise specified; HPV, human papilloma virus; LNM, lymph node metastases.

alncluding three cases with unknown hrHPV status. 'Excluding missing cases. Comparing the two hrHPV subgroups. Independent sample t-test for continuous variables, chi-square, or Fishers exact test for categorical variables. 'Divided in SCC NOS, unfavorable subtypes (basaloid, mixed basaloid-warty, and sarcomatoid) and favorable subtypes (papillary, verrucous,

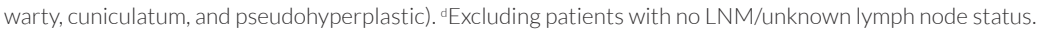
Bold numbers are statistically significant. 
respectively (log-rank $p=0.02$; Figure 1 ) at mean follow-up of 169.5 vs. 160.5 months. Among hrHPV+ tumors, HPV16 was the predominant type 79\% (41/52). ${ }^{7}$

\section{Classical and non-classical HLA expression and PD-L1 expression patterns} Immune characteristics are summarized in Figure $\mathbf{2}$ and Table $\mathbf{S 2}$ in Supplementary Material. Aberrant classical and non-classical HLA expression was equally distributed among hrHPV- subgroups. Interestingly, hrHPV tumors were significantly more often PD-L1+ (49.4 vs. 32.7\% of hrHPV+; $p=0.03$ ). Also, there was a trend toward hrHPV - tumors having relatively more of both PD-L1 expression patterns compared with hrHPV ${ }^{+}$tumors $(p=0.09) .{ }^{11}$

\section{Tumor-infiltrating cytotoxic T-cells and Tregs}

The presence of CD8 ${ }^{+}$T-cells and FoxP3 ${ }^{+}$Tregs was determined by standard IHC staining. Representative examples of CD8 and Foxp3 presence are depicted in Figures 3A-D. Interestingly, CD8 and FoxP3 pixel counts were much higher in stromal areas than in tumor areas, in both hrHPV ${ }^{-}$and $\mathrm{hrHPV}^{+}$tumors (Figure 2). No differences in T-cell numbers or CD8/FoxP3-ratio were found between hrHPV ${ }^{+}$and hrHPV ${ }^{-}$tumors (Figure 2; Table S2 in Supplementary Material).

\section{Tumor-infiltrating macrophages}

Representative examples of CD163 IHC stainings are depicted in Figures 3E,F. No significant differences in $\mathrm{CD}_{163^{+}}$macrophage intratumoral or stromal infiltration were observed between $\mathrm{hrHPV}^{-}$and $\mathrm{hrHPV}^{+}$samples. In addition, to determine the subtype of macrophages infiltrating penile tumors, a fluorescent double staining of CD163 and CD68 was performed (Figures 4A,B) and the majority of cells were found to be $\mathrm{CD} 68^{+} \mathrm{CD} 163^{+}$both intratumoral and in stromal areas, indicative of $\mathrm{M} 2$-polarization of virtually all macrophages in these tumors.

\section{Univariable analyses}

\section{Associations between TME factors and LNM}

Results from the univariable analysis are presented in Table 2. With clinicopathological parameters and updated follow-up of patients, results resembled our previous reports.,7,11 Tumor PD-L1 expression was significantly associated with LNM; diffusely PD-L1-positive tumors had higher odds of LNM in comparison to tumors with marginal PD-L1 expression only [OR 4.16, $p<$ 0.01 ] and to tumors with combined negative/margin PD-L1 expression (OR 3.28, $p<0.01$ ). Presence of PD-L1+ TIMs was associated with higher chance of LNM but not on a level of conventional statistical significance (OR 1.91, p > 0.05). 







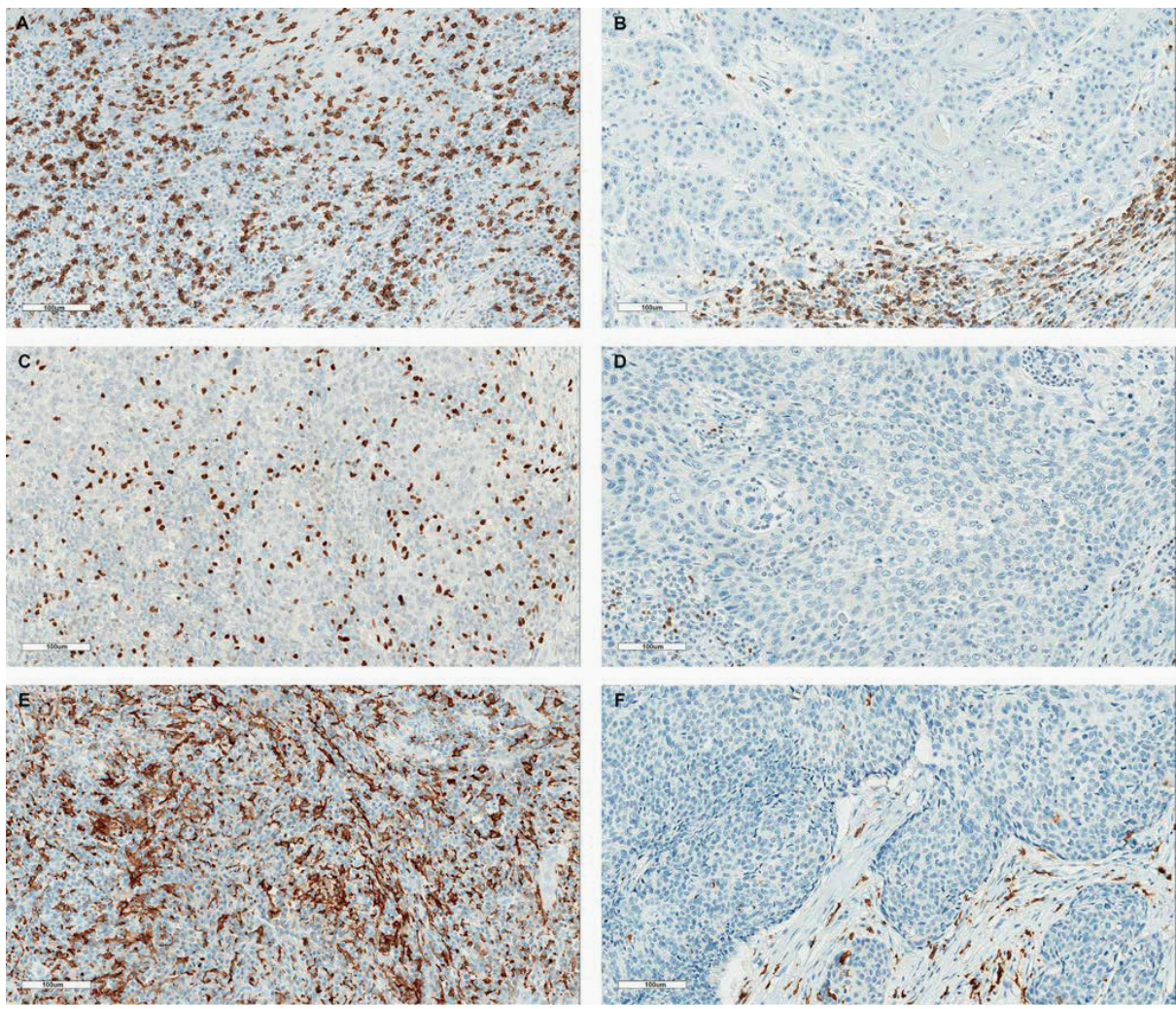

Figure 3. Examples of representative stainings for high and low infiltration of $C D 8^{+} T$ cells (A,B), FoxP3+ regulatory T-cells (C,D), and CD163+ macrophages (E,F). Scale bars: $100 \mu \mathrm{m}$.
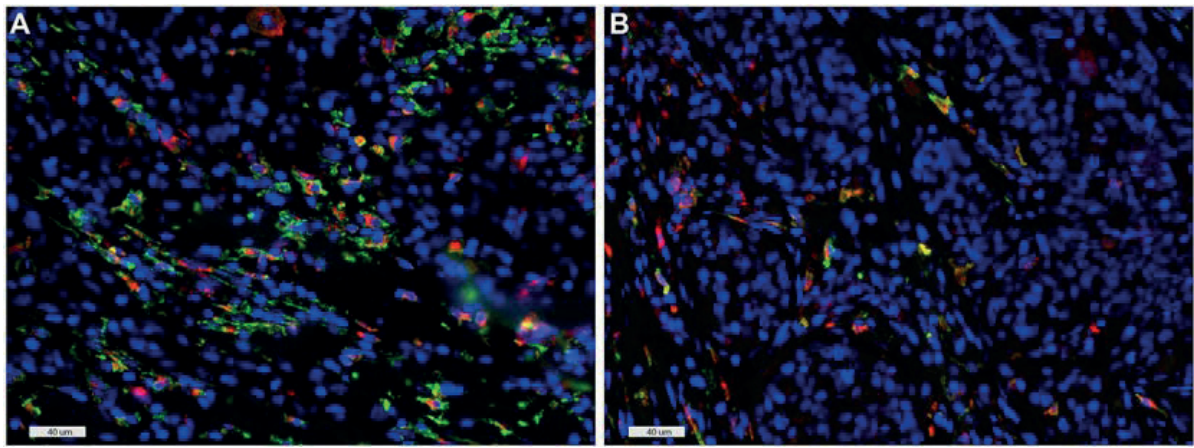

Figure 4. CD163 and CD68 double staining of an hrHPV ${ }^{-}$(A) and $\mathrm{hrHPV}^{+}$(B) case, indicative of M2 macrophage polarization. Colors: green, CD163; red, CD68; and blue, DAPI. Scale bars: $40 \mu \mathrm{m}$. 
The presence of high numbers of intratumoral CD163+ M2 macrophages was significantly associated with higher LNM incidence (OR 2.45, $p<0.01$ ).

Aberrant classical HLA class I expression patterns (combined score of HLA-A, $\mathrm{HLA}-\mathrm{B} / \mathrm{C}$, and $\beta 2 \mathrm{~m}$ ) did not show significant associations with LNM. Interestingly, upregulation of non-classical HLA class I molecules (combined score of HLA-E and HLA-G) was associated with a higher odds of LNM compared with normal expression (OR 2.28, $p=0.02$ ).

The only T-cell infiltration parameter showing significant association with LNM, was increased CD8 ${ }^{+}$T-cell infiltration rate in tumor-associated stroma (OR 0.60, $p=0.04)$ albeit with a confidence interval (95\% Cl) almost including 1: 0.37-0.98.

\section{Associations between TME factors and DSS}

High-risk human papilloma virus negativity was associated with worse survival (HR 4.82, $p=0.03$ ), and complete downregulation of classical HLA class I with better survival than partial downregulation (HR 0.12, $p<0.05$, note questionable 95\% Cl of 0.02-0.96) (Table 2). A diffuse PD-L1 tumor expression pattern was associated with higher risk of disease-specific death than marginal PD-L1 expression (HR 4.35, $p<0.01$ ), and negative/ margin PD-L1 expression (HR 3.70, $p<0.01)$

Although we saw some evidence of associations of DSS with intratumoral Tregs (HR 36.39, $p=0.06$ ) and high intratumoral CD163+ M2-macrophage infiltration (HR 2.10, $p \geq 0.05)$, these associations were not significant.

\section{Multivariable analysis}

Classical and non-classical HLA were non-significant in the multivariable models (data not shown). These variables limited the number of included cases in the multivariable models because of a relatively high number of missing values, and therefore they were excluded from the final models to increase the sample size.

In the multivariable analysis (Table 3 ), diffuse PD-L1 expression was the only immunological factor that remained significantly associated with LNM, although the lower limit of the confidence interval was just above 1 (OR 2.81, 95\% Cl [1.01-7.81], $p<0.05)$. hrHPV negativity and diffuse PD-L1 expression were immune factors predicting poor survival in the multivariable model (OR 9.73, $p<$ 0.01 , and OR 2.78, $p=0.03$, respectively). 
Table 2: Univariable analysis.

Variable Contrast

\begin{tabular}{ll}
\hline Tumor-microenvironmental parameters \\
\hline High-risk HPV & Negative vs. positive \\
PD-L1 pattern & Negative vs. margin \\
& Diffuse vs. margin \\
& Diffuse vs. negative/margin \\
& Positive vs. negative \\
PD-L1 stroma & Present vs. absent \\
PD-L1 TIM & Complete vs. partial downregulation \\
Classical HLA class I & Normal expression vs. partial downregulation \\
& Upregulated vs. normal \\
Non-classical HLA class I & Per 100,000 pixels \\
CD8 intratumoral & Per 100,000 pixels \\
CD8 stromal & Per 100,000 pixels \\
FoxP3 intratumoral & Per 100,000 pixels \\
FoxP3 stromal & Continuous \\
T-cell ratio intratumoral & Continuous \\
T-cell ratio stromal & High vs. low infiltration \\
CD163 intratumoral & High vs. low infiltration \\
CD163stromal &
\end{tabular}

\section{Clinicopathological parameters}

\begin{tabular}{ll}
\hline Age & Per year \\
Tumor size & Percm \\
pTstage & pT2 vs. pT1a/b \\
GT3-4 vs. pT1a/b \\
Prade of differentiation & $\begin{array}{l}\text { Intermediate vs. goo } \\
\text { Poor vs. good differ }\end{array}$ \\
LVI & Present vs. absent \\
Exophytic growth & Present vs. absent \\
Lymph node status & pN+ vs. pNO \\
Extranodal growtha & Present vs. absent \\
\hline
\end{tabular}

OR, odds ratio; HR, hazard ratio; LVI, lymphovascular invasion; HPV, human papilloma virus;

HLA, human leukocyte antigen; PD-L1, programmed death ligand-1; TIM, tumor-infiltrating macrophages. aExcluding cases with no LNM.

Bold numbers are statistically significant. 


\begin{tabular}{|c|c|c|c|}
\hline \multicolumn{2}{|c|}{ Lymph node metastasis (InM) } & \multicolumn{2}{|c|}{ Disease-specific survival (Dss) } \\
\hline Or [ci] & $p$-Value & $\mathrm{hr}[\mathrm{ci}]$ & $p$-Value \\
\hline $1.07[0.55-2.11]$ & 0.84 & $4.82[1.15-20.27]$ & 0.03 \\
\hline $1.44[0.68-3.03]$ & 0.34 & $1.28[0.44-3.68]$ & 0.65 \\
\hline $4.16[1.71-10.17]$ & $<0.01$ & $4.35[1.53-12.34]$ & $<0.01$ \\
\hline $3.28[1.58-6.84]$ & $<0.01$ & $3.70[1.75-7.82]$ & $<0.01$ \\
\hline $0.78[0.39-1.55]$ & 0.48 & $1.38[0.52-3.63]$ & 0.52 \\
\hline $1.91[0.99-3.70]$ & $>0.05$ & $1.74[0.79-3.83]$ & 0.17 \\
\hline $1.26[0.45-3.58]$ & 0.18 & $0.12[0.02-0.96]$ & $<0.05$ \\
\hline $0.69[0.22-2.19]$ & 0.66 & $0.45[0.10-2.00]$ & 0.29 \\
\hline $2.28[1.08-4.81]$ & 0.02 & $0.53[0.15-1.84]$ & 0.32 \\
\hline $1.32[0.50-3.50]$ & 0.58 & $0.83[0.21-3.31]$ & 0.79 \\
\hline $0.60[0.37-0.98]$ & 0.04 & $0.84[0.49-1.44]$ & 0.52 \\
\hline $24.74[0.40-1,532.10]$ & 0.13 & $36.39[0.92-1,433.75]$ & 0.06 \\
\hline $0.54[0.18-1.62]$ & 0.27 & $0.61[0.14-2.57]$ & 0.50 \\
\hline $1.01[0.97-1.05]$ & 0.71 & $0.96[0.88-1.05]$ & 0.39 \\
\hline $0.98[0.92-1.04]$ & 0.42 & $1.00[0.93-1.06]$ & 0.93 \\
\hline $2.45[1.35-4.43]$ & $<0.01$ & $2.10[0.99-4.44]$ & $>0.05$ \\
\hline $1.75[0.85-3.62]$ & 0.13 & $1.99[0.69-5.74]$ & 0.20 \\
\hline $1.00[0.98-1.02]$ & 0.95 & $1.01[0.98-1.04]$ & 0.40 \\
\hline $1.11[0.97-1.26]$ & 0.13 & $1.21[1.07-1.37]$ & \\
\hline $2.33[1.10-4.91]$ & 0.03 & $1.32[0.48-3.67]$ & 0.59 \\
\hline 6.57 [2.25-19.17] & $<0.01$ & $7.19[2.46-21.07]$ & $<0.01$ \\
\hline 8.01 [3.16-20.27] & $<0.01$ & $2.11[0.74-5.98]$ & 0.16 \\
\hline $21.14[7.32-61.11]$ & $<0.01$ & $5.99[2.11-17.01]$ & $<0.01$ \\
\hline $4.65[2.11-10.23]$ & $<0.01$ & $3.21[1.45-7.10]$ & $<0.01$ \\
\hline $0.62[0.32-1.18]$ & 0.14 & $0.65[0.28-1.53]$ & 0.33 \\
\hline- & - & $38.51[9.15-162.16]$ & $<0.01$ \\
\hline- & - & $2.11[0.93-4.78]$ & 0.08 \\
\hline
\end{tabular}


Table 3: Multivariable backward regression analysis.

\begin{tabular}{|c|c|c|c|}
\hline \multicolumn{4}{|l|}{ Lymph node metastasis } \\
\hline Variable & Contrast & Or [ci] & $p$-Value \\
\hline Tumor PD-L1 & Diffuse vs. negative/margin & $2.81[1.01-7.81]$ & 0.05 \\
\hline $\mathrm{PD}-\mathrm{L} 1^{+} \mathrm{TIM}$ & Present vs. absent & - & - \\
\hline CD8 stromal & Per 100,000 pixels increase & $0.54[0.27-1.05]$ & 0.07 \\
\hline CD163 & High vs. low infiltration & - & - \\
\hline \multicolumn{4}{|l|}{ intratumoral } \\
\hline LVI & Present vs. absent & $3.18[1.08-9.35]$ & 0.04 \\
\hline \multirow[t]{2}{*}{ Grade of differentiation } & Intermediate vs. gooddifferentiation & $6.76[2.11-21.63]$ & $<0.01$ \\
\hline & Poor vs. good differentiation & $12.07[3.19-45.70]$ & $<0.01$ \\
\hline \multirow[t]{2}{*}{ pTstage } & pT2 vs. pT1a/b & - & - \\
\hline & pT3-4vs.pT1a/b & - & - \\
\hline \multicolumn{4}{|l|}{ Disease-specific survival } \\
\hline Variable & Contrast & Or [ci] & $p$-Value \\
\hline High-risk HPV & Absent vs. present & $9.73[2.12-44.72]$ & $<0.01$ \\
\hline Tumor PD-L1 & Diffuse vs. negative/margin & $2.78[1.10-6.98]$ & 0.03 \\
\hline FoxP3 intratumoral & Per 1,000 pixels increase & - & - \\
\hline CD163 intratumoral & High vs. low infiltration & - & - \\
\hline Tumor size & Per cm & $1.31[1.11-1.53]$ & $<0.01$ \\
\hline \multirow[t]{2}{*}{ Lymph node status } & $p N+$ vs. pNO & 63.21 & $<0.01$ \\
\hline & & [12.36-323.23] & \\
\hline \multirow[t]{2}{*}{ Grade of differentiation } & Intermediate vs. good differentiation & $0.30[0.09-1.06]$ & 0.06 \\
\hline & Poor vs. good differentiation & $0.87[0.26-2.90]$ & 0.81 \\
\hline
\end{tabular}

OR, odds ratio; $\mathrm{Cl}$, 95\% confidence interval for OR/HR; PD-L1, programmed death ligand-1; TIM, tumor-infiltrating macrophages LVI, lymphovascular invasion; HR, hazard ratio; HPV, human papilloma virus; -, excluded during regression analysis. Bold numbers are statistically significant.

\section{Subgroup analyses}

$\mathrm{hrHPV}^{+}$and $\mathrm{hrHPV}^{-}$penile cancer can be seen as two different tumor entities, and patients with hrHPV ${ }^{-}$tumors have a higher risk of dying from this disease. ${ }^{7}$ Also, various histological subtypes of SCC have a distinct better or poorer prognosis. ${ }^{38}$ Therefore, analyses were repeated in the hrHPV- subgroup, and the subgroup with usual histological subtype SCC (Tables 4 and $\mathbf{5}$ ).

\section{hrHPV-Negative Subgroup}

In univariable analysis of the hrHPV' subgroup ( $n=158$ ), three factors were significantly associated with LNM: a diffuse PD-L1 expression pattern (OR 
$4.18, p<0.01$ ), high intratumoral infiltration rates of $C D 163^{+}$macrophages (OR 2.17, $p=0.03$ ), and - associated with lower risk of LNM-high stromal CD8+ T-cell infiltration (OR 0.45, $p=0.02$ ). Diffuse PD-L1 expression pattern and high intratumoral CD163+ macrophage infiltration were also significantly associated with worse DSS (HR 6.19, $p<0.01$ and HR 2.17, $p<0.05$ ).

Multivariable regression analysis of the hrHPV ${ }^{-}$subgroup, showed grade of differentiation as the only significant factor associated with LNM (OR 15.30 and 19.34 for grades 2 and 3 compared with grade 1 , both $p<0.01$ ). High stromal $\mathrm{CD}^{+} \mathrm{T}$ cell infiltration showed some evidence of negative association with LNM but was not statistically significant (OR 0.44, $p=0.06$ ). PD-L1 expression pattern was eliminated during backward selection.

For DSS in the hrHPV' subgroup, LNM (HR 82.22, $p<0.01)$ and diffuse PD-L1 expression pattern (OR 5.03, $p<0.01$ ) remained the most important factors in the multivariable model. High FoxP3 ${ }^{+}$Treg infiltration rates were associated with worse DSS but did not meet statistical significance (OR 183.89, $p \geq 0.05$ ).

\section{Usual histological subtype SCC}

Univariable analysis in the usual histological subtypes $(n=180)$, showed-similar to the hrHPV ${ }^{-}$subgroup-significant associations with LNM for PD-L1 expression pattern (OR 3.17, $p=0.02$ ) and high intratumoral CD 163 ${ }^{+}$macrophage infiltration rates (OR 2.36, $p<0.01$ ), and a negative association with LNM for high stromal $\mathrm{CD}^{+}$T-cell infiltration (OR 0.45, $p=0.03$ ) (Tables 4 and 5). Unlike the hrHPV ${ }^{-}$ subgroup, LNM were also associated with PD-L1-expressing TIMs (OR 2.10, $p=0.04)$. Poor DSS was associated with presence of diffuse PD-L1 expression pattern ( HR 4.22, $p=0.02)$ and high intratumoral CD163 ${ }^{+}$macrophage infiltration (HR 2.28, $p<0.05)$.

After multivariable regression, the final model for LNM included grade of differentiation (similar values as $\mathrm{hrHPV}^{-}$), high stromal CD8 (OR 0.38, $p=0.01$ ) and pT stage (OR 10.14, $p=0.02$ for T3/T4 vs. T1). Like in the hrHPV ${ }^{-}$subgroup, PD-L1 was eliminated during backward selection. For DSS, having Iymph node metastases was the most important predictor of survival (HR 124.33, $p<0.01$ ). The multivariable model also included hrHPV negativity (HR 6.82, $p<0.01)$ and other clinical predictors. 


\section{DISCUSSION}

This is the largest study that reports on associations of multiple TME factors with patient outcomes adjusted for clinical predictors in penile cancer.

In the total cohort, diffuse PD-L1 tumor-cell expression, CD163+ macrophage infiltration, non-classical HLA class I upregulation and low stromal CD8 ${ }^{+}$T-cell infiltration, were all associated with LNM. In the multivariable model, only PD-L1 expression remained a significant predictor for LNM (OR 2.81, p = 0.05). hrHPV negativity and diffuse PD-L1 tumor-cell expression were significantly associated with poor DSS and remained so upon correction for clinical parameters (HR 9.73, $p<0.01$ and HR 2.81, $p=0.03)$.

The strong prognostic value for hrHPV reflects two tumor entities, similar to headand-neck SCC and vulvar SCC. ${ }^{39-41}$ One is hrHPV-mediated, more immunogenic, and associated with better prognosis. ${ }^{41,42}$ The other is HPV-independent, induced by chronic irritation, inflammation and genetic alterations. ${ }^{39,40,43}$ Interestingly, the only immune factor that differed from $\mathrm{HPV}^{+}$to $\mathrm{HPV}^{-}$tumors was PD-L1 expression, with higher PD-L1 expression rates in the latter ( $p=0.03$ ). In the $\mathrm{HPV}^{-}$cohort $(\mathrm{n}=158)$, LNM were associated with diffuse PD-L1 tumor-cell expression, high intratumoral CD $163^{+}$macrophage infiltration and low number of stromal CD8 ${ }^{+}$T-cells, while only the first two parameters were associated with DSS. In the HPV ${ }^{-}$subgroup multivariable regression model, diffuse PD-L1 expression remained significantly associated with poor DSS (HR 5.03, $p<0.01$ ). Similar results were obtained when the cohort analysis was restricted to the usual histological subtype SCC.

The contrasting associations of diffuse PD-L1 expression with poor outcomes and PD-L1 expression at the tumor-stroma margin with more favorable outcomes can be explained by two different pathways of PD-L1 expression, identified in melanoma and gynecological SCC. ${ }^{44-47}$ The first has a genetic background (deregulated signaling pathways, transcription factors and numerical aberrations) resulting in CD274 overexpression, and concomitant diffuse PDL1 expression. ${ }^{15,44,46}$ The other is a reactive, interferon-gamma (IFNY) induced expression at the tumor-stroma margin, explaining its favorable role. ${ }^{45,47} \mathrm{We}$ hypothesized that the better survival of cases with tumor-margin PD-L1 expression is explained by accumulation of activated T-cells and IFNy release in the adjacent stroma. ${ }^{11}$ But among the PD-L1-positive tumors, stromal CD8 ${ }^{+}$T-cell infiltration was not associated with a marginal expression pattern (data not shown, 


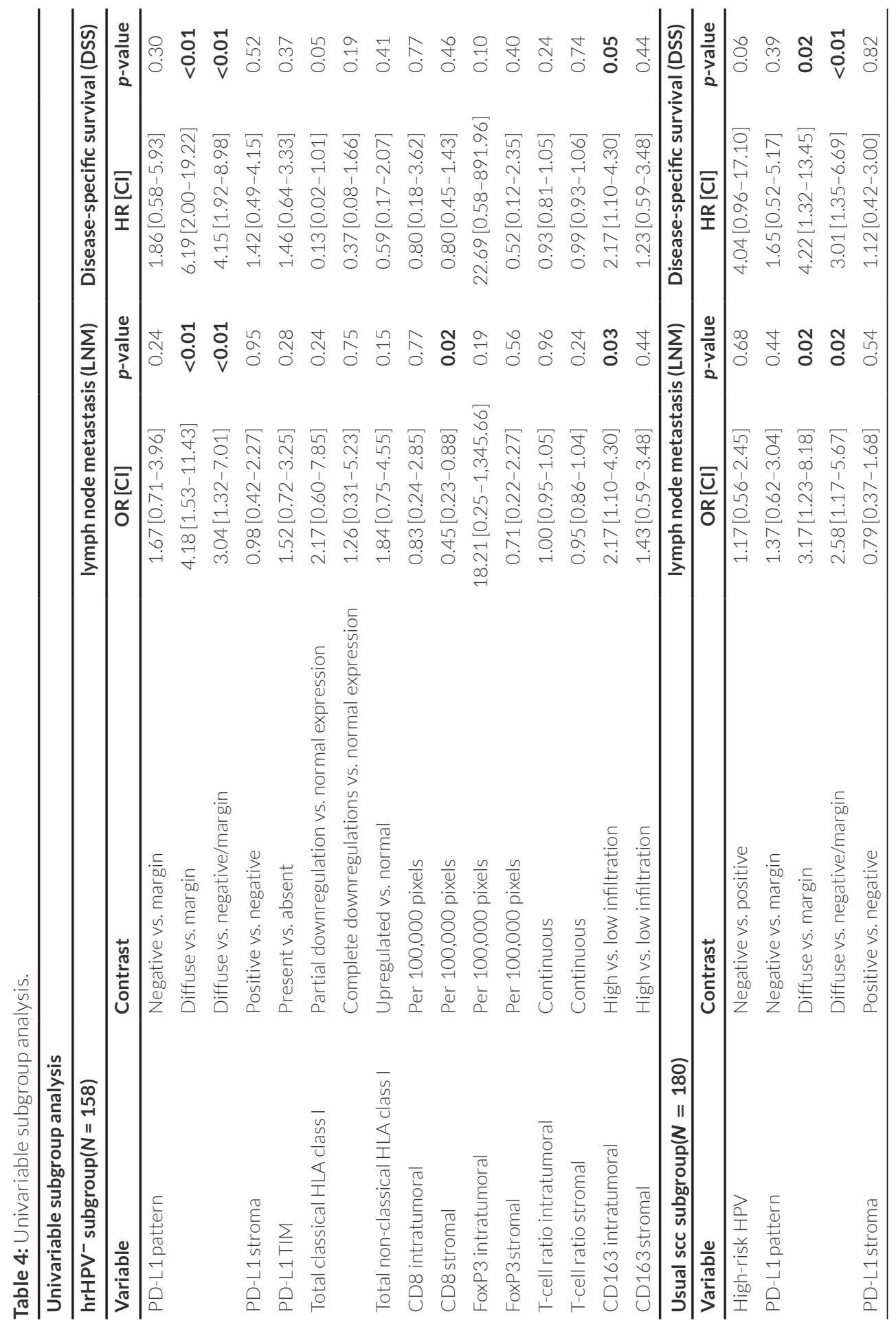




\section{Chapter 3}

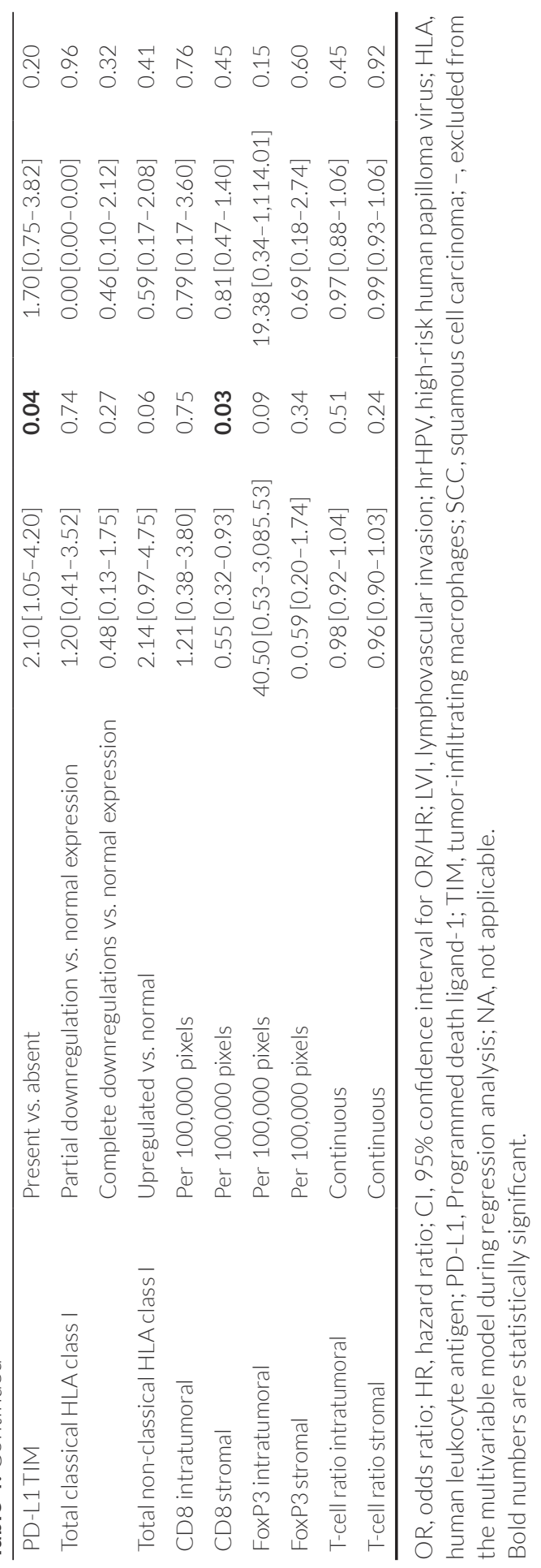









\section{Chapter 3}

Spearman, $p=0.819)$. The higher number of diffusely PD-L1 positive tumors in the hrHPV- group of our cohort, however, fits the hypothesis of a more mutated tumor type with higher T-cell inhibition properties, partially explaining poorer survival. Deng et al. studied PD-L1 expression and tumor infiltrating lymphocytes in penile cancer and also did functional analyses on cell lines. ${ }^{14}$ They found PD-L1 expression positively correlated with IFNy and CD8 ${ }^{+}$gene expression, suggesting that indeed PD-L1 expression was induced by activated T-cells. ${ }^{14,45}$ The proportion of hrHPV ${ }^{+}$tumors in their study is presumably low (prevalence in Asia around 13\%). ${ }^{14}$ Recent studies in oropharyngeal SCC reported on a prognostic role for CD8 ${ }^{+}$T-cell infiltration rates and not for PD-L1 expression. ${ }^{17,48}$ Like us, Oguejiofor et al. found higher PD-L1 expression in HPV- tumors. ${ }^{17}$ However, they also investigated CD8 ${ }^{+}$T-cells expressing the $\mathrm{PD}$ - $\mathrm{L} 1$ receptor $\mathrm{PD}-1$ and found higher proportions of $\mathrm{CD} 8^{+} \mathrm{PD}-1^{+} \mathrm{T}$-cells in stroma than in tumor. Considering higher PD-L1 expression in hrHPV- tumors, this suggests pronounced T-cell inhibition in this unfavorable group. In HNSCC, CD8 ${ }^{+}$T-cells were more frequent in HPV ${ }^{+}$ tumors, and also more capable of producing IFNy. ${ }^{20}$ Another study found that not only composition but also location of suppressive factors matter; PD-L1 ${ }^{+}$ or FoxP3 ${ }^{+}$cells close to CD8 ${ }^{+}$T-cells (within $30 \mu \mathrm{m}$ ) are associated with worse overall survival. ${ }^{48}$ We did not assess PD-1 expression, IFNy-producing capacity or proximity of suppressive factors in our cohort, but these factors may influence the different outcomes of patients with hrHPV ${ }^{+}$and hrHPV ${ }^{-}$tumors.

Cocks et al. found a decreased CD8 ${ }^{+} \mathrm{T}$ cell/FoxP3 ${ }^{+}$Treg-ratio associated with tumor progression during follow-up in penile cancer patients, but no associations with overall survival or DSS. ${ }^{12}$ We also found no associations with this ratio and did not use progression during follow-up as outcome. These discrepancies can be partially explained by technical differences (they performed hot-spot analysis in TMAs). But also by factors that are not included in our analysis, such as other checkpoint molecules (e.g., CTLA-4) and PD-1 expression on T-cells.

Based on our results, can we inverse tumor escape in penile carcinomas, and how?

First, with PD-L1 as one of the most important predictors of prognosis in penile SCC, trials with PD-(L)1-checkpoint-inhibitors are warranted. Systemic treatment with these agents has been FDA-approved for various cancers, including SCCs. ${ }^{49}$ In the Netherlands Cancer Institute, we are currently planning a clinical trial with such agents in advanced penile cancer. 
Second, the favorable high stromal CD8 ${ }^{+} \mathrm{T}$ cell and low intratumoral CD163 ${ }^{+}$ macrophage infiltration should be notified as important mechanisms. M2polarized macrophages play a crucial role in T-cell response suppression, angiogenesis and treatment evasion, but can be reprogrammed towards activated M1-macrophages by $\mathrm{CD}^{+}$helper T-cells. ${ }^{30,31,50}$ In the future, combinational immunotherapies should be applied to counter the adverse effects of the complex microenvironment in these tumors. ${ }^{51}$

Limitations of the study include the relatively few cases with LNM and disease associated deaths in this cohort, and the substantial missing values in HLAexpression due to insufficient tissue material for TMA sampling. ${ }^{9}$ Both limited the statistical analysis. Second, we did not determine PD-1 expression, distance from CD8 ${ }^{+}$T-cells to PD-L1 expressing tumor cells and tumor-associated macrophages, or functionality. ${ }^{48}$ Furthermore, our results ideally are externally validated.

Nevertheless, our results favor the rationale for immunotherapy for this mutilating disease. Any effectiveness of immunotherapy on primary tumor or LNM has to be revealed by future clinical studies, stratifying patients based on TME parameters, eventually leading to personalized immunotherapy. We are currently focusing on comparing the TME of primary tumors to metastatic lymph nodes.

In conclusion, in this study, we showed that the penile cancer microenvironment is highly complex and contains various targets for immunotherapy. These results can aid risk-stratification and importantly, the here described TME factors should be evaluated in future immunotherapy clinical studies to ultimately lead to patient tailored treatment.

\section{Acknowledgments}

We like to acknowledge the NKI-AVL Core Facility Molecular Pathology \& Biobanking (CFMPB) for supplying Netherlands Cancer Institute-Antoni van Leeuwenhoek biobank material, staining, and technical support. We like to thank René Musters for using the digital imaging fluorescence microscope and thank Judith Bosschieter for her efforts in scoring histological slides. 


\section{REFERENCES}

1. Hansen BT, Orumaa M, Lie AK, et al: Trends in incidence, mortality and survival of penile squamous cell carcinoma in Norway 1956-2015. Int. J. cancer 2017.

2. Barnholtz-Sloan JS, Maldonado JL, Pow-sang J, et al: Incidence trends in primary malignant penile cancer. Urol. Oncol. 2007; 25: 361-367.

3. Kirrander P, Sherif A, Friedrich B, et al: Swedish National Penile Cancer Register: incidence, tumour characteristics, management and survival. BJU Int. 2016; 117: 287-92.

4. Hakenberg OW (chair), Compérat E, Minhas S, et al: EAU Guidelines on Penile Cancer. 2020. Available at: http://uroweb.org/guideline/penile-cancer/, accessed December 12, 2020.

5. Nyitray AG and lannacone MR: The epidemiology of human papillomaviruses. Curr. Probl. Dermatol. 2014; 45: 75-91.

6. Chaux A, Cubilla AL, Haffner MC, et al: Combining routine morphology, p16(INK4a) immunohistochemistry, and in situ hybridization for the detection of human papillomavirus infection in penile carcinomas: a tissue microarray study using classifier performance analyses. Urol. Oncol. 2014; 32: 171-177.

7. Djajadiningrat RS, Jordanova ES, Kroon BK, et al: Human papillomavirus prevalence in invasive penile cancer and association with clinical outcome. J. Urol. 2015; 193 : 526-31.

8. Lohneis P, Boral S, Kaufmann AM, et al: Human papilloma virus status of penile squamous cell carcinoma is associated with differences in tumour-infiltrating $T$ lymphocytes. Virchows Arch. 2015; 466: 323-331.

9. Djajadiningrat RS, Horenblas S, Heideman DAM, et al: Classic and nonclassic HLA class I expression in penile cancer and relation to HPV status and clinical outcome. J. Urol. 2015; 193: 1245-1251.

10. Vassallo J, Rodrigues AFF, Campos AHJFM, et al: Pathologic and imunohistochemical characterization of tumoral inflammatory cell infiltrate in invasive penile squamous cell carcinomas: Fox-P3 expression is an independent predictor of recurrence. Tumour Biol. 2015; 36: 2509-16.

11. Ottenhof SR, Djajadiningrat RS, de Jong J, et al: Expression of Programmed Death Ligand 1 (PD-L1) in penile cancer is of prognostic value and associated with HPV status. J. Urol. 2016.

12. Cocks M, Taheri D, Ball MW, et al: Immune checkpoint status in penile squamous cell carcinoma: A North American Cohort. Hum. Pathol. 2016; 59: 55-61.

13. Udager AM, Liu T-Y, Skala SL, et al: Frequent PD-L1 expression in primary and metastatic penile squamous cell carcinoma: potential opportunities for immunotherapeutic approaches. Ann. Oncol. Off. J. Eur. Soc. Med. Oncol. 2016; 27 : 1706-12.

14. Deng C, Li Z, Guo S, et al: Tumor PD-L1 expression is correlated with increased TILs and poor prognosis in penile squamous cell carcinoma. Oncoimmunology 2017; 6: e1269047.

15. Fridman WH, Zitvogel L, Sautes-Fridman C, et al: The immune contexture in cancer prognosis and treatment. Nat. Rev. Clin. Oncol. 2017. 
16. Blank CU, Haanen JB, Ribas A, et al: The Cancer Immunogram. Science (80-. ). 2016; 352: 658-60.

17. Oguejiofor K, Galletta-Williams H, Dovedi SJ, et al: Distinct patterns of infiltrating CD8+ T cells in HPV+ and CD68 macrophages in HPV- oropharyngeal squamous cell carcinomas are associated with better clinical outcome but PD-L1 expression is not prognostic. Oncotarget 2017; 8: 14416-14427.

18. de Ruiter EJ, Ooft ML, Devriese LA, et al: The prognostic role of tumor infiltrating T-lymphocytes in squamous cell carcinoma of the head and neck: A systematic review and meta-analysis. Oncoimmunology 2017; 6: e1356148.

19. Zhang D, Tang W-J, Tang D, et al: The ratio of CD4/CD8 T-cells in human papillomavirus-positive laryngeal squamous cell carcinoma accounts for improved outcome. Acta Otolaryngol. 2016; 136: 826-833.

20. Partlova S, Boucek J, Kloudova K, et al: Distinct patterns of intratumoral immune cell infiltrates in patients with HPV-associated compared to non-virally induced head and neck squamous cell carcinoma. Oncoimmunology 2015; 4: e965570.

21. Gooden MJM, de Bock GH, Leffers N, et al: The prognostic influence of tumourinfiltrating lymphocytes in cancer: a systematic review with meta-analysis. Br. J. Cancer 2011; 105: 93-103.

22. Adurthi S, Krishna S, Mukherjee G, et al: Regulatory T cells in a spectrum of HPVinduced cervical lesions: Cervicitis, cervical intraepithelial neoplasia and squamous cell carcinoma. Am. J. Reprod. Immunol. 2008; 60: 55-65.

23. De Meulenaere A, Vermassen T, Aspeslagh S, et al: TILs in Head and Neck Cancer: Ready for Clinical Implementation and Why (Not)? Head Neck Pathol. 2017; 11: 354-363.

24. Zhao S, Jiang $T$, Zhang L, et al: Clinicopathological and prognostic significance of regulatory $T$ cells in patients with non-small cell lung cancer: A systematic review with meta-analysis. Oncotarget 2016; 7: 36065-36073.

25. van Herk EH and Te Velde AA: Treg subsets in inflammatory bowel disease and colorectal carcinoma: Characteristics, role, and therapeutic targets. J. Gastroenterol. Hepatol. 2016; 31: 1393-1404.

26. Punt S, Dronkers EAC, Welters MJP, et al: A beneficial tumor microenvironment in oropharyngeal squamous cell carcinoma is characterized by a high T cell and low IL17(+) cell frequency. Cancer Immunol. Immunother. 2016; 65: 393-403.

27. Chen P-L, Roh W, Reuben A, et al: Analysis of Immune Signatures in Longitudinal Tumor Samples Yields Insight into Biomarkers of Response and Mechanisms of Resistance to Immune Checkpoint Blockade. Cancer Discov. 2016; 6: 827-837.

28. Hamid O, Schmidt H, Nissan A, et al: A prospective phase II trial exploring the association between tumor microenvironment biomarkers and clinical activity of ipilimumab in advanced melanoma. J. Transl. Med. 2011; 9: 204.

29. Becht E, Giraldo NA, Beuselinck B, et al: Prognostic and theranostic impact of molecular subtypes and immune classifications in renal cell cancer (RCC) and colorectal cancer (CRC). Oncoimmunology 2015; 4: e1049804.

30. Qian B-Z and Pollard JW: Macrophage diversity enhances tumor progression and metastasis. Cell 2010; 141: 39-51. 
31. De Palma M, Murdoch C, Venneri MA, et al: Tie2-expressing monocytes: regulation of tumor angiogenesis and therapeutic implications. Trends Immunol. 2007; 28 : 519-524.

32. Alves AM, Diel LF and Lamers ML: Macrophages and prognosis of oral squamous cell carcinoma: A systematic review. J. Oral Pathol. Med. 2017.

33. Chen X-J, Han L-F, WuX-G, et al: Clinical Significance of CD163+ and CD68+ Tumorassociated Macrophages in High-risk HPV-related Cervical Cancer. J. Cancer 2017; 8: 3868-3875.

34. Leijte JAP, Kroon BK, Valdés Olmos RA, et al: Reliability and safety of current dynamic sentinel node biopsy for penile carcinoma. Eur. Urol. 2007; 52: 170-7.

35. Ruiter DJ, Ferrier CM, van Muijen GN, et al: Quality control of immunohistochemical evaluation of tumour-associated plasminogen activators and related components. European BIOMED-1 Concerted Action on Clinical Relevance of Proteases in Tumour Invasion and Metastasis. Eur. J. Cancer 1998; 34: 1334-1340.

36. Keller MD, Neppl C, Irmak Y, et al: Adverse prognostic value of PD-L1 expression in primary resected pulmonary squamous cell carcinomas and paired mediastinal lymph node metastases. Mod. Pathol. 2018; 31: 101-110.

37. Ilie M, Hofman V, Dietel M, et al: Assessment of the PD-L1 status by immunohistochemistry: challenges and perspectives for therapeutic strategies in lung cancer patients. Virchows Arch. 2016; 268: 511-25.

38. Guimaraes GC, Cunha IW, Soares FA, et al: Penile squamous cell carcinoma clinicopathological features, nodal metastasis and outcome in 333 cases. J. Urol. 2009; 182: 528-34; discussion 534.

39. McAlpine JN, Leung SCY, Cheng A, et al: Human papillomavirus (HPV)-independent vulvar squamous cell carcinoma has a worse prognosis than HPV-associated disease: a retrospective cohort study. Histopathology 2017; 71: 238-246.

40. Krupar R, Robold K, Gaag D, et al: Immunologic and metabolic characteristics of HPV-negative and HPV-positive head and neck squamous cell carcinomas are strikingly different. Virchows Arch. 2014; 465: 299-312.

41. MannweilerS, Sygulla S, Winter E, et al: Two major pathways of penile carcinogenesis: HPV-induced penile cancers overexpress p16ink4a, HPV-negative cancers associated with dermatoses express p53, but lack p16ink4a overexpression. J. Am. Acad. Dermatol. 2013; 69: 73-81.

42. Mentrikoski MJ, Stelow EB, Culp S, et al: Histologic and immunohistochemical assessment of penile carcinomas in a North American population. Am. J. Surg. Pathol. 2014; 38: 1340-1348.

43. Russell S, Angell T, Lechner M, et al: Immune cell infiltration patterns and survival in head and neck squamous cell carcinoma. Head Neck Oncol. 2013; 5: 24.

44. Taube JM, Young GD, McMiller TL, et al: Differential Expression of ImmuneRegulatory Genes Associated with PD-L1 Display in Melanoma: Implications for PD-1 Pathway Blockade. Clin. Cancer Res. 2015; 21: 3969-3976.

45. Taube JM, Anders RA, Young GD, et al: Colocalization of inflammatory response with B7-h1 expression in human melanocytic lesions supports an adaptive resistance mechanism of immune escape. Sci. Transl. Med. 2012; 4: 127ra37. 
46. Howitt BE, Sun HH, Roemer MGM, et al: Genetic Basis for PD-L1 Expression in Squamous Cell Carcinomas of the Cervix and Vulva. JAMA Oncol. 2016; 2: 518522.

47. Garcia-Diaz A, Shin DS, Moreno BH, et al: Interferon Receptor Signaling Pathways Regulating PD-L1 and PD-L2 Expression. Cell Rep. 2017; 19: 1189-1201.

48. Feng Z, Bethmann D, Kappler M, et al: Multiparametric immune profiling in HPVoral squamous cell cancer. JCl insight 2017; 2.

49. Administration USF and D: Hematology/Oncology (Cancer) Approvals \& Safety Notifications. 2017.Available at: https://www.fda.gov/Drugs/InformationOnDrugs/ ApprovedDrugs/ucm279174.htm, accessed July 14, 2017.

50. Heusinkveld M, de Vos van Steenwijk PJ, Goedemans R, et al: M2 macrophages induced by prostaglandin E2 and IL-6 from cervical carcinoma are switched to activated M1 macrophages by CD4+ Th1 cells. J. Immunol. 2011; 187: 1157-1165.

51. Sharma P and Allison JP: Immune checkpoint targeting in cancer therapy: toward combination strategies with curative potential. Cell 2015; 161: 205-214. 
Supplementary Table 1: Immunohistochemical stainings.

\begin{tabular}{|c|c|c|c|c|}
\hline Antibody & Clone & $\begin{array}{l}\text { Catalog } \\
\text { number }\end{array}$ & Manufacturer & Tissue sections \& preparation \\
\hline HLA-A & HCA2 & - & $\begin{array}{l}\text { Provided by } \\
\text { prof. Neefjes }\end{array}$ & \multirow{5}{*}{$\begin{array}{l}\text { Tissue microarray. } \\
\text { Deparaffinisation and } \\
\text { rehydration with graded } \\
\text { ethanol to distilled water. } \\
\text { Endogenous peroxidase } \\
\text { activity was blocked with } \\
0.03 \% \mathrm{H}_{2} \mathrm{O}_{2} / \mathrm{MeOH} \text { for 20'. }\end{array}$} \\
\hline $\mathrm{HLA}-\mathrm{B} / \mathrm{C}$ & HC10 & - & $\begin{array}{l}\text { (NCl, Ihe } \\
\text { Netherlands) }\end{array}$ & \\
\hline$\beta 2$ micro-globulin & A0072 & anti- $\beta-2 M$ & $\begin{array}{l}\text { DAKO, } \\
\text { Denmark }\end{array}$ & \\
\hline HLA-E & MEM-E/O2 & MCA2193 & $\begin{array}{l}\text { Bio-Rad, USA } \\
\text { (formerly AbD } \\
\text { Serotec, UK) }\end{array}$ & \\
\hline HLA-G & $4 \mathrm{H} 84$ & 557577 & $\begin{array}{l}\text { BD Pharmingen, } \\
\text { USA }\end{array}$ & \\
\hline CD8 & C8/144B & M7103 & $\begin{array}{l}\text { DAKO / Agilent, } \\
\text { Denmark }\end{array}$ & \multirow{4}{*}{$\begin{array}{l}\text { Whole mount sections. } \\
\text { BenchMark Ultra autostainer } \\
\text { (Ventana Medical Systems, } \\
\text { USA). Paraffin sections } \\
\text { were heated }\left(28^{\prime} 75^{\circ} \mathrm{C}\right) \text { and } \\
\text { deparaffinized with EZ prep } \\
\text { solution (Ventana Medical } \\
\text { Systems, USA). }\end{array}$} \\
\hline PD-L1 & E1L3N & 13684 & $\begin{array}{l}\text { Cell Signaling } \\
\text { Technology, USA }\end{array}$ & \\
\hline FoxP3 & 236A/E7 & vab20034 & AbCam, UK & \\
\hline CD163 & MRQ-26 & 5973929001 & $\begin{array}{l}\text { Cell Marque, } \\
\text { USA }\end{array}$ & \\
\hline $\begin{array}{l}\text { Double staining } \\
\text { CD68/CD163 }\end{array}$ & $\begin{array}{l}514 \mathrm{H} 12 / \\
10 \mathrm{D} 6\end{array}$ & $\begin{array}{l}\text { MCA1815/ } \\
\text { NCL-CD163 }\end{array}$ & $\begin{array}{l}\text { Bio-Rad, UK } \\
\text { / Novocastra } \\
\text { Germany }\end{array}$ & Whole mount sections. \\
\hline
\end{tabular}

$\mathrm{NCl}$, Netherlands Cancer Institute; RT, Room temperature; ', minutes; ${ }^{\circ} \mathrm{C}$, degrees Celsius. 


\begin{tabular}{|c|c|c|c|c|}
\hline $\begin{array}{l}\text { Heat induced antigen } \\
\text { retrieval }\end{array}$ & $\begin{array}{l}\text { Primary antibody } \\
\text { incubation }\end{array}$ & $\begin{array}{l}\text { Secondary } \\
\text { antibody }\end{array}$ & Detection & Counterstain \\
\hline \multirow{2}{*}{$\begin{array}{l}10 \text { ' boiling } 0.01 \mathrm{M} \text { citrate } \\
\text { buffer at } \mathrm{pH} 6.0 \text { for } \\
\text { HLA-A, HLA-B/C, } \beta 2 \mathrm{M} \text {, } \\
\text { and HLA-E. }\end{array}$} & $\begin{array}{l}\text { 1:600 } \\
\text { Overnight, RT }\end{array}$ & \multirow{5}{*}{$\begin{array}{l}\text { 30' Bright Vision } \\
\text { (ImmunoLogic BV, } \\
\text { The Netherlands) }\end{array}$} & \multirow{5}{*}{$\begin{array}{l}10^{\prime} \\
\text { applying a } 0.05 \mathrm{M} \\
\text { Tris- } \mathrm{HCl} \text { buffer } \\
\text { containing } 0.05 \% \\
\text { of 3,3'-diamino- } \\
\text { benzidine- } \\
\text { tetrahydrochloride } \\
\text { and } 0.0018 \% \mathrm{H}_{2} \mathrm{O}_{2} \text {. }\end{array}$} & \multirow[t]{5}{*}{$\begin{array}{l}\text { Mayer's } \\
\text { haematoxylin }\end{array}$} \\
\hline & $\begin{array}{l}\text { 1:1000 } \\
\text { Overnight, RT }\end{array}$ & & & \\
\hline \multirow[t]{3}{*}{$\begin{array}{l}\text { 10' boiling Tris/EDTA } \\
\text { buffer at } \mathrm{pH} 9.0\end{array}$} & $\begin{array}{l}\text { 1:4000 } \\
\text { Overnight, RT }\end{array}$ & & & \\
\hline & $\begin{array}{l}\text { 1:250 } \\
\text { Overnight, RT }\end{array}$ & & & \\
\hline & $\begin{array}{l}\text { 1:100 } \\
\text { Overnight, RT }\end{array}$ & & & \\
\hline $\begin{array}{l}32^{\prime} 95^{\circ} \mathrm{C} \text { pH8.5 } \\
\text { Cell conditioning } 1 \\
\text { (Ventana Medical } \\
\text { Systems, USA) }\end{array}$ & $\begin{array}{l}1: 100 \\
32^{\prime} 37^{\circ} \mathrm{C}\end{array}$ & \multirow{2}{*}{\multicolumn{2}{|c|}{$\begin{array}{l}\text { OptiView DAB Detection Kit (Ventana } \\
\text { Medical Systems, USA) }\end{array}$}} & $\begin{array}{l}\text { Hematoxylin } \\
\text { II and Blueing } \\
\text { Reagent } \\
\text { (Ventana }\end{array}$ \\
\hline \multirow{3}{*}{$\begin{array}{l}64^{\prime} 95^{\circ} \mathrm{C} \text { pH8.5 } \\
\text { Cell conditioning } 1 \\
\text { (Ventana Medical } \\
\text { Systems, USA) }\end{array}$} & $\begin{array}{l}1: 200 \\
60^{\prime} R T\end{array}$ & & & $\begin{array}{l}\text { Medical } \\
\text { Systems, USA) }\end{array}$ \\
\hline & $\begin{array}{l}1: 40 \\
120^{\prime} R T\end{array}$ & \multirow{2}{*}{\multicolumn{2}{|c|}{$\begin{array}{l}\text { UltraView DAB Detection kit (Ventana } \\
\text { Medical Systems, USA) }\end{array}$}} & \\
\hline & $\begin{array}{l}\text { Ready to use } \\
\text { dispenser } \\
32^{\prime} 37^{\circ} \mathrm{C}\end{array}$ & & & \\
\hline $\begin{array}{l}\text { 10' boiling Tris/EDTA } \\
\text { buffer at } \mathrm{pH} 9.0\end{array}$ & $\begin{array}{l}\text { 1:50 / 1:100 } \\
\text { Overnight, RT }\end{array}$ & \multicolumn{2}{|c|}{$\begin{array}{l}\text { Secondary antibodies: Goat-anti-Mouse } \\
\text { IgG2a Alexa-Fluor-594 / Goat-anti- } \\
\text { Mouse IgG1 Alexa-Fluor-488 (both } \\
\text { from Life Technologies, USA) }\end{array}$} & DAPI \\
\hline
\end{tabular}


Supplementary table 2: Tumour-microenvironmental characteristics of all cases and of hrHPV subgroups.

\begin{tabular}{|c|c|c|c|c|}
\hline Variable & $\begin{array}{c}\text { hrHPV- } \\
\mathrm{N}=158(\%)\end{array}$ & $\begin{array}{c}\text { hrHPV+ } \\
\mathrm{N}=52(\%)\end{array}$ & $\begin{array}{c}\text { Total } \\
\mathrm{N}=213(\%)\end{array}$ & p-value* \\
\hline \multicolumn{5}{|c|}{ Tumour-microenvironmental characteristics } \\
\hline $\begin{array}{l}\text { High-risk HPV } \\
\text { Positive } \\
\text { Negative } \\
\text { Missing }\end{array}$ & $\begin{array}{c}- \\
158 \\
-\end{array}$ & $\begin{array}{c}52 \# \\
- \\
-\end{array}$ & $\begin{array}{c}52(24.4) \\
158(74.2) \\
3(1.4)\end{array}$ & - \\
\hline $\begin{array}{l}\text { Total classical HLA expression } \\
\text { Normal } \\
\text { Partial downregulation } \\
\text { Complete downregulation } \\
\text { Missing }\end{array}$ & $\begin{array}{l}17 \#(10.8) \\
40(25.3) \\
25(15.8) \\
76(48.1) \\
\end{array}$ & $\begin{array}{c}4(7.7) \\
21(40.4) \\
14(26.9) \\
13(25.0) \\
\end{array}$ & $\begin{array}{l}21(9.9) \\
62(29.1) \\
39(18.3) \\
91(42.7) \\
\end{array}$ & 0.36 \\
\hline $\begin{array}{l}\text { Non-classical HLA score } \\
\text { Normal (absent) } \\
\text { Upregulated } \\
\text { Missing }\end{array}$ & $\begin{array}{l}76(48.1) \\
27(17.1) \\
55(34.8)\end{array}$ & $\begin{array}{l}32(61.5) \\
13(25.0) \\
7(13.5)\end{array}$ & $\begin{array}{l}108(50.7) \\
40(18.8) \\
65(30.5)\end{array}$ & 0.74 \\
\hline $\begin{array}{l}\text { Tumour PD-L1 } \\
\text { Negative } \\
\text { Positive } \\
\text { Diffuse } \\
\text { Margin } \\
\text { Missing }\end{array}$ & $\begin{array}{l}70(44.3) \\
78(49.4) \\
29(18.4) \\
49(31.0) \\
10(6.3)\end{array}$ & $\begin{array}{l}32(61.5) \\
17(32.7) \\
7(13.5) \\
10(19.2) \\
3(5.8)\end{array}$ & $\begin{array}{c}104(48.8) \\
96(45.1) \\
13(6.1)\end{array}$ & $\begin{array}{c}0.03(\mathrm{np}) \\
0.09 \\
\text { (pat) }\end{array}$ \\
\hline $\begin{array}{l}\text { Stromal PD-L1 } \\
\text { Negative } \\
\text { Positive } \\
\text { Missing } \\
\end{array}$ & $\begin{array}{c}32(20.3) \\
114(72.2) \\
12(7.6) \\
\end{array}$ & $\begin{array}{c}15(28.8) \\
34(65.4) \\
3(5.8) \\
\end{array}$ & $\begin{array}{c}48(22.5) \\
150(70.4) \\
15(7.0) \\
\end{array}$ & 0.14 \\
\hline $\begin{array}{l}\text { PD-L1+ TIM } \\
\text { Present } \\
\text { Absent } \\
\text { Missing } \\
\end{array}$ & $\begin{array}{l}44(27.8) \\
99(62.7) \\
15(9.5) \\
\end{array}$ & $\begin{array}{c}10(19.2) \\
38(73.1) \\
4(4.4) \\
\end{array}$ & $\begin{array}{c}140(65.7) \\
54(25.4) \\
19(8.9) \\
\end{array}$ & 0.19 \\
\hline $\begin{array}{l}\text { Cytotoxic T-cells (CD8) } \\
\text { Tumour (median, (IQR)) } \\
\text { Stromal (median, (IQR)) } \\
\text { Missing (number,(\%)) }\end{array}$ & $\begin{array}{c}13128.8(19980) \\
70798.2(85803) \\
36(22.8) \\
\end{array}$ & $\begin{array}{c}12209.5(20287) \\
60357.4(80246) \\
2(3.9) \\
\end{array}$ & $\begin{array}{c}12426.4(19544) \\
66633.0(85510) \\
38(17.8) \\
\end{array}$ & $\begin{array}{l}0.49 \\
0.09\end{array}$ \\
\hline $\begin{array}{l}\text { Regulatory T-cells (FoxP3) } \\
\text { Tumour (median, (IQR)) } \\
\text { Stromal (median, (IQR)) } \\
\text { Missing (number, (\%)) }\end{array}$ & $\begin{array}{c}3638.8(5715.8) \\
25441.0(26698.6) \\
11(7.0)\end{array}$ & $\begin{array}{c}3113.3250(3913.9) \\
24907.4300(20230.7) \\
2(3.9)\end{array}$ & $\begin{array}{c}3463.3(5250.6) \\
25293.9(25353.4) \\
14(6.6)\end{array}$ & $\begin{array}{l}0.16 \\
0.47\end{array}$ \\
\hline $\begin{array}{l}\text { T-cell ratio tumour } \\
\text { Median, (IQR) } \\
\text { CD8>FoxP3 } \\
\text { CD8<FoxP3 } \\
\text { Missing }\end{array}$ & $\begin{array}{l}2.7529(4.2) \\
15(9.5) \\
95(60.1) \\
45(30.4)\end{array}$ & $\begin{array}{c}3.8101,(7.7) \\
6(12.2) \\
43(81.7) \\
3(5.8) \\
\end{array}$ & $\begin{array}{l}3.1074(5.5) \\
23(10.8) \\
138(64.8) \\
52(24.4)\end{array}$ & 0.29 \\
\hline $\begin{array}{l}\text { T-cell ratio stroma } \\
\text { Median, (IQR) } \\
\text { CD8>FoxP3 } \\
\text { CD8<FoxP3 } \\
\text { Missing }\end{array}$ & $\begin{array}{l}3.0899(5.01) \\
17(10.8) \\
83(52.5) \\
58(36.7)\end{array}$ & $\begin{array}{l}2.2455(3.9) \\
6(11.5) \\
35(67.3) \\
11(21.2)\end{array}$ & $\begin{array}{l}2.6186(4.0) \\
24(11.3) \\
119(55.8) \\
70(32.8)\end{array}$ & 0.33 \\
\hline
\end{tabular}




\begin{tabular}{lcccc}
\hline Tumour macrophages (CD163) & & & 0.28 \\
High tumour infiltration & $65(41.1)$ & $29(55.8)$ & $95(44.6)$ & \\
Low tumour infiltration & $89(56.3)$ & $23(44.2)$ & $114(53.5)$ & \\
Missing & $4(2.5)$ & - & $4(1.9)$ & 0.11 \\
& & & & \\
\hline Stromal macrophages (CD163) & & & $157(73.7)$ & \\
High stromal infiltration & $123(77.8)$ & $33(63.5)$ & $51(23.9)$ & \\
Low stromal infiltration & $30(19.0)$ & $19(36.5)$ & $5(2.3)$ & \\
Missing & $5(3.2)$ & - & & \\
& &
\end{tabular}

$\mathrm{Np}$, as tested negative or positive; pat, as tested over the three patterns of expression (negative, diffuse or at tumour-stroma margin); IQR, interquartile range; SCC, squamous cell carcinoma; HPV, human papilloma virus; HLA, human leukocyte antigen; PD-L1, programmed death-ligand 1; TIM, tumour infiltrating macrophages.

* Excluding missing cases. Comparing the two HPV-subgroups. Independent sample t-test for continuous variables, Chi-square or Fishers exact test for categorical variables.

\# One case was excluded because the majority of other variables was missing.[3,11] 


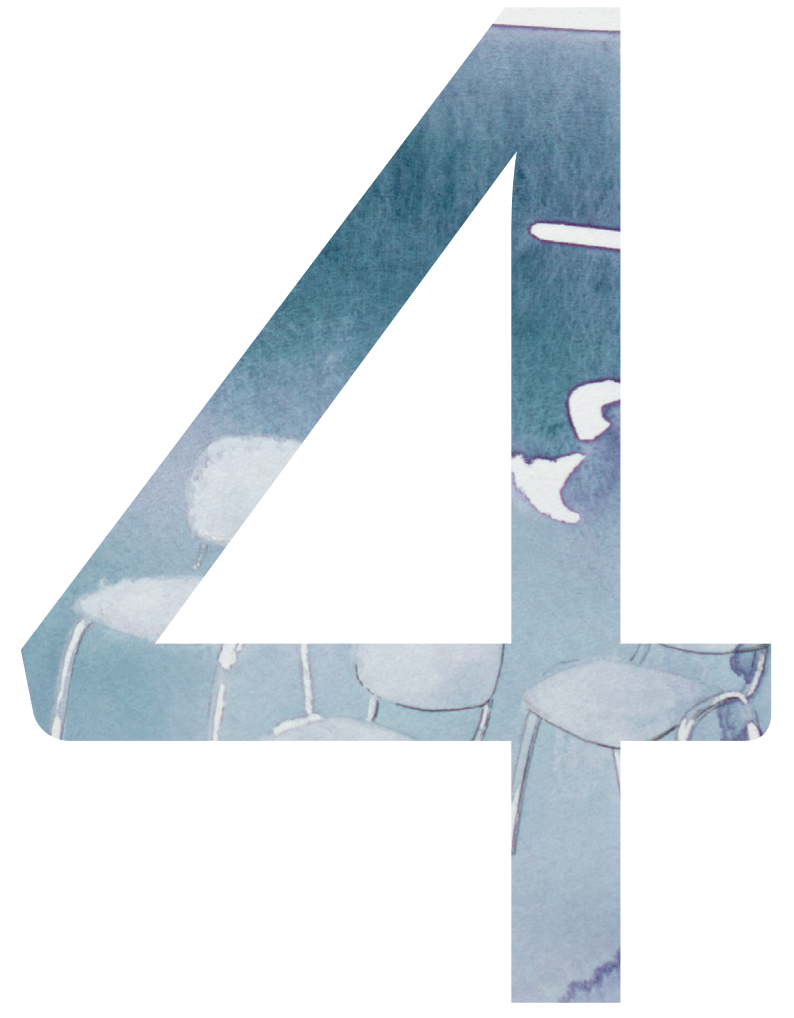


Chapter 4

\section{Advancements in staging and imaging for penile cancer}

Sarah R. Ottenhof, Andrew R. Leone, Simon Horenblas, Philippe E. Spiess, Erik Vegt 


\section{ABSTRACT}

Purpose of review: we review recent advancements in staging and imaging of penile cancer, including surveillance after therapy.

Recent findings: For cNO patients, the sentinel lymph node biopsy (SNB) is currently considered the preferred way for invasive staging. I thas largely replaced other modalities such as staging inguinal lymphadenectomy. Its diagnostic value increases when combined with other staging modalities such as ultrasound with fine needle aspiration cytology (US-FNAC) or FDG-PET/CT.

In patients with palpably suspicious nodes ( $\mathrm{cN}+$ ), imaging is more useful. PET/ CT has shown good accuracy in a limited number of small studies. US-FNAC can confirm nodal metastatic disease. A staging inguinal lymphadenectomy is of therapeutic value, but is associated with significant morbidity. Omitting staging inguinal lymphadenectomy was recently described; one study showed safe use of SNB combined with intraoperative ultrasound-guided resection of suspicious nodes in $\mathrm{cN}+$ patients. Therapeutic inguinal Iymphadenectomy was only performed in the $42 \%$ of groins with metastases confirmed by pathology.

For M-staging, PET/CT has shown good sensitivity and its role should be further evaluated. Follow-up and surveillance rely on physical examination and US-FNAC.

Summary: Over the past decade, staging and treatment of penile cancer have become less invasive, while survival tends to improve. 


\section{INTRODUCTION}

Penile cancer, squamous cell carcinoma in $>95 \%$ of cases, is a rare (1/100,000 men in the US) yet potentially lethal malignancy which has significant geographic variations in incidence. ${ }^{1}$ Over the past few decades the staging of penile cancer has improved patient risk stratification. Patients with extensive metastatic penile cancer still have dismal prognoses. However, in localized disease, advances in imaging and staging have enabled identification of patients at high risk of progression. This includes axial imaging with computed tomography (CT), magnetic resonance imaging (MRI) and positron emission tomography with CT (PET/CT) using the radiotracer fluorodeoxyglucose (FDG), and surgical lymph node assessment techniques such as (dynamic) sentinel lymph node sampling biopsy (SNB) and modified inguinal lymphadenectomy. One study suggests that, despite a decrease in surgery for cNO patients, their survival has improved, likely as a result of improved diagnostic modalities. ${ }^{2}$ In this review, we present advances in staging and imaging of penile cancer with regard to clinical TNM-staging (table 1) and surveillance methods. Our recommendations are summarized in table 2.

\section{T-STAGING}

Penile cancer is staged clinically and pathologically according to the AJCC TNM classification. ${ }^{3}$ Clinical T-staging of the primary lesion has traditionally relied on physical examination. Visual inspection and palpation has generally been considered sufficient to clinically stage the primary tumor. ${ }^{4}$ Penile ultrasound has been examined in order to identify corporal infiltration. However, ultrasound has limited clinical utility especially in proximal tumors. CT has limited utility given its poor soft tissue resolution. 5,6 MRI has far superior soft tissue resolution (figure 1, $\left.{ }^{7}\right)$. MRI with artificial erection was described in 2007 in order to identify corporal invasion. MRI has some utility in patients suspected of having corporal invasion with inconclusive physical examination but desiring penile sparing treatments. ${ }^{8-10}$ A recent series of 25 patients staged with MRI (no artificial erection) and physical examination found that MRI accurately predicted pathological staging in 18/25 (72\%) of patients compared to $13 / 25$ (52\%) with physical examination alone. ${ }^{11}$ Another study using MRI after inducing artificial erection in 100 patients found that MRI detected tunica albuginea invasion with $82 \%$ sensitivity and $74 \%$ specificity. However, for detection of urethral invasion the sensitivity and specificity were 63\% and $82 \% .{ }^{12}$ Despite these advancements, physical examination remains the primary means of assessing clinical T-stage. 
Table 1: TNM Classification for Penile Cancer, 7th edition, 2009(3)

\section{TNM Clinical Classification}

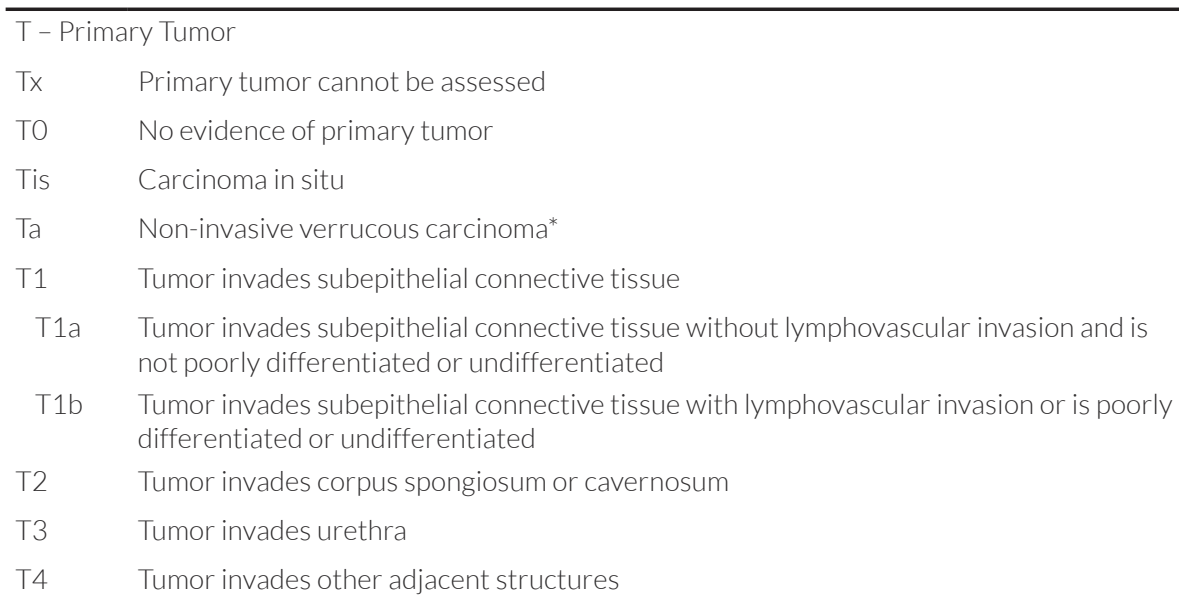

*Note 1: Verrucous carcinoma not associated with destructive invasion.

$\mathrm{N}$ - Regional Lymph Nodes

Nx Regional lymph nodes cannot be assessed

NO No palpable or visibly enlarged inguinal lymph nodes

N1 Palpable mobile unilateral inguinal lymph node

N2 Palpable mobile multiple or bilateral inguinal lymph nodes

N3 Fixed inguinal nodal mass or pelvic lymphadenopathy unilateral or bilateral

M - Distant Metastasis

MO No distant metastasis

M1 Distant metastasis

pTNM Pathological Classification

The $\mathrm{pT}$ categories correspond to the T categories. The pN categories are based upon biopsy, or surgical excision. Of the pM categories, only pM1 is a valid category (distant metastasis microscopically confirmed).

pNx Regional lymph nodes cannot be assessed

pNO No regional lymph node metastasis

pN1 Metastasis in a single inguinal lymph node

pN2 Metastasis in multiple or bilateral inguinal lymph nodes

pN3 Metastasis in pelvic lymph node(s), unilateral or bilateral or extranodal extension of regional lymph node metastasis

G - Histopathological Grading

Gx Grade of differentiation cannot be assessed

G1 Well differentiated

G2 Moderately differentiated

G3-4 Poorly differentiated/undifferentiated 
Table 2: Summary of our recommendations per clinical TNM stage

\begin{tabular}{|c|c|c|}
\hline $\begin{array}{l}\text { Clinical stage } \\
\text { TNM } 2009\end{array}$ & $\begin{array}{l}\text { Best imaging / staging } \\
\text { modality }\end{array}$ & Remarks \\
\hline $\mathrm{T} 1-4$ & $\begin{array}{l}\text { Physical examination } \\
\text { MRI on indication }\end{array}$ & $\begin{array}{l}\text { Indications for MRI: desired penile sparing surgery with } \\
\text { inconclusive physical examination. }\end{array}$ \\
\hline NO & US guided FNAC, SNB & \\
\hline N1 & US guided FNAC, SNB & $\begin{array}{l}\text { With repeated FNAC for suspicious lymph nodes. If } \\
\text { pathology is negative but suspicion remains, surgical } \\
\text { removal of the suspected node. }\end{array}$ \\
\hline N2 & $\begin{array}{l}\text { FDG-PET/CT and US } \\
\text { guided FNAC }\end{array}$ & If tumor-positive: ILND. \\
\hline N3 & $\begin{array}{l}\text { FDG-PET/CT and US } \\
\text { guided FNAC }\end{array}$ & $\begin{array}{l}\text { If tumor-positive: ILND (with or without neoadjuvant } \\
\text { chemotherapy or chemoradiation. }\end{array}$ \\
\hline MO & - & \\
\hline M1 & FDG-PET/CT & To determine extent of metastatic disease. \\
\hline Follow-up & $\begin{array}{l}\text { Physical examination, } \\
\text { US guided FNAC }\end{array}$ & $\begin{array}{l}\text { CT or FDG-PET/CT may be used for confirmation of } \\
\text { suspected recurrence / metastases. }\end{array}$ \\
\hline
\end{tabular}

TNM, classification of malignant tumours; MRI, magnetic resonance imaging; US, ultrasound; FNAC, fine needle aspiration cytology; SNB, sentinel lymph node biopsy; ILND, inguinal lymph node dissection; PET/CT, positron emission tomography with computed tomography; CT, computed tomography.

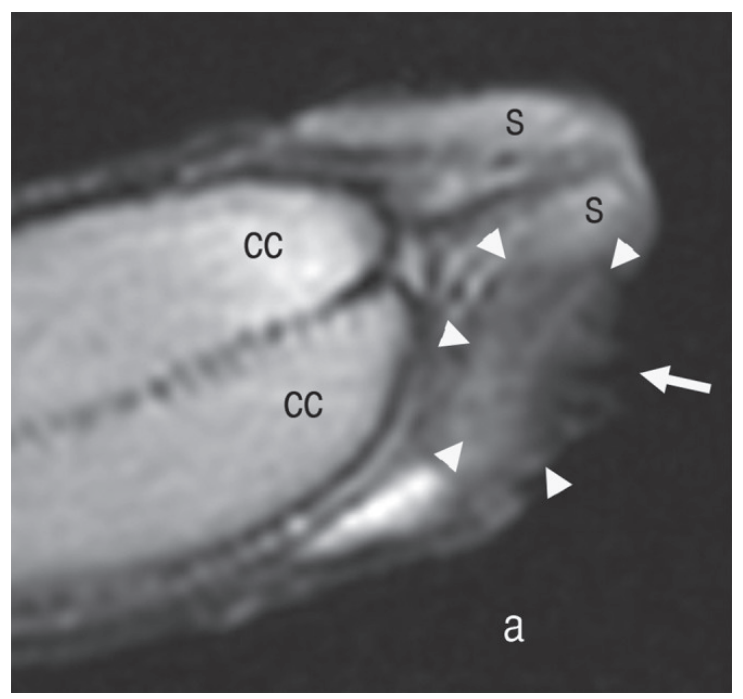

Figure 1. Magnetic resonance imaging (MRI) of penile cancer. Ulcerating lesion on the glans (white arrowheads, with a white arrow showing the ulcerated part), pT2 on histology and correctly called T2 on MRI. CC, corpus cavernosum; S, the spongiosal part of the glans. Reproduced with permission from Br J Radiol. ${ }^{7}$ 


\section{N-STAGING}

\subsection{Introduction}

Penile cancer metastasizes according to a consistent pattern: first to the inguinal lymph nodes, then sequentially to pelvic nodes, higher nodes and distant organs. Accurate lymph node staging is of the utmost importance to determine the optimal treatment. The prognosis of patients without lymph node metastases is excellent (cure in $>80 \%$ ), but decreases progressively with higher stages of lymph node involvement. 2,4

\subsection{Physical examination}

At physical examination, the groins are palpated for suspicious lymph nodes, their number, size, and mobility. Physical examination is not very accurate, especially in detecting small metastases, but grossly identifies two risk groups: those with palpable nodes $(\mathrm{cN}+)$ and those without (cNO). The majority of new patients present without palpable nodes, but $10-25 \%$ of them have occult metastases. ${ }^{13-15}$ Of patients with palpable lymph nodes in the groins, the majority have metastatic disease. Fixed inguinal nodes are almost always metastatic. ${ }^{4}$ If physical examination is complicated, e.g. by obesity, imaging can be used.

\subsection{Prediction of lymph node metastases}

Lymphovascular invasion (LVI) at the primary tumor site is one of the strongest predictors of occult lymph node metastases. ${ }^{16,17}$ Other predictive factors are perineural invasion, grade of differentiation, superoxide dismutase-2 expression, tumor depth, and clear cell differentiation. ${ }^{18-20}$ Several authors developed nomograms to predict lymph node involvement using aforementioned factors, physical examination and other factors. Nomograms varied from complex, including detailed pathological features, ${ }^{21}$ to more simplified ${ }^{17,22}$ with concordances (the proportion of correctly predicted outcomes) between 88\% and $74 \%$. A nomogram composed of primary tumor features only, resulted in an index-score that significantly correlated with lymph node status $(p<0.01) .^{23}$ Another nomogram, tested in cNO patients only, showed a concordance of $79 \% .{ }^{24}$ None of these nomograms have been externally validated.

Prediction is not accurate enough for reliable clinical N-staging. Intermediate and high risk tumors (pT1 grade 2 and worse) require further clinical and/or pathological staging. Lymph node metastases of the pelvis are best predicted by pathological characteristics of the inguinal lymph node dissection (ILND) specimen. ${ }^{25}$ 


\subsection{Further staging of non-palpable lymph nodes Conventional Imaging}

Few studies have evaluated computed tomography (CT) for non-palpable inguinal node staging. In the most recent study, CT detected all 4 inguinal metastases in 44 cNO groins. ${ }^{26}$ However, CT mainly detects lymph node metastases based on size, and therefore is not sensitive for small metastases, despite improving spatial resolution and $\mathrm{C} T$ technology.

MRI is considered the most sensitive for lymph node staging, because of its better soft tissue resolution and identification of intranodal features. ${ }^{27}$ Features such as necrosis are very specific for lymph node involvement, but certainly not all metastases show such features. A recent study compared preoperative MRI with pathologic evaluation after LND. MRI correctly staged 13 out of 15 patients (86.7\%), with the remaining two cases false-positively classified as N1. Although there were no false-negatives in this per-patient analysis, a missed case of inguinal lymph node involvement is mentioned in the manuscript. ${ }^{11} \mathrm{~A}$ relatively new technique for imaging lymph node metastases is lymphotropic nanoparticleenhanced MRI. It has shown favorable results in prostate cancer. ${ }^{28}$ One study has shown promising results in seven penis cancer patients, but requires further validation. ${ }^{29}$

Conventional imaging is associated with false-positive detection of enlarged reactive lymph nodes, and failure to detect micrometastases in normal-sized lymph nodes. Therefore, MRI and CT are of limited value for inguinal lymph node staging, but do aid staging when physical examination is difficult.,10

\section{PET/CT Imaging}

A high FDG-uptake in most primary penile tumors and lymph node metastases suggests that FDG PET/CT is suitable for penile cancer staging. ${ }^{30}$ However, PET/ $\mathrm{CT}$ is also hampered by low sensitivities for smaller metastases. In initially CNO staged patients, detection of inguinal involvement using FDG PET/CT established sensitivities from $20 \%$ to $80 \% .{ }^{26,30,31}$ In a meta-analysis, the pooled sensitivity in cNO patients was only $57 \% .^{32}$ Therefore, FDG-PET/CT is not recommended for cNO patients.

\section{Ultrasound and Fine Needle Aspiration Cytology}

Ultrasonography (US) of the groins is a noninvasive, inexpensive and quick method to detect suspicious nodes. Lymph nodes are well assessable and USguided fine needle aspiration cytology (FNAC) can prove metastatic lymph nodes 
in an outpatient setting. ${ }^{33}$ In a study assessing 83 cNO groins, 34 groins were suspicious on US and subsequently underwent aspiration cytology. Nine groins contained malignant cells, resulting in immediate (i.e. first operation) ILND in 9 of 23 positive groin regions (sensitivity 39\%, specificity 100\%). In the other 14, nodal metastases first had to be proven by SNB before ILND was performed in a second operation. ${ }^{34}$

Because of its low sensitivity, staging with US-FNAC should be combined with more invasive staging, such as SNB, in FNAC-negative cases. Combined procedures will be discussed in the sentinel node biopsy section. FNAC is recommended in both $\mathrm{cNO}$ and $\mathrm{cN}+$ groins. ${ }^{35}$

\section{Sentinel Node Biopsy}

In penile cancer the sentinel node is always located in the inguinal region, and is typically found by injecting a blue dye and a radioactive tracer in/around the primary tumor. ${ }^{36-38}$ Preoperative localization of the sentinel nodes by scintigraphy helps intraoperative navigation. In addition to static lymphoscintigraphic images, dynamic images may show the route of drainage to the lymph nodes in a so-called dynamic sentinel node biopsy (DSNB) procedure. ${ }^{39}$ A study $(n=280)$ showed slightly but insignificantly superior results for lymphoscintigraphy on the same day ( $n=65$ groins) compared to the day before SNB ( $n=215$ groins). ${ }^{40}$ Besides removal of the sentinel nodes, the procedure also entails a thorough intraoperative palpation of the groin area and excision of any suspicious lymph nodes.

As an alternative to traditional radioactive tracers combined with blue dye, recently the use of an investigational hybrid tracer was introduced, which is both radioactive ( $99 \mathrm{~m} \mathrm{Tc}$-nanocolloid) and fluorescent (indocyanine green), and follows the same drainage patterns as radioactive-only tracer. ${ }^{41,42}$ This hybrid tracer can aid intraoperative navigation to sentinel nodes, by enabling visual detection of the radioactive nodes (figure 2 ). ${ }^{43}$ Its detection rate appears to be higher than the detection rate of blue dye alone. ${ }^{41,44}$

The contemporary sentinel node procedure is a reliable staging tool with minimal morbidity and acceptable sensitivity. ${ }^{45-47}$ In a two center analysis the falsenegative rate (FNR) was 7\%, with corresponding 93\% sensitivity. ${ }^{48}$ Nevertheless, for every (false) negative procedure, the patient's prognosis decreases greatly when metastases become apparent. False negatives in SNB may be caused by macroscopic metastases blocking influx into the actual sentinel node(s). ${ }^{49}$ 

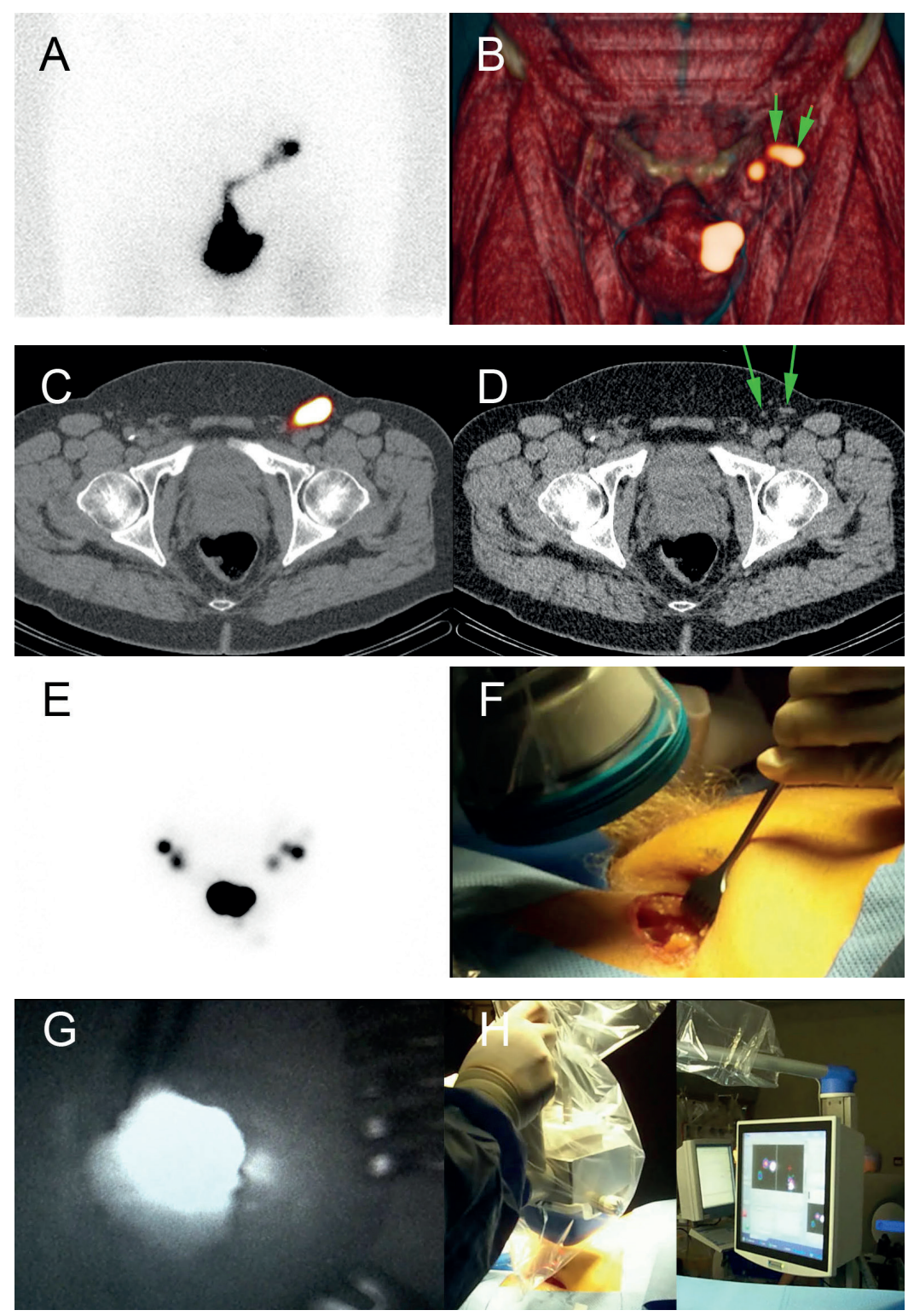

Figure 2. Dynamic sentinel node biopsy procedure of penile cancer using a hybrid radioactivefluorescent tracer ( ${ }^{99 \mathrm{~m} T c}$-nanocolloid-ICG). Planar scintigraphic images $10 \mathrm{~min}$ after injection of radiotracer in four deposits around the penis (A) show lymph vessels from the tumor to left inguinal sentinel nodes (SNs). Volume rendered (B) and transversal (C and D) SPECT/ CT images show the exact location of the SNs preoperatively. Because of right-sided nonvisualization, a reinjection was performed. Scintigraphy at 1 to $2 \mathrm{~h}$ after reinjection (E) also shows SNs in the right groin. During surgery, a fluorescence camera (F) enables easier identification of fluorescent SNs $(G)$. A mobile gamma camera $(H)$ can be used to check whether all radioactive $\mathrm{SN}$ s are successfully removed. 
Combining the (D)SNB with other staging tools that detect macroscopic metastases may reduce the FNR. Various studies used a combination of preoperative US with or without FNAC and (D)SNB. ${ }^{35,47,50,51}$ The FNR was a very acceptable 5\%; lower than the FNR of DSNB alone. ${ }^{47}$

A Danish study ( $\mathrm{N}=129$ patients) combined FDG-PET/CT imaging with SNB. ${ }^{13}$ The combined procedure showed a sensitivity over 94\% (FNR 5.6\%). ${ }^{13}$ This supports the idea that the different modalities should be used in a complimentary fashion.

\section{Modified Inguinal Lymphadenectomy}

A modified inguinal lymphadenectomy (MIL) entails the surgical removal of all the lymph nodes containing first-line lymphatic invasion. One of the problems associated with MIL is that no consensus exists on the boundaries of the dissection. Two studies have suggested that the proposed boundaries should be extended. ${ }^{37,52}$ Unfortunately, both studies used different anatomical fields, and the optimal boundaries of MIL remain to be defined. Furthermore, its oncological safety has been questioned, although its false-negative rate seems comparable to that of SNB. ${ }^{53}$ Nowadays, the MIL is largely replaced by the SNB procedure, but it can be used as an alternative if identification of a sentinel node fails. ${ }^{54}$

\subsection{Further staging of palpable nodes $(\mathrm{cN}+)$ Conventional Imaging}

CT and MRI can detect pelvic and retroperitoneal nodes that cannot be detected by physical examination. However, their sensitivity is limited, especially for small metastases, since increased nodal size is the main criterion for malignancy. Additional criteria, such as central necrosis and irregularity of the lymph node border on CT performed well in preoperative risk stratification. ${ }^{55}$ Nevertheless CT has a sensitivity of only 20 - 38\% for the detection of pelvic lymph nodes. ${ }^{25,55}$ Risk stratification by inguinal lymph node characteristics such as number and extranodal extension on pathologic evaluation was more reliable. ${ }^{25}$ In an aforementioned study, MRI correctly staged all N3 patients, but this concerned only 3 patients. ${ }^{11}$

In a meta-analysis comparing CT and MRI of pelvic nodes in prostate cancer patients, pooled results were comparable, although the results of the individual studies varied widely. The pooled sensitivity was $42 \%$ for CT and $39 \%$ for MRI and pooled specificity was $82 \%$ for both. ${ }^{56}$ 


\section{FDG-PET/CT}

In a meta-analysis, detection of inguinal metastases with FDG-PET/CT in clinically suspected groins had a pooled sensitivity and specificity of 96 and 100\% respectively. ${ }^{32}$ Only one study evaluated FDG-PET/CT detection of pelvic nodes in penis cancer. With pathologically proven inguinal lymph node metastases, its sensitivity was $91 \%$ and its specificity was 100\%. ${ }^{57}$ PET/CT is likely to be more accurate than $\mathrm{CT}$ alone in the preoperative staging of the pelvic lymph nodes, as shown in other malignancies. ${ }^{58-60}$

\section{Ultrasound and fine needle aspiration cytology}

In clinically node-positive patients, FNAC of suspicious nodes can confirm metastases with a higher sensitivity than in cNO patients. A study with $16 \mathrm{cN}+$ patients showed a sensitivity of $93 \%$ and a specificity of $91 \%$ of FNAC without US. ${ }^{61}$ Another series of 28 patients showed sensitivity and specificity of both $100 \%$ in cN+ groins. ${ }^{62}$ Nevertheless, a risk of false-negatives exists and negative aspiration biopsies in $\mathrm{cN}+$ patients should be repeated.

\section{Sentinel node biopsy}

As a sentinel node biopsy also includes excision of clinically suspicious nodes, this could be performed in patients where FNAC fails to prove metastases but clinical suspicion remains. However, in those cases an SNB is less reliable, as rerouting of tracer due to tumorous obstruction is likely. ${ }^{49}$ Therefore, repeated FNAC and excision biopsy are indicated for palpable lymph nodes. A recent study ( $n=36$ groins) combined the sentinel node procedure with intraoperative US examination and surgical removal of suspicious Iymph nodes. Therapeutic inguinal lymphadenectomy was only performed if metastases were confirmed by pathology, and could be omitted in 58\% of groins. No relapses occurred during a median follow-up of 42 (range 16-84) months, yielding a false-negative rate of $0 \%$ (sensitivity 100\%). ${ }^{51}$

\section{Inguinal lymphadenectomy}

Traditionally, an inguinal lymphadenectomy was performed for staging, but this is associated with significant complications. ${ }^{63,64}$ Its therapeutic value is advantageous, especially in highly suspicious cases. However, cases with fixed inguinal nodes (clinically N3) require multimodal treatment such as neoadjuvant chemotherapy prior to surgery. ${ }^{65}$ 


\section{M-STAGING}

\subsection{Introduction}

In patients with inguinal nodal disease, M-staging is indicated. Considering the poor prognosis of patients with distant metastases, $\mathrm{M}$-staging is mainly important to prevent futile invasive treatments.

\subsection{Conventional imaging}

Pelvic, abdominal and thoracic imaging is recommended with CT or MRI scanning. A chest $\mathrm{X}$-ray is considered sufficient for thoracic imaging, but $\mathrm{CT}$ is considered more sensitive. PET/CT can be made as an alternative. ${ }^{4}$

\subsection{FDG-PET/CT}

Various distant metastases of penile cancer detected by FDG-PET/CT have been described in literature. ${ }^{66-68}$

In a recent study among 48 stage 3 and 4 patients, FDG-PET/CT was compared to conventional imaging (validation by both follow-up scans and biopsy) and showed a total sensitivity of $82 \%$ and specificity of $93 \%$. In biopsy-proven lesions only, the sensitivity was $83 \%{ }^{69}$ However, selection bias and limited follow-up in this study should be taken into account with interpretation. The exact role of PET/CT for metastases detection needs further evaluation. ${ }^{70}$

\section{SURVEILLANCE, RESPONSE EVALUATION AND FOLLOW UP}

Surveillance of all penile cancer patients relies upon physician and patient examination. Local recurrence is more common after penile sparing surgery than after partial or total penectomy, and occurs in up to $28 \%$ of patients..$^{71}$ US-FNAC for suspicious findings may improve diagnosis of regional recurrences. ${ }^{33,34,72}$ In patients with pathologically positive nodes $(\mathrm{pN}+)$ at initial treatment, regular physical examination with optional imaging (CT/MRI) and US-FNAC is recommended according to NCCN and EAU guidelines., ${ }^{4,65}$ In N2/N3 patients, NCCN guidelines recommend routine imaging of chest, abdomen and pelvis. There have been few recent advances in surveillance of penile cancer patients. $\mathrm{PET} / \mathrm{CT}$ is generally reserved for confirmation of possible recurrence and is not recommended for routine surveillance. 


\section{CONCLUSIONS}

T-staging relies on physical examination, but MRI can aid a more sensitive staging if needed.

$\mathrm{N}$-staging is most complicated for small metastases, as they are prone to be missed by physical examination, sectional imaging modalities, and FNAC. Larger metastases are more likely to be detected by all aforementioned methods. For the detection of small metastases, the (dynamic) sentinel node biopsy procedure is preferred because it provides accurate pathological staging without the side effects and complications of an inguinal lymph node dissection. SNB should be preceded by US-guided FNAC to avoid undetected macrometastases. FNAC also is a valuable tool to confirm metastases in suspicious groins. Nevertheless, micrometastases can be missed with every non-invasive or minimally invasive staging tool. Additional efforts should be made to further reduce false-negative rates.

For M-staging, conventional anatomical imaging is recommended according to guidelines. High sensitivity has been described for FDG-PET/CT, but its role needs further evaluation.

Follow-up and surveillance rely on physical examination and US-FNAC. PET/CT may have a role in localization of suspected recurrence, but is not recommended for routine surveillance.

\section{Key points}

- T-staging of penile cancer relies mainly on physical examination, but MRI can provide a more accurate staging if needed.

- The diagnostic value of the sentinel node biopsy procedure increases when combined with other diagnostic procedures such as US-FNAC, PET/CT or intraoperative ultrasound examination.

- FDG-PET/CT has shown good accuracy in both clinically suspicious groins and in detecting distant metastases, but its role needs further evaluation.

- Follow-up and surveillance rely primarily on physical examination and US-FNAC. 


\section{Special and outstanding references}

(11) Confirms an additional value of MRI, without artificial erection.

(13) This study shows improvement of the sentinel lymph node biopsy (SNB) by adding FDG-PET/CT, improving sensitivity to 94\%. As the prognosis drops sharply after a false-negative SNB, efforts should be made to further improve sensitivity.

(51) This study presents the feasibility of minimally invasive staging in cN+ patients. They performed SNB in patients with clinically suspicious groins, and combined it with intraoperative US-guided removal of suspicious lymph nodes. Traditionally there is no role for SNB in clinically suspicious groins, but the results from this study suggest that minimally invasive staging is also safe in a selected group of $\mathrm{cN}+$ patients.

(14) This study from the National Penile Cancer Register provides a nice overview of incidence and patient characteristics and tumor properties. They also provide detailed information on their staging procedures and the prognosis per clinical stage.

(69) This study evaluates FDG-PET/CT performance for staging or re-staging of penile cancer. Detailed information on accuracy for detection of metastases is given. Unfortunately, figures for lymph node staging are not specified separately for inguinal and pelvic lymph nodes. 


\section{REFERENCES}

1. Chaux A, Netto GJ, Rodriguez IM, Barreto JE, Oertell J, Ocampos S, et al. Epidemiologic profile, sexual history, pathologic features, and human papillomavirus status of 103 patients with penile carcinoma. World J Urol. Germany; 2013 Aug;31(4):861-7.

2. Djajadiningrat RS, Graafland NM, van Werkhoven E, Meinhardt W, Bex A, van der Poel HG, et al. Contemporary management of regional nodes in penile cancerimprovement of survival? J Urol. United States; 2014 Jan;191(1):68-73.

3. International Union Against Cancer. TNM Classification of Malignant Tumours. 7thed. Sobin LH, Gospodarowics M, Wittekind C, editors. Willy-Blackwell; 2009. 239-42 p.

4. Hakenberg OW, Compérat EM, Minhas S, Necchi A, Protzel C, Watkin N. EAU Guidelines on Penile Cancer: 2014 Update. Eur Urol. Switzerland; 2015 Jan;67(1):142-50.

5. Bertolotto M, Serafini G, Dogliotti L, Gandolfo N, Gandolfo NG, Belgrano M, et al. Primary and secondary malignancies of the penis: ultrasound features. Abdom Imaging. United States; 2005;30(1):108-12.

6. Lont AP, Besnard APE, Gallee MPW, van Tinteren H, Horenblas S. A comparison of physical examination and imaging in determining the extent of primary penile carcinoma. BJU Int. England; 2003 Apr;91(6):493-5.

7. Kirkham A. MRI of the penis. Br J Radiol. England; 2012 Nov;85(Spec No 11):S8693.

8. Kayes O, Minhas S, Allen C, Hare C, Freeman A, Ralph D. The role of magnetic resonance imaging in the local staging of penile cancer. Eur Urol. Switzerland; 2007 May;51(5):1313-9.

9. Petralia G, Villa G, Scardino E, Zoffoli E, Renne G, de Cobelli O, et al. Local staging of penile cancer using magnetic resonance imaging with pharmacologically induced penile erection. Radiol Med. Italy; 2008 Jun;113(4):517-28.

10. Gupta S, Rajesh A. Magnetic resonance imaging of penile cancer. Magn Reson Imaging Clin N Am. United States; 2014 May;22(2):191-9, vi.

11. Lucchesi FR, Reis RB, Faria EF, Machado RD, Rossini RR, Borregales LD, et al. Incremental value of MRI for preoperative penile cancer staging. J Magn Reson Imaging. $2017 \mathrm{Jul} ; 45(1): 118-24$.

12. Hanchanale V, Yeo L, Subedi N, Smith J, Wah T, Harnden P, et al. The accuracy of magnetic resonance imaging (MRI) in predicting the invasion of the tunica albuginea and the urethra during the primary staging of penile cancer. BJU Int. England; 2016 Mar;117(3):439-43.

13. Jakobsen JK, Alslev L, Ipsen P, Costa JC, Krarup KP, Sommer P, et al. DaPeCa-3: promising results of sentinel node biopsy combined with (18) F-fluorodeoxyglucose positron emission tomography/computed tomography in clinically lymph nodenegative patients with penile cancer - a national study from Denmark. BJU Int. England; 2016 Jul;118(1):102-11.

14. Kirrander P, Sherif A, Friedrich B, Lambe M, Håkansson U. Swedish National Penile Cancer Register: incidence, tumour characteristics, management and survival. BJU Int. 2016;117(2):287-92. 
15. Hughes BE, Leijte JAP, Kroon BK, Shabbir MA, Swallow TW, Heenan SD, et al. Lymph node metastasis in intermediate-risk penile squamous cell cancer: a two-centre experience. Eur Urol. Switzerland; 2010 Apr;57(4):688-92.

16. Winters BR, Mossanen MN, Holt SK, Lin DW, Wright JL. Predictors of Nodal Upstaging in Clinical Node Negative Patients with Penile Carcinoma: a National Cancer Database Analysis. Urology. 2016 Jul;96:29-34.

17. Bhagat SK, Gopalakrishnan G, Kekre NS, Chacko NK, Kumar S, Manipadam MT, et al. Factors predicting inguinal node metastasis in squamous cell cancer of penis. World J Urol. Germany; 2010 Feb;28(1):93-8.

18. Termini L, Fregnani JH, Boccardo E, da Costa WH, Longatto-Filho A, Andreoli MA, et al. SOD2 immunoexpression predicts lymph node metastasis in penile cancer. BMC Clin Pathol. England; 2015;15:3.

19. Mannweiler S, Sygulla S, Tsybrovskyy O, Razmara Y, Pummer K, Regauer S. Clearcell differentiation and lymphatic invasion, but not the revised TNM classification, predict lymph node metastases in PT1 penile cancer: a clinicopathologic study of 76 patients from a low incidence area. Urol Oncol. United States; 2013 Oct;31(7):1378-85.

20. Graafland NM, Lam W, Leijte JAP, Yap T, Gallee MPW, Corbishley C, et al. Prognostic factors for occult inguinal lymph node involvement in penile carcinoma and assessment of the high-risk EAU subgroup: a two-institution analysis of 342 clinically node-negative patients. Eur Urol. Switzerland; 2010 Nov;58(5):742-7.

21. Ficarra V, Zattoni F, Artibani W, Fandella A, Martignoni G, Novara G, et al. Nomogram predictive of pathological inguinal lymph node involvement in patients with squamous cell carcinoma of the penis. J Urol. 2006 May;175(5):1700-4; discussion 1704-5.

22. Alkatout I, Naumann CM, Hedderich J, Hegele A, Bolenz C, Junemann K-P, et al. Squamous cell carcinoma of the penis: predicting nodal metastases by histologic grade, pattern of invasion and clinical examination. Urol Oncol. United States; 2011;29(6):774-81.

23. Chaux A, Caballero C, Soares F, Guimaraes GC, Cunha IW, Reuter V, et al. The prognostic index: a useful pathologic guide for prediction of nodal metastases and survival in penile squamous cell carcinoma. Am J Surg Pathol. United States; 2009 Jul;33(7):1049-57.

24. Zhu Y, Zhang H-L, Yao X-D, Zhang S-L, Dai B, Shen Y-J, et al. Development and evaluation of a nomogram to predict inguinal lymph node metastasis in patients with penile cancer and clinically negative lymph nodes. J Urol. United States; 2010 Aug;184(2):539-45.

25. Zhu Y, Zhang SL, Ye DW, Yao XD, Jiang ZX, Zhou XY. Predicting pelvic lymph node metastases in penile cancer patients: a comparison of computed tomography, Cloquet's node, and disease burden of inguinal lymph nodes. Onkologie. Switzerland; 2008 Feb;31(1-2):37-41.

26. Souillac I, Rigaud J, Ansquer C, Marconnet L, Bouchot O. Prospective evaluation of (18)F-fluorodeoxyglucose positron emission tomography-computerized tomography to assess inguinal lymph node status in invasive squamous cell carcinoma of the penis. J Urol. United States; 2012 Feb;187(2):493-7. 
27. Hedgire SS, Pargaonkar VK, Elmi A, Harisinghani AM, Harisinghani MG. Pelvic nodal imaging. Radiol Clin North Am. United States; 2012 Nov;50(6):1111-25.

28. Eisner BH, Feldman AS. Nanoparticle imaging for genitourinary cancers. Cancer Biomark. Netherlands; 2009;5(2):75-9.

29. Tabatabaei S, Harisinghani M, McDougal WS. Regional lymph node staging using lymphotropic nanoparticle enhanced magnetic resonance imaging with ferumoxtran-10 in patients with penile cancer. J Urol. 2005 Sep;174(3):923-7; discussion 927.

30. Scher B, Seitz M, Reiser M, Hungerhuber E, Hahn K, Tiling R, et al. 18F-FDG PET/CT for staging of penile cancer. J Nucl Med. 2005 Sep;46(9):1460-5.

31. Leijte JAP, Graafland NM, Valdés Olmos RA, van Boven HH, Hoefnagel CA, Horenblas S. Prospective evaluation of hybrid 18F-fluorodeoxyglucose positron emission tomography/computed tomography in staging clinically node-negative patients with penile carcinoma. BJU Int. 2009 Sep;104(5):640-4.

32. Sadeghi R, Gholami H, Zakavi SR, Kakhki VRD, Horenblas S. Accuracy of 18F-FDG PET/CT for diagnosing inguinal lymph node involvement in penile squamous cell carcinoma: systematic review and meta-analysis of the literature. Clin Nucl Med. United States; 2012 May;37(5):436-41.

33. Krishna RP, Sistla SC, Smile R, Krishnan R. Sonography: an underutilized diagnostic tool in the assessment of metastatic groin nodes. J Clin Ultrasound. Wiley Subscription Services, Inc., A Wiley Company; 2008 May 1;36(4):212-7.

34. Kroon BK, Horenblas S, Deurloo EE, Nieweg OE, Teertstra HJ. Ultrasonographyguided fine-needle aspiration cytology before sentinel node biopsy in patients with penile carcinoma. BJU Int. 2005 Mar;95(4):517-21.

35. Mir MC, Herdiman O, Bolton DM, Lawrentschuk N. The role of lymph node fineneedle aspiration in penile cancer in the sentinel node era. Adv Urol. Egypt; 2011;2011:383571.

36. Daseler EH, Anson BJ, Reimann AF. Radical excision of the inguinal and iliac lymph glands; a study based upon 450 anatomical dissections and upon supportive clinical observations. Surg Gynecol Obstet. 1948 Dec;87(6):679-94.

37. Leijte JAP, Valdés Olmos RA, Nieweg OE, Horenblas S. Anatomical mapping of lymphatic drainage in penile carcinoma with SPECT-CT: implications for the extent of inguinal lymph node dissection. Eur Urol. 2008 Oct;54(4):885-90.

38. Kroon BK, Valdés Olmos RA, van der Poel HG, Nieweg OE, Horenblas S. Prepubic sentinel node location in penile carcinoma. Clin Nucl Med. 2005 Oct;30(10):649-50.

39. Horenblas S, Jansen L, Meinhardt W, Hoefnagel CA, de Jong D, Nieweg OE. Detection of occult metastasis in squamous cell carcinoma of the penis using a dynamic sentinel node procedure. J Urol. 2000 Jan;163(1):100-4.

40. Dimopoulos P, Christopoulos P, Shilito S, Gall Z, Murby B, Ashworth D, et al. Dynamic sentinel lymph node biopsy for penile cancer: a comparison between 1- and 2-day protocols. BJU Int. England; 2016 Jun;117(6):890-6.

41. Brouwer OR, van den Berg NS, Matheron HM, van der Poel HG, van Rhijn BW, Bex A, et al. A hybrid radioactive and fluorescent tracer for sentinel node biopsy in penile carcinoma as a potential replacement for blue dye. Eur Urol. Switzerland; 2014 Mar;65(3):600-9. 
42. Brouwer OR, Buckle T, Vermeeren L, Klop WMC, Balm AJM, van der Poel HG, et al. Comparing the hybrid fluorescent-radioactive tracer indocyanine green-99mTcnanocolloid with 99mTc-nanocolloid for sentinel node identification: a validation study using lymphoscintigraphy and SPECT/CT. J Nucl Med. United States; 2012 Jul;53(7):1034-40.

43. Klein Jan GH, van den Berg NS, van Oosterom MN, Wendler T, Miwa M, Bex A, et al. Toward (hybrid) navigation of a fluorescence camera in an open surgery setting. J Nucl Med. 2016 May;57(10):1650-3.

44. van den Berg NS, Simon H, Kleinjan GH, Engelen T, Bunschoten A, Welling MN, et al. First-in-human evaluation of a hybrid modality that allows combined radio- and (near-infrared) fluorescence tracing during surgery. Eur J Nucl Med Mol Imaging. 2015;42(11):1639-47.

45. Leijte JAP, Kroon BK, Valdés OImos RA, Nieweg OE, Horenblas S. Reliability and safety of current dynamic sentinel node biopsy for penile carcinoma. Eur Urol. 2007 Jul;52(1):170-7.

46. Kroon BK, Lont AP, Valdés Olmos RA, Nieweg OE, Horenblas S. Morbidity of dynamic sentinel node biopsy in penile carcinoma. J Urol. 2005 Mar;173(3):813-5.

47. Lam W, Alnajjar HM, La-Touche S, Perry M, Sharma D, Corbishley C, et al. Dynamic sentinel lymph node biopsy in patients with invasive squamous cell carcinoma of the penis: a prospective study of the long-term outcome of 500 inguinal basins assessed at a single institution. Eur Urol. Switzerland; 2013 Apr;63(4):657-63.

48. Leijte JAP, Hughes B, Graafland NM, Kroon BK, OImos RAVV, Nieweg OE, et al. Twocenter evaluation of dynamic sentinel node biopsy for squamous cell carcinoma of the penis. J Clin Oncol. United States; 2009 Jul 10;27(20):3325-9.

49. Leijte JAP, van der Ploeg IMC, Valdes Olmos RA, Nieweg OE, Horenblas S. Visualization of tumor blockage and rerouting of lymphatic drainage in penile cancer patients by use of SPECT/CT. J Nucl Med. United States; 2009 Mar;50(3):364-7.

50. Crawshaw JW, Hadway P, Hoffland D, Bassingham S, Corbishley CM, Smith Y, et al. Sentinel lymph node biopsy using dynamic lymphoscintigraphy combined with ultrasound-guided fine needle aspiration in penile carcinoma. Br J Radiol. England; 2009 Jan;82(973):41-8.

51. Naumann CM, van der Horst S, van der Horst C, Kahler KC, Seeger M, Osmonov D, et al. Reliability of dynamic sentinel node biopsy combined with ultrasound-guided removal of sonographically suspicious lymph nodes as a diagnostic approach in patients with penile cancer with palpable inguinal lymph nodes. Urol Oncol. 2015 Apr;33(9):389. e9-14.

52. Zhu YY-P, Zhang S-L, Ye D-W, Yao X-D, Dai B, Zhang H-L, et al. Prospectively packaged ilioinguinal lymphadenectomy for penile cancer: the disseminative pattern of lymph node metastasis. J Urol. United States; 2009 May;181(5):2103-8.

53. d'Ancona CAL, de Lucena RG, Querne FA de O, Martins MHT, Denardi F, Netto NR. Long-term followup of penile carcinoma treated with penectomy and bilateral modified inguinal lymphadenectomy. J Urol. 2004 Aug;172(2):498-501; discussion 501.

54. Ferreira U, Ribeiro MA V, Reis LO, Prudente A, Matheus WE. Sentinel lymph node biopsy in penile cancer: a comparative study using modified inguinal dissection. Int Braz J Urol. Brazil; 2008;34(6):723-5. 
55. Graafland NM, Teertstra HJ, Besnard APE, van Boven HH, Horenblas S. Identification of high risk pathological node positive penile carcinoma: value of preoperative computerized tomography imaging. J Urol. United States; 2011 Mar;185(3):881-7.

56. Hovels AM, Heesakkers RAM, Adang EM, Jager GJ, Strum S, Hoogeveen YL, et al. The diagnostic accuracy of CT and MRI in the staging of pelvic lymph nodes in patients with prostate cancer: a meta-analysis. Clin Radiol. England; 2008 Apr;63(4):38795.

57. Graafland NM, Leijte JAP, Valdés Olmos RA, Hoefnagel CA, Teertstra HJ, Horenblas S. Scanning with 18F-FDG-PET/CT for detection of pelvic nodal involvement in inguinal node-positive penile carcinoma. Eur Urol. Switzerland; 2009 Aug;56(2):339-45.

58. Lardinois D, Weder W, Hany TF, Kamel EM, Korom S, Seifert B, et al. Staging of nonsmall-cell lung cancer with integrated positron-emission tomography and computed tomography. N Engl J Med. 2003 Jun 19;348(25):2500-7.

59. Antoch G, Saoudi N, Kuehl H, Dahmen G, Mueller SP, Beyer T, et al. Accuracy of wholebody dual-modality fluorine-18-2-fluoro-2-deoxy-D-glucose positron emission tomography and computed tomography (FDG-PET/CT) for tumor staging in solid tumors: comparison with CT and PET. J Clin Oncol. 2004 Nov 1;22(21):4357-68.

60. Ng S-H, Yen T-C, Chang JT-C, Chan S-C, Ko S-F, Wang H-M, et al. Prospective study of [18F]fluorodeoxyglucose positron emission tomography and computed tomography and magnetic resonance imaging in oral cavity squamous cell carcinoma with palpably negative neck. J Clin Oncol. 2006 Sep 20;24(27):4371-6.

61. Saisorn I, Lawrentschuk N, Leewansangtong S, Bolton DM. Fine-needle aspiration cytology predicts inguinal lymph node metastasis without antibiotic pretreatment in penile carcinoma. BJU Int. 2006 Jun;97(6):1225-8.

62. Senthil Kumar MP, Ananthakrishnan N, Prema V. Predicting regional lymph node metastasis in carcinoma of the penis: a comparison between fine-needle aspiration cytology, sentinel lymph node biopsy and medial inguinal lymph node biopsy. $\mathrm{Br} J$ Urol. ENGLAND; 1998 Mar;81(3):453-7.

63. Stuiver MM, Djajadiningrat RS, Graafland NM, Vincent AD, Lucas C, Horenblas S. Early wound complications after inguinal lymphadenectomy in penile cancer: a historical cohort study and risk-factor analysis. Eur Urol. Switzerland; 2013 Sep;64(3):486-92.

64. Gopman JM, Djajadiningrat RS, Baumgarten AS, Espiritu PN, Horenblas S, Zhu Y, et al. Predicting postoperative complications of inguinal lymph node dissection for penile cancer in an international multicentre cohort. BJU Int. 2015 Aug;116(2):196-201.

65. Spiess PE. New treatment guidelines for penile cancer. J Natl Compr Canc Netw. United States; 2013 May;11(5 Suppl):659-62.

66. Banzo J, Ubieto MA, Andres A, Tardin L, Rambalde EF, Cancer LF, et al. The contribution of (1)(8)F-FDG PET/CT in a patient with cutaneous metastases of squamous cell carcinoma of the penis. Rev Esp Med Nucl Imagen Mol. Spain; 2014;33(5):293-5.

67. Kaya ZR, Sager S, Halac M, Sonmezoglu K. Disseminated metastatic penile squamous cell carcinoma detected by fluorodeoxyglucose PET/computerized tomography. Indian J Nucl Med. India; 2012 Jul;27(3):189-91. 
68. Sharma P. Late metastatic recurrence of penile carcinoma after 10 years: Demonstration with (18)F-fluorodeoxyglucose positron emission tomography/ computed tomography. Indian J Nucl Med. India; 2016;31(3):204-6.

69. Zhang S, Li W, Liang F. Clinical value of fluorine-18 2-fluoro-2-deoxy-D-glucose positron emission tomography/computed tomography in penile cancer. Oncotarget. 2016;7(30):48600-6.

70. Barski D, Georgas E, Gerullis H, Ecke T. Metastatic penile carcinoma - an update on the current diagnosis and treatment options. Cent Eur J Urol. Poland; 2014;67(2):126-32.

71. Theodorescu D, Russo P, Zhang ZF, Morash C, Fair WR. Outcomes of initial surveillance of invasive squamous cell carcinoma of the penis and negative nodes. J Urol. 1996 May;155(5):1626-31.

72. Djajadiningrat RS, Teertstra HJ, van Werkhoven E, van Boven HH, Horenblas S. Ultrasound examination and fine needle aspiration cytology-useful for followup of the regional nodes in penile cancer? J Urol. United States; 2014 Mar;191(3):652-5. 


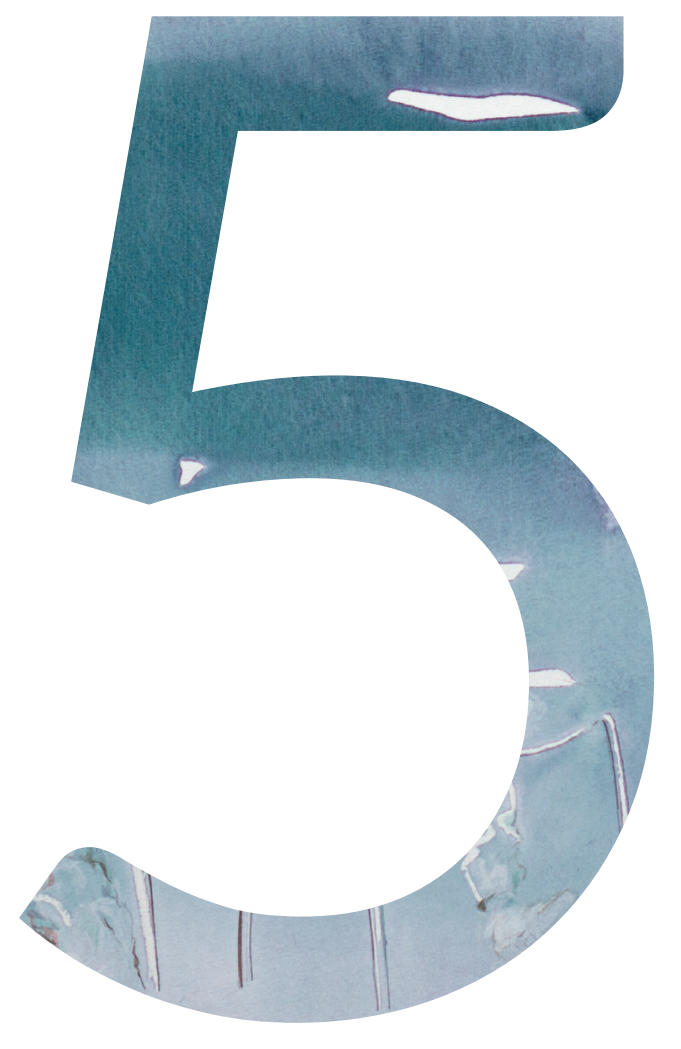


Chapter 5

\section{The role of PET/CT imaging in penile cancer}

Sarah R. Ottenhof, Erik Vegt 


\section{ABSTRACT}

Positron emission tomography (PET) imaging with ${ }^{18} \mathrm{~F}$-fluorodeoxyglucose (FDG) combined with computed tomography (CT) provides functional imaging combined with anatomic information, improving diagnostic accuracy and confidence.

Although virtually all primary penile tumors are FDG-avid, PET/CT is not recommended for primary tumor staging as it has limited spatial resolution and is hampered by urinary FDG excretion.

The accuracy of PET/CT for lymph node staging seems to improve with the pretest likelihood of metastatic nodes. In groins with normal physical examination, sensitivity is only $57 \%$. In groins with palpably enlarged lymph nodes, sensitivity of PET/CT reaches $96 \%$. For pelvic lymph nodes and distant metastases, PET/CT is more accurate if inguinal metastases are present. However, these results are based on a very limited number of studies.

Overall, the role of PET/CT imaging in penile cancer remains ambiguous, especially in inguinal lymph nodes. During staging and follow-up, it may be particularly useful in detecting pelvic lymph node metastases and occult distant metastates prior to systemic chemotherapy and/or extensive surgery, insuring a better selection of patients that are most likely to benefit from such therapies. 


\section{BACKGROUND}

Cancer of the penis is a rare disease with an incidence of 0.6-2.1 in Western countries. ${ }^{1-3}$ The majority of these cancers are squamous cell carcinoma, but other histological types and subtypes such as basaloid and warty squamous cell, and melanoma can occur. The worldwide incidence has significant geographic variations, which is mainly explained by circumcision, sexual practices and socioeconomic circumstances. ${ }^{2}$

Imaging and other staging techniques have improved the risk stratification of penile cancer. Ultrasound-guided fine needle aspiration biopsy, (dynamic) sentinel node biopsy, and various forms of lymph node dissections are invasive techniques that have improved lymph node staging. In addition, axial imaging such as CT, MRI and PET/CT have also evolved in the past decades.

Positron emission tomography (PET) imaging with ${ }^{18} \mathrm{~F}$-fluorodeoxyglucose (FDG) is based on cellular uptake of glucose and FDG, which is elevated in malignant cells and other tissues with an elevated glycolytic rate. ${ }^{4}$ FDG-PET combined with computed tomography (CT) provides functional imaging combined with anatomic information, improving diagnostic accuracy and confidence. PET/CT scanners stack PET and CT images in a single scanner, and are nowadays widely used.

In various malignant diseases, PET/CT is used for staging and monitoring. Combining functional with anatomical imaging, PET/CT outperforms both PET alone and $\mathrm{CT}$ alone in lymph node staging of many types of tumors..$^{5-7}$ Here we review the role of PET/CT in the diagnosis and management of penile cancer.

In penile cancers, both the primary tumors and lymph node metastases generally show high uptake of FDG. Hence, suitability for staging penile cancer is likely. However, sensitivity of PET/CT is limited by its spatial resolution, reducing sensitivity for small metastases. In addition, false-positives may occur due to inflammation, such as in reactive lymph nodes.

\section{PRIMARY TUMOR STAGING}

In their first study on PET in penile cancer, Scher et al. found that only 6 out of 8 primary tumors were detected by FDG-PET/CT ${ }^{8}$, but this can be explained by the small size of the two undetected tumors, which was below the spatial resolution 
of PET (one residual lesion after incomplete resection of a T1 tumor, and one very small $(<0.5 \mathrm{~cm})$ T1 tumor. The authors even describe that in retrospect both lesions did show some FDG-uptake.

In our experience, almost all primary penile tumors are FDG-avid. An example is shown in Figure 1. However, PET/CT is not very useful for primary tumor staging, because its limited spatial resolution makes it unsuitable for evaluating ingrowth in surrounding structures or even the exact size of the tumor. Additionally, FDG is excreted via the urine, which can interfere with imaging of the primary tumor. Physical examination and, in selected cases MRI, have excellent accuracy for staging primary penile tumors. ${ }^{9}$
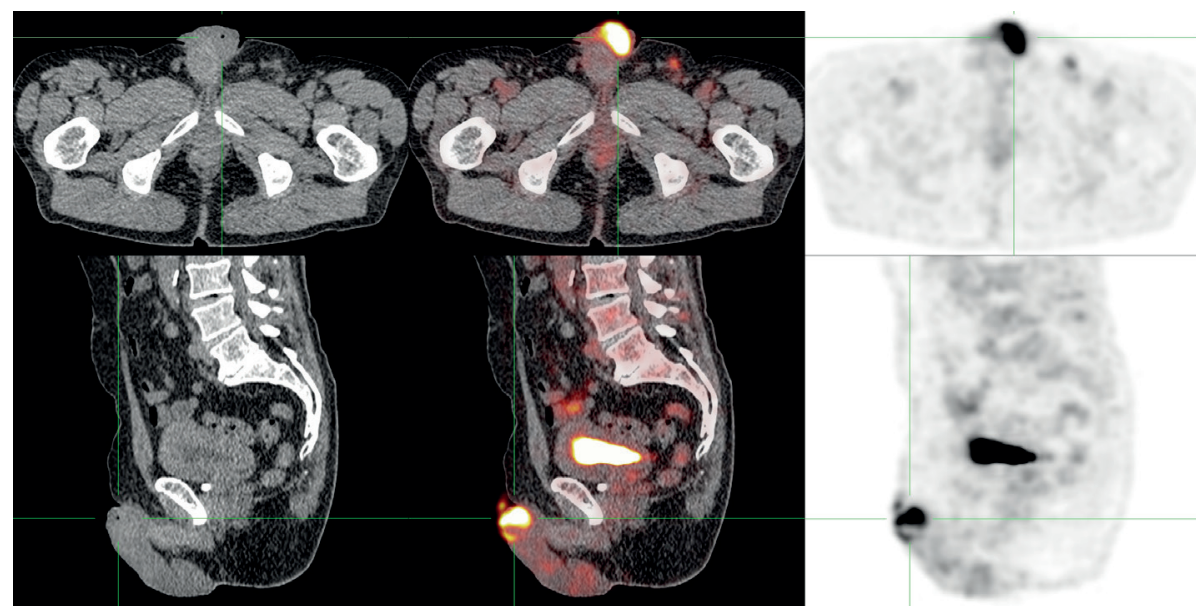

Figure 1. FDG-PET/CT of a penile cancer patient. The primary tumor exhibits high FDG uptake $\left(S \cup V_{\max }\right.$ 11.7).

\section{LYMPH NODE STAGING}

The diagnostic value of FDG-PET/CT for lymph node staging varies in different types of cancer. Often, reported sensitivities are higher than for conventional modalities such as CT and MRI, but are not always satisfactory. ${ }^{4}$ In pancreatic cancer for example, PET/CT shows a sensitivity in N-staging of only $30 \% .{ }^{10}$ Somewhat better results appear in clinically lymph node negative non-small cell lung cancer (stage I) and head and neck cancer (cNO) patients, with sensitivities for regional lymph nodes of $57 \%$ and $67 \%$ respectively. ${ }^{11,12}$ Specificities may be higher, but identification of patients where invasive staging or therapy can be omitted requires high sensitivity. 


\subsection{Inguinal lymph nodes Non-palpable lymph nodes}

Detection of inguinal involvement using FDG-PET/CT in penile cancer patients that were initially staged as node negative (cNO) was evaluated in several studies.

In 2005, Scher et al. examined thirteen mostly cNO patients. Of 16 positive lymph nodes, FDG PET/CT correctly identified 15 as positive, with only one false negative lesion, resulting in a sensitivity per lesion of $94 \%$. The sensitivity for superficial inguinal lymph nodes was $89 \%$ per lesion and $80 \%$ per patient. ${ }^{8}$

Later, Leijte et al. published PET/CT results of solely cNO groins. Five out of 42 groins had lymph node metastases, but PET/CT only identified one, resulting in a sensitivity of only $20 \%$. The true positive lymph node metastasis was larger than the other four (30 mm vs. 10, 10, 1 and $1 \mathrm{~mm}$ ). This study emphasizes the limited sensitivity of PET/CT in detecting small metastases. ${ }^{13}$

In 2012, Souillac et al. showed better sensitivity for PET/CT in cNO patients, albeit in a small set of patients. PET/CT correctly identified 3 out of 4 metastases (75\% sensitivity). ${ }^{14}$

In all these three studies, specificity of PET/CT was higher than sensitivity: Scher et al. 100\%, Leijte et al. 92\% and Souillac et al. 88\%. Negative predictive values (NPV) were 89\%, 90\% and 83\% respectively.

In a meta-analysis of seven studies by Sadeghi et al., the pooled sensitivity per groin for FDG-PET/CT in cNO patients was only 57\%. ${ }^{15}$ Positive predictive values were also disappointing (between 25 and 37 percent). Therefore, surgical staging is necessary to identify small inguinal lymph node metastases and FDG-PET/CT is not recommended for staging of cNO patients.,13-15

\section{Palpable lymph nodes}

For patients that present with palpable lymph nodes in the groin, PET/CT has a different clinical value (Figure 2). The aforementioned meta-analysis by Sadeghi et al. found that detection of inguinal metastases with FDG-PET/CT in clinically suspicious groins had a pooled sensitivity and specificity of 96 and 100\% per groin respectively. ${ }^{15}$ Thus, PET/CT is more accurate in patients with palpable Iymph nodes. Assessing the number of lymph nodes involved with PET/CT may be useful when neoadjuvant chemotherapy will be considered in case of multiple or bulky inguinal metastases. ${ }^{16}$ 


\subsection{Pelvic lymph nodes}

On pelvic lymph nodes, literature is scarce. In a study on 18 patients with proven inguinal metastases, the diagnostic accuracy of FDG-PET/CT was evaluated for staging pelvic lymph nodes. ${ }^{17}$ The clinical benchmark this was compared to was either histopathology, clinical follow-up, or radiologic imaging. Twenty-eight of 36 pelvic basins were eligible for analysis, and results were good. Analysis showed a sensitivity of $91 \%$, specificity of $100 \%$, and similar negative and positive predictive values (94 and 100 percent respectively). FDG-PET/CT gave a correct prediction in $96 \%$. This is the only study that provides numbers on pelvic lymph node evaluation of PET/CT.

In stage 3 and 4 patients, Zhang et al. showed good results for lymph nodes (all locations) with a sensitivity of $93 \%$ and a specificity of $85 \% .{ }^{18}$ Also in other malignancies and lymph node areas, results suggest that FDG-PET/CT has higher accuracy than CT only in staging pelvic lymph nodes. ${ }^{5,6,19,20}$ However, results are not always optimistic. A prospective multicenter trial in advanced cervical cancer found no significant improvement of sensitivity nor specificity for detection of pelvic lymph node metastases with adding FDG-PET/CT to diagnostic contrast enhanced $\mathrm{CT}^{21}$ In addition, Lin et al. found lower diagnostic accuracy for PET/ $\mathrm{CT}$ than $\mathrm{CT}$ or $\mathrm{MRI}$ in a per scan receiver operating characteristic (ROC) curve analysis for metastatic pelvic lymph nodes or distant metastases in vulvar carcinoma. 22

\section{DISTANT METASTASES}

Literature on distant penile cancer metastases detected with FDG-PET/CT consists largely of case reports. ${ }^{23-26}$ In the aforementioned study by Graafland et al. among 18 patients with pathologically confirmed inguinal lymph node metastases, five patients were diagnosed with distant metastases by PET/ CT. ${ }^{17}$ Four of these five metastases were confirmed with either $\mathrm{CT}$ alone or histopathology. ${ }^{17}$ Although this was a small number of patients, these results suggest that PET/CT is useful for accurate M-staging.

The largest series by Zhang et al. (2016) compared FDG-PET/CT to conventional CT in 42 patients with suspicious lesions on CT or MRI, leading to an implicit selection bias. ${ }^{18}$ With histopathology or follow-up imaging as a reference, sensitivity and specificity of FDG-PET/CT were $85 \%$ and $86 \%$ respectively for all metastatic sites, including lymph nodes, lung, bone, etc. In a patient-based 
analysis this was $82 \%$ and $93 \%$ respectively. Drawbacks of this study are a short follow-up of patients as well as the aforementioned selection bias.

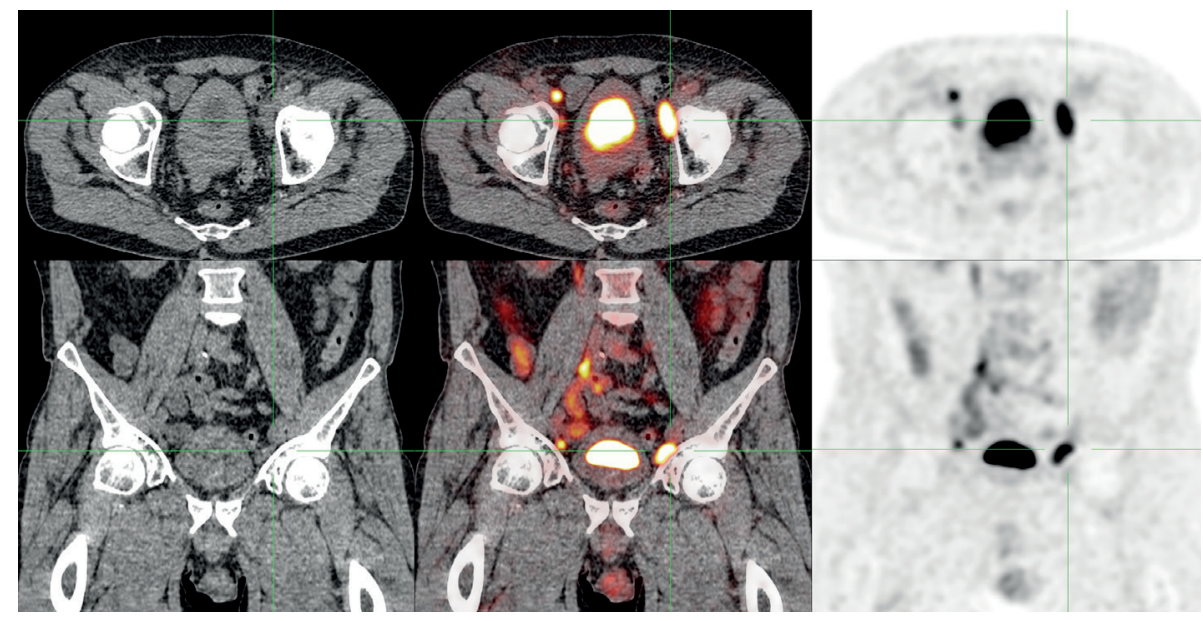

Figure 2. FDG-PET/CT of the same penile cancer patient, who was clinically staged as positive for inguinal lymph node metastases $(\mathrm{cN}+)$. The PET shows extensive pelvic lymph node metastases. Bilateral inguinal metastases were also FDG-positive.
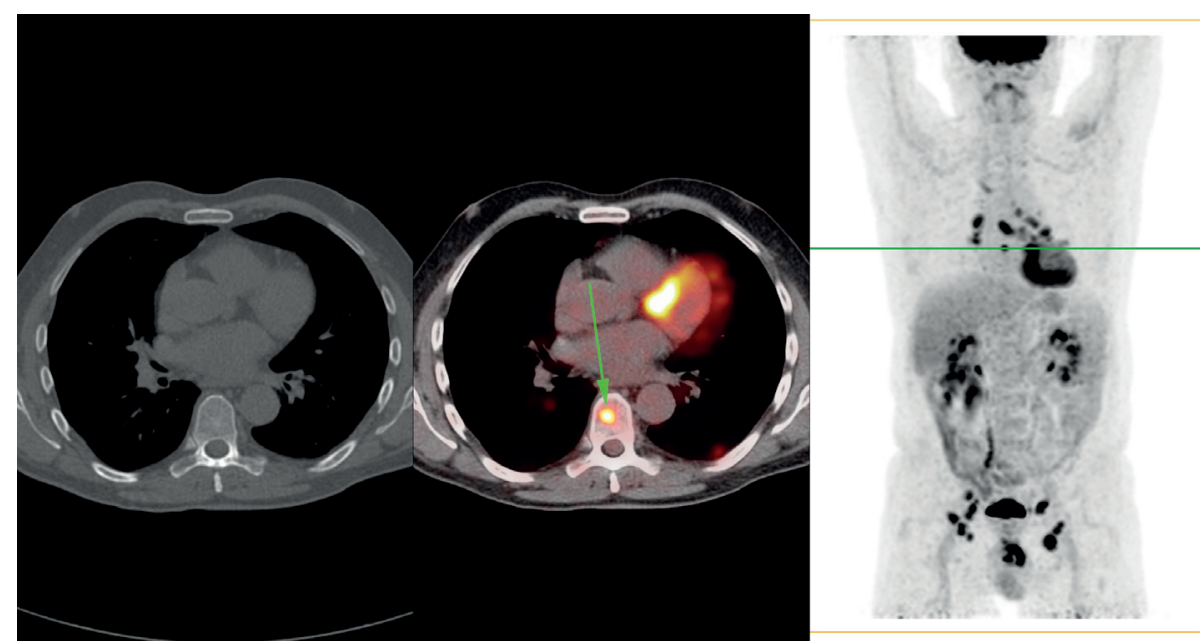

Figure 3. FDG-PET/CT of the same penile cancer patient, showing a solitary skeletal metastasis in the 8th thoracic vertebra, which was not visible on CT. In addition, extensive mediastinal and hilar lymphadenopathy was visible with small pulmonary and pleural lesions, which were thought to be possible sarcoidosis or metastases. Follow-up CT after 3 months showed gross progression, with multiple metastases in bone, liver, spleen and pelvic lymph nodes. In contrast, the lesions in the lungs and mediastinum were stable, increasing the likelihood of those being caused by a separate process such as sarcoidosis. 
The whole body imaging aspect of PET/CT scanning can be of crucial impact on clinical decision making. If distant metastases are found in patients scheduled for locoregional therapy (Figure 3), this changes their indicated treatment to systemic or palliative regimens. ${ }^{18}$

\section{OTHER SETTINGS}

\subsection{Surveillance}

In general, surveillance after treatment of penile cancer depends on physical examination by the physician and the patient himself. In our experience, PET/ $\mathrm{CT}$ can be of value for identification of the location and extent of suspected recurrence. Routine surveillance with $\mathrm{PET/CT}$ is not recommended.

\subsection{Combined modalities}

A recent study with 129 patients used FDG-PET/CT scanning complementary to sentinel node biopsy. ${ }^{27}$ In this cohort, FDG-PET/CT found one additional metastatic lymph node that was not detected with the radiotracer of the sentinel node biopsy procedure. The combined procedure had a sensitivity of $94 \%$, reducing the false negative rate to an acceptable level.

\section{CONCLUSION AND FUTURE PERSPECTIVES}

In conclusion, the exact role of FDG-PET/CT imaging in penile cancer remains ambiguous. So far, PET/CT has shown to have significant limitations, especially in inguinal lymph node staging. Results seem to improve with the pre-test likelihood of metastatic involvement.

PET/CT may be particularly useful in assessing pelvic metastases and occult distant metastatic burden prior to systemic chemotherapy and/or prior to an extensive surgical resection. This would improve the selection of those who are most likely to benefit from an aggressive multimodal approach. However, evaluation of this indication for FDG-PET/CT in larger cohorts is warranted. ${ }^{28}$ 


\section{REFERENCES}

1. Kirrander P, Sherif A, Friedrich B, Lambe M, Håkansson U. Swedish National Penile Cancer Register: incidence, tumour characteristics, management and survival. BJU Int. 2016;117(2):287-92.

2. Barnholtz-Sloan JS, Maldonado JL, Pow-sang J, Giuliano AR. Incidence trends in primary malignant penile cancer. Urol Oncol. United States; 2007;25(5):361-7.

3. Arya M, Li R, Pegler K, Sangar V, Kelly JD, Minhas S, et al. Long-term trends in incidence, survival and mortality of primary penile cancer in England. Cancer Causes Control. Netherlands; 2013 Dec;24(12):2169-76.

4. Fletcher JW, Djulbegovic B, Soares HP, Siegel BA, Lowe VJ, Lyman GH, et al. Recommendations on the use of 18F-FDG PET in oncology. J Nucl Med. United States; 2008 Mar;49(3):480-508.

5. Lardinois D, Weder W, Hany TF, Kamel EM, Korom S, Seifert B, et al. Staging of nonsmall-cell lung cancer with integrated positron-emission tomography and computed tomography. N Engl J Med. 2003 Jun 19;348(25):2500-7.

6. Antoch G, Saoudi N, Kuehl H, Dahmen G, Mueller SP, Beyer T, et al. Accuracy of wholebody dual-modality fluorine-18-2-fluoro-2-deoxy-D-glucose positron emission tomography and computed tomography (FDG-PET/CT) for tumor staging in solid tumors: comparison with CT and PET. J Clin Oncol. 2004 Nov 1;22(21):4357-68.

7. Ng S-H, Yen T-C, Chang JT-C, Chan S-C, Ko S-F, Wang H-M, et al. Prospective study of [18F]fluorodeoxyglucose positron emission tomography and computed tomography and magnetic resonance imaging in oral cavity squamous cell carcinoma with palpably negative neck. J Clin Oncol. 2006 Sep 20;24(27):4371-6.

8. Scher B, Seitz M, Reiser M, Hungerhuber E, Hahn K, Tiling R, et al. 18F-FDG PET/CT for staging of penile cancer. J Nucl Med. 2005 Sep;46(9):1460-5.

9. Lont AP, Besnard APE, Gallee MPW, van Tinteren H, Horenblas S. A comparison of physical examination and imaging in determining the extent of primary penile carcinoma. BJU Int. England; 2003 Apr;91(6):493-5.

10. Kauhanen SP, Komar G, Seppanen MP, Dean KI, Minn HR, Kajander SA, et al. A prospective diagnostic accuracy study of 18F-fluorodeoxyglucose positron emission tomography/computed tomography, multidetector row computed tomography, and magnetic resonance imaging in primary diagnosis and staging of pancreatic cancer. Ann Surg. United States; 2009 Dec;250(6):957-63.

11. Schoder H, Carlson DL, Kraus DH, Stambuk HE, Gonen M, Erdi YE, et al. 18F-FDG $\mathrm{PET} / \mathrm{CT}$ for detecting nodal metastases in patients with oral cancer staged NO by clinical examination and CT/MRI. J Nucl Med. United States; 2006 May;47(5):755-62.

12. Darling GE, Maziak DE, Inculet RI, Gulenchyn KY, Driedger AA, Ung YC, et al. Positron emission tomography-computed tomography compared with invasive mediastinal staging in non-small cell lung cancer: results of mediastinal staging in the early lung positron emission tomography trial. J Thorac Oncol. United States; 2011 Aug;6(8):1367-72. 
13. Leijte JAP, Graafland NM, Valdés Olmos RA, van Boven HH, Hoefnagel CA, Horenblas S. Prospective evaluation of hybrid 18F-fluorodeoxyglucose positron emission tomography/computed tomography in staging clinically node-negative patients with penile carcinoma. BJU Int. 2009 Sep;104(5):640-4.

14. Souillac I, Rigaud J, Ansquer C, Marconnet L, Bouchot O. Prospective evaluation of (18)F-fluorodeoxyglucose positron emission tomography-computerized tomography to assess inguinal lymph node status in invasive squamous cell carcinoma of the penis. J Urol. United States; 2012 Feb;187(2):493-7.

15. Sadeghi R, Gholami H, Zakavi SR, Kakhki VRD, Horenblas S. Accuracy of 18F-FDG PET/CT for diagnosing inguinal lymph node involvement in penile squamous cell carcinoma: systematic review and meta-analysis of the literature. Clin Nucl Med. United States; 2012 May;37(5):436-41.

16. Clark PE, Spiess PE, Agarwal N, Biagioli MC, Eisenberger MA, Greenberg RE, et al. Penile cancer: Clinical Practice Guidelines in Oncology. J Natl Compr Canc Netw. United States; 2013 May;11(5):594-615.

17. Graafland NM, Leijte JAP, Valdés Olmos RA, Hoefnagel CA, Teertstra HJ, Horenblas S. Scanning with 18F-FDG-PET/CT for detection of pelvic nodal involvement in inguinal node-positive penile carcinoma. Eur Urol. Switzerland; 2009 Aug;56(2):339-45.

18. Zhang S, Li W, Liang F. Clinical value of fluorine-18 2-fluoro-2-deoxy-D-glucose positron emission tomography/computed tomography in penile cancer. Oncotarget. 2016;7(30):48600-6.

19. Uttam M, Pravin N, Anish B, Nandita K, Arup M. Is [F-18]-fluorodeoxyglucose FDGPET/CT better than ct alone for the preoperative lymph node staging of muscle invasive bladder cancer? Int Braz J Urol. Brazil; 2016;42(2):234-41.

20. Kitajima K, Murakami K, Yamasaki E, Fukasawa I, Inaba N, Kaji Y, et al. Accuracy of 18F-FDG PET/CT in detecting pelvic and paraaortic lymph node metastasis in patients with endometrial cancer. AJR Am J Roentgenol. United States; 2008 Jun;190(6):1652-8.

21. Atri M, Zhang Z, Dehdashti F, Lee SI, Ali S, Marques H, et al. Utility of PET-CT to evaluate retroperitoneal lymph node metastasis in advanced cervical cancer: Results of ACRIN6671/GOG0233 trial. Gynecol Oncol. United States; 2016 Sep;142(3):413-9.

22. Lin G, Chen C-Y, Liu F-Y, Yang L-Y, Huang H-J, Huang Y-T, et al. Computed tomography, magnetic resonance imaging and FDG positron emission tomography in the management of vulvar malignancies. Eur Radiol. Germany; 2015 May;25(5):1267-78.

23. Banzo J, Ubieto MA, Andres A, Tardin L, Rambalde EF, Cancer LF, et al. The contribution of (1)(8)F-FDG PET/CT in a patient with cutaneous metastases of squamous cell carcinoma of the penis. Rev Esp Med Nucl Imagen Mol. Spain; 2014;33(5):293-5.

24. Kaya ZR, Sager S, Halac M, Sonmezoglu K. Disseminated metastatic penile squamous cell carcinoma detected by fluorodeoxyglucose PET/computerized tomography. Indian J Nucl Med. India; 2012 Jul;27(3):189-91.

25. Sharma P. Late metastatic recurrence of penile carcinoma after 10 years: Demonstration with (18)F-fluorodeoxyglucose positron emission tomography/ computed tomography. Indian J Nucl Med. India; 2016;31(3):204-6. 
26. Leijte JAP, Valdes Olmos RA, Mens J-WM, Horenblas S. Use of positron emission tomography in spindle cell carcinoma of the penis. Urology. United States; 2006 Nov;68(5):1121.e17-9.

27. Jakobsen JK, Alslev L, Ipsen P, Costa JC, Krarup KP, Sommer P, et al. DaPeCa-3: promising results of sentinel node biopsy combined with (18) F-fluorodeoxyglucose positron emission tomography/computed tomography in clinically lymph nodenegative patients with penile cancer - a national study from Denmark. BJU Int. England; 2016 Jul;118(1):102-11.

28. Barski D, Georgas E, Gerullis H, Ecke T. Metastatic penile carcinoma - an update on the current diagnosis and treatment options. Cent Eur J Urol. Poland; 2014;67(2):126-32. 


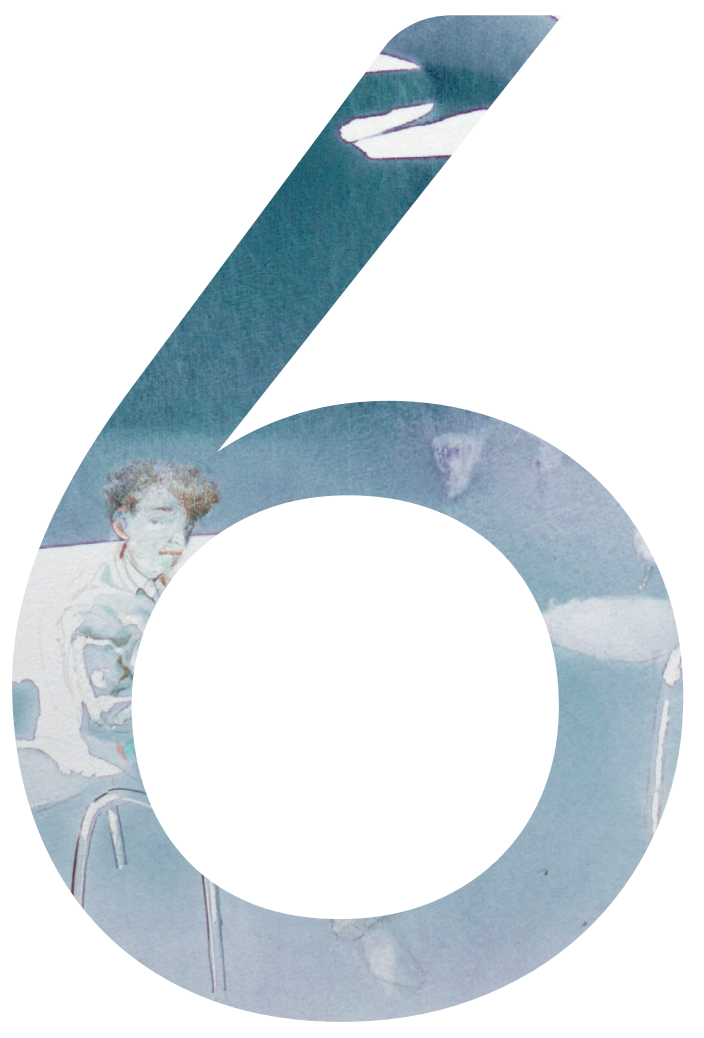


Chapter 6

F-18 Fluorodeoxyglucose positron emission tomography with computed tomography has high diagnostic value for pelvic and distant staging in patients with high-risk penile carcinoma

Sarah R. Ottenhof, Rosa S. Djajadiningrat, Michelle W. J. Versleijen, Maarten L. Donswijk, Vincent van der Noort, Oscar R. Brouwer, M Niels M. Graafland, Erik Vegt, Simon Horenblas 


\section{ABSTRACT}

Background: For penile cancer patients with pelvic metastases multimodal treatment is advised, but pelvic lymph node metastases are often found upon surgical resection only. Early selection for multimodal treatment requires reliable non-invasive staging.

Objective: To evaluate the diagnostic value of 18F-fluorodeoxyglucose positron emission tomography with computed tomography (FDG-PET/CT) for staging pelvic lymph nodes and distant metastases in high-risk penile cancer patients.

Design, setting and participants: FDG-PET/CT scans performed in patients with clinically overt inguinal lymph node metastases and/or high-risk primary tumors (bulky T3 or T4) were retrospectively analyzed.

Outcome Measurements and Statistical analysis: All scans were reviewed by two independent nuclear medicine physicians staging the pelvic nodes and distant metastases. FDG-PET/CT findings were compared to histology after node dissection if available, or to positive imaging or follow-up of at least 1 year.

Results and limitations: Between 2006 and 2016, 61 patients met the inclusion criteria. For staging of pelvic nodes, sensitivity was 85\% (specificity 75\%, negative predictive value (NPV) 90\%, positive predictive value (PPV) 65\%). For the detection of distant metastases FDG-PET/CT had a PPV of 93\%. Results are limited by the retrospective design and the lack of direct comparison to CT scanning alone.

Conclusions: FDG-PET/CT has a high sensitivity and NPV for staging of pelvic lymph nodes in high-risk penile cancer. FDG-PET/CT also has high PPV for detection of distant metastases, which were found in $23 \%$ of patients. Therefore, FDG-PET/CT enables early selection for multimodal treatment of patients with pelvic metastases, and may help avoid futile treatment of patients with distant metastases.

Patient summary: We studied whether PET/CT-scans in patients with advanced penile cancer can detect metastases before lymph node surgery is done. PET/CTscans can detect or rule out pelvic lymph node metastases and can detect distant metastases. This helps making timely treatment decisions (before surgery). 


\section{INTRODUCTION}

Penile cancer is a rare disease with an incidence of 1.3/100.000 in Western countries. ${ }^{1}$ It invariably metastasizes first to the inguinal lymph nodes on one or both sides, and then to the ipsilateral iliac lymph nodes. Patients with early stage disease have a good prognosis, but this decreases rapidly with the extent of lymph node involvement. ${ }^{2-4}$

Patients diagnosed with clinically overt pelvic lymph node metastases do not fare well with surgery alone.5,6 Multimodality treatment is considered essential. The most propagated scenario so far is neoadjuvant chemotherapy followed by surgery. Whether chemoradiation with or without surgery is a viable option is not clear at this moment. 7,8 Pelvic node involvement is often found or confirmed after surgery only. In order to select these patients at the outset for neoadjuvant chemotherapy or chemoradiation, reliable non-invasive staging of the pelvic nodes would be very helpful.

Unfortunately, early detection of pelvic nodal involvement with computed tomography (CT) and/or magnetic resonance imaging (MRI) is not very accurate. Both have a high specificity (60-100\%) especially with the use of additional criteria besides lymph node size, such as central necrosis and irregularity of the lymph node border, but their sensitivity is low (20-40\%), resembling performances in other malignancies. ${ }^{9-11}$

${ }^{18}$ F-fluorodeoxyglucose (FDG) positron emission tomography (PET) with noncontrast-enhanced low dose CT (further mentioned as FDG-PET/CT) has the ability to detect suspicious normal-sized lymph nodes and could therefore be more sensitive in detecting lymph node metastases than MRI or contrast enhanced CT alone. ${ }^{12}$ It also provides whole body staging, which could be helpful for detection of distant metastases. A previous small series from our group showed its benefits for pelvic staging. ${ }^{13-15}$ However, that small series of 18 patients excluded a substantial part of contralateral pelvic sides from the analysis and did not provide a per patient analysis. ${ }^{15}$

To ultimately improve patient selection for multimodal treatment, the present study evaluates the accuracy of FDG-PET/CT for pelvic and distant staging in a larger cohort of penile cancer patients at high risk of pelvic lymph node metastases. 


\section{PATIENTS \& METHODS}

\section{Patients}

This study was approved by the institutional medical ethical committee and the need for written informed consent was waived. We retrospectively analyzed all staging FDG-PET/CT scans performed in patients with advanced local or inguinal disease. Patients at the Netherlands Cancer Institute who underwent a staging FDG-PET/CT for penile cancer were included if they had:

1. Clinically high suspicion of inguinal lymph node metastases (N2-N3: palpable multiple unilateral, bilateral or immobile lymph nodes), and/or

2. Bulky primary tumor (bulky T3) or clinically T4 disease.

Patients that had underwent invasive staging of the groins (sentinel node procedure, excision biopsy or lymph node dissection) at the time of scanning, were excluded. PET/CT scans for staging disease recurrences were not excluded. All included patients had no previous treatment of the lymph nodes (i.e. no lymph node dissections, chemotherapy or radiotherapy before PET/CT).

\section{FDG-PET/CT preparation and acquisition}

Patients fasted for $\geq 6$ hours and received oral prehydration before intravenous injection of 190-240 MBq FDG. One hour after injection, images were acquired with the patient in supine position. FDG-PET/CT was acquired on integrated PET/CT scanners (Gemini TF or Gemini TF Big Bore, Philips, Amsterdam, the Netherlands). No contrast agents were used. First, a low-dose CT scan (dose modulated, 40mAs, $2 \mathrm{~mm}$ slice thickness) from the groins to the skull base was performed. Afterwards, a PET scan was made (2 minutes per bed position). Images were corrected for attenuation using the СТ images and reconstructed with $4 \mathrm{~mm}$ isotropic voxels.

\section{FDG-PET/CT interpretation}

Each FDG-PET/CT scan was separately revised by two experienced nuclear medicine physicians (authors MV, MD and/or EV) blinded for patient data. It is important to note that only pelvic areas were studied, not the inguinal areas. Right and left sided pelvic lymph nodes and distant lesions were evaluated. An example of a PET-positive iliac node is provided in Figure 1. Pelvic sides and distant lesions were scored for clinical suspicion using a 4-point scale (Table 1). Scores 0 and 1 were regarded not suspicious, scores 2 and 3 were regarded suspicious 
for metastasis. If discrepancy in scoring occurred between the two readers, a consensus reading was done. All scores (0-3) were included in the analyses.

Secondly, FDG-uptake of regions was scored using adjusted Deauville criteria (Supplementary Table S1).

For the interpretation of distant lesions, a distinction was made between distant metastases and additional findings. Additional findings were spots with increased uptake in locations unusual for penile cancer metastases and likely to be of other aetiology (or noise).
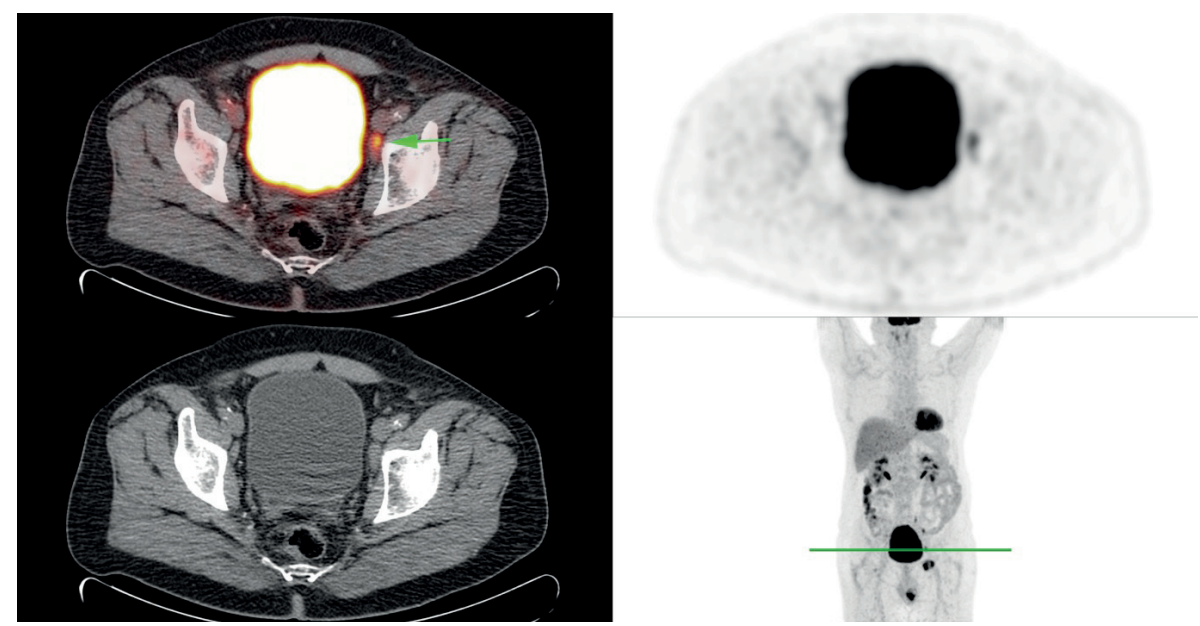

Figure 1. FDG-PET/CT images. Images of a patient with left iliac lymph node metastasis detected with FDG-PET/CT. Transaxial low-dose CT (bottom left), PET (upper right) and PET/ CT fused (upper left) images, and coronal maximum intensity projection of PET (bottom right).

Table 1: Probability score for pelvic sides and distant lesions based on clinical suspicion

\begin{tabular}{ll}
\hline Score & Clinical suspicion (estimated risk of malignancy) \\
\hline 0 & not at all suspicious $(\sim 10 \%)$ \\
1 & probably benign $(\sim 30 \%)$ \\
2 & probably malignant $(\sim 70 \%)$ \\
3 & highly suspicious for malignancy $(\sim 90 \%)$ \\
\hline
\end{tabular}




\section{Reference standard}

PET findings were compared to histopathology after dissection, other imaging modalities, or to clinical follow-up of at least 1 year (with confirmed metastases or death due to disease within one year, or no evidence of disease for at least one year). Additional imaging (such as simultaneous contrast enhanced CT or followup imaging) was used as a reference for positive findings only. With clinical followup, metastases were considered to have been present at the time of PET if they became apparent within one year after PET. Absence of signs of disease for at least one year after PET was considered indicative for absence of disease at the time of PET.

For distant metastases observed on FDG-PET/CT, reference was cytological or histological proof, follow-up imaging, death of disease within a year (true positive detection), or clinical follow-up of at least one year without signs of disease (false positive detection).

\section{Per patient scoring}

Analyses were performed per pelvic side and per patient. A decision tree for per patient scoring is provided in Figure 2. In short, metastasis outcome was the dominant finding if present. Any false negative pelvic detection was dominant to other findings. Only patients with bilateral true negative findings were scored true negative.

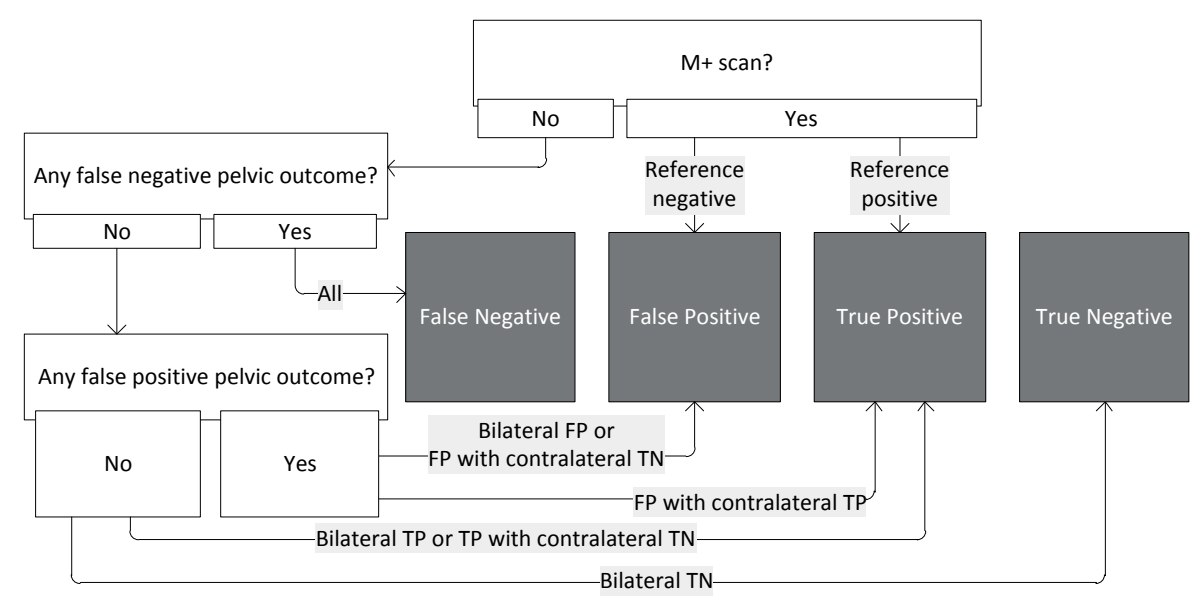

Figure 2. Decision tree for patient scoring. FP, false positive; FN, false negative; $\mathrm{TP}$, true positive; TN, true negative. 


\section{Statistical analysis}

Medianfollow-up was estimated with inversed Kaplan-Meier method. Interobserver agreement in score 0-3 between the nuclear medicine physicians before consensus was measured with quadratic-weighted kappa analysis in Stata Statistical Software (release 11, StataCorp. College station, Texas, USA). After consensus, scores 0-1 were regarded as negative, scores 2-3 as positive for metastases. A $2 \times 2$ table was constructed for pelvic and patient analysis. Test performance (sensitivity, specificity, positive predictive value (PPV), negative predictive value (NPV) and accuracy) were calculated with 95\% confidence intervals ( $\mathrm{Cl}$ ) using R software (version 4.4.3, The R Project for Statistical Computing, R Core Team. Vienna, Austria).

For distant metastases, only positive findings were compared to the reference standard and the PPV was calculated.

Survival was estimated with the Kaplan-Meier method and the LogRank test using SPSS software (version 22, IBM, Armonk, USA).

\section{RESULTS}

\section{Inclusion of patients}

Between March 2006 and August 2016, a total of 177 potentially eligible penile cancer patients underwent FDG-PET/CT. Based on the inclusion criteria 80 patients were eligible. Six patients' scans were unavailable for revision (no images available, no CT images available or poor-quality images) and 13 patients were not included because no good reference was available at all. The remaining 61 patients were analyzed, their characteristics are summarized in Table 2. Of these, nine had no available reference for bilateral pelvic lymph nodes (but did have reference for patient-based analysis), and ten had only reference for one pelvic side. This resulted in a per-pelvis analysis of 94 pelvic sides in 52 patients. Eight of 61 patients were included in a previous analysis by Graafland et al. ${ }^{15}$

The indication for FDG-PET/CT scanning was clinical stage N2-3 in 46 cases, large primary tumor in 12 cases, and both in 3 cases.

\section{Interobserver agreement}

The interobserver agreement was high. Pelvic scoring based on clinical suspicion resulted in quadratic-weighted Kappa of $81.8 \%$ respectively. For metastases this was lower: $73.4 \%$. 
Table 2: Patient characteristics

\begin{tabular}{llc}
\hline Variable & Category & Patients (\%) N=61 \\
\hline Indication for FDG-PET/CT n (\%) & cN2/3 & $46(75)$ \\
& Bulky T3/T4 & $12(20)$ \\
& Both & $3(5)$ \\
\hline Follow-up Median (IQR) & Months & $52(21-60)$ \\
\hline Died within one year $n$ (\%) & Curative treatment & $16(26)$ \\
& Palliative treatment & $6(10)$ \\
& No treatment & $4(7)$ \\
\hline Multimodal therapy $n$ (\%) & Neoadjuvant chemotherapy & $12(20)$ \\
& Palliative chemotherapy & $3(5)$ \\
& Chemoradiation & $4(7)$ \\
& Palliative chemoradiation & $1(2)$ \\
& Adjuvant radiation & $3(5)$ \\
& Palliative radiation & $1(2)$ \\
& Palliative surgery & $1(2)$ \\
\hline Reference standard $n$ (\%), total of 122 & PLND & $44 / 122(36)$ \\
& Positive imaging* & $17 / 122(14)$ \\
& Negative follow-up & $33 / 122(27)$ \\
& No reference & $28 / 122(23)$ \\
\hline
\end{tabular}

IQR, interquartile range; PLND, pelvic lymph node dissection.

* Imaging of 17 pelvic sides (in 11 patients) consisted of follow-up FDG-PET/CT in seven patients, concurrent or follow-up CT in one patient, a sequence of both in two patients, and MRI in one patient.

\section{Staging of pelvic lymph nodes}

The results of pelvic staging with FDG-PET/CT are depicted in Table 3. Of 94 analyzed pelvic sides, 33 showed pelvic nodes on FDG-PET/CT of which 28 were confirmed (14 with PLND, 14 with additional imaging). Fifty-one pelvic sides did not show positive nodes on FDG-PET/CT. Five of which later proved false negative (all unilaterally, further described in Supplementary Table S3), and twenty of which proved true-negative on prophylactic PLND. Thirteen cases had a false-positive result on one or both sides. Overall, accuracy of FDG-PET/CT per pelvis was 79\% (sensitivity 85\%, specificity 75\%, PPV 65\%, NPV 90\%).

These analyses include fourteen patients that had neoadjuvant chemotherapy or chemoradiation between FDG-PET/CT scanning and reference. Their 
results included seven false-positive findings and three true negative findings that are possibly skewed by the therapy. Without these fourteen patients, test performance is slightly better ( $N=38$, sensitivity 86\%, specificity 84\%, PPV 69\%, NPV 93\%).

Table 3: Results and calculated test performances of FDG-PET/CT according to the clinical suspicion score

\section{A. Cross table FDG-PET/CT per pelvis}

\begin{tabular}{llll}
\hline & Reference+ & Reference- & total \\
\hline PET+ & 28 & 15 & 43 \\
PET- & 5 & 46 & 51 \\
total & 33 & 61 & 94 \\
\hline
\end{tabular}

B. Per patient

\begin{tabular}{llll}
\hline & Reference+ & Reference- & total \\
\hline PET + & 30 & 10 & 40 \\
PET- & 6 & 15 & 21 \\
total & 36 & 25 & 61 \\
\hline
\end{tabular}

C. Calculated test performances of FDG-PET/CT for pelvic lymph node staging

\begin{tabular}{lll}
\hline & Per Pelvis (\%) & Per patient (\%) \\
\hline Sensitivity & 85 & 83 \\
Specificity & 75 & 60 \\
NPV & 90 & 75 \\
PPV & 65 & 73 \\
Accuracy & 79 & 74 \\
\hline
\end{tabular}

$\mathrm{Cl}$, confidence interval; NPV, negative predictive value; PPV, positive predictive value.

\section{Detection of distant metastases}

Fourteen patients had lesions suspicious for distant metastases, of whom 13 were confirmed (PPV 93\%). Lesions described as metastases were mostly abdominal/thoracic lymph nodes or lung lesions (both $n=7$ ).

Additional findings occurred in 17 patients. These findings mostly concerned foci in the gastrointestinal tract ( $n=5$, considered to be most likely due to imaging noise) or liver $(n=5)$, and lymph nodes in patterns atypical for metastases (e.g. sarcoid-like mediastinal nodes, $n=3$ ). 


\section{Considering the whole patient}

Based on patient's bilateral pelvic and distant outcomes, a per-patient result was scored (Figure 2). False positive outcomes were found in 6 patients, true negative outcomes in 15 patients. Sensitivity was 83\%, specificity 60\%. PPV was 73\%, NPV 75\%, and overall accuracy was 74\% (Table 3). Leaving out the patients with neoadjuvant chemotherapy and curative CRT, specificity improved to 71\% (NPV to $79 \%$, PPV and accuracy to $78 \%$ ).

\section{Overall survival}

Median follow-up was 52 months. Evaluation of overall survival was done for three groups of patients: 1) those without suspicion of pelvic or distant metastases, 2) those with suspicion of pelvic but not distant metastases, and 3) those with suspicion of distant metastases. The estimated median survival was 45, 34 and 8 months respectively, Log Rank p<0.01 (Figure 3).

\section{FDG uptake (adjusted Deauville criteria)}

The FDG uptake score of lesions using adjusted Deauville criteria (Supplementary Table S1), gave similar sensitivity and NPV as the visual analysis described above (clinical suspicion score, Table 3C; Supplementary Table S2). The FDG uptake score led to more false-positive results (20 vs. 15) and one less false-negative result (Table 3, Supplementary Table S2. For pelvic staging based on FDG uptake score, accuracy was 74\%, sensitivity 89\%, and specificity 67\% (Supplementary Table S2).

\section{DISCUSSION}

We studied FDG-PET/CT performance for staging pelvic lymph nodes in penile cancer patients at significant risk for pelvic metastases. The rationale being able to start multimodality treatment as early as possible and avoiding unnecessary surgery. It is important to note that FDG-PET/CT cannot replace invasive staging of the inguinal lymph nodes, and therefor, only pelvic areas were studied.

We found good test performance, especially regarding sensitivity and negative predictive value (83-85\% and $75-90 \%$ respectively). Also, FDG-PET/CT accurately identified 10 cases (16\%) with distant metastases, and FDG-PET/CT positivity was associated with decreased survival. The adjusted Deauville criteria performed similarly to the clinical suspicion score and may serve as a reference for PET imaging analysis; nodes with higher FDG uptake than the blood pool can be regarded malignant, albeit with more false-positive detections. 
Our study shows that FDG-PET/CT is an accurate non-invasive staging modality for pelvic lymph nodes for patients at high risk of pelvic metastases. Its sensitivity is much higher than sensitivities published for contrast enhanced CT and MRI. ${ }^{16,17}$ In addition, distant metastases are visualized on FDG-PET/CT in a significant percentage of patients, with a high PPV.

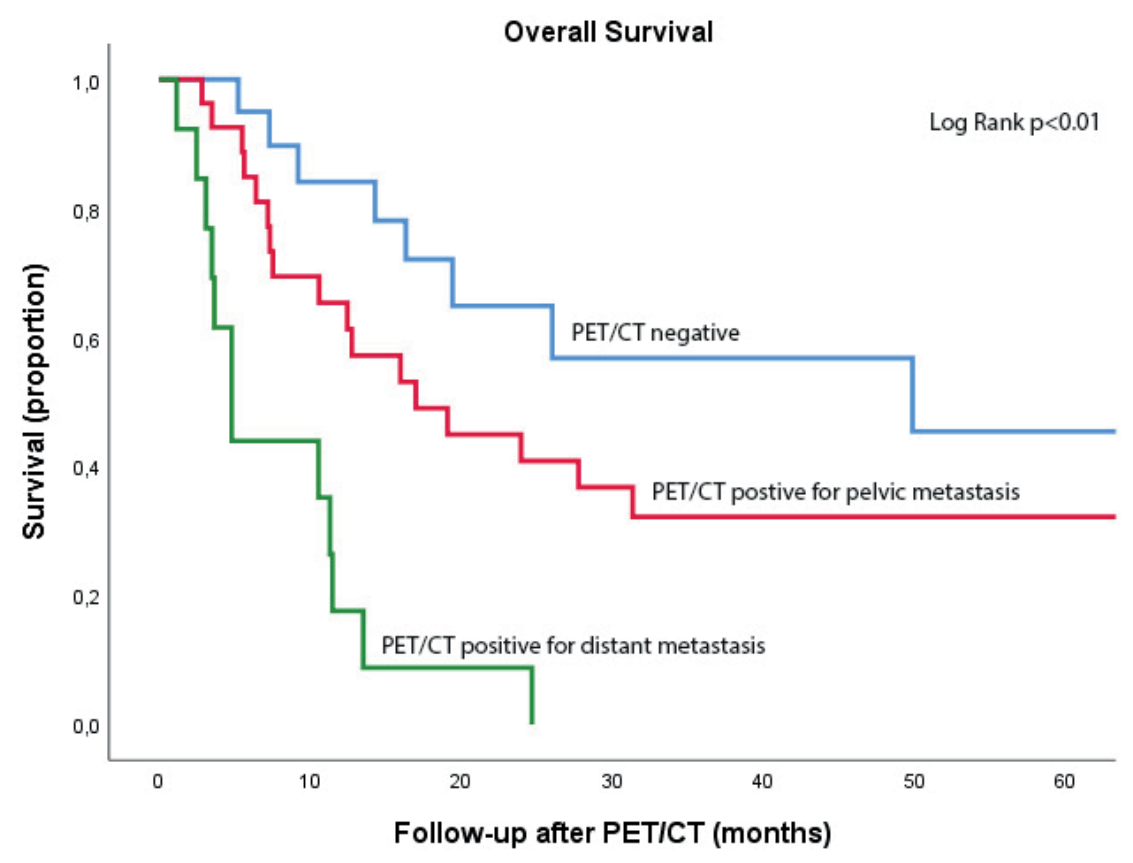

Figure 3. Survival after FDG-PET/CT

\begin{tabular}{lcccc}
\hline No at risk & 0 months & 20 months & 40 months & 60 months \\
\hline Negative & 20 & 9 & 6 & 2 \\
Pelvic+ & 27 & 11 & 7 & 3 \\
$M+$ & 14 & 1 & 0 & 0 \\
\hline
\end{tabular}

Overall survival of patients without suspicion of pelvic or distant metastases (blue line), patients with suspicion of unilateral or bilateral pelvic metastases (red line) and patients with suspicion of distant metastases (green line). Log Rank test $p<0.01$. 
Given the suboptimal specificity, clinical implementation of FDG-PET/CT will expectedly result in a number of false-positive detections with subsequent overtreatment. Adverse consequences of false negative FDG-PET/CT will be infrequent, given the high sensitivity and NPV.

The suboptimal specificity (60-75\%) in this study contrasts to a previous series of our institute by Graafland et al. that found a specificity of $100 \%$, possibly explained by our larger sample size. Zhang et al. also studied FDG-PET/CT for detection of metastases ${ }^{21}$. In a per-lymph node analysis irrespective of location, they found a higher sensitivity and specificity than we did. This may be due to their inclusion of inguinal node staging in patients already suspected of inguinal metastases. In a per patient analysis, they reported a similar sensitivity (81\%), but a higher specificity (93\% vs. 60\% in the present series). This can be explained by their scoring system; Zhang et al. classified all patients as true positive with one true positive lesion, even if another lesion was false positive or false negative. In our analysis, false negative findings on one side were dominant, except for positive distant metastatic findings.

In other malignancies, several studies investigating FDG-PET/CT for pelvic lymph node staging reported a higher accuracy than contrast enhanced CT alone. 16,17,22,23 In penile cancer, this has not been shown before.

A meta-analysis studied FDG-PET/CT for groin assessment in penile cancer. ${ }^{24}$ In clinically node-negative groins, the pooled sensitivity of FDG-PET/CT was only $57 \%$, but in patients with palpably enlarged nodes this increased to a pooled sensitivity and specificity of $77 \%$ and $81 \%$ respectively after Egger's correction for publication bias. $^{24}$

This study is not devoid of limitations. Its retrospective nature has inherent biases that cannot be accounted for. During the years, not all patients with clinical stage N2-3 or large primary tumors underwent FDG-PET/CT before invasive staging. Our study possibly includes the most suspicious cases, that possibly led to higher positive predictive values. Also, we did not exclude patients that underwent either curative or palliative chemotherapy or chemoradiation. Some of the results in these patients (false-positive and true-negative) may be skewed by therapy effect. Thirdly, patients with residual or intercurrent local or inguinal disease were not excluded; in very few patients, new metastases that developed in the year following FDG-PET/CT may have caused false-negative findings. Lastly, the gold standard (pathology) was not performed in all patients. Hence, the reference standard is based on a combination of tests (pathology, imaging and 
follow-up) with possible influences on the outcomes. Also, no direct comparison could be made with contrast enhanced CT or MRI since only a low dose CT for attenuation correction was available. These results should be prospectively validated including a comparison to contrast-enhanced CT.

Nonetheless we advocate the use of FDG-PET/CT for staging patients with clinical stage N2-N3 and/or bulky stage T3 or T4 primary tumors. In these highrisk patients, FDG-PET/CT provides adequate non-invasive staging of pelvic Iymph nodes, guiding treatment choices for multimodal therapy. In other words, FDG-PET/CT can select patients with pelvic metastasis for e.g. neoadjuvant chemotherapy or chemoradiation. It also provides timely detection of distant metastases with consequent omission of futile lymphadenectomies.

\section{CONCLUSIONS}

FDG-PET/CT has a high sensitivity and moderate specificity for pelvic staging, and high PPV for distant staging in penile cancer patients at risk of pelvic metastases. We advocate implementation of FDG-PET/CT in clinical practice for staging these patients and improvement of patient selection for multimodal therapy.

\section{Acknowledgements}

We would like to thank our colleagues from the radiology archive of our institute for retrieving scans from the archive that were primarily inaccessible.

\section{Compliance with ethical standards}

This study was conducted in accordance with institutional ethical standards and with the 1964 Helsinki declaration and its later amendments or comparable ethical standards. This study was approved by the medical ethical committee of our institute. 


\section{REFERENCES}

1. Arya M, Li R, Pegler K, et al: Long-term trends in incidence, survival and mortality of primary penile cancer in England. Cancer Causes Control 2013; 24: 2169-2176.

2. Graafland NM, Moonen LMF, van Boven $\mathrm{HH}$, et al: Inguinal recurrence following therapeutic lymphadenectomy for node positive penile carcinoma: outcome and implications for management. J. Urol. 2011; 185: 888-893.

3. Thuret R, Sun M, Abdollah F, et al: Conditional survival predictions after surgery for patients with penile carcinoma. Cancer 2011; 117: 3723-3730.

4. Shah AA, Shah HA, Panjwani GN, et al: Prognostic factors and 5-year survival of patients with carcinoma penis: Tertiary health center study. Indian J. Cancer 2016; 53: 309-312.

5. Sharma P, Djajadiningrat R, Zargar-Shoshtari K, et al: Adjuvant chemotherapy is associated with improved overall survival in pelvic node-positive penile cancer after lymph node dissection: A multi-institutional study. Urol. Oncol. 2015; 33: 496.e1723.

6. Djajadiningrat RS, Graafland NM, van Werkhoven E, et al: Contemporary management of regional nodes in penile cancer-improvement of survival? J. Urol. 2014; 191: 68-73.

7. Yuan Z, Naghavi AO, Tang D, et al: The relationship between HPV status and chemoradiotherapy in the locoregional control of penile cancer. World J. Urol. 2018.

8. Pond GR, Milowsky MI, Kolinsky MP, et al: Concurrent chemoradiotherapy for men with locally advanced penile squamous cell carcinoma. Clin. Genitourin. Cancer 2014; 12: 440-446.

9. Hovels AM, Heesakkers RAM, Adang EM, et al: The diagnostic accuracy of CT and MRI in the staging of pelvic lymph nodes in patients with prostate cancer: a metaanalysis. Clin. Radiol. 2008; 63: 387-395.

10. Graafland NM, Teertstra HJ, Besnard APE, et al: Identification of high risk pathological node positive penile carcinoma: value of preoperative computerized tomography imaging. J. Urol. 2011; 185: 881-887.

11. Zhu Y, Zhang SL, Ye DW, et al: Predicting pelvic lymph node metastases in penile cancer patients: a comparison of computed tomography, Cloquet's node, and disease burden of inguinal lymph nodes. Onkologie 2008; 31: 37-41.

12. Ottenhof SR and Vegt E: The role of PET/CT imaging in penile cancer. Transl. Androl. Urol. 2017; 6: 833-838.

13. Drager DL, Heuschkel M, Protzel C, et al: [18F]FDG PET/CT for assessing inguinal lymph nodes in patients with penile cancer - correlation with histopathology after inguinal lymphadenectomy. Nuklearmedizin. 2018; 57: 26-30.

14. Leijte JAP, Graafland NM, Valdes Olmos RA, et al: Prospective evaluation of hybrid 18F-fluorodeoxyglucose positron emission tomography/computed tomography in staging clinically node-negative patients with penile carcinoma. BJU Int. 2009; 104: 640-4.

15. Graafland NM, Leijte JAP, Valdés Olmos RA, et al: Scanning with 18F-FDG-PET/CT for detection of pelvic nodal involvement in inguinal node-positive penile carcinoma. Eur. Urol. 2009; 56: 339-45. 
16. Gong Y, Wang Q, Dong L, et al: Different imaging techniques for the detection of pelvic lymph nodes metastasis from gynecological malignancies: a systematic review and meta-analysis. Oncotarget 2017; 8: 14107-14125.

17. Fletcher JW, Djulbegovic B, Soares HP, et al: Recommendations on the use of 18F-FDG PET in oncology. J. Nucl. Med. 2008; 49: 480-508.

18. Lughezzani G, Catanzaro M, Torelli T, et al: The relationship between characteristics of inguinal lymph nodes and pelvic lymph node involvement in penile squamous cell carcinoma: a single institution experience. J. Urol. 2014; 191: 977-982.

19. Djajadiningrat RS, van Werkhoven E and Horenblas S: Prophylactic pelvic lymph node dissection in patients with penile cancer. J. Urol. 2015; 193: 1976-1980.

20. Zargar-Shoshtari K, Djajadiningrat R, Sharma P, et al: Establishing Criteria for Bilateral Pelvic Lymph Node Dissection in the Management of Penile Cancer: Lessons Learned from an International Multicenter Collaboration. J. Urol. 2015; 194: 696-701.

21. Zhang S, Li W and Liang F: Clinical value of fluorine-18 2-fluoro-2-deoxy-D-glucose positron emission tomography/computed tomography in penile cancer. Oncotarget 2016; 7: 48600-6.

22. Uttam M, Pravin N, Anish B, et al: Is [F-18]-fluorodeoxyglucose FDG-PET/CT better than ct alone for the preoperative lymph node staging of muscle invasive bladder cancer? Int. Braz J Urol 2016; 42: 234-241.

23. Kitajima K, Murakami K, Yamasaki E, et al:Accuracy of 18F-FDG PET/CT in detecting pelvic and paraaortic lymph node metastasis in patients with endometrial cancer. AJR. Am. J. Roentgenol. 2008; 190: 1652-1658.

24. Sadeghi R, Gholami H, Zakavi SR, et al: Accuracy of 18F-FDG PET/CT for diagnosing inguinal lymph node involvement in penile squamous cell carcinoma: systematic review and meta-analysis of the literature. Clin. Nucl. Med. 2012; 37: 436-441. 
Supplementary Table S1: Lesion score systems based on intensity of FDG uptake (adjusted Deauville criteria).

\begin{tabular}{ll}
\hline Score & FDG uptake \\
\hline 0 & none \\
1 & $\leq$ blood pool \\
2 & $>$ blood pool $\leq$ liver \\
3 & $>$ liver \\
\hline
\end{tabular}

FDG, ${ }^{18}$ F-fluorodeoxyglucose.

Supplementary Table S2: FDG uptake score: results \& calculated test performances of FDG-PET/CT

A. Cross tables of PET-results and reference outcome (per pelvis)

\begin{tabular}{llll}
\hline Per pelvis & Reference+ & Reference- & total \\
\hline PET+ & 29 & 20 & 49 \\
PET- & 4 & 41 & 45 \\
total & 33 & 61 & 94 \\
\hline
\end{tabular}

B. Cross tables of PET-results and reference outcome (per patient)

\begin{tabular}{llll}
\hline Per patient & Reference+ & Reference- & total \\
\hline PET + & 30 & 13 & 43 \\
PET- & 5 & 13 & 18 \\
total & 35 & 26 & 61 \\
\hline
\end{tabular}

C. Calculated test performances of FDG-PET/CT for pelvic lymph node staging using the FDG uptake score

\begin{tabular}{lll}
\hline & Per Pelvis (\%) & Per patient (\%) \\
\hline Sensitivity & 89 & 86 \\
Specificity & 67 & 50 \\
NPV & 91 & 72 \\
PPV & 59 & 70 \\
Accuracy & 74 & 70 \\
\hline
\end{tabular}

$\mathrm{Cl}$, confidence interval; NPV, negative predictive value; PPV, positive predictive value. 


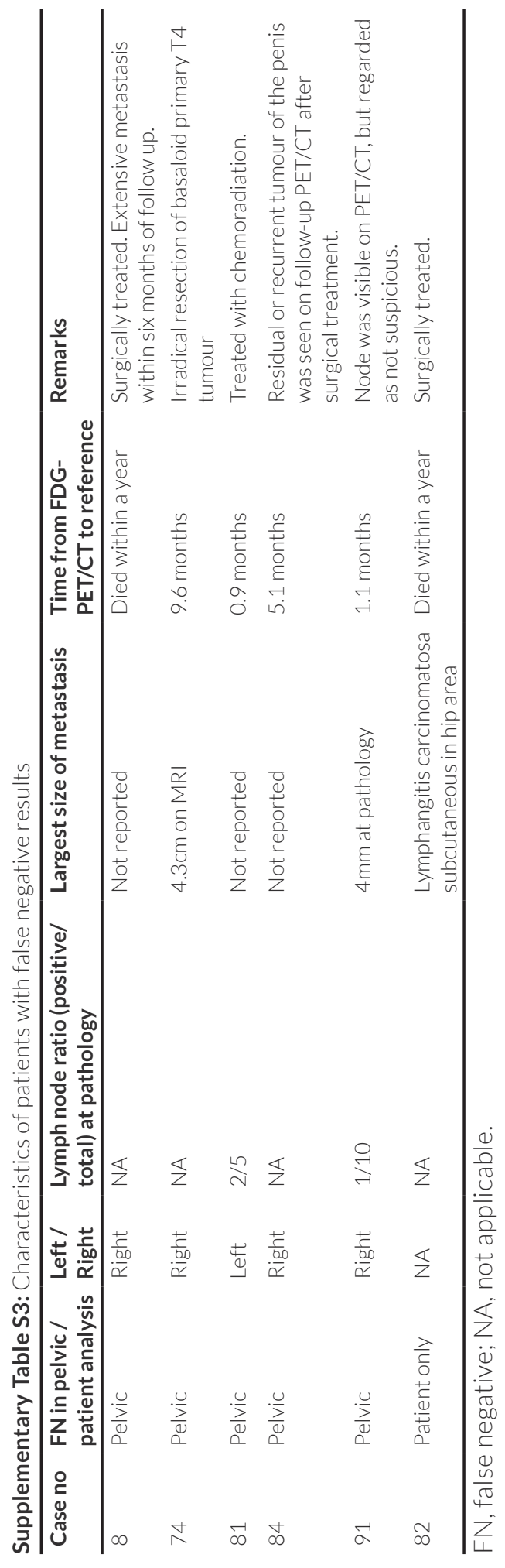




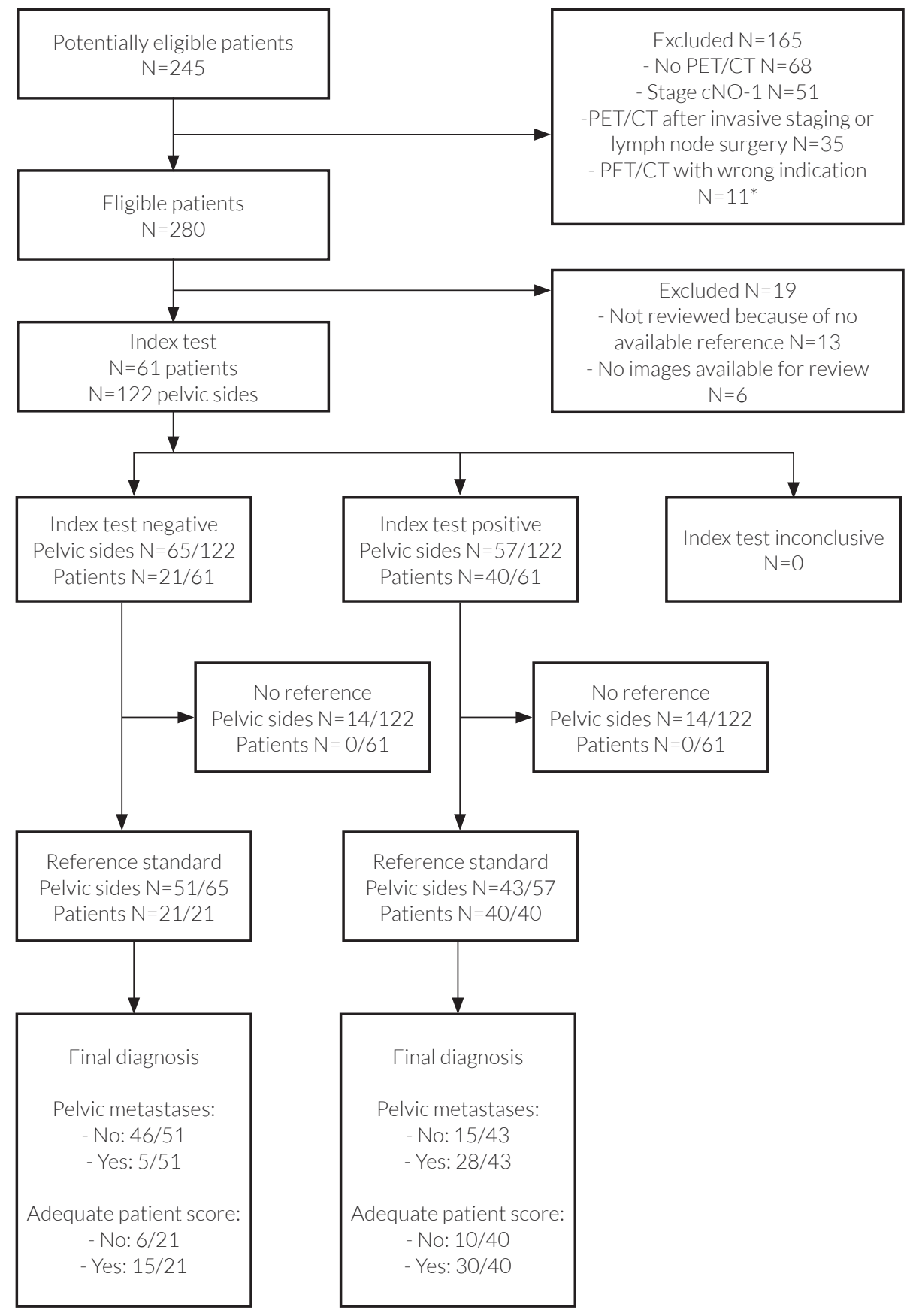

\section{Supplementary Figure 1.}

* examples are: response evaluation PET/CTS, PET/CT because of other malignancies, or because of a suspicion of $\mathrm{M}+$ 


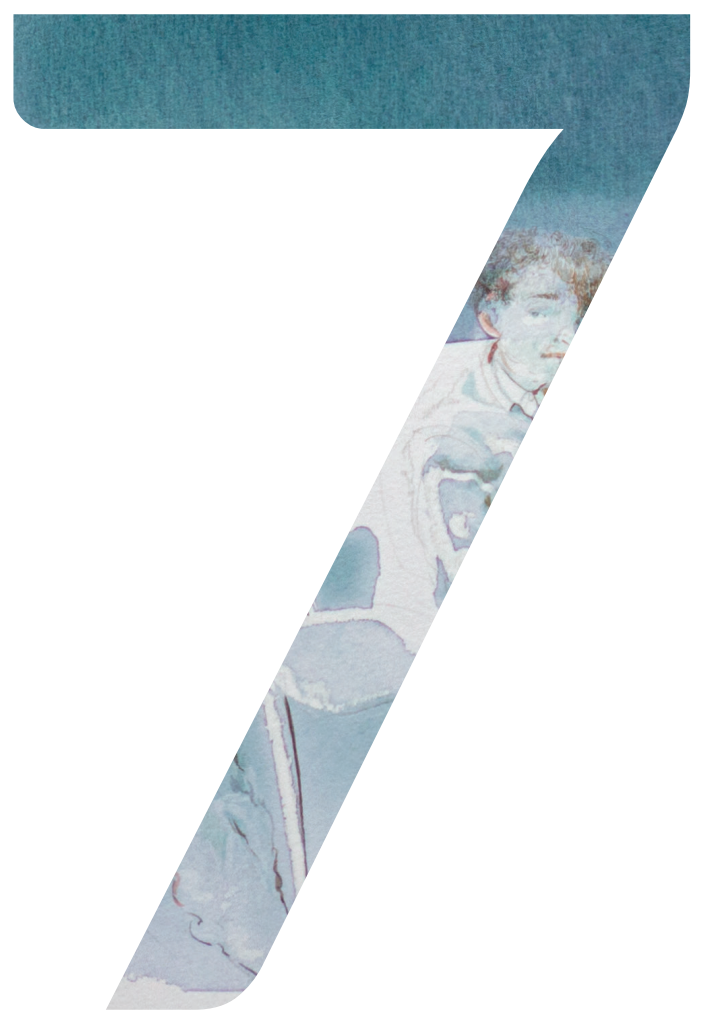


Chapter 7

Surgical and oncological outcomes in patients after vascularized flap reconstruction for loco-regionally advanced penile cancer

Sarah R. Ottenhof, Andrew Leone, Rosa S. Djajadiningrat, Mounsif Azizi, Kamran Zargar, Laura C. Kidd, Gregory Diorio, Gerard Mosiello, Niels M. Graafland, Philippe E. Spiess, Simon Horenblas 


\section{ABSTRACT}

Background: Treatment of locoregionally advanced penile cancer (LAPSCC) is challenging. The exact role (in terms of oncological benefit) of extensive surgery is not well established. Moreover, surgery invariably leads to large defects requiring reconstructive surgery. Rectus abdominis myocutaneous (RAM) and abdominal advancements flaps have independent and constant blood supply, are easily harvested, and provide substantial skin coverage and soft tissue.

Objective: To determine the surgical and oncological outcome in patients with LAPSCC undergoing surgical resection with RAM flaps.

Design, Setting and Participants: From 2002-2016, a multi-institutional database identified fifteen LAPSCC patients undergoing flap reconstructions.

Intervention: Local surgical resection with RAM or abdominal advancement flap reconstruction.

Outcome measurements and Statistical analysis: Perioperative and pathologic data were collected. Postoperative complications were identified using the Clavien-Dindo classification of surgical complications.

Results and limitations: Fifteen patients (median age: 61) were treated; ten with curative intent. Thirteen patients received induction chemotherapy. Thirteen of 15 patients (87\%) experienced wound complications including five ClavienDindo grade III complications. In 11/15 patients (73\%) disease recurred (median recurrence-free interval: 106 days). The majority of recurrences (91\%) were locoregional, four of which also had lesions in distant organs. Ten of 15 (67\%) died of disease. Overall median follow-up interval was 10.5 months. This study was limited by its retrospective design, absence of quality-of-life measurements, and cohort size.

Conclusions: The results of this study show that surgical resections with reconstruction is associated with a risk of perioperative complications, including high grade according to Clavien-Dindo classification. With a cure-rate of $27 \%$, surgery needs careful consideration, with a need for alternative treatments. Also lack of robust quality-of-life-data is a serious shortcoming in the decision process for this patient category. 
Patient summary: Surgery in locoregionally advanced penile cancer has a low cure rate. Reconstruction of defects is surgically feasible, albeit with a high risk of complications. Further, decision making lacks robust data on quality-of-life after surgery.

\section{INTRODUCTION}

Treatment of extensive locoregional penile cancer is challenging. Some patients delay treatment and seek care only when disease is far advanced with extensive local and/or regional involvement. These lesions may lead to large fungating masses with destruction of skin and soft tissue. These patients have poor qualityof-life because of pain, fetor, lymphedema, lymphorrhea and infection, that may leave the patient bedridden, debilitated and difficult to manage by family and/or health workers. Surgery has been used in the past to alleviate complaints of large tumours deposits, and in some cases, to attain cure. However, the exact role of surgery in locally advanced disease, either palliative or curative, is not well known. Moreover, surgical removal of all tumour deposits leads invariably to large wound defects (Figures 1 and S1) necessitating reconstructive surgery in collaboration with plastic and reconstructive surgeons.

Even if cure turns out to be an unattainable goal, surgery for palliative motives can be considered. ${ }^{1}$ Primary coverage with a skin graft is usually impossible with exposed bones, nerves, fascia and vessels as it lacks vessels for skin graft ingrowth. Therefore, vascularized reconstructive techniques like myocutaneous and advancement flaps are first choice. Advantages include independent and constant blood supply, ability to harvest in supine position, adequate bulk to obliterate dead space and provide protection to femoral vessels, ease of closure of the donor site and additional skin to allow tension free closure of the defect.2,3 Additionally, this technique is of value in salvage procedures following previous surgery or radiation therapy.

The surgical management of advanced penile carcinoma has only been reported in small series with a maximum of five patients, summarized in Table $3 .^{3-13}$ In this study, we aim to evaluate surgical and oncological results in a twoinstitutional experience, including fourteen patients who underwent flap reconstruction after surgery for advanced locoregional penile carcinoma in both palliative and curative settings. 


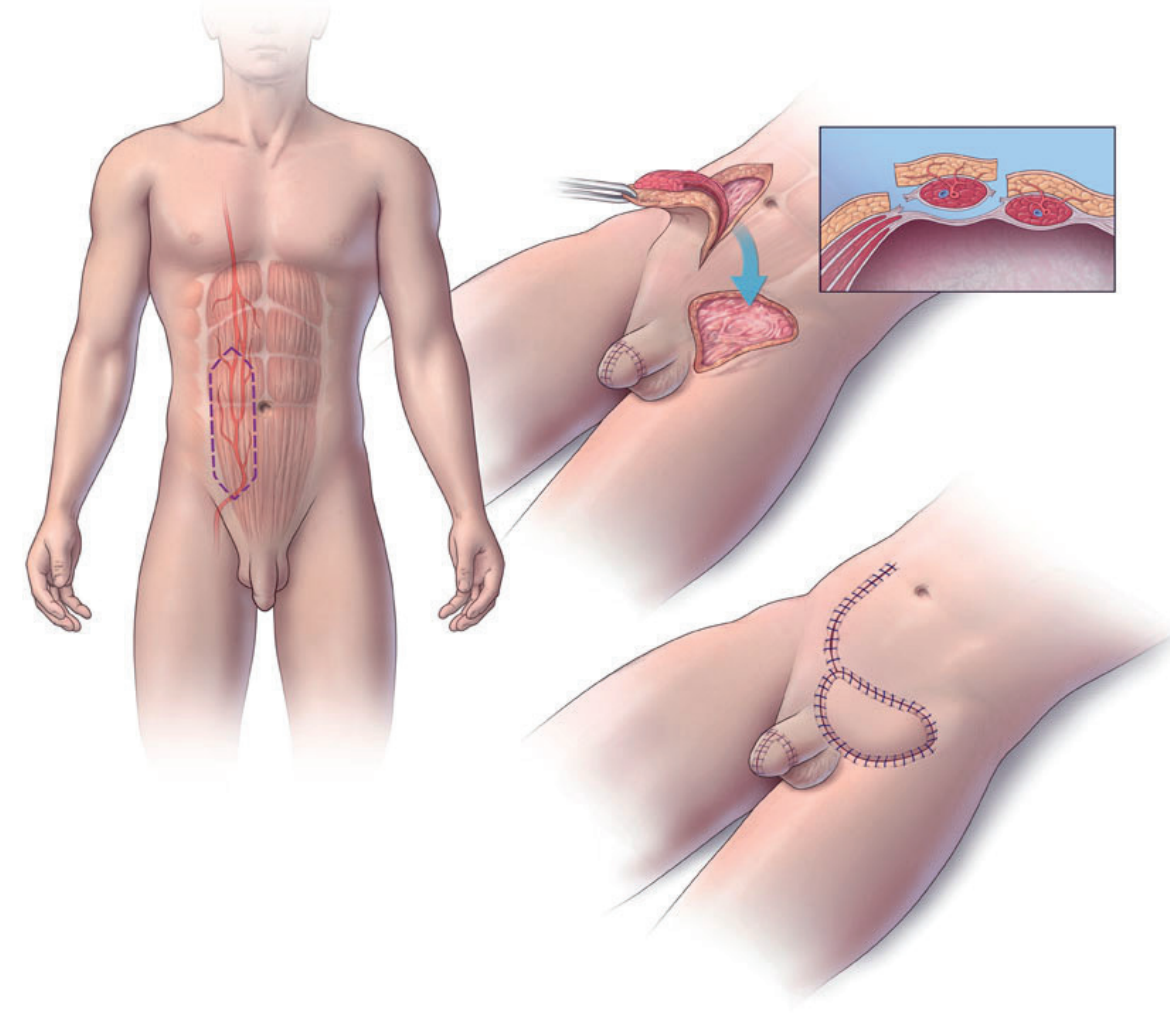

Figure 1: Anatomy of Rectus Muscle and Illustrating Flap Anatomy (made with Adobe PhotoShop)

\section{PATIENTS AND METHODS}

\section{Patients}

Between September 2002 and December 2016, 15 patients were seen at two referral centres with extensive locoregional disease, in whom resection would leave a defect that required reconstructive surgery. All patients were identified from a prospectively kept database, staged according to the 2009 TNM classification of penile cancer and retrospectively analysed. ${ }^{7}$

\section{Surgical treatment}

All patients had extensive surgery with removal of inguinal and/or penile skin, inguinal and sometimes pelvic lymphatic tissue, further specified in Table 1. In 
patients treated with palliative intent, the main goal was to obtain local control, loss of pain, fetor and easy management of the local situation.

The operative technique of VRAM, ORAM (vertical or oblique rectus abdominis myocutaneous flap) or abdominal advancement was performed in collaboration with a plastic surgeon. He/she decided which reconstructive technique was used and performed the reconstructive procedure. The patients were able to remain in the supine position throughout the procedure. After preparation of the recipient site the defect was measured (Figure S1) and an appropriately sized flap was marked on the skin of the ipsilateral or contralateral rectus abdominis, depending on location and size of the defect. Flaps were incised through skin, subcutaneous tissue, anterior rectus sheet and muscle. After identification and preparation of the inferior epigastric artery (for an increased range of motion; Figure S2) the flaps were mobilized (Figure 2A) and transferred to the recipient area (Figure 2B). VRAM flaps use the rectus abdominis muscle with the skin island directly on the muscle. ORAM flaps leave more of the muscle in situ. Their skin paddle is taken in oblique direction, based on the umbilical perforating vessels. VRAM flaps have excellent blood supply and are easily adjusted to the requested size. ORAM flaps have lower donor site morbidity, but the skin island partially depends on communicating perforating vessels. Figure 3 shows VRAM donor site reapproximation with a biological mesh (Figure $\mathbf{3 A}$ ) and with a knitted monofilament polypropylene mesh (Figure 3B). In all patients undergoing inguinal surgery, low suction drainage was placed in the inguinal defect.

\section{Post-operative care}

Subcutaneous prophylaxis for deep vein thrombosis was started post operatively. Patients were kept in bed for at least 24 hours. Drains were removed when output decreased to $\pm 50 \mathrm{~mL}$ per day.

\section{Outcome Measurements and Statistical Analysis}

Surgical results were measured in terms of perioperative and postoperative complications, classified according to the Clavien-Dindo classification of surgical complications. ${ }^{14}$ As oncological outcomes, we reported resection margin status, disease recurrence, whether it recurred within the resected site, recurrencefree survival (RFS) and disease-specific mortality (DSM). Pain was measured on a visual analogous scale (VAS). This study was done in accordance with institutional ethical guidelines, based on good clinical practice. 


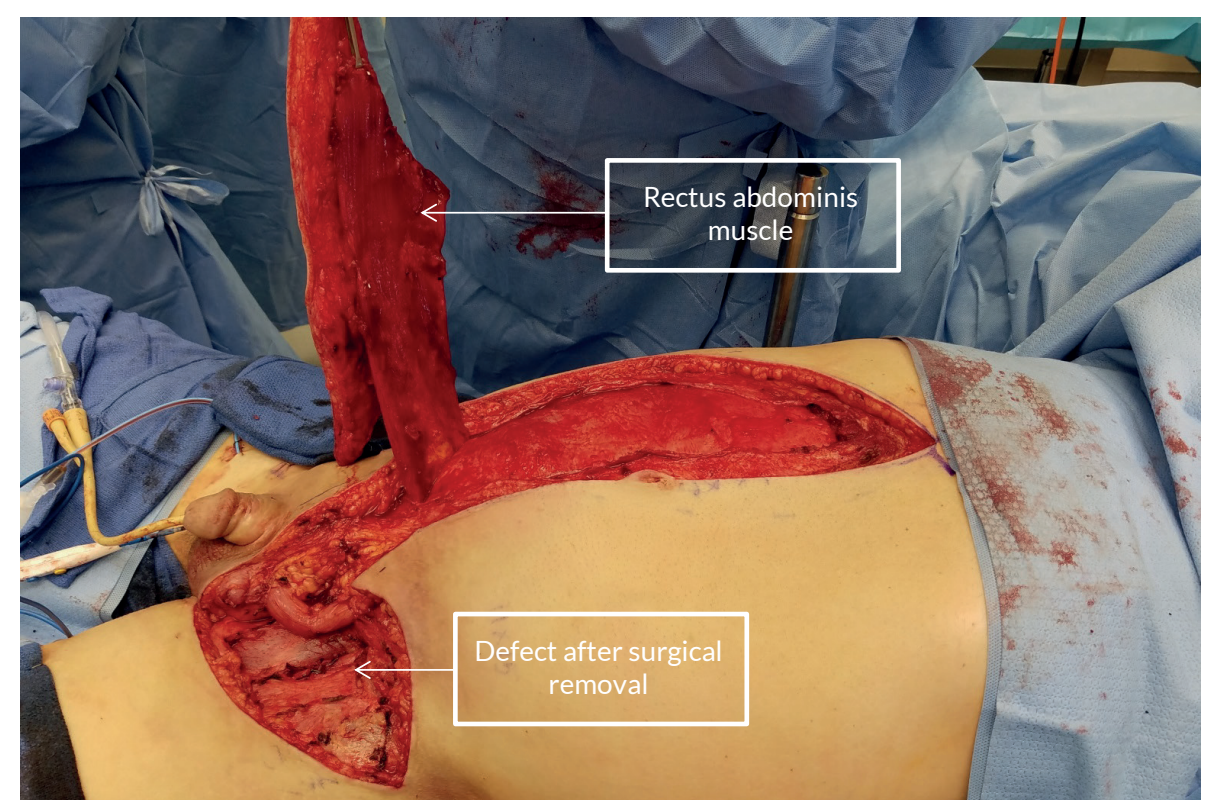

Figure 2A. Free flap prior to tunneling to defect.

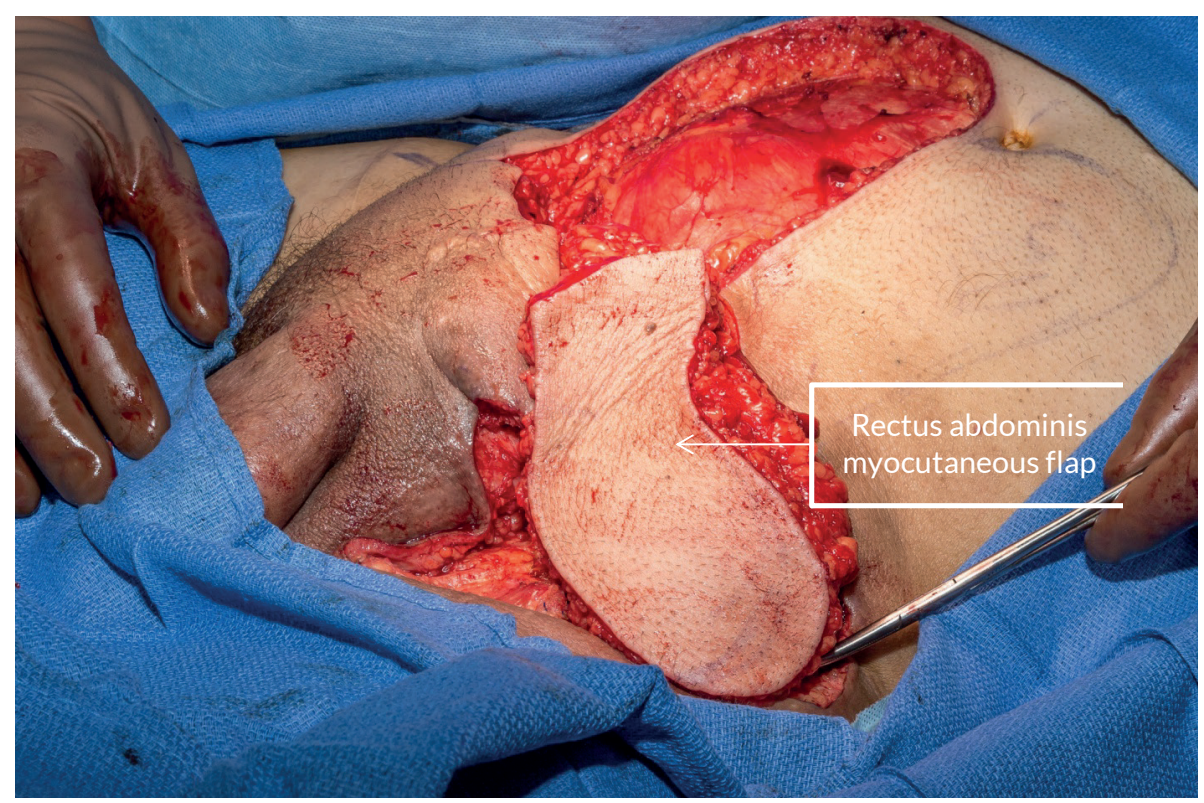

Figure 2B. Rectus Flap is rotated with inferior pubic attachments and skin attachments released. 


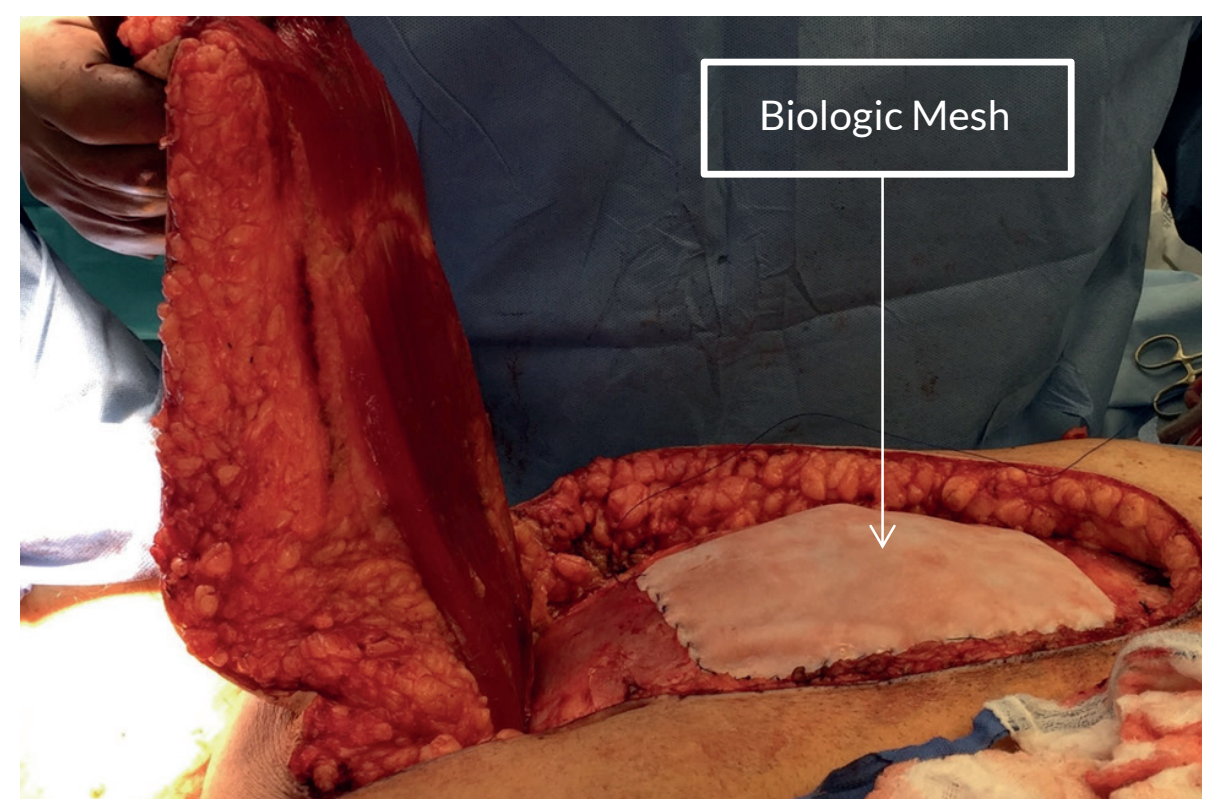

Figure 3A. Demonstration of Biologic Mesh placement in Rectus Defect.

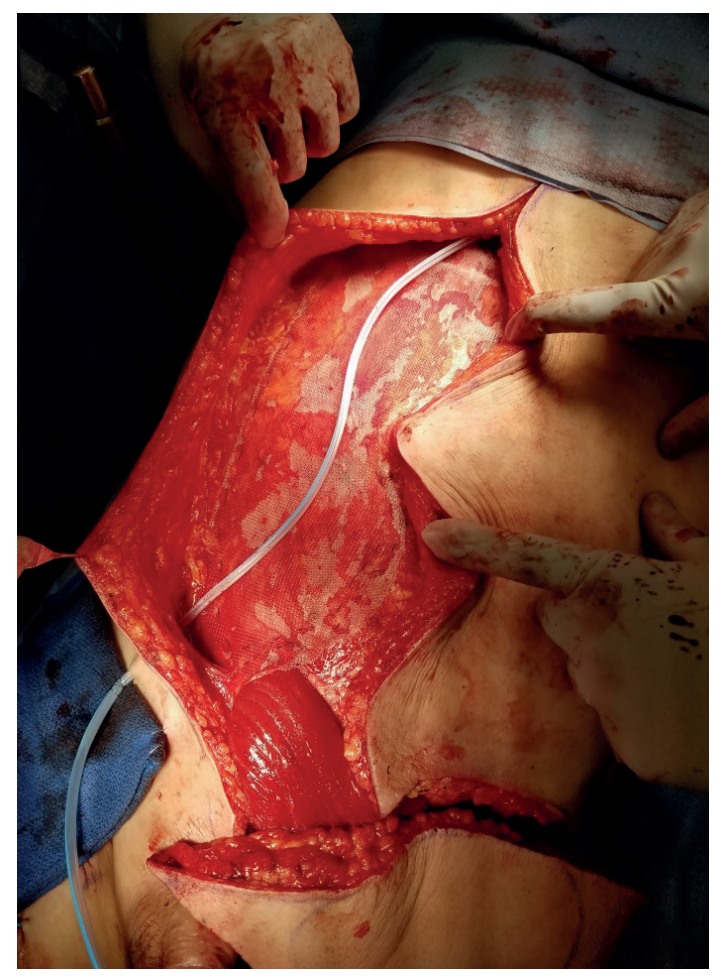

Figure 3B. Demonstration of Knitted Monofilament Polypropylene Mesh placement in Rectus Defect. 


\section{RESULTS}

\section{Patients}

Fifteen patients (median age 61 years (range: 39-85) are described in Table 1. All had squamous cell carcinoma (SCC) of the penis. Eight of these patients (53\%) presented with locoregionally advanced primary disease and seven (47\%) had locoregional recurrences. Thirteen patients received induction chemotherapy prior to surgery. Five patients (33\%) were operated with palliative intent only, as they progressed through chemotherapy. The remaining ten men (67\%) underwent operation with curative intent. Postoperative radiation was administered to eight patients (53\%), three of which were palliative cases, in order to improve local control. Wounds had to be healed before radiation was started.

Ten patients (67\%) underwent VRAM-flap reconstruction, in four cases combined with other reconstructive techniques such as abdominal advancement (Table 1). Four patients (27\%) underwent ORAM, and one patient (7\%) abdominal advancement only.

\section{Surgical results}

All but one flaps remained vital. One flap slowly became ischemic and necrotic despite no signs of entrapment per-operatively. Initially, this flap was managed conservatively, but needed necrotectomy on day 11 after surgery. Five of 8 patients that underwent adjuvant radiotherapy, received it elsewhere. Reports from those centers, and clinical follow-up indicated that all flaps remained vital during radiation.

Twelve of 15 patients (80\%) experienced wound complications, including five grade III complications (Table 1). One patient experienced a postoperative ileus and two patients had a delirium as general complications additionally to their wound complications. All complications could be managed conservitavely unless stated otherwise in Table 1.The median hospital stay was 13 days (range: 4 - 57 days). All but one patients were discharged to home, patient 7 was discharged to a nursing home.

Of the palliative surgery group, pain was evaluated by Visual Analogue Scale (VAS) in four patients. In two patients, the VAS was reduced by 5 points between presentation and day of discharge. The pain of the third patient was reduced from unknown VAS to VAS 1 during reduced analgesics use. The fourth patient reported no pain at presentation, but was operated to relief managerial problems related 
to his large inguinal fungating mass. The fifth patient was operated because bulky nodes were encasing the femoral vessels.

\section{Oncological results}

Median follow-up was 10.5 months (range: 1.7 to 74.2 months). During that time, disease recurred in eleven of fifteen patients (73\%; Table 2). The median RFS was 106 days after resection (3.5 months, range: 9 - 556 days). Three patients (20\%), two of which were palliative cases, experienced cutaneous metastatic disease in or around the reconstructed skin before postoperative radiotherapy could be given, one additional patient after adjuvant radiation was given. Another patient had preoperative clinical evidence of cutaneous metastasis, that recurred clinically only 9 days postoperatively. The other recurrences included locoregional recurrences, as well as a groin metastases in non-dissected areas. Five cases had distant metastases.

Ten patients, all with disease recurrences, died of disease after a median time of 4.7 months (range: 1.7-23.0 months) from resection. This resulted in a DSM of $67 \%$. Four men had no evidence of disease at follow-up, with median follow-up in these men of 54.6 months, ranging from 8 to 74 months. All four underwent an excision with tumour negative margins. On the other hand, four of eight patients with tumour-free margins had recurrent disease, and three died of their disease. One had histopathologic evidence of lymphangitis carcinomatosis, two died of a recurrence with distant spread, one is still alive after having a regional recurrence and an perirectal mass.

\section{DISCUSSION}

The management of extensive locoregional disease of penile cancer is challenging. Three aspects have to be considered: technical aspects of resection and reconstruction, oncological aspects (recurrence-free survival and diseasespecific survival), and effect on palliation.

Technically, complete resection of extensive disease was not always feasible, despite wide local excision. Pre-operative determination of surgical feasibility by physical examination in combination with imaging is not always easy. Our results emphasize the difficulty in judging oncologically sound resection pre- and peroperatively. MRI could aid planning of resection and prediction of resectability. Reconstruction could always be performed, but not without complications. 


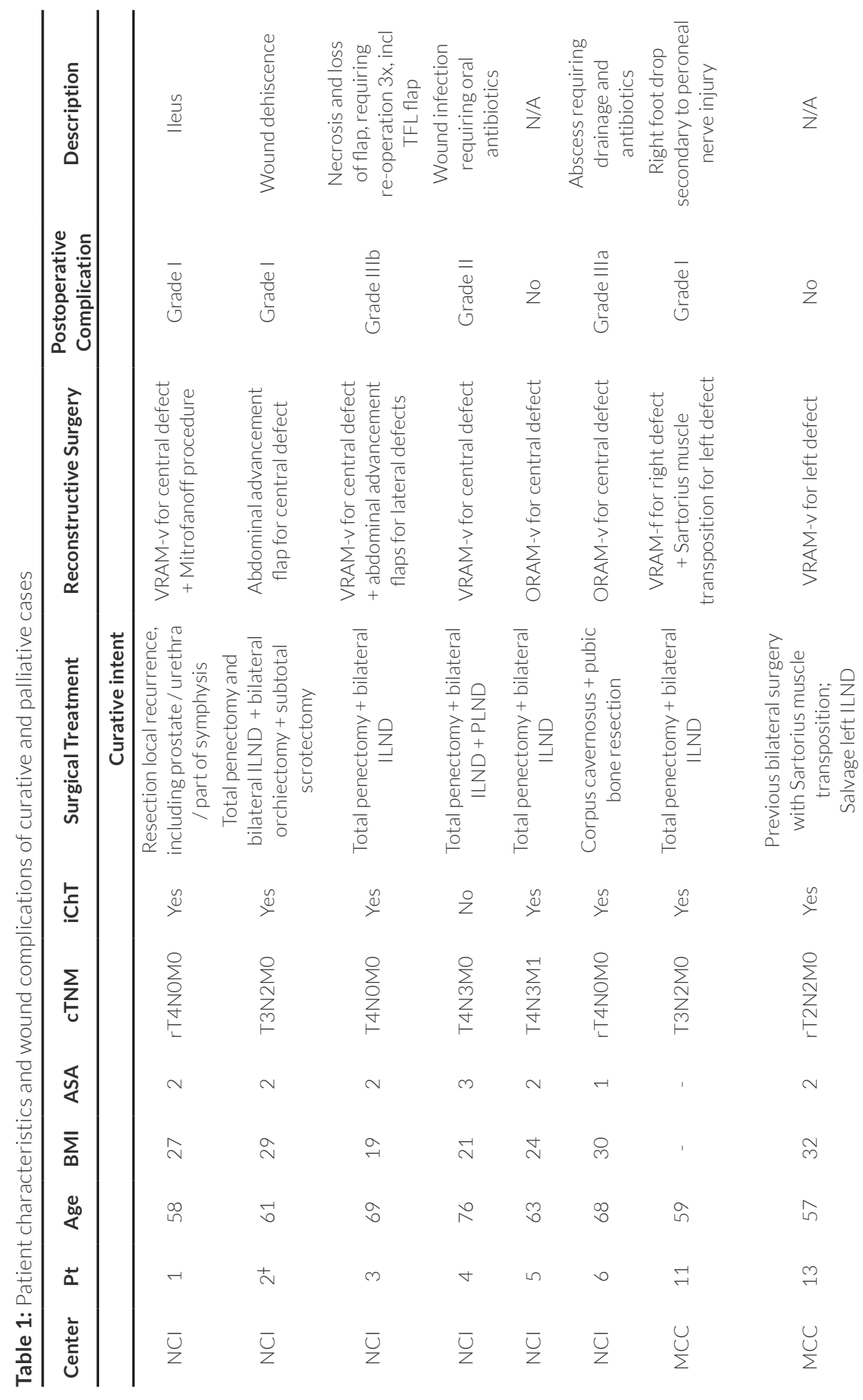




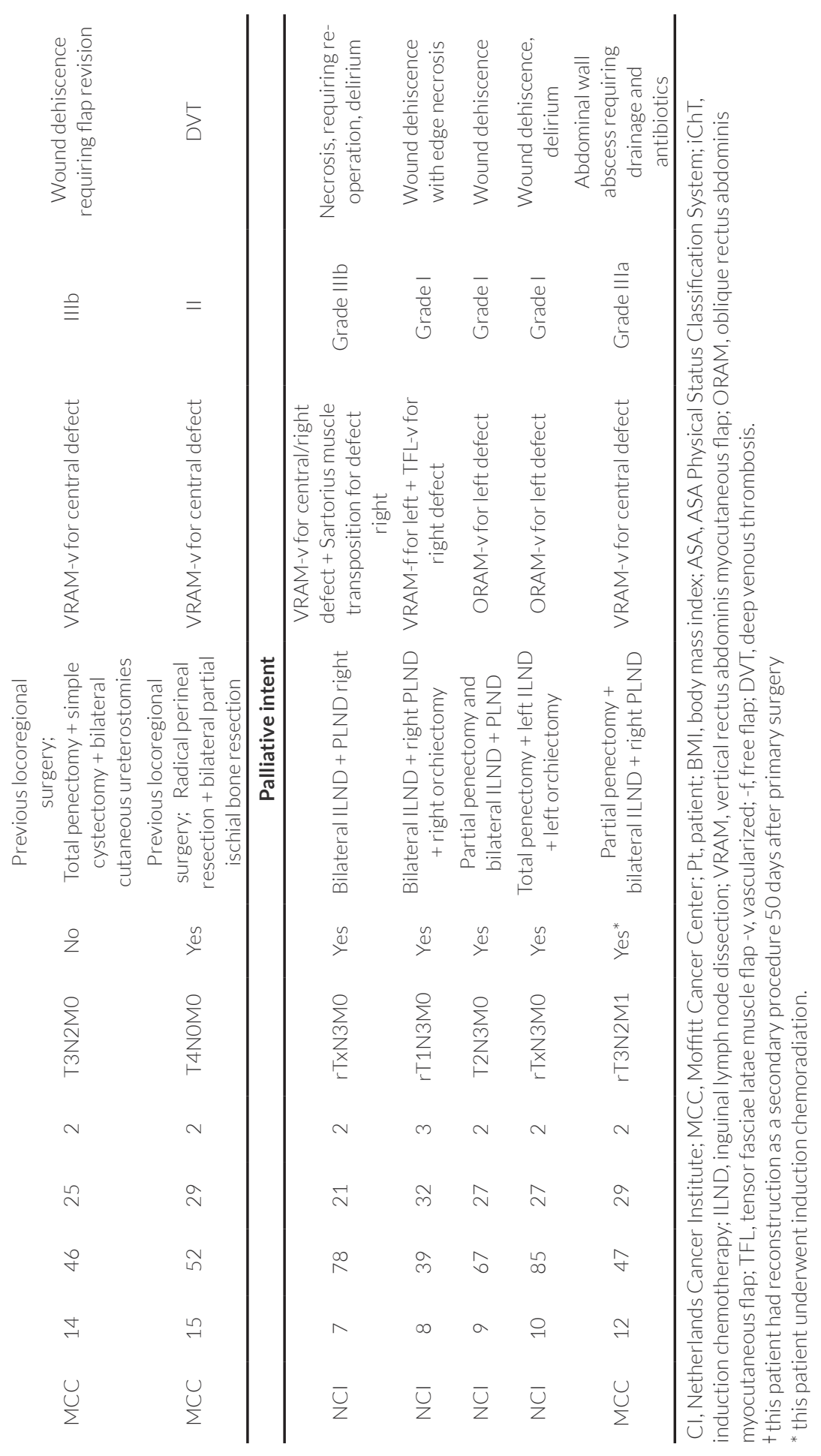


The VRAM flap, with its dual blood supply, has shown to represent an excellent means to achieve wound coverage with low morbidity following resection of advanced penile carcinoma in a small series of four patients. ${ }^{9}$ In that study, postoperative morbidity was low and improvement of quality-of-life was reported. In a similar series of five patients with penile SCC undergoing VRAM flap, only one patient experienced donor site wound edge necrosis. ${ }^{5}$ Likewise, Kuntscher et al. published a series of fifteen VRAM patients, one of whom had advanced penile SCC and suffered no major complications, only minor abdominal bulging (as mesh was not used at the donor site). ${ }^{10}$ However, our findings do not mirror those above. Most patients experienced wound complications, including three who required additional surgery (debridement for wound necrosis, flap revision and flap loss). A plausible explanation is that the extent of disease and surgery are not comparable between both studies. Table 3 illustrates a summary of the available literature on VRAM flaps in advanced penile cancer, including the findings of the present series.

In terms of oncological control, a minority of the group (four men) treated with curative intent had long lasting recurrence-free survival and diseasespecific survival. In the patients undergoing palliative surgery, recurrence-free survival was disappointing (one developed a regional skin recurrence 9 days postoperatively).

Our series show predominantly local and regional recurrences after extensive surgery and induction chemotherapy. Five patients developed distant metastasis. This is somewhat in contrast to another study, which reported early death from distant metastasis (two out of four patients, with shorter follow-up). ${ }^{9}$ In general, SCC has a strong tendency for locoregional growth. Penile cancer is no exception, and our patient series reflects this predilection.

Probability of local and regional recurrence is understandably higher when tumour-negative margins cannot be obtained. Unfortunately, as in the whole field of surgical oncology, negative surgical margins are no guarantee for cure, as half of the patients with tumour-free margins eventually had recurrent disease (albeit all after more than three months).

Additionally, after irradical resection, adjuvant radiotherapy, started after the surgical wounds have closed, can improve local control. Two patients had a relatively long recurrence free survival. Clinical signs of Iymphangitis carcinomatosa or satellite skin lesions are ominous with a very high likelihood 


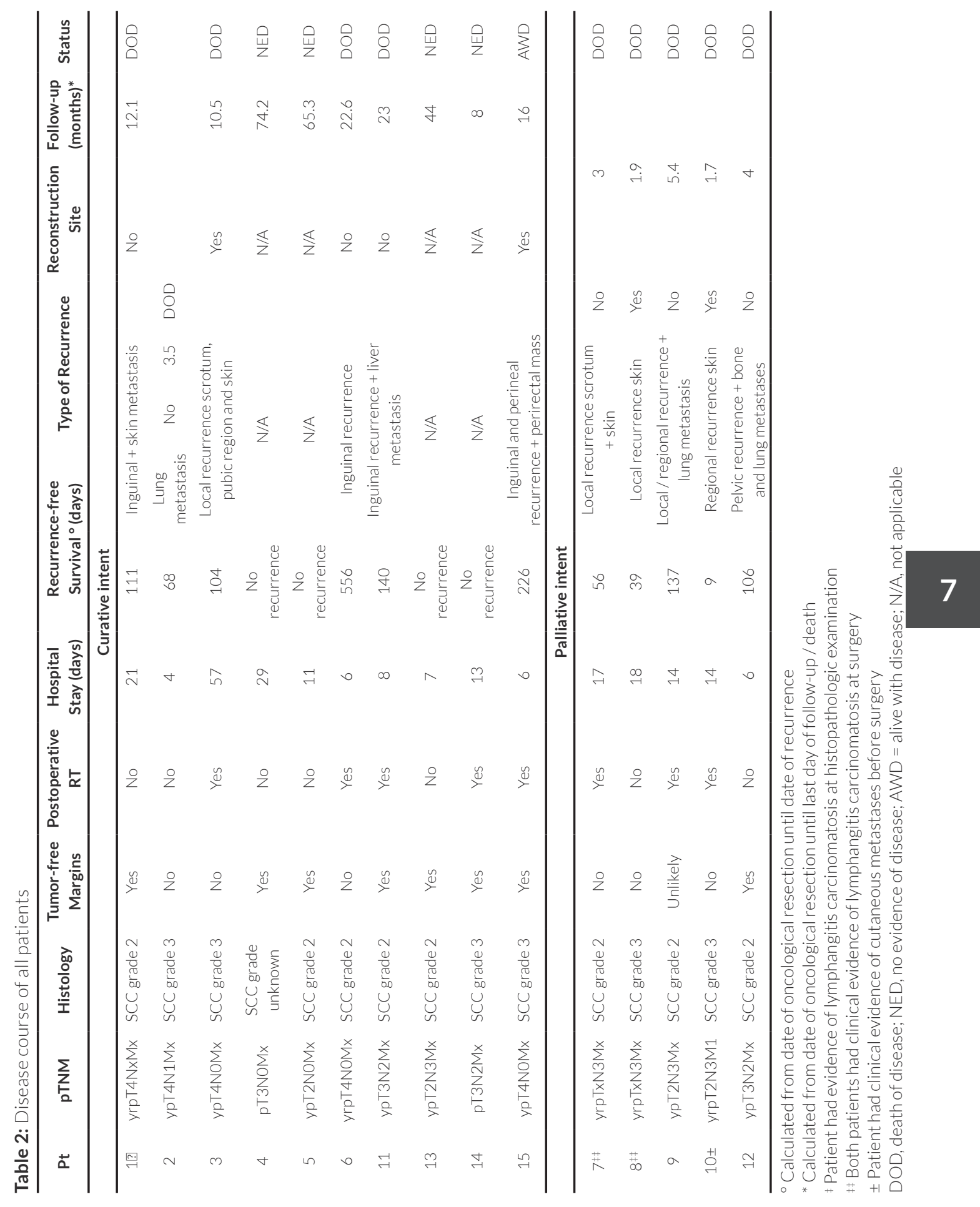


of local recurrence, even in patients with response to chemotherapy or tumourfree margins at surgery. These patients are poor candidates for extensive surgery, as the meagre benefits, if any, do not outweigh such surgical procedure and it's complications.

Meaningful palliation was hard to determine in our series. However, absence of local recurrence can likely be considered a meaningful palliation, as suffering from local problems, such as pain, discharge and fetor, can be considerable and quite difficult to manage. ${ }^{1}$ Hence, in terms of pain management, some palliation is achieved. However, considering the short life expectancy, this patient category likely warrants other than surgical treatment. Although pain was measured in the palliative cases, a robust quality-of-life analysis is lacking. Therefore it remains unknown how helpful these interventions truly were for these patients.

As oncological results are disappointing in our series, a re-evaluation of the role of surgery in locoregionally advanced penile tumours is suggested. Especially in patients where no tumour-free margins can be obtained based on presence of extensive nodal metastases, signs of lymphangitis carcinomatosa or satellite skin lesions. Based on our series, surgical resection and reconstruction can be attempted at least in patients in whom, by all available means, tumour free margins seem achievable. Otherwise enthusiasm for surgery needs to be mitigated. Our results underline the need of a realistic evaluation of survival odds with surgery, alternative treatments, and earlier involvement of palliative care.

Other treatment modalities are currently available. Chemoradiation has replaced surgery as first line treatment in advanced SCC of the anus, cervix, vulva and head and neck. ${ }^{15-18}$ Chemoradiation showed excellent locoregional control rates in patients with inoperable stage III/IV head and neck SCC. ${ }^{19}$

In penile cancer, variable results have been observed regarding chemoradiation. Some small series comparing chemoradiation to radiation alone have shown favourable outcomes. ${ }^{20-22}$ Two case reports revealed promising results with chemoradiation only in advanced cases. ${ }^{23,24}$ Contrarily, two recent retrospective reviews showed more disappointing outcomes for both concurrent neoadjuvant and salvage chemoradiotherapy. ${ }^{25,26}$ Currently, chemoradiation for both locally and regionally advanced penile cancer is prospectively evaluated at the Netherlands Cancer Institute ( NCI). 


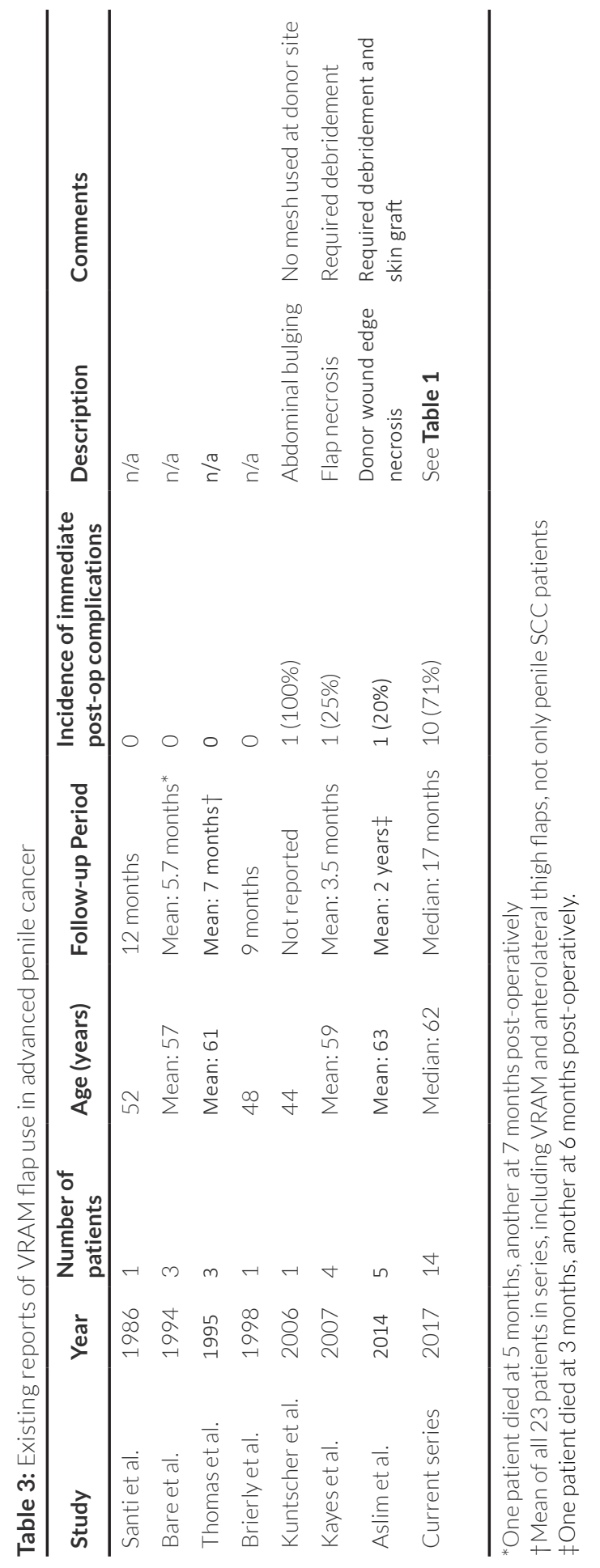


Another option is induction therapy with pan-HER tyrosine kinase inhibitor targeted therapy, in which showed promising results for regionally extended disease. One-year progression free survival was comparable to the results with neoadjuvant chemotherapy in a European study, but had a somewhat lower objective response rate in comparison to neoadjuvant chemotherapy in an American study. ${ }^{27-29}$ With a grade 3 complication rate of $11 \%$, this therapy is well tolerated and can be considered for patients unfit to undergo combination chemotherapy.

The results in SCCs at other sites, together with the limited experience in penile carcinoma, suggest that chemoradiation should be considered in order to attempt local control in patients in whom it is unlikely that tumour-free margins can be obtained. However, management decisions remain difficult because of lack of robust data and conflicting results in the current literature.

This study suffers from the following limitations. Firstly, this is a retrospective case series with all the well-known biases. Also, this study lacks robust qualityof-life measurements, crucial for evaluating management effect in the palliative group. Thirdly, the low number of patients limited meaningful statistical analyses.

\section{Conclusions}

Despite extensive surgical resection and reconstruction with myocutaneous flaps of defects, recurrence-free survival was unsatisfying in the majority of patients with locoregionally advanced penile carcinoma. The oncological outcome was especially limited in those treated with palliative intent. Extensive surgery in this difficult patient group is associated with significant postoperative complications, and good quality-of-life measurements are lacking.

Based on these results, we suggest limiting surgery to patients in whom tumourfree margins seem achievable by all reasonable means. Likewise, for those patients in whom this goal is very unlikely, we suggest avoidance of surgery in favour of other treatment modalities, such as chemoradiation. Lastly, for future studies or case series, we suggest quality-of-life measurements in advanced penile cancer cases, as to evaluate what treatment is really adding compared to best supportive care.

\section{Patient summary}

Surgery with vascularized flap reconstruction in the treatment of large primary penis cancer tumours is associated with a considerable risk of complications, 
and cure is obtained in about a quarter of patients. Therefore, we advise to limit this treatment to patients in whom tumour-free margins seem achievable by all available means.

\section{Acknowledgments}

We are grateful to the plastic surgeons of our institutes for their reconstructive efforts in this group of patients. We would also like to acknowledge our medical illustrator, Myriam Oh for her schematic depiction of this VRAM flap and the steps in its creation and positioning. 


\section{REFERENCES}

1. Shukla CJ, Shabbir M, Feneley MR, Withey S, Muneer A, Minhas S (2010) Palliation of male genital cancers. Clinical oncology 22 (9):747-754

2. Abbas S, Seitz M (2011) Systematic review and meta-analysis of the used surgical techniques to reduce leg lymphedema following radical inguinal nodes dissection. Surg Oncol 20 (2):88-96. doi:10.1016/j.suronc.2009.11.003

3. Brierly RD, Pereira JA, Arnstein PM (1998) Use of a vertical rectus abdominis myocutaneous flap in bilateral groin dissection for recurrent carcinoma of the penis. Urol Int 61 (4):243-246. doi:30339

4. Airhart RA, deKernion JB, Guillermo EO (1982) Tensor fascia lata myocutaneous flap for coverage of skin defect after radical groin dissection for metastatic penile carcinoma. J Urol 128 (3):599-601

5. Aslim EJ, Rasheed MZ, Lin F, Ong YS, Tan BK (2014) Use of the anterolateral thigh and vertical rectus abdominis musculocutaneous flaps as utility flaps in reconstructing large groin defects. Arch Plast Surg 41 (5):556-561. doi:10.5999/ aps.2014.41.5.556

6. Bare RL, Assimos DG, McCullough DL, Smith DP, DeFranzo AJ, Marks MW (1994) Inguinal lymphadenectomy and primary groin reconstruction using rectus abdominis muscle flaps in patients with penile cancer. Urology 44 (4):557-561

7. Hakenberg OW, Comperat EM, Minhas S, Necchi A, Protzel C, Watkin N, European Association of U (2015) EAU guidelines on penile cancer: 2014 update. Eur Urol 67 (1):142-150. doi:10.1016/j.eururo.2014.10.017

8. Hanash KA, Tur JJ (1986) One-stage plastic reconstruction of a totally amputated cancerous penis using a unilateral myocutaneous gracilis flap. J Surg Oncol 33 (4):250-253

9. Kayes OJ, Durrant CA, Ralph D, Floyd D, Withey S, Minhas S (2007) Vertical rectus abdominis flap reconstruction in patients with advanced penile squamous cell carcinoma. BJU Int 99 (1):37-40. doi:10.1111/j.1464-410X.2007.06582.x

10. Kuntscher MV, MansouriS, NoackN, Hartmann B (2006) Versatility of vertical rectus abdominis musculocutaneous flaps. Microsurgery 26 (5):363-369. doi:10.1002/ micr.20253

11. Santi P, Berrino P, Canavese G, Galli A, Rainero ML, Badellino F (1988) Immediate reconstruction of the penis using an inferiorly based rectus abdominis myocutaneous flap. Plast Reconstr Surg 81 (6):961-964

12. Tabatabaei S, McDougal WS (2003) Primary skin closure of large groin defects after inguinal lymphadenectomy for penile cancer using an abdominal cutaneous advancementflap. J Urol 169(1):118-120. doi:10.1097/01.ju.0000035363.77382. b2

13. Thomas JA, Matanhelia SS, Dickson WA, Rees RW, Matthews PN (1995) Use of the rectus abdominis myocutaneous flap in treating advanced carcinomas of the penis. Br J Urol 75 (2):214-219

14. Dindo D, Demartines N, Clavien PA (2004) Classification of surgical complications: a new proposal with evaluation in a cohort of 6336 patients and results of a survey. Ann Surg 240 (2):205-213 
15. Chemoradiotherapy for Cervical Cancer Meta-analysis C (2010) Reducing uncertainties about the effects of chemoradiotherapy for cervical cancer: individual patient data meta-analysis. Cochrane Database Syst Rev (1):CD008285. doi:10.1002/14651858.CD008285

16. Lim F, Glynne-Jones R (2011) Chemotherapy/chemoradiation in anal cancer: a systematic review. Cancer Treat Rev 37 (7):520-532. doi:10.1016/j. ctrv.2011.02.003

17. Pignon JP, le Maitre A, Maillard E, Bourhis J, Group M-NC (2009) Meta-analysis of chemotherapy in head and neck cancer (MACH-NC): an update on 93 randomised trials and 17,346 patients. Radiother Oncol 92 (1):4-14. doi:10.1016/j. radonc.2009.04.014

18. Shylasree TS, Bryant A, Howells RE (2011) Chemoradiation for advanced primary vulval cancer. Cochrane Database Syst Rev (4):CD003752. doi:10.1002/14651858. CD003752.pub3

19. Blasco MA, Svider PF, Raza SN, Jacobs JR, Folbe AJ, Saraf P, Eloy JA (2017) Systemic therapy for head and neck squamous cell carcinoma: Historical perspectives and recent breakthroughs. doi:10.1002/lary.26629

20. Edsmyr F, Andersson L, Esposti PL (1985) Combined bleomycin and radiation therapy in carcinoma of the penis. Cancer 56 (6):1257-1263

21. Gotsadze D, Matveev B, Zak B, Mamaladze V (2000) Is conservative organ-sparing treatment of penile carcinoma justified? Eur Urol 38 (3):306-312. doi:20298

22. Modig H, Duchek M, Sjodin JG (1993) Carcinoma of the penis. Treatment by surgery or combined bleomycin and radiation therapy. Acta Oncol 32 (6):653-655

23. Palmieri G, Gridelli C, Vitale A, Bianco AR (1988) Contemporary chemotherapy and radiotherapy for inguinal metastases of carcinoma of the penis: a case report. Tumori 74 (5):585-586

24. Chhabra A, Schwartz D, Leaf A, Karanikolas N, Weiss JP, Schreiber D (2014) Neoadjuvant concurrent chemoradiation for curative treatment of penile squamous cell carcinoma. Case Rep Oncol Med 2014:479376. doi:10.1155/2014/479376

25. Pond GR, Milowsky MI, Kolinsky MP, Eigl BJ, Necchi A, Harshman LC, Di Lorenzo G, Dorff TB, Lee RJ, Sonpavde G (2014) Concurrent chemoradiotherapy for men with locally advanced penile squamous cell carcinoma. Clin Genitourin Cancer 12 (6):440-446. doi:10.1016/j.clgc.2014.03.009

26. Wang J, Pettaway CA, Pagliaro LC (2015) Treatment for Metastatic Penile Cancer After First-line Chemotherapy Failure: Analysis of Response and Survival Outcomes. Urology 85 (5):1104-1110. doi:10.1016/j.urology.2014.12.049

27. Necchi A, Lo Vullo S, Perrone F, Raggi D, Giannatempo P, Calareso G, Nicolai N, Piva L, Biasoni D, Catanzaro M, Torelli T, Stagni S, Togliardi E, Colecchia M, Busico A, Gloghini A, Testi A, Mariani L, Salvioni R (2017) First-line therapy with dacomitinib, an orally available pan-HER tyrosine kinase inhibitor, for locally advanced or metastatic penile squamous cell carcinoma: results of an open-label, single-arm, single-centre, phase 2 study. BJU Int. doi:10.1111/bju.14013 


\section{Chapter 7}

28. Djajadiningrat RS, Bergman AM, van Werkhoven E, Vegt E, Horenblas S (2015) Neoadjuvant taxane-based combination chemotherapy in patients with advanced penile cancer. Clin Genitourin Cancer 13 (1):44-49. doi:10.1016/j.clgc.2014.06.005

29. Pagliaro LC, Williams DL, Daliani D, Williams MB, Osai W, Kincaid M, Wen S, Thall PF, Pettaway CA (2010) Neoadjuvant paclitaxel, ifosfamide, and cisplatin chemotherapy for metastatic penile cancer: a phase II study. Journal of clinical oncology: official journal of the American Society of Clinical Oncology 28 (24):38513857. doi:10.1200/jco.2010.29.5477 


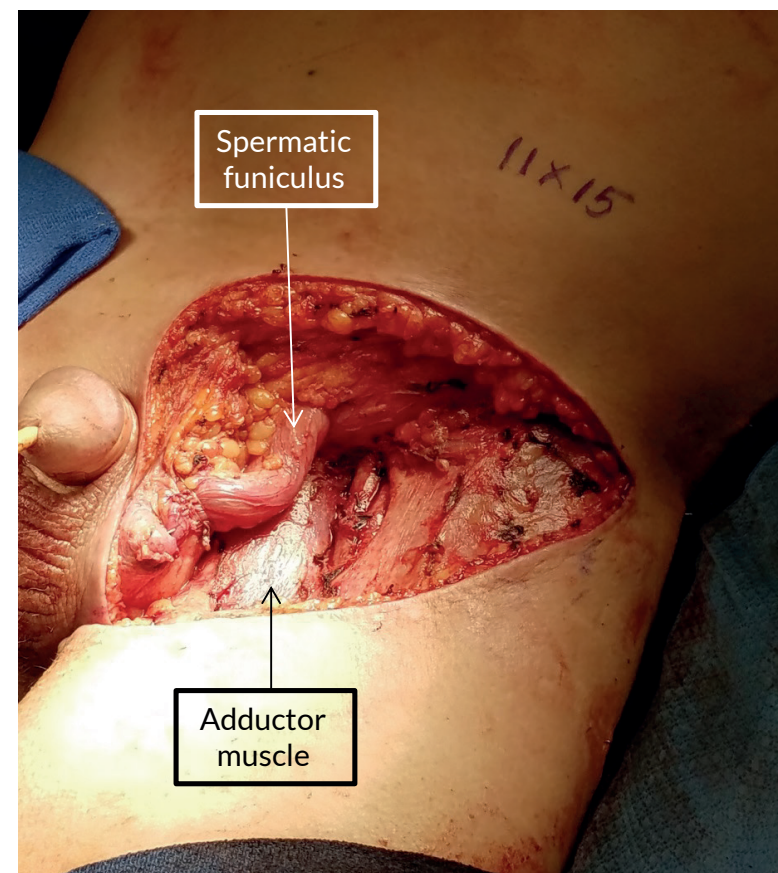

Figure S1: Inguinal Defect Measured



Figure S2: Demonstration of preserved blood supply to RAM flap 


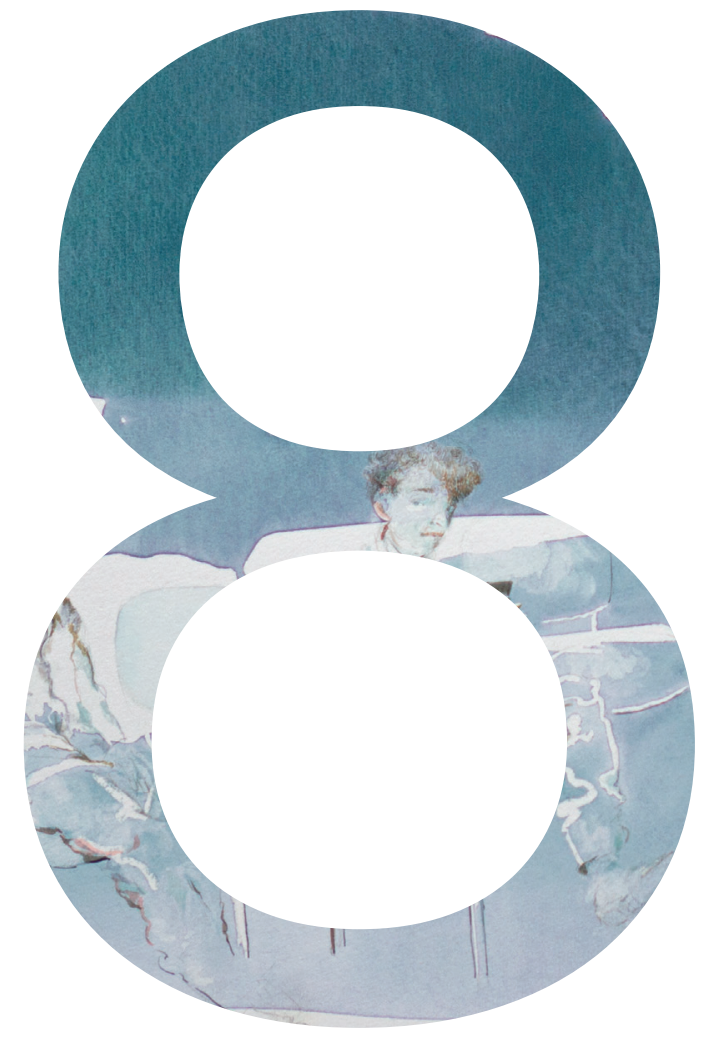


Chapter 8

\section{Chemoradiotherapy as primary treatment of locoregionally advanced penile cancer}

Sarah R. Ottenhof, Hielke-Martijn de Vries, Barry Doodeman, Gerrit L. Vrijenhoek, Oscar R. Brouwer, Vincent van der Noort, Michiel van der Heijden, Simon Horenblas, Floris J. Pos 


\section{ABSTRACT}

Background: Locoregionally advanced penile cancer (LAPSCC) is associated with high treatment associated morbidity and poor survival rates, even with multimodal treatment. Chemoradiotherapy (CRT) is applied in squamous cell carcinoma from other organ sites, but its value has hardly been studied in penile cancer.

Objective: To evaluate the efficacy and toxicity of CRT for LAPSCC

Design setting and participants: We included patients fit for CRT with LAPSCC, defined as a large, with satellite lesions accompanied, or inoperable primary tumour, palpable nodes $>3 \mathrm{~cm}$ in diameter (N2/N3), suspicion of extranodal extension (ENE), or pelvic nodal involvement (N3), with no evidence of distant metastases.

Outcome Measurements and Statistical Analysis: The primary endpoint was 1-year progression free survival (PFS). Secondary endpoints were treatment response, toxicity, and overall survival. CRT consisted of 49.5 Gy in 33 daily fractions of $1.5 \mathrm{~Gy}$ on affected inguinal and pelvic areas, combined with mitomycin C (intravenous bolus injection 10mg/m2, maximum $15 \mathrm{mg}$ ) on day one and capecitabine ( $825 \mathrm{mg} / \mathrm{m} 2$ twice daily) on radiation days. Primary tumours and PET/ CT-positive tumour deposit received a higher dose of 59.5 in daily fractions of 1.8 Gy. Responses were measured according to the PERCIST criteria for PET/CT response evaluation. Patients with incomplete responses were eligible for salvage surgery or palliative therapy.

Results and Limitations: 40 patients were included. All but one completed CRT. One-year and two-year PFS were 32\%. Overall survival was 70\% and 52\% respectively (median follow-up of 27 months). Upon first evaluation, responses were complete (35\%), partial (35\%) and progressive disease (30\%). At the end of follow-up, sixteen patients (40\%) are alive with no evidence of disease. Sixteen patients (40\%) experienced one or more therapy related severe toxicity (all grade 3) during therapy or follow-up. No therapy related grade 4 or 5 events occurred. Disease recurred or progressed in 26 patients, six had in-field failure only, six had failure outside the irradiated field only, seven had both. This study is limited by its small sample size and lack of direct comparison to treatment alternatives.

Conclusion: CRT is feasible for LAPSCC. It has acceptable survival and toxicity rates, reduces the necessity of surgical resection and can result in long-term disease free survival. 


\section{INTRODUCTION}

Penile cancer is a rare malignancy. The majority of patients can be cured with surgery alone if they have no or minimal lymph node metastases. ${ }^{1}$ However, the treatment of locoregionally advanced penile cancer (LAPSCC) remains challenging. Surgical removal only of large, multiple or pelvic lymph node metastases, as well as large primary tumours, can be burdensome and lead to disappointing disease control. ${ }^{2-6}$ Therefore multimodal treatment is considered essential for advanced disease. ${ }^{7}$ The most applied combination so far is neoadjuvant chemotherapy followed by surgery. Yet, even with neoadjuvant or adjuvant chemotherapy, survival rates are unsatisfactory (1-year overall survival (OS) approx. 50\%) and toxicity is high (grade $3-4$ events in up to $65 \%$ of patients). ${ }^{8-12}$

Chemoradiotherapy (CRT) plays an important role in the management of other squamous cell carcinomas such as anal carcinoma, gynaecological tumours and head and neck carcinoma. ${ }^{13-15}$ Its role in penile cancer management has been described in smaller series and case reports, but remains largely unknown. ${ }^{16,17}$

In this observational study, we evaluated the therapeutic value of CRT for LAPSCC in terms of survival, toxicity and local control.

\section{PATIENTS \& METHODS}

\section{Participants}

We conducted an observational cohort study in LAPSCC patients fit for CRT. Locally advanced tumour was defined as cT4, tumours with satellite lesions, tumours with a very large surface, tumours in the penile basis/bulb or tumours where radical resection was deemed unattainable. Regionally advanced tumour was defined as palpable nodes $>3 \mathrm{~cm}$ in diameter (cN2-3), fixed nodes or suspicion of extranodal extension (ENE) on imaging, or pelvic nodal involvement (cN3). LAPSCC definition included no evidence of distant metastases on baseline 18-fluorodeoxyglucose (FDG) positron emission tomography (PET) with computer tomography (CT). All patients were discussed in multidisciplinary tumour board meetings. Surgery prevailed CRT for primary tumours.

This study was approved by the institutional medical ethical committee (institutional study numbers X15PEN and N15PEN), and all participants gave written informed consent. 


\section{Chemoradiotherapy}

CRT consisted of simultaneous integrated boost (SIB) intensity modulated radiotherapy (IMRT) 49.5 Gy in 33 daily fractions of 1.5 Gy on affected inguinal and pelvic areas. This was combined with mitomycin C (intravenous bolus injection $10 \mathrm{mg} / \mathrm{m} 2$, maximum $15 \mathrm{mg}$ ) on day one and capecitabin on radiation days (825 $\mathrm{mg} / \mathrm{m} 2$ twice daily, or an adjusted dose when diagnosed with DPD-deficiency). Primary tumours and PET/CT-positive tumour deposit received a higher dose (integrated boost) of 59.5 Gy in daily fractions of $1.8 \mathrm{~Gy}$. Tumour deposits could shrink substantially during treatment, necessitating an adjusted radiation field in some patients.

\section{Response Evaluation \& Follow-up}

Physical examination was repeated three weeks after completion of therapy. Six weeks after completion of CRT, an FDG-PET/CT was used for response evaluation, according to the PERCIST criteria for PET/CT response evaluation. Follow-up consisted of three-monthly outpatient visits to the urologist of our institute, including physical examination and an ultrasound of the inguinal nodes, with fine-needle aspiration cytology and a PET/CT scan. Deviations happened on indication and were discussed in the multidisciplinary tumour board.

\section{Salvage Surgery \& Palliative Therapy}

Non-responders and partial responders with residual disease were offered salvage surgery for local disease (primary tumour) and/or inguinal and/or pelvic lymph nodes. Delayed salvage surgery was also offered to patients with locoregional recurrence or progression. If curation was not deemed possible, patients could progress with palliative therapy. Salvage surgery and palliative treatment was not considered part of study treatment.

\section{Endpoints and Outcome Measurements}

The primary endpoint was 1-year progression free survival (PFS). Secondary endpoints were 2-year PFS, overall survival (OS), local control, and serious adverse events during therapy and follow-up.

Progression free survival was measured in months from start of CRT treatment to date of progression or recurrence. A mixed response was also considered progression. Overall survival was measured from date of start treatment to date of death. 
Response was measured on PET/CT imaging according to PERCIST criteria. Also, if salvage surgery was done, pathology analysis was used as a measure for response.

Toxicity, complications and other complaints were classified according to the Common Terminology Criteria for Adverse Events (CTCAE) version 4.0. Adverse events (AE's) are grouped into therapy-related AE's, disease-related AE's and other AE's.

Therapy-related AE's are those that are regarded as (possibly) CRT related. Disease related AE's are complaints caused directly by penile tumours or metastases (e.g. tumour pain or urinary tract obstruction as a result of tumour growth). AE's classified as of other cause include complications of salvage surgery after CRT, complications of previous surgery (e.g. urostomy stenosis after partial penectomy), and other adverse events during therapy or follow-up. We excluded toxicity related to palliative therapy, and complaints in the very terminal phase can be considered incomplete as most patients were attended by their family doctor at that time.

\section{Statistical Analysis}

Median follow-up was estimated with the inversed Kaplan-Meier method. For progression free survival and overall survival, the Kaplan-Meier was used. Descriptive statistics was done with SPSS v24 (IBM SPSS Statistics, Version 24, (C) IBM Corp.).

\section{RESULTS}

Between March 2014 and November 2018, we included 40 patients (characteristics summarized in Table 1). All patients were treated with curative intent, 29 cases with primary disease, eleven with recurrent disease.

All but one patient, were able to finish CRT. That patient had radiation therapy for a lymphoma in the past and suffered from substantial skin toxicity in the overlapping area at day ten of treatment. He stopped therapy and proceeded with palliative radiation therapy on a single painful lesion.

Seven additional patients underwent an adjusted regimen of CRT. In three patients this was due to toxicity, in four patients this was due to other reasons: 


\section{Chapter 8}

one had an inguinal hernia (lower RT dose), one received a higher RT dose (66Gy) on a primary tumour, one received an adjusted schedule (25×2Gy) on a prepubic lesion, the last patient received mitomycin instead of capecitabin because of a poor kidney function at baseline.

Table 1: Patient characteristics

\begin{tabular}{|c|c|c|}
\hline Patients included & & 40 \\
\hline Median age (IQR) & & $64(42-82)$ \\
\hline WHO performance score & $0 / 1 / 2$ & 24/15/1 \\
\hline Setting & Primary / recurrent & $29 / 11$ \\
\hline cT stage* & $\begin{array}{c}\text { x or } 0 \\
1 \\
2 \\
3 \\
4\end{array}$ & $\begin{array}{c}6 \\
3 \\
11 \\
16 \\
4\end{array}$ \\
\hline cN stage* $\sim$ & $\begin{array}{c}\text { x or } 0 \\
1 \\
2 \\
3 \text { (with pelvic LN) }\end{array}$ & $\begin{array}{c}3 \\
1 \\
5 \\
31(25) \\
\end{array}$ \\
\hline $\begin{array}{l}\text { Histological or cytological } \\
\text { proof inguinal lymph node } \\
\text { metastasis }\end{array}$ & $\begin{array}{l}\mathrm{pNx} \\
\mathrm{pNO} \\
\mathrm{pN}+\end{array}$ & $\begin{array}{c}5 \\
1 \\
34 \\
\end{array}$ \\
\hline Clinical stage & $\begin{array}{l}\mathrm{Ilb} \\
\mathrm{IIla} \\
\mathrm{IIIb} \\
\mathrm{IV}\end{array}$ & $\begin{array}{c}2 \\
1 \\
4 \\
33 \\
\end{array}$ \\
\hline CRT field & $\begin{array}{c}\text { Primary tumour region } \\
\text { Lymph nodes } \\
\text { Both }\end{array}$ & $\begin{array}{c}1 \\
25 \\
14\end{array}$ \\
\hline
\end{tabular}

*Staging according to 2017 TNM classification. At physical examination or imaging.

\section{Response, Locoregional control and recurrences}

Upon first evaluation after therapy (mean 6.7 weeks after therapy), fourteen patients (35\%) had a complete response, another fourteen patients (35\%) had a partial response, and twelve patients (30\%) showed progression (the latter including four patients with mixed response). Twenty-five patients (63\%) achieved a complete remission of disease during the study period. However, only sixteen of them (40\% of total cohort) were disease free at the end of follow-up. Responses and endpoints are listed in Table 2, disease course of all patients is graphically depicted in Figure 1. 


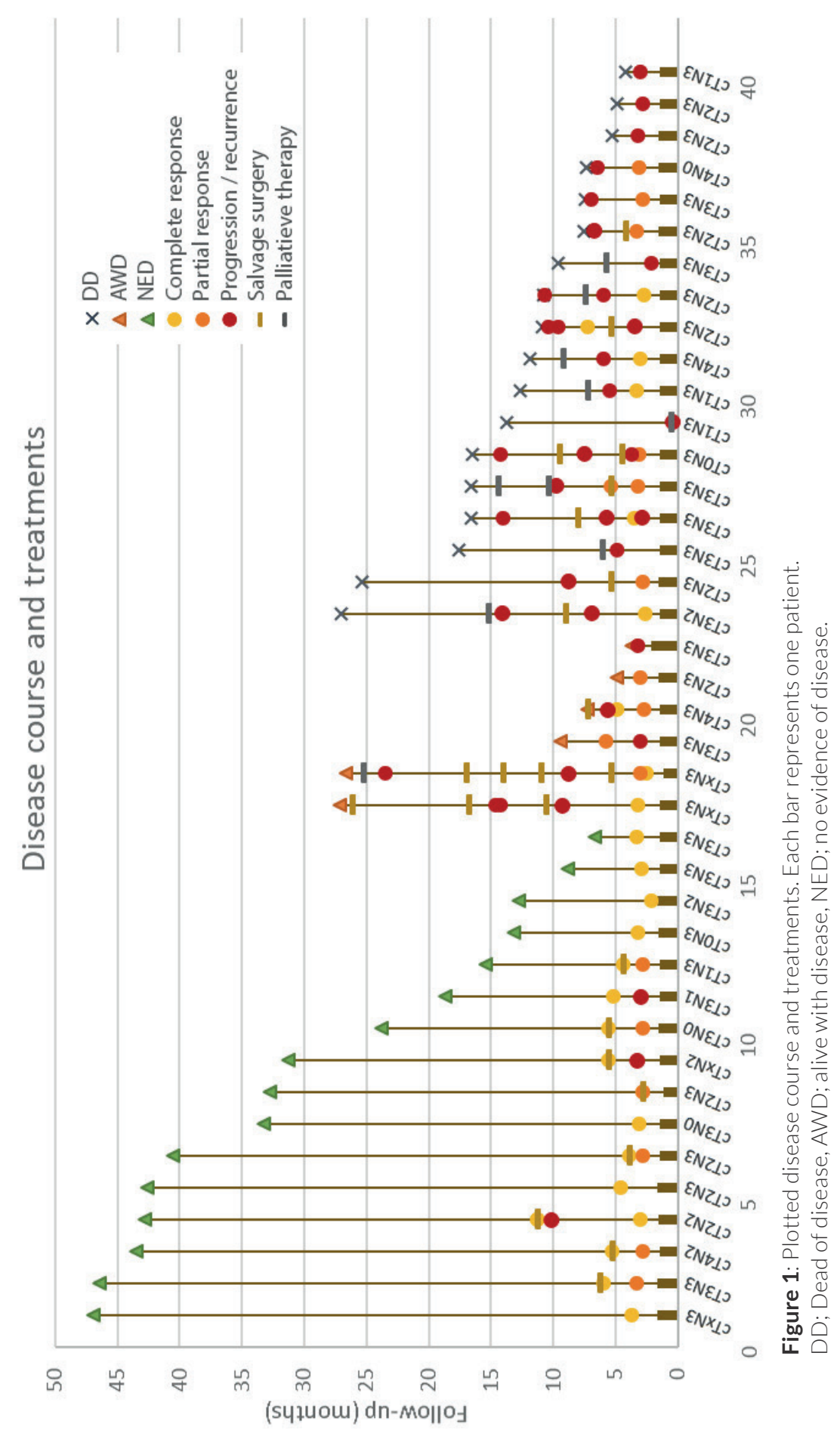


Fourteen patients remained free of recurrence or progression during followup, half of them with initial complete response, the other half with initial partial response. Disease recurred or progressed (so-called treatment failures) in 26 patients, seven of whom had multiple failures during the study period. Thirteen of 26 patients had in-field failures (50\%), four with initial complete response, four with initial partial response, five with failure upon first evaluation. Of six patients with out-field failure only, just one initially responded to CRT (partial responder). Of seven patients that failed both in and out of the radiated fields, three had initially responded completely to CRT, two initially had a partial response.

\section{Salvage Surgery \& Palliative Therapy}

A schematic overview of additional treatments such as salvage surgery and palliative therapies is provided in Figure 2. In total, nineteen patients underwent either immediate (after first response evaluation, $n=11$ ), delayed (median 8.0 months, $n=7$ ) or palliative $(n=1)$ surgical resection. Surgery included the primary tumour $(n=6)$, lymph nodes $(n=10)$, or both $(n=3)$. Immediate surgery was done at a median of 5.4 months after start of chemoradiation therapy (range 2.8-5.6). Delayed surgery was done at a median of 8.0 months after start of chemoradiation therapy (range 4.5-11.3). The indication for additional surgery was: recurrence, progression, or persistent disease defined as ambiguity or residual metabolic activity. One resection was done only for palliative reasons.

Of fourteen complete responders, four patients (29\%) underwent immediate or delayed salvage surgery. Of fourteen partial responders, eleven underwent salvage surgery (79\%). Palliative treatment was given to nine patients.

\section{Survival}

Median follow-up was 27 months (95\%CI[20-35]). All deaths were penile cancer related. PFS was 32\% at both 1 and 2 years (Figure 3). Median time to progression was 6.9 months (95\%Cl[3.7-10.1]). Progression/recurrence during the second year of follow-up did occur only in patients who previously had progression, recurrence or a mixed response in the first year. In other words, all patients that remained free of progression or recurrence in the first year $(n=11)$, remained progression-free for the rest of their follow-up.

Of the entire cohort, 1- and 2-year OS was 70\% and 52\% respectively (Figure 4). Median OS was 25.3 months (95\%CI[9.7-41.0]). Of those with progression, 1- and 2-year OS was 55\% and 31\% respectively (median just over one year but with a very wide confidence interval (95\% Cl[6.6-20.9]). 


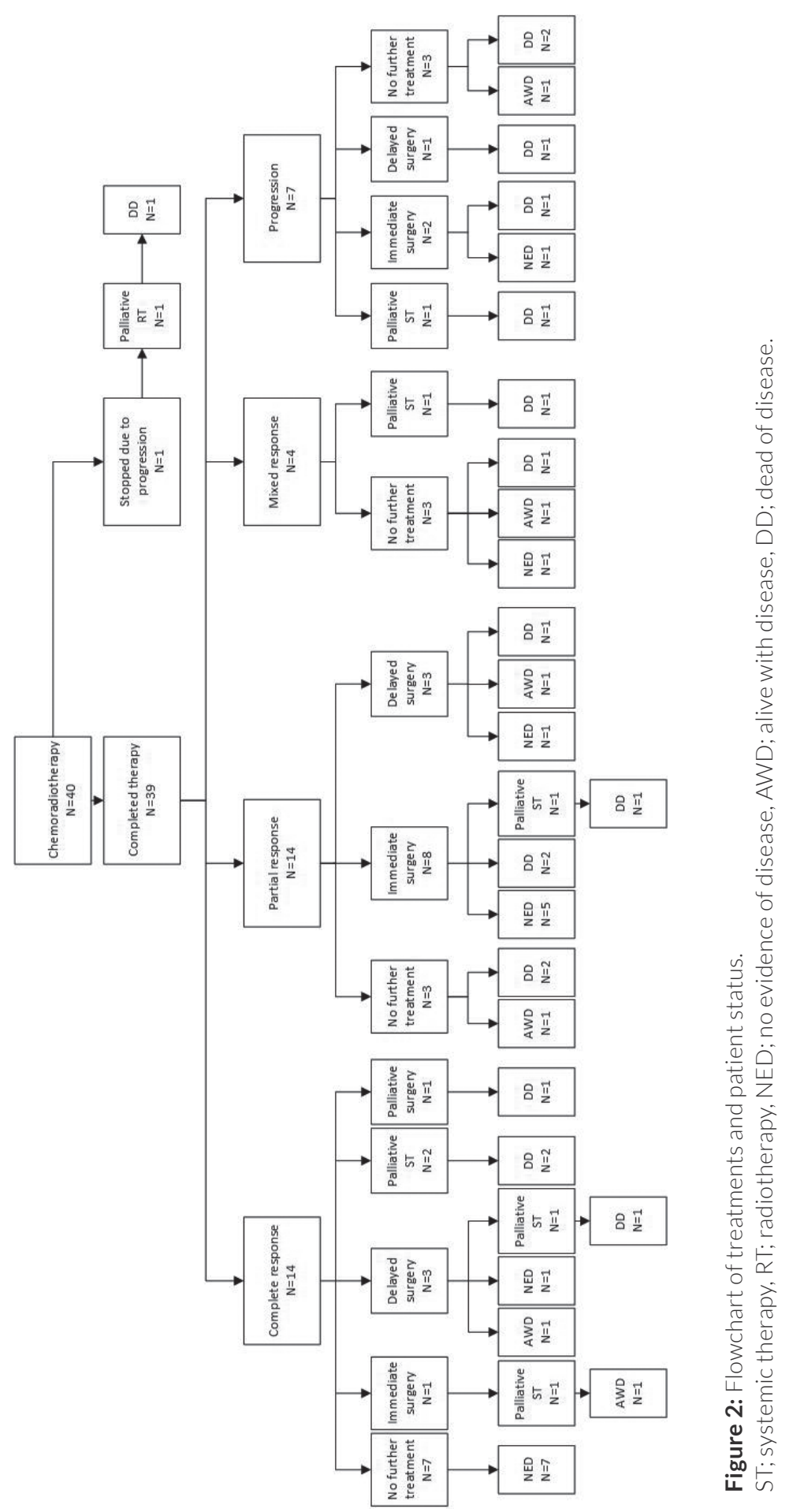


Chapter 8

Table 2: Response to treatment, failures and patient status

\begin{tabular}{|c|c|c|c|c|c|c|c|}
\hline \multirow[t]{2}{*}{ Initial response } & \multicolumn{3}{|c|}{ Best response* } & Failures & \multicolumn{3}{|c|}{ Status at end of follow-up } \\
\hline & $\mathrm{N}$ & & $\mathrm{N}$ & $\mathrm{N}$ (multiple*) & NED & AWD & $\mathrm{DD}$ \\
\hline Complete & 14 & Complete & 14 & $\begin{array}{r}\text { In-field } 4(2) \\
\text { Both } 3(1)\end{array}$ & 8 & 2 & 4 \\
\hline \multirow[t]{2}{*}{ Partial } & 14 & Complete & 7 & In-field 1 & 6 & 1 & 0 \\
\hline & & Partial & 7 & $\begin{aligned} \text { In-field } & 3 \\
\text { Out-field } & 1(1) \\
\text { Both } & 2\end{aligned}$ & 0 & 1 & 6 \\
\hline \multirow[t]{3}{*}{ Progression } & 12 & Complete & 4 & In-field 4(2) & 2 & 0 & 2 \\
\hline & & Partial & 1 & Out-field 1 & 0 & 1 & 0 \\
\hline & & Progression & 7 & $\begin{array}{rr}\text { In-field } & 1 \\
\text { Out-field } & 4 \\
\text { Both } & 2\end{array}$ & 0 & 1 & 6 \\
\hline Total & 40 & & 40 & 26 & 16 & 6 & 18 \\
\hline
\end{tabular}

Responses according to PERCIST criteria. * Response to CRT or remission achieved during study period. NED; no evidence of disease, AWD; alive with disease, DD; dead of disease.

*later failures include in-field failure, out-field failure and/or both.

\section{Toxicity}

All toxicities and surgical complications are described in Table 3. No therapy related deaths occurred. One patient (2,5\%) discontinued therapy because of toxicity in the radiated field (described under participants). Three patients $(7,5 \%)$ stopped capecitabin early or continued with a lower dose. One of them received an extra course of intravenous mitomycin.

In total, 114 events were registered: 72 grade 2, 39 grade 3 , and 3 grade 4 events. Thereof, respectively 50 grade 2 and 22 grade 3 events were (possibly) therapy related. All three grade 4 events were septicaemia, two wound infections after ILND, and one exceptional case of an abdominal sepsis due to intestinal metastatic lesions causing faecal leakage.

Seven patients (18\%) finished therapy and follow-up with only mild therapy related symptoms (grade 1 toxicity), five of them who also did not experience disease related or other symptoms.

Sixteen of 40 patients (40\%) experienced one or more (possibly) therapy related grade 3 toxicity during therapy or follow-up. The majority (11/16, 69\%) with onset during therapy, two with onset before therapy (tumour pain and a 
skin infection) and four with onset during follow-up (worsening skin problems, anaemia and lymphedema).

Seventeen surgery-related events were registered in 9 patients that underwent lymph node surgery. Lymphedema was mostly due to Iymph node dissection, only two patients had Iymphedema due to the study treatment (three events, as one later progressed from grade 2 to grade 3 ).

Overall, toxicities were transient. Ofall 114 registered toxicities and complications, 20 (18\%) resolved within a week, an additional 56 events (49\%) resolved within one month. Only four events (3,5\%, all lymphedema) lasted longer than a year.

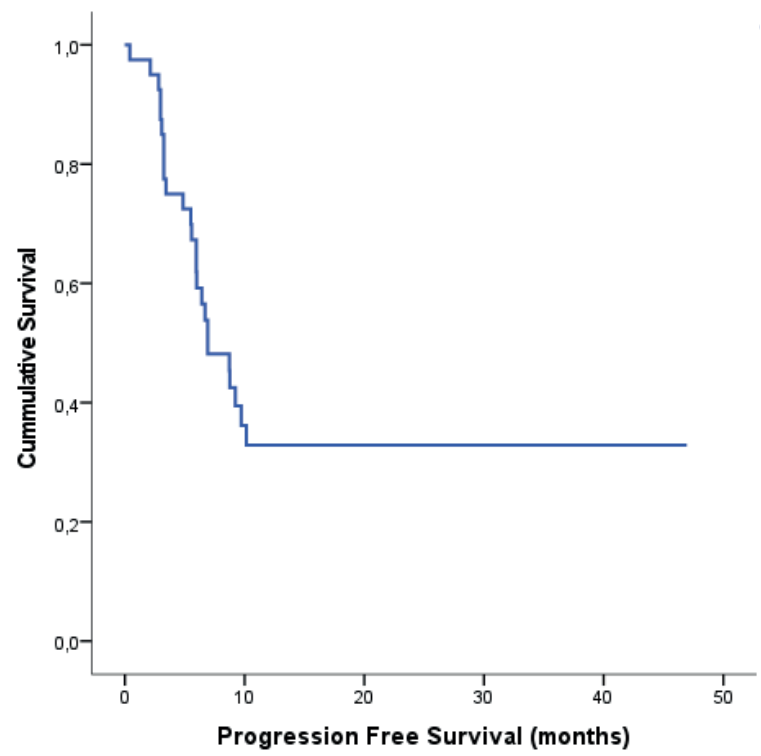

Figure 3: Progression free survival according to Kaplan-Meier estimates

\begin{tabular}{lccccc}
\hline Time interval & $\mathbf{1} \mathbf{y r}$ & $\mathbf{2} \mathbf{y r}$ & $\mathbf{3} \mathbf{y r}$ & $\mathbf{4} \mathbf{y r}$ & $\mathbf{5} \mathbf{y r}$ \\
\hline No at risk & 40 & 11 & 7 & 5 & 0 \\
Events & 26 & 0 & 0 & 0 & - \\
Cum. PFS & $32 \%$ & $32 \%$ & $32 \%$ & $32 \%$ & - \\
\hline
\end{tabular}




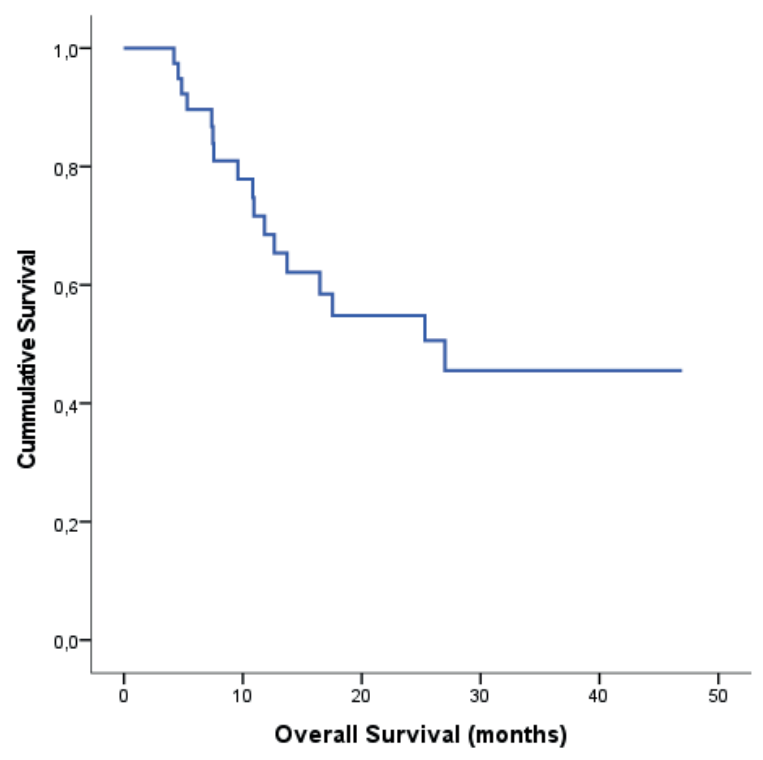

Figure 4: Overall survival according to Kaplan-Meier estimates

\begin{tabular}{lccccc}
\hline Time interval & $\mathbf{1} \mathbf{y r}$ & $\mathbf{2} \mathbf{y r}$ & $\mathbf{3 y r}$ & $\mathbf{4} \mathbf{y r}$ & $\mathbf{5} \mathbf{y r}$ \\
\hline No at risk & 40 & 22 & 13 & 6 & 0 \\
Events & 11 & 5 & 2 & 0 & - \\
Cum. OS & $70 \%$ & $52 \%$ & $42 \%$ & $42 \%$ & - \\
\hline
\end{tabular}

\section{Histopathological findings after surgery}

No vital tumour cells were found in resected tissue of six patients that were suspected of tumour deposits. In four of these patients this regarded the groin where surgery was preceded by tumour-positive fine needle aspiration cytology (FNAC) 5-8 weeks earlier. For the other two, PET/CT showed a partial response (of the primary tumour in one patient, of the groins in the other). None of these six patients had a disease recurrence during follow up.

Vital tumour cells were found in thirteen cases; in seven patients after immediate surgery, in five patients after delayed surgery, in one after palliative resection. After immediate resection of vital tumour deposits, two patients remained free of disease recurrence. After delayed surgery and finding vital tumour deposits, only one patient remains free of recurrence (but had no follow-up imaging after surgery yet, classified alive with disease). 
Fifteen patients were treated with CRT on their primary tumour lesions. Nine of them $(9 / 15=60 \%)$ received either immediate $(n=4)$ or delayed $(n=5)$ surgical resection. Histopathological evaluation showed no vital tumour cells in four, and vital tumour residue in five patients. No relation was found between timing of surgery and pathological results.

Table 3: Toxicities and surgical complications

UTI; urine tract infection.

\begin{tabular}{|c|c|c|c|c|c|c|}
\hline \multirow[b]{2}{*}{ Skin } & \multicolumn{3}{|c|}{ Grade 2} & \multicolumn{3}{|c|}{ Grade 3/4 } \\
\hline & Therapy & Disease & Unrelated & Therapy & Disease & Unrelated \\
\hline Radiation dermatitis & 19 & - & - & 9 & - & - \\
\hline Other skin problems & 1 & - & - & 2 & - & - \\
\hline \multicolumn{7}{|l|}{ Gastro-intestinal } \\
\hline Diarrhoea/radiation enteritis/cystitis & 4 & - & & 1 & & - \\
\hline Nausea/anorexia/vomiting & 2 & - & - & - & & 1 \\
\hline Weight loss & 2 & - & & - & & - \\
\hline Dysphagia & - & - & - & - & - & 1 \\
\hline \multicolumn{7}{|l|}{ Local } \\
\hline Pain & 8 & 2 & 1 & 1 & 1 & - \\
\hline Urethral/meatal obstruction & 3 & 2 & 1 & - & 1 & - \\
\hline Urinary fistula & - & 1 & & - & & - \\
\hline Genital infections & - & 1 & - & - & 1 & - \\
\hline \multicolumn{7}{|l|}{ General } \\
\hline Anaemia & 2 & - & - & 1 & - & - \\
\hline Electrolytes/other laboratory findings & 4 & 1 & & 2 & & - \\
\hline Collapse & - & - & & 1 & & 1 \\
\hline Thrombo-embolic event & - & - & - & - & 1 & - \\
\hline UTI & - & - & 1 & - & - & - \\
\hline Infections (other than local or wound) & - & - & 2 & 2 & 1 & 2 \\
\hline Fatigue/dyspnoea & 3 & 1 & - & 1 & & - \\
\hline Fever e.c.i. & - & - & 1 & - & - & - \\
\hline Malaise & - & - & - & 1 & - & - \\
\hline \multicolumn{7}{|l|}{ Groins and wounds } \\
\hline Inguinal wound infections/seroma & - & - & 4 & - & $\begin{array}{c}1 \\
\text { (sepsis) }\end{array}$ & $\begin{array}{c}5 \\
\text { (2 sepsis) }\end{array}$ \\
\hline Wound dehiscence & - & - & 1 & - & - & - \\
\hline Lymphedema & 2 & - & 3 & 1 & - & 4 \\
\hline Total & 50 & 8 & 14 & 22 & 6 & 14 \\
\hline Total per grade & \multicolumn{3}{|c|}{72 grade 2} & \multicolumn{3}{|c|}{42 grade $3 / 4$} \\
\hline
\end{tabular}




\section{Chapter 8}

The same was found for salvage surgery of the groins. Thirty-nine patients underwent CRT of one or both groins, thirteen underwent immediate $(n=8)$ or delayed ( $n=5$ ) lymphadenectomy. Six with no vital tumour, seven with vital tumour residue, and no relation between timing of surgery and pathological results.

\section{DISCUSSION}

This study shows that CRT (mitomycin, six weeks of capecitabin and radiation) is a well-tolerated treatment for patients with advanced stages of disease. We found 1 - and 2-year PFS of 32\%. Overall survival was $70 \%$ and $52 \%$ respectively (median follow-up of 27 months). These survival rates are comparable to those of other multimodal approaches. Despite a toxicity rate of 40\% (grade 3 therapy related events), CRT appeared less toxic than neoadjuvant chemotherapy because complaints were mostly transient and therapy could be continued. These study results mean that CRT is a treatment alternative to neoadjuvant chemotherapy or adjuvant radiation with surgical resection.

In studies with neoadjuvant chemotherapy, some find lower toxicity rates, but high rates are not unusual.4,10,12,18,19 In our experience with neoadjuvant chemotherapy (TPF) for locoregionally advanced disease, $23 \%$ of the patients had to stop therapy due to toxicity, an additional 30\% because of disease progression. This contrasts with only one patient discontinuing in the current study. Furthermore, in just over half of the patients in current study surgery was avoided.

In terms of progression free and overall survival current results resemble previous findings, although response rates vary in previous studies. ${ }^{8,10,12,20}$ In aforementioned TPF cohort 1-year PFS was 31\%, (32\% in the current cohort), and further decreased to $12 \%$ after 2 years, while in current cohort the remainder of patients stayed free of recurrence. ${ }^{8}$ OS seems better in current cohort, $70 \%$ vs. $46 \%$ in the first year of follow up, and $52 \%$ vs. $27 \%$ in the second year. This may be partly explained by including lower stages of disease, as current study also included bulky T3 tumours and large inguinal lymph nodes (cN2) instead of only T4 and N3 disease.

A study by Kent et al. described chemoradiation in a cohort $(n=26)$ of men with primary urethral carcinomas. One year disease free survival was 61\%, 1-year disease specific survival was 83\%. Their higher rates of disease control and survival is probably due to earlier disease stages in their cohort: only nine 
patients had nodal disease (N2 at worst). ${ }^{21}$ Their results also suggest that trials with chemoradiation in lower stages of penile cancer may be of value.

A Danish study cohort recently described CRT adjuvant to ILND for inguinal Iymph nodes with extranodal extension (N3). In only one of eleven patients PLND was performed. The 5-year penile cancer survival probability was 57\%, which is comparable to survival rates described by Li et al for the N3 patients without positive pelvic lymph nodes. ${ }^{22,23}$ The Danish penile cancer study group shows that CRT can be used as curative therapy instead of a prophylactic PLND. Whether this reduces toxicity remains unestablished. Neither the population or the setting of CRT is comparable to our current study.

In this study we were unable to identify the optimal timing of salvage surgery, the optimal timing of response measurement, or the reliability of response measurements. Based on few cases in our study, CRT may not be feasible for previously irradiated areas and fine needle aspiration biopsy may not be reliable in discriminating PET-positive nodes with and without residual disease. The cases where FNAC showed tumour cells but surgery did not suggest that a treatment effect is ongoing in the weeks between. Also, the role of CRT in pain control is insufficiently evaluated in this cohort. A few patients had remarkably less pain during treatment then before, however, some patients had pain due to tumour necrosis or tumour growth.

Showing that CRT is an alternative treatment is important because treatment of advanced stages is burdensome and despite treatment associated with rapid disease course. Optimizing treatment combinations in a multimodal approach is essential in order to improve patient outcomes. In comparison to perioperative chemotherapy studies, the omission of surgery is a potential advantage of CRT, with only half of our patients proceeding to surgery, compared to over $75 \%$ with perioperative chemotherapy. ${ }^{8,10}$

Our findings are subject to several limitations. This is a small observational cohort study, despite being the largest so far, with inherent bias due to the design. As penile cancer is a rare disease (in total $n=150$ per year in the Netherlands), a randomized trial was not feasible. ${ }^{24}$ Therefore, only indirect comparisons to treatment alternatives such as neoadjuvant chemotherapy can be made. 


\section{Chapter 8}

Secondly, no quality of life (QOL) data in the form of patient reported outcome measures (PROMs) were collected. With the ultimate goal not only to improve survival but also patient's QOL, we feel the lack of PROMs as a serious omission.

Lastly, we did not determine human papilloma virus (HPV) positivity in tumour samples of our subjects. HPV+ penile tumours have better disease outcomes, and a better response to CRT is shown for $\mathrm{HPV}^{+}$tumours on other sites.25,26

Strengths of this study include a single centre design where all treatment decisions were made by an experienced multidisciplinary team, and the novelty of primary CRT as a treatment approach for penile cancer. Further follow up of this cohort will provide more insights in response endurance and survival. More experience with CRT and other (multicentre) studies will also aid treatment optimization.

\section{Conclusions}

Chemoradiotherapy is feasible as a treatment for advanced non-metastatic penile cancer, with a median OS of 23 months, and an enduring remission in $>25 \%$ of patients. Associated toxicity rate is acceptable (40\%). Although salvage surgery following CRT is feasible, it can be avoided in $50 \%$ of patients.

\section{Acknowledgements}

We thank Dr. Erik Vegt for helping with the PET/CT measurements. We thank the trial data registration department for their help. 


\section{REFERENCES}

1. Lont AP, Kroon BK, Gallee MPW, et al: Pelvic lymph node dissection for penile carcinoma: extent of inguinal lymph node involvement as an indicator for pelvic lymph node involvement and survival. J. Urol. 2007; 177: 947-52; discussion 952.

2. Stuiver MM, Djajadiningrat RS, Graafland NM, et al: Early wound complications after inguinal lymphadenectomy in penile cancer: a historical cohort study and riskfactor analysis. Eur. Urol. 2013; 64: 486-492.

3. Houédé N, Dupuy L, Fléchon A, et al: Intermediate analysis of a phase II trial assessing gemcitabine and cisplatin in locoregional or metastatic penile squamous cell carcinoma. BJU Int. 2016; 117: 444-449.

4. Dickstein RJ, Munsell MF, Pagliaro LC, et al: Prognostic factors influencing survival from regionally advanced squamous cell carcinoma of the penis after preoperative chemotherapy. BJU Int. 2014; 117: 118-125.

5. Zhang K, Wan X, Xu H, et al: Surgical treatment of advanced penile cancer. J. Cancer Res. Clin. Oncol. 2017.

6. Verhoeven RHA, Janssen-Heijnen MLG, Saum KU, et al: Population-based survival of penile cancer patients in Europe and the United States of America: no improvement since 1990. Eur. J. Cancer 2013; 49: 1414-1421.

7. Hakenberg OW, Compérat E, Minhas S, et al: EAU Guidelines on Penile Cancer. 2020. Available at: https://uroweb.org/guideline/penile-cancer/, accessed August 22, 2020.

8. Djajadiningrat RS, Bergman AM, van Werkhoven E, et al: Neoadjuvant taxanebased combination chemotherapy in patients with advanced penile cancer. Clin. Genitourin. Cancer 2015; 13: 44-49.

9. Necchi A, Pond GRGR, Raggi D, et al: Clinical Outcomes of Perioperative Chemotherapy in Patients With Locally Advanced Penile Squamous-Cell Carcinoma: Results of a Multicenter Analysis. Clin. Genitourin. Cancer 2017; 15

10. Pagliaro LC, Williams DL, Daliani D, et al: Neoadjuvant paclitaxel, ifosfamide, and cisplatin chemotherapy for metastatic penile cancer: a phase II study. J. Clin. Oncol. 2010; 28: 3851-3857.

11. Hakenberg OW, Nippgen JBW, Froehner M, et al: Cisplatin, methotrexate and bleomycin for treating advanced penile carcinoma. BJU Int. 2006; 98: 1225-1227.

12. Nicholson S, Hall E, Harland SJ, et al: Phase II trial of docetaxel, cisplatin and 5FU chemotherapy in locally advanced and metastatic penis cancer (CRUK/09/001). Br. J. Cancer 2013; 109: 2554-2559.

13. Valvo F, Ciurlia E, Avuzzi B, et al: Cancer of the anal region. Crit. Rev. Oncol. Hematol. 2019; 135: 115-127.

14. Moore DH: Chemotherapy and radiation therapy in the treatment of squamous cell carcinoma of the vulva: Are two therapies better than one? Gynecol. Oncol. 2009; 113: 379-383.

15. Strigari L, Pinnaro P, Carlini P, et al: Efficacy and mucosal toxicity of concomitant chemo-radiotherapy in patients with locally-advanced squamous cell carcinoma of the head-and-neck in the light of a novel mathematical model. Crit. Rev. Oncol. Hematol. 2016; 102: 101-110. 


\section{Chapter 8}

16. Lapierre A, Riou O, Flechon A, et al: Advanced penile cancer with iliac lymph node involvement treated with radiation and concurrent gemcitabine. Cancer Radiother. 2017; 21: 134-137.

17. Yuan Z, Naghavi AO, Tang D, et al: The relationship between HPV status and chemoradiotherapy in the locoregional control of penile cancer. World J. Urol. 2018.

18. Hussein AM, Benedetto $P$ and Sridhar KS: Chemotherapy with cisplatin and 5-fluorouracil for penile and urethral squamous cell carcinomas. Cancer 1990; 65: 433-438.

19. Theodore C, Skoneczna I, Bodrogi I, et al: A phase II multicentre study of irinotecan (CPT 11) in combination with cisplatin (CDDP) in metastatic or locally advanced penile carcinoma (EORTC PROTOCOL 30992). Ann. Oncol. Off. J. Eur. Soc. Med. Oncol. 2008; 19: 1304-1307.

20. Leijte JAP, Kerst JM, Bais E, et al: Neoadjuvant chemotherapy in advanced penile carcinoma. Eur. Urol. 2007; 52: 488-94.

21. Kent M, Zinman L, Girshovich L, et al: Combined chemoradiation as primary treatment for invasive male urethral cancer. J. Urol. 2015; 193: 532-537.

22. Maibom SL, Jakobsen JK, Aagaard M, et al: DaPeCa-4: outcome in penile cancer patients with N3 disease due to extra nodal extension treated with surgery and chemo-irradiation. Scand. J. Urol. 2020; 54: 334-338.

23. Li ZZ, Guo S, Wu Z, et al: Subclassification of pN3 staging systems for penile cancer: Proposal for modification of the current TNM classification. Urol. Oncol. 2017; 35: 543.e1-543.e6.

24. Anon: NKR-cijfers / IKNL. Ned. Kankerregist. (NKR), IKNL 2020. Available at: iknl. $\mathrm{nl} / \mathrm{nkr}$-cijfers.

25. Glynne-Jones R, Saleem W, Harrison M, et al: Background and Current Treatment of Squamous Cell Carcinoma of the Anus. Oncol. Ther. 2016; 4: 135-172.

26. Korzeniowski MA and Crook JM: Contemporary role of radiotherapy in the management of penile cancer. Transl. Androl. Urol. 2017; 6: 855-867. 





Chapter 9

General discussion and future prospects 


\section{GENERAL DISCUSSION AND FUTURE PROSPECTS}

Penile cancer is a rare but potentially mutilating and lethal disease. Disease management has evolved towards penile sparing surgery for primary tumours and minimally invasive staging of lymph node metastases (sentinel node biopsy). The majority of patients have no metastases at presentation, a smaller part (1020\%) presents with lymph node metastases (LNM) or worse. Curing metastatic disease can be challenging, especially with LNM and extranodal extension or with pelvic LNM.

In this thesis we focussed on the advanced stages of penile cancer: we found targets for new therapies, we described early detection of metastases, and we evaluated the current surgical treatment and an experimental treatment for advanced disease.

\section{Immunology and immunotherapy}

The patients' immune system plays a critical role in various tumour types, including squamous cell carcinomas. Immunomodulatory mechanisms exploited by malignant cells aim to cripple or bypass anti-tumour immunity. One of these mechanisms is targeting key signalling events for T-cell responses such as coinhibitory or co-stimulatory molecules, also known as check-points. Although the introduction of checkpoint inhibitors has revolutionized the treatment of advanced stages of cancer, only a small percentage of patients responds to this treatment and biomarkers to predict response to immunotherapy are currently an active field of investigation. Even well-studied checkpoint markers such as PD$\mathrm{L} 1$ and PD-1 are imperfect selectors for immunotherapy. ${ }^{1-4}$

Different immune escape mechanisms have been described in penile cancer, amongst other in chapter 2 and chapter 3..$^{5-10}$ The results presented in this thesis show that primary penile tumours use different immune escape mechanisms, including PD-L1, non-classical HLA, regulatory T-cells and immunemodulating macrophages. Chapter 2 describes that almost half (48\%) of penile tumours express PD-L1. Of the PD-L1 positive tumours, a pattern of expression mainly at the tumour margin is associated with a better survival while a diffuse expression pattern is associated with worse survival. In chapter 3 PD-L1 expression is analysed together with hrHPV status, HLA class I expression, presence of regulatory and cytotoxic T-cells and presence of tumour infiltrating myeloid cells. In univariable analysis, unfavourable clinical outcomes were associated with tumour PD-L1 expression, negative hrHPV status, presence of CD163 ${ }^{+}$tumour 
infiltrating macrophages, non-classical HLA class I upregulation and low stromal CD8 ${ }^{+}$T-cell infiltration. In multivariable analysis, PD-L1 expression and HPVstatus remained significant predictors of outcome. Although this is the most comprehensive immunohistochemical study so far and the results favour trials of immunotherapy in penile cancer treatment, the complexity and dynamic immune cell-tumour interplay of the TME is far from unravelled. We have not analysed activation status of T-cells, nor expression of checkpoint molecules on T-cells (e.g., PD-1, CTLA-4, TIM3, LAG3) on tumour cells, we have not performed proximity analysis, nor have we studied soluble immunemodulating factors (e.g. IFNY), etcetera. Moreover, both studies regard primary tumours, and most patients die from metastases.

Unpublished work from our group (manuscript in preparation), focused on a comprehensive analysis of the various T-cell subsets present in $\mathrm{HPV}^{+}$and HPV ${ }^{-}$ primary penile tumours and tumour draining lymph nodes. Multicolour flowcytometry was performed on fresh material from resected inguinal lymph nodes of penile cancer patients in a similar manner as previously published for cervical cancer patients. ${ }^{11}$ Notably higher rates of activated and proliferating T-cells (and co-inhibitory marker positive T-cells (CTLA-4, PD-1) were seen in HPV ${ }^{+}$ tumours compared to HPV- tumours. This suggests that $\mathrm{HPV}^{+}$tumours are more immunogenic because of their viral causation. In tumour positive lymph nodes, there were significantly higher rates of regulatory T-cells, and more expression of the checkpoint molecules CTLA-4/PD-1 and LAG3 checkpoint molecules on various T-cell subpopulations. This indicates that combinational immunotherapy targeting CTLA-4 and PD-1 might be beneficial in metastatic penile cancer. This has been given in early phase trials with promising results warranting further analyses. ${ }^{12,13}$

Of course, immune response and escape mechanisms are dynamic processes that cannot be fully studied with resected specimen immunohistochemistry alone. Besides aforementioned additional markers and factors, it would be interesting to look further into different mechanisms of PD-L1 expression as discussed in chapter 2 and compare these data with genetic profiles of the primary tumour. The study on the microenvironment of tumour-draining lymph nodes will improve with more samples and validation. Also tissue imprints from bisected lymph nodes can be used for proximity analysis and pattern recognition (like in chapter 2 a marginal PD-L1 expression pattern was recognised). For the present and near future it is crucial to have close immune-monitoring during immunotherapy trials, including at least typing of tumour cells, T-cells and myeloid cells (including activation and/ 
or exhaustion markers, proliferation status and checkpoint expression), possibly complemented with analysis of tumour-derived factors (interleukins, interferons, growth factors). Analyses are preferably done before, during and after therapy as this would provide insights in the immunological changes in the TME with therapy, and mechanisms exploited in and around tumour residues after therapy.

The ample presence of i.a. Tregs and PD-L1 expression provide a rationale for immunotherapy trials (chapters 2 and 3). However, the clinical value and effect of immune modulating agents in penile cancer remains largely unknown as hardly any clinical trial has finished yet. Based on the results of chapter $\mathbf{2}$ and $\mathbf{3}$, the PERICLES clinical trial started in the Netherlands Cancer Institute and is still running (checkpoint inhibitor anti PD-L1 with or without radiotherapy; EudraCTnumber: 2018-000603-17). Trials targeting CTLA-4 (Tregs) or combination trials that target both CTLA-4 and PD-1/PD-L1 also seem rational as we found that these checkpoints were expressed in our studies (manuscript in preparation). Hopefully, immunotherapy can be of value to those with distant metastases where cure is now impossible. Importantly, immunotherapy dramatically changed the prognosis of stage 3 melanoma and metastasized renal cell carcinoma. ${ }^{14,15}$ Whether immunotherapy can improve disease control in patients with multiple lymph node metastases where surgery alone is not sufficient, also needs further investigation.

The human papilloma virus (HPV) is associated with $25-50 \%$ of invasive penile cancers, with oncogenic HPV type 16 being the most prevalent. ${ }^{16-18} \mathrm{HPV}$-positive $\left(\mathrm{HPV}^{+}\right)$tumours generally have a better prognosis than HPV-negative (HPV $\left.{ }^{-}\right)$ tumours, even the metastasised tumours. ${ }^{18}$ A tendency to respond better to treatment is presumably contributing to this survival benefit. ${ }^{19,20}$

Vaccination against HPV, reduces the incidence of HPV-associated lesions and was included in the Dutch national immunisation programme years ago, for girls only. ${ }^{21}$ In June 2019, the Health Council of the Netherlands advised vaccination for boys as well. ${ }^{22}$ From 2021 boys will be offered the vaccine at 9 years of age. ${ }^{23}$ This is expected to reduce the incidence of penile and other HPV-induced cancers in men and women in the future.

Beyond prevention, there may also be a therapeutic role for HPV vaccination for penile lesions. Studies in cervical intraepithelial neoplasia (CIN, virtually always $\mathrm{HPV}^{+}$) show a lower recurrence rate after conisation and vaccination as compared to the control group that underwent conisation alone, as reviewed by Jentschke 
et al. ${ }^{24}$. In men, HPV vaccination was moderately effective against persistent anogenital HPV infection (47\% efficacy) and anal intraepithelial neoplasia (4762\%). ${ }^{25}$ These studies support the expectation that adjuvant vaccination will be of value in PelN as well, but this still needs scientific evaluation.

Although outside the scope of this thesis, the association between HPV status and patient outcomes in penile cancer is in part mediated by epigenetic effects of viral oncogenes or mutational status of the patient. Possibly, expression of immunogenic viral oncogenes is a favourable factor in $\mathrm{HPV}^{+}$tumours, contributing to a better tumour recognition and T-cell reactivity. Studies on mutational burden in penile cancer show a relatively low mutational burden (3.6-4.4 mutations/ $\mathrm{Mb}$ ) compared to e.g. melanoma and bladder cancer that both respond well to immunotherapy. ${ }^{26,27}$ A high mutational burden results in a more diverse neoantigen repertoire that can be presented to cytotoxic T-cells, that - after removal of the supressing checkpoint mechanisms - results in a strong anti-tumour response. ${ }^{28}$ Following this line of thought, the low mutational burden of penile cancer may suggest a moderate response to checkpoint inhibitor therapy. However, clear cell renal cancer has an even lower mutational burden (around 1.1 mutations/Mb), while immunotherapy has substantially improved its prognosis. ${ }^{15,29,30}$

In various squamous cell cancers including penile cancers, TP53 is associated with HPV- tumours and with inferior survival. ${ }^{26,31,32}$ PIK3CA mutations were more often seen in $\mathrm{HPV}^{+}$anal and oral SCC than in HPV- tumours. ${ }^{31,33}$ PIK3CA mutations have also been described as mostly associated with early stages (PeIN) of penile malignancies, not with poor survival or LNM.34,35

Neither covered in this thesis is targeted therapy for penile cancer. The epithelial growth factor receptor (EGFR) is frequently expressed in penile cancers, and a study by Necchi et al showed that targeting EGFR signalling with anti-tyrosine kinase therapy is safe and effective. ${ }^{36,37}$ Possibly, targeted therapies can be used when chemotherapy is not an option. Also, combination therapies can be further explored. ${ }^{38}$

\section{Imaging and staging}

Currently in penile cancer, FDG-PET/CT imaging is not used to its full potential in advanced stages of the disease (chapters 4, 5 and 6). In the nearby future, it may be used for earlier and non-invasive diagnosis of tumour-positive pelvic lymph nodes, and early discovery of distant metastases, as suggested in this thesis. Also, one study described a possibly relevant role in clinically node-negative patients 
when used with the sentinel node biopsy. ${ }^{39,40}$ Note that small metastases can be missed with all imaging modalities, and that pathologic staging prevails for definitely ruling out metastases. ${ }^{41}$

The role of PET/CT for response evaluation after systemic or radiation therapy should be evaluated for penile cancer. ${ }^{42}$ Currently this is hardly described in literature, while in this thesis (chapter 8), FDG-PET/CT was used to measure response.

Ideally, PET/CT will become more specific for penile cancer, comparable to the successful PSMA-PET/CT for prostate cancer. ${ }^{43}$ In other cancers different PET tracers are studied, for example markers of proliferation, hypoxia and angiogenesis. ${ }^{44,45}$ Such detection methods possibly improve test performances of PET/CT and hopefully lead to a better diagnosis and monitoring. Yet, these prospects are still far away in penile cancer staging. In lung cancer, PD-L1 has been labelled for PET/CT. ${ }^{46}$ Although it has not been correlated to checkpoint inhibition response, it could be a way to non-invasively quantify PD-L1 expression in patients.

Staging and treatment of penile cancer involves more factors than the current TNM classification includes. Since 2020, the EAU guidelines recommend assessment of HPV-status of resected tumour specimens as a prognosticator. A more precise clinical staging system including HPV-status will lead to better risk stratification. Another example is a subclassification of N3 that was proposed by Li et al. ${ }^{47}$ They showed that dividing the inguinal metastases with extranodal extension (ENE; N3a) from the pelvic metastases (N3b) better reflects the prognosis of these subgroups.

So far, however, HPV-status does not impact disease management. ${ }^{48}$ Besides a better prognosis, studies also suggest a better response to treatment for HPV+ tumours. ${ }^{18,20,49}$ Therefore the treatment of $\mathrm{HPV}^{+}$tumours may become less aggressive than the treatment of $\mathrm{HPV}^{-}$tumours in the future. This has already been suggested for chemoradiotherapy in oropharyngeal tumours. ${ }^{50,51}$

Although risk stratification with (sub)staging is useful, the real importance is that staging and treatment is adequate and optimal. This is best reached by timely referral to a specialized centre. 
Literature shows that penile cancer care is best in specialized centres. Williams et al reviewed the impact of centralization in genitourinary cancer and found better utilization of surgery, lower morbidity and better survival outcomes in high-volume centres, especially for major surgical procedures. ${ }^{52}$ For penile cancer specifically, an American study showed that patients treated in non-academic centres were less likely to undergo invasive lymph node staging when indicated, while this notoriously results in a higher risk of mortality.53,54 Furthermore, centralization also improves histopathological diagnostic accuracy and adherence to guidelines. ${ }^{55,56}$

In penile cancer therapy, there is a pressing need to decrease the morbidity associated with inguinal lymph node dissections. There are at least three approaches: 1) improvements of surgical techniques, 2) alternative staging methods and 3) alternative treatments.

1. Various modifications of ILND techniques have been reported to lead to lower complication rates. Endoscopic ILND showed promising results in various studies ${ }^{57}$ and efforts are made in wound treatment after ILND. ${ }^{58}$ However, patient numbers are small and complication rates remain high. Also, a reporting bias is may be present as it regards complications.

2. The most effective strategy to prevent complications from ILND is to avoid ILND completely. This goal has been reached by introducing the sentinel node biopsy procedure and modified ILND instead of staging radical ILNDs. Nevertheless, a tumour-positive SN procedure is always followed by ILND. In stage III melanoma patients, inguinal sentinel node procedure can safely be followed by close followup. An immediate completion lymph node dissection was shown to improve regional control, but not melanoma specific survival. ${ }^{59,60}$ Whether this also applies to penile cancer is unknown. Currently a European collaboration study investigates the factors predicting metastatic non-sentinel lymph nodes. Preliminary results suggest a relation between size of the metastasis in the sentinel node and additional metastases in the completion ILND. ${ }^{61}$ Replacing a staging ILND with a minimal invasive procedure requires careful investigation, as delayed resection of occult metastases can be fatal. ${ }^{54}$ In 2007, for vulvar cancer a suggestion was made to replace a staging inguinal Iymphadenectomy at the time of primary tumour resection with radiotherapy. The authors concluded that radiation was optional for early-stage vulvar cancer, and that prospective studies were warranted. ${ }^{62}$ Later, a review described lower morbidity of radiation, but a possibly higher risk of recurrence. ${ }^{63}$ With a limited quality of studies it is difficult to determine exactly the potential of radiotherapy. 
3. Therapeutic ILND can also be avoided with treatment alternatives. Better non-invasive staging (imaging) before ILND can reveal that multimodal therapy is indicated (chapters $\mathbf{6}$ and $\mathbf{8}$ ). And in cases of complete response, or at worst, progression to incurable disease, therapeutic lymph node dissections may be avoided. Between 2000 and 2014, 13\% of all patients that underwent pathologic staging at the $\mathrm{NCl}$ were staged pN3 (unpublished data). These patients account for $40 \%$ of therapeutic ILNDs and would ideally be identified beforehand.

\section{Therapy for advanced stages of disease}

More surgery is not always successful. The results in chapter 7 of this thesis describe a small cohort $(n=15)$. Nevertheless, these data support previous reports where experts describe that major surgery should only be performed when carefully considered. ${ }^{64}$ Given the poor oncological and surgical outcomes, such major surgery should be mainly used for palliative reasons such as tumour pain and (other) daily care problems. Its use in curative setting will be mostly in a combination of multiple therapies, or after carefully considering its benefits and risks. ${ }^{64,65}$

For the treatment of the inguinal lymph nodes significant differences exists, even between neighbouring countries. Treatment strategies range from ILND with adjuvant radiation therapy to ILND with neoadjuvant and adjuvant chemotherapy. It would be of great value to compare experiences in treatment strategies between centres in terms of efficacy, toxicity and complications, recurrences and also quality of life. This would be possible within an international collaboration. A project of that nature is the InPACT trial that prospectively evaluates benefits and sequencing of surgery, chemotherapy and chemoradiation therapy. ${ }^{66}$ Results are eagerly awaited.

Despite advancements in treatment of lymph node metastasis, survival of advanced stages of the disease is low. Clinically N3 patients have a 5 year survival of 20-35\%.65,67,68 Large primary lesions do not fare well either as described in chapter 7. According to guidelines multimodal treatment is indicated in these advanced stages. Neoadjuvant chemotherapy is the most studied option so far with platinum based regimens now considered the most efficacious, and taxane based regimens the most toxic. ${ }^{69}$

Although radiotherapy is not recommended in current EAU guidelines, we saw good radiosensitivity in the chemoradiation trial (chapter 8). ${ }^{48,70}$ Also, radiotherapy has been used as adjuvant to lymph node surgery in our centre 
for years, showing survival benefit in a four-centre report. ${ }^{71}$ On the other hand, some patients' disease progressed during chemoradiation therapy, some even had disease progression within the radiated fields. What is needed is a marker of sensitivity for radiotherapy. Yuan et al studied radiosensitivity of penile tumours and advocate dose prescription based on the individual tumour biology, as radioresistance was mostly present but varied significantly. ${ }^{72}$

HPV-status could be one of these markers as better response was seen in $\mathrm{HPV}^{+}$ head and neck cancer and has also been suggested in penile cancer. ${ }^{19,20,73,74}$ Some studies investigated oxygen levels within tumours to predict response to radiation. ${ }^{74,75}$ Also injection of immunotherapeutic agents within tumours masses has been studied, showing response in both injected and other lesions in melanoma. ${ }^{76-78}$ Results in cervical carcinoma are awaited. ${ }^{79}$

But even if all best reported results of current options were achieved in all hospitals, a problem remains with therapy resistant, large, inoperable and widely spread disease. Whether it consists of combinations of current options, targeted therapies, immune-modulating treatments or best supportive care: more options need to be explored and compared with each other in order to find solace for these patients with a poor prognosis. Considering quality of life and other patient reported outcome measures in such studies is crucial.

The major flaw of the last chapters of this thesis (chapter $\mathbf{7}$ and $\mathbf{8}$ ) is the lack of quality of life data. Although patient reported outcome measures (PROMS) may not provide all information (e.g. coping strategies, expectations) it is essential information in the management of such disease. Patients may experience advantages and disadvantages of the treatment options differently than we think. Quality of life data will definitely contribute to making the best treatment decisions with the patient.

In conclusion, in the present thesis we point to possible immunotherapy for penile cancer targeting the PD-L1 and/or CTLA-4 checkpoints. We advocate earlier detection of pelvic lymph nodes and distant metastases with better use of FDG-PET/CT, careful consideration of large surgical procedures, and present chemoradiation as a multimodal treatment alternative for advanced stages of penile cancer. 


\section{REFERENCES}

1. Gjoerup O, Brown CA, Ross JS, et al: Identification and Utilization of Biomarkers to Predict Response to Immune Checkpoint Inhibitors. AAPS J. 2020; 22: 132.

2. Kemp Bohan PM, Chick RC, Hickerson AT, et al: Correlation of tumor microenvironment from biopsy and resection specimens in untreated colorectal cancer patients: a surprising lack of agreement. Cancer Immunol. Immunother. 2020: 1-10.

3. Taube JM, Young GD, McMiller TL, et al: Differential Expression of ImmuneRegulatory Genes Associated with PD-L1 Display in Melanoma: Implications for PD-1 Pathway Blockade. Clin. Cancer Res. 2015; 21: 3969-3976.

4. Herbst RS, Soria J-C, Kowanetz M, et al: Predictive correlates of response to the anti-PD-L1 antibody MPDL3280A in cancer patients. Nature 2014; 515: 563-567.

5. Lohneis P, Boral S, Kaufmann AM, et al: Human papilloma virus status of penile squamous cell carcinoma is associated with differences in tumour-infiltrating $T$ lymphocytes. Virchows Arch. 2015; 466: 323-331.

6. Djajadiningrat RS, Horenblas S, Heideman DAM, et al: Classic and nonclassic HLA class I expression in penile cancer and relation to HPV status and clinical outcome. J. Urol. 2015; 193: 1245-1251.

7. Vassallo J, Rodrigues AFF, Campos AHJFM, et al: Pathologic and imunohistochemical characterization of tumoral inflammatory cell infiltrate in invasive penile squamous cell carcinomas: Fox-P3 expression is an independent predictor of recurrence. Tumour Biol. 2015; 36: 2509-16.

8. Cocks M, Taheri D, Ball MW, et al: Immune checkpoint status in penile squamous cell carcinoma: A North American Cohort. Hum. Pathol. 2016; 59: 55-61.

9. Udager AM, Liu T-Y, Skala SL, et al: Frequent PD-L1 expression in primary and metastatic penile squamous cell carcinoma: potential opportunities for immunotherapeutic approaches. Ann. Oncol. Off. J. Eur. Soc. Med. Oncol. 2016; 27 : 1706-12.

10. Deng C, Li Z, Guo S, et al: Tumor PD-L1 expression is correlated with increased TILS and poor prognosis in penile squamous cell carcinoma. Oncoimmunology 2017; 6: e1269047.

11. Heeren AM, de Boer E, Bleeker MCG, et al: Nodal metastasis in cervical cancer occurs in clearly delineated fields of immune suppression in the pelvic lymph catchment area. Oncotarget 2015; 6: 32484-32493.

12. McGregor BA, Campbell MT, Xie W, et al: Phase II study of nivolumab and ipilimumab for advanced rare genitourinary cancers. J. Clin. Oncol. 2020; 38: 5018.

13. Wallis CJ, da Motta Girardi D, Niglio SA, et al: Final Results From a Phase I Trial and Expansion Cohorts of Cabozantinib and Nivolumab Alone or With Ipilimumab For Metastatic Genitourinary Tumors. In: ASCO GU 2021. 2021.

14. Weber J, Mandala M, Del Vecchio M, et al: Adjuvant Nivolumab versus Ipilimumab in Resected Stage III or IV Melanoma. N. Engl. J. Med. 2017; 377: 1824-1835. 
15. Motzer RJ, Rini BI, McDermott DF, et al: Nivolumab plus ipilimumab versus sunitinib in first-line treatment for advanced renal cell carcinoma: extended follow-up of efficacy and safety results from a randomised, controlled, phase 3 trial. Lancet. Oncol. 2019; 20: 1370-1385.

16. Alemany L, Cubilla A, Halec G, et al: Role of Human Papillomavirus in Penile Carcinomas Worldwide. Eur. Urol. 2015; 69: 953-961.

17. Olesen TB, Sand FL, Rasmussen CL, et al: Prevalence of human papillomavirus DNA and p16(INK4a) in penile cancer and penile intraepithelial neoplasia: a systematic review and meta-analysis. Lancet. Oncol. 2019; 20: 145-158.

18. Djajadiningrat RS, Jordanova ES, Kroon BK, et al: Human papillomavirus prevalence in invasive penile cancer and association with clinical outcome. J. Urol. 2015; 193 : 526-31.

19. Giannatempo P, Bandini M, Zhu Y, et al: Impact of human papillomavirus (HPV) infection on the outcome of perioperative treatments for penile squamous-cell carcinoma (PSCC). J. Clin. Oncol. 2020; 38: 5088.

20. Bandini M, Ross JS, Zhu Y, et al: Association Between Human Papillomavirus Infection and Outcome of Perioperative Nodal Radiotherapy for Penile Carcinoma. Eur. Urol. Oncol. 2020.

21. Harper DM and DeMars LR: HPV vaccines - A review of the first decade. Gynecol. Oncol. 2017; 146: 196-204.

22. Health Council of the Netherlands: Vaccination against HPV. 2019: publication no. 2019/09. Available at: https://www.healthcouncil.nl/documents/advisoryreports/2019/06/19/vaccination-against-hpv.

23. Anon: State Secretary Blokhuis: boys will also be vaccinated against HPV virus. Natl. Inst. Public Heal. Environ. 2019. Available at: https://www.rivm.nl/en/news/ state-secretary-blokhuis-boys-will-also-be-vaccinated-against-hpv-virus, accessed February 1, 2021.

24. Jentschke M, Kampers J, Becker J, et al: Prophylactic HPV vaccination after conization: A systematic review and meta-analysis. Vaccine 2020; 38: 6402-6409.

25. Harder T, Wichmann O, Klug SJ, et al: Efficacy, effectiveness and safety of vaccination against human papillomavirus in males: a systematic review. BMC Med. 2018; 16: 110 .

26. Jacob JM, Ferry EK, Gay LM, et al: Comparative Genomic Profiling of Refractory and Metastatic Penile and Nonpenile Cutaneous Squamous Cell Carcinoma: Implications for Selection of Systemic Therapy. J. Urol. 2019; 201: 541-548.

27. Chalmers ZR, Connelly CF, Fabrizio D, et al: Analysis of 100,000 human cancer genomes reveals the landscape of tumor mutational burden. Genome Med. 2017; 9 : 34.

28. Fumet J-D, Truntzer C, Yarchoan M, et al: Tumour mutational burden as a biomarker for immunotherapy: Current data and emerging concepts. Eur. J. Cancer 2020; 131 : 40-50.

29. Yakirevich $E$ and Patel NR: Tumor mutational burden and immune signatures interplay in renal cell carcinoma. Ann. Transl. Med. 2020; 8: 269. 
30. Rini BI, Plimack ER, Stus V, et al: Pembrolizumab plus Axitinib versus Sunitinib for Advanced Renal-Cell Carcinoma. N. Engl. J. Med. 2019; 380: 1116-1127.

31. Zhu X, Jamshed S, Zou J, et al: Molecular and immunophenotypic characterization of anal squamous cell carcinoma reveals distinct clinicopathologic groups associated with HPV and TP53 mutation status. Mod. Pathol. 2021.

32. Prapiska FF and Warli SM: P53 and Survival Rate in Penile Cancer. Open access Maced. J. Med. Sci. 2019; 7: 1170-1173.

33. Nichols AC, Palma DA, ChowW, et al: High frequency of activating PIK3CA mutations in human papillomavirus-positive oropharyngeal cancer. JAMA Otolaryngol. Head Neck Surg. 2013; 139: 617-22.

34. Adimonye A, Stankiewicz E, La-Touche S, et al: PIK3CA copy number aberration and activation of the PI3K-AKT-mTOR pathway in varied disease states of penile cancer. PLoS One 2018; 13: e0198905.

35. Ferrandiz-Pulido C, Hernandez-Losa J, Masferrer E, et al: Identification of somatic gene mutations in penile squamous cell carcinoma. Genes. Chromosomes Cancer 2015; 54: 629-637.

36. Necchi A, Lo Vullo S, Perrone F, et al: First-line therapy with dacomitinib, an orally available pan-HER tyrosine kinase inhibitor, for locally advanced or metastatic penile squamous cell carcinoma: results of an open-label, single-arm, single-centre, phase 2 study. BJU Int. 2018; 121: 348-356.

37. Gou H-F, Li X, Qiu M, et al: Epidermal growth factor receptor (EGFR)-RAS signaling pathway in penile squamous cell carcinoma. PLoS One 2013; 8: e62175.

38. Carthon BC, Ng CS, Pettaway CA, et al: Epidermal Growth Factor ReceptorTargeted Therapy in Locally Advanced or Metastatic Squamous Cell Carcinoma of the Penis. BJU Int. 2014; 113: 871-877.

39. Jakobsen JK, Alslev L, Ipsen P, et al: DaPeCa-3: promising results of sentinel node biopsy combined with (18) F-fluorodeoxyglucose positron emission tomography/ computed tomography in clinically lymph node-negative patients with penile cancer - a national study from Denmark. BJU Int. 2016; 118: 102-111.

40. Bandini M, Albersen M, Chipollini J, et al: Optimising the selection of candidates for neoadjuvant chemotherapy amongst patients with node-positive penile squamous cell carcinoma. BJU Int. 2020; 125: 867-875.

41. Rosevear HM, Williams H, Collins M, et al: Utility of (1)(8)F-FDG PET/CT in identifying penile squamous cell carcinoma metastatic lymph nodes. Urol. Oncol. 2012; 30: 723-726.

42. Helsen N, Van den Wyngaert T, Carp L, et al: FDG-PET/CT for treatment response assessment in head and neck squamous cell carcinoma: a systematic review and meta-analysis of diagnostic performance. Eur. J. Nucl. Med. Mol. Imaging 2018; 45: 1063-1071.

43. Eapen RS, Nzenza TC, Murphy DG, et al: PSMA PET applications in the prostate cancer journey: from diagnosis to theranostics. World J. Urol. 2019; 37: 1255-1261.

44. Cheng G:Non-Small-Cell Lung CancerPETImaging BeyondF18Fluorodeoxyglucose. PET Clin. 2018; 13: 73-81. 
45. Chen YJ, Rath T and Mohan S: PET-Computed Tomography in Head and Neck Cancer: Current Evidence and Future Directions. Magn. Reson. Imaging Clin. N. Am. 2018; 26: 37-49.

46. Niemeijer AN, Leung D, Huisman MC, et al: Whole body PD-1 and PD-L1 positron emission tomography in patients with non-small-cell lung cancer. Nat. Commun. 2018; 9: 4664.

47. Li ZZ, Guo S, Wu Z, et al: Subclassification of pN3 staging systems for penile cancer: Proposal for modification of the current TNM classification. Urol. Oncol. 2017; 35: 543.e1-543.e6.

48. Hakenberg OW (chair), Compérat E, Minhas S, et al: EAU Guidelines on Penile Cancer. 2020. Available at: http://uroweb.org/guideline/penile-cancer/, accessed December 12, 2020.

49. Yuan Z, Naghavi AO, Tang D, et al: The relationship between HPV status and chemoradiotherapy in the locoregional control of penile cancer. World J. Urol. 2018.

50. Pearlstein KA, Wang K, Amdur RJ, et al: Quality of Life for Patients With Favorable-Risk HPV-Associated Oropharyngeal Cancer After De-intensified Chemoradiotherapy. Int. J. Radiat. Oncol. Biol. Phys. 2019; 103: 646-653.

51. Cheraghlou S, Yu PK, Otremba MD, et al: Treatment deintensification in human papillomavirus-positive oropharynx cancer: Outcomes from the National Cancer Data Base. Cancer 2018; 124: 717-726.

52. Williams SB, Ray-Zack MD, Hudgins HK, et al: Impact of Centralizing Care for Genitourinary Malignancies to High-volume Providers: A Systematic Review. Eur. Urol. Oncol. 2019; 2.

53. Woldu SL, Ci B, Hutchinson RC, et al: Usage and survival implications of surgical staging of inguinal lymph nodes in intermediate- to high-risk, clinical localized penile cancer: A propensity-score matched analysis. Urol. Oncol. 2017.

54. Kroon BK, Horenblas S, Lont AP, et al: Patients with penile carcinoma benefit from immediate resection of clinically occult lymph node metastases. J. Urol. 2005; 173 : 816-9.

55. Tang V, Clarke L, Gall Z, et al: Should centralized histopathological review in penile cancer be the global standard? BJU Int. 2014; 114: 340-343.

56. Vanthoor J, Thomas A, Tsaur I, et al: Making surgery safer by centralization of care: impact of case load in penile cancer. World J. Urol. 2020; 38: 1385-1390.

57. Nabavizadeh R and Master V: Minimally invasive approaches to the inguinal nodes in cNO patients. Curr. Opin. Urol. 2019; 29: 165-172.

58. Schmid SC, Seitz AK, Haller B, et al: Final results of the PräVAC trial: prevention of wound complications following inguinal lymph node dissection in patients with penile cancer using epidermal vacuum-assisted wound closure. World J. Urol. 2020.

59. Leiter U, Stadler R, Mauch C, et al: Final Analysis of DeCOG-SLT Trial: No Survival Benefit for Complete Lymph Node Dissection in Patients With Melanoma With Positive Sentinel Node. J. Clin. Oncol. 2019; 37: 3000-3008.

60. Faries MB, Thompson JF, Cochran AJ, et al: Completion Dissection or Observation for Sentinel-Node Metastasis in Melanoma. N. Engl. J. Med. 2017; 376: 2211-2222. 
61. Nowers J, Afshar M, Ottenhof SR, et al: 493 International multi-center analysis of factors predicting the presence of non-sentinel node inguinal metastases in penile cancer patients undergoing completion inguinal lymph node dissection following positive sentinel node biopsy. Eur. Urol. Suppl. 2019.

62. Hallak S, Ladi L and Sorbe B: Prophylactic inguinal-femoral irradiation as an alternative to primary lymphadenectomy in treatment of vulvar carcinoma. Int. J. Oncol. 2007; 31: 1077-1085.

63. van der Velden J, Fons G and Lawrie TA: Primary groin irradiation versus primary groin surgery for early vulvar cancer. Cochrane database Syst. Rev. 2011: CD002224.

64. Shukla CJ, Shabbir M, Feneley MR, et al: Palliation of male genital cancers. Clin. Oncol. 2010; 22: 747-754.

65. Alnajjar HM, MacAskill F, Christodoulidou M, et al: Long-term outcomes for penile cancer patients presenting with advanced N3 disease requiring a myocutaneous flap reconstruction or primary closure-a retrospective single centre study. Transl. Androl. Urol. 2019; 8: S13-S21.

66. Canter DJ, Nicholson S, Watkin N, et al: The International Penile Advanced Cancer Trial (InPACT): Rationale and Current Status. Eur. Urol. Focus 2019; 5: 706-709.

67. Dickstein RJ, Munsell MF, Pagliaro LC, et al: Prognostic factors influencing survival from regionally advanced squamous cell carcinoma of the penis after preoperative chemotherapy. BJU Int. 2014; 117: 118-125.

68. Djajadiningrat RS, Graafland NM, van Werkhoven E, et al: Contemporary management of regional nodes in penile cancer-improvement of survival? J. Urol. 2014; 191: 68-73.

69. Azizi M, Aydin AM, Hajiran A, et al: Systematic Review and Meta-Analysis: Is there a Benefit in Using Neoadjuvant Systemic Chemotherapy for Locally Advanced Penile Squamous Cell Carcinoma? J. Urol. 2020; 203: 1147-1155.

70. Robinson R, Marconi L, MacPepple E, et al: Risks and Benefits of Adjuvant Radiotherapy After Inguinal Lymphadenectomy in Node-positive Penile Cancer: A Systematic Review by the European Association of Urology Penile Cancer Guidelines Panel. Eur. Urol. 2018.

71. Johnstone PAS, Boulware D, Djajadiningrat R, et al: Primary Penile Cancer: The Role of Adjuvant Radiation Therapy in the Management of Extranodal Extension in Lymph Nodes. Eur. Urol. Focus 2019; 5: 737-741.

72. Yuan Z, Yang GQ, Ahmed KA, et al: Radiation therapy in the management of the inguinal region in penile cancer: What's the evidence? Urol. Oncol. 2020.

73. Nichols AC, Faquin WC, Westra WH, et al: HPV-16 infection predicts treatment outcome in oropharyngeal squamous cell carcinoma. Otolaryngol. Head. Neck Surg. 2009; 140: 228-234.

74. Mirghani H, Amen F, Tao Y, et al: Increased radiosensitivity of HPV-positive head and neck cancers: Molecular basis and therapeutic perspectives. Cancer Treat. Rev. 2015; 41: 844-852.

75. Horsman MR and Overgaard J: The impact of hypoxia and its modification of the outcome of radiotherapy. J. Radiat. Res. 2016; 57 Suppl 1: i90-i98. 
76. Ray A, Williams MA, Meek SM, et al: A phase I study of intratumoral ipilimumab and interleukin-2 in patients with advanced melanoma. Oncotarget 2016; 7: 6439064399.

77. Franke V, Berger DMS, Klop WMC, et al: High response rates for T-VEC in early metastatic melanoma (stage IIIB/C-IVM1a). Int. J. cancer 2019; 145: 974-978.

78. Koster BD, van den Hout MFCM, Sluijter BJR, et al: Local Adjuvant Treatment with Low-Dose CpG-B Offers Durable Protection against Disease Recurrence in Clinical Stage I-II Melanoma: Data from Two Randomized Phase II Trials. Clin. Cancer Res. 2017; 23: 5679-5686.

79. Rotman J, Mom CH, Jordanova ES, et al: "DURVIT": a phase-I trial of single low-dose durvalumab (Medi4736) IntraTumourally injected in cervical cancer: safety, toxicity and effect on the primary tumour- and lymph node microenvironment. BMC Cancer 2018; 18: 888. 

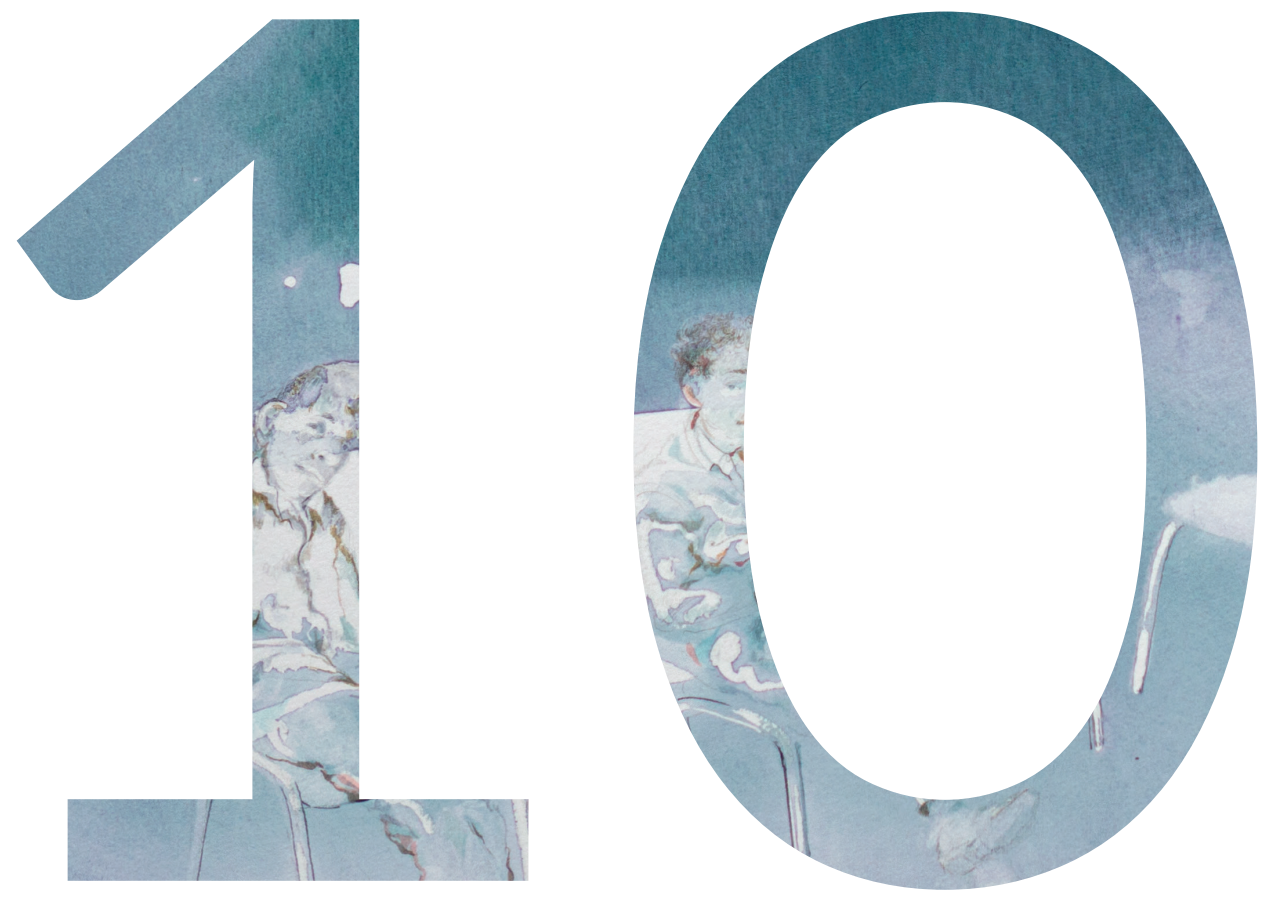
Chapter 10

Summary / Samenvatting 


\section{SUMMARY}

Penile cancer is introduced in chapter 1, describing in short the epidemiology, aetiology and risk factors, tumour-immunology, imaging and treatment of the disease.

Chapter 2 and $\mathbf{3}$ cover immunological aspects of penile cancer. We compared expression of various immune factors with disease specific survival (DSS) and lymph node metastases (LNM) at diagnosis. Therefore we used archived tumour tissue. The role of programmed death ligand-1 (PD-L1) was studied in chapter 2. PD-L1 is an immune checkpoint molecule that can be expressed by tumour cells or immune cells. It inhibits T-cell function when bound to its receptor. Anti PD-L1/PD-1 immunotherapy can block its function and enhance tumour eradication by T-cells. We looked at PD-L1 expression in different areas of the tumour microenvironment (TME): tumour, stroma, and tumour-infiltrating macrophages. Also, the pattern of expression was noted, that is diffuse or predominantly present at the tumour-stroma margin.

Of 200 tumours 96 (48\%) were PD-L1 positive (scored 1\% or greater). Of PD-L1+ tumours, 59 (62\%) had a marginal expression pattern and 79 (82\%) were high risk human papilloma virus (hrHPV) negative, compared to $75 \%$ in the whole cohort ( $p=0.03$ ). Compared to PD- L1 negative tumours, the PD-L1 expression patterns had different prognostic values in the whole cohort as well as in the high risk HPV negative subgroup. On multivariable analyses a marginal expression pattern was associated with absent lymph node metastases (odds ratio (OR) 0.4) while diffuse expression was associated with poor survival (hazard ratio (HR) 2.58). These results were more prominent in the high risk HPV negative subgroup (OR 0.25, HR 3.92).

In chapter 3, more immune factors of the tumour microenvironment are studied. Analysis included previously described hrHPV status, immunohistochemical scores for classical and non-classical human leukocyte antigen (HLA) class I, PD-L1, and novel data on tumour-infiltrating macrophages and cytotoxic and regulatory T-cells. Clinicopathological characteristics and extended follow-up were also included.

In the total cohort $(n=216)$, diffuse PD-L1 tumour-cell expression, CD163+ macrophage infiltration, non-classical HLA class I upregulation, and low stromal CD8 ${ }^{+}$T-cell infiltration were all associated with LNM. In the multivariable model, 
only tumour PD-L1 expression remained a significant predictor for LNM (OR 2.8, $p=0.05)$. hrHPV negativity and diffuse PD-L1 tumour-cell expression were significantly associated with poor DSS and remained so upon correction for clinical parameters (HR 9.7, $p<0.01$ and HR 2.8, $p=0.03$ ). The only immune factor with different expression in $\mathrm{HPV}^{+}$and HPV- tumours was PD-L1, with higher PD-L1 expression in the latter $(p=0.03)$.

In the HPV- cohort ( $n=158$ ), LNM were associated with diffuse PD-L1 tumourcell expression, high intra-tumoral $C D 163^{+}$macrophage infiltration, and low number of stromal CD8 ${ }^{+}$T-cells. The first two parameters were also linked to DSS. In the multivariable regression model, diffuse PD-L1 expression remained significantly unfavourable for DSS (HR 5.0, $p<0.01)$.

These results emphasize the complexity of the tumour microenvironment in penile cancer and point toward several possible immunotherapy targets. Here described immune factors can aid risk-stratification and should be evaluated in clinical immunotherapy studies to ultimately lead to patient tailored treatment.

Chapter 4 reviews staging and imaging of penile cancer. According to the literature reviewed, T-staging relies on physical examination, but MRI can aid a more sensitive staging if needed. N-staging is most complicated for small metastases, as they are prone to be missed. For the detection of small metastases, the (dynamic) sentinel node biopsy (SNB) procedure is preferred because it provides accurate pathological staging without the side effects and complications of an inguinal lymph node dissection (ILND). SNB should be preceded by USguided FNAC to avoid undetected macrometastases. FNAC also is a valuable tool to confirm metastases in suspicious groins. Nevertheless, micrometastases can be missed with every non-invasive or minimally invasive staging tool. Additional efforts should be made to further reduce false-negative rates.

Highly suspicious groins require inguinal lymph node dissection as it is of great therapeutic value. For M-staging, conventional anatomical imaging is recommended. High sensitivity has been described for FDG-PET/CT. Its role was further evaluated in chapter $\mathbf{5}$ and $\mathbf{6}$ for both $\mathrm{N}$ and $\mathrm{M}$-staging. Follow-up and surveillance rely on physical examination and US-FNAC. PET/CT may have a role in confirmation of suspected recurrence, but is not recommended for routine surveillance. 
In chapter 5 we reviewed the role of FDG-PET/CT in staging and monitoring penile cancer. Combining functional with anatomical imaging, PET/CT outperforms both PET alone and CT alone in lymph node staging of many types of tumours. And although virtually all primary penile tumours are FDG-avid, PET/CT is not recommended for primary tumour staging as it has limited spatial resolution and urinary FDG excretion cause artefacts. The accuracy of PET/ CT for lymph node staging seems to improve with the pre-test likelihood of metastatic nodes. In groins with normal physical examination, sensitivity is only 57\%. In groins with palpably enlarged lymph nodes, sensitivity of PET/CT is up to $96 \%$. For pelvic lymph nodes and distant metastases, PET/CT is more accurate if inguinal metastases are present. However, these results are based on a very limited number of studies. Overall, the role of PET/CT imaging in penile cancer remains ambiguous, especially in inguinal lymph nodes.

In chapter 6 we conducted a retrospective study on the PET/CT scan. In our review we found suggestions that PET/CT may be particularly useful in detecting pelvic lymph node metastases and occult distant metastases prior to systemic chemotherapy and/or extensive surgery. In order to improve selection of patients that are most likely to benefit from such therapies, we looked at PET/CT results in patients with clinically overt lymph node metastases and/or large primary tumours (bulky T3 or T4).

FDG-PET/CT has a high sensitivity and negative predictive value (NPV) for staging of pelvic lymph nodes (sensitivity 85\%, specificity 75\%, NPV 90\%, positive predictive value (PPV) 65\%). FDG-PET/CT also has high PPV for detection of distant metastases (93\%), which were found in $23 \%$ of patients. With these test properties, FDG-PET/CT enables early selection for multimodal treatment of patients with pelvic metastases, and may help avoid futile treatment of patients with distant metastases. These results are limited by the retrospective design and the lack of direct comparison to CT scanning alone.

Patients requiring extensive treatment are studied in chapter $\mathbf{7}$ and $\mathbf{8}$. The treatment of locoregionally advanced penile squamous cell carcinoma (LAPSCC) is challenging. Due to the rarity of the disease and especially advanced stages of the disease, the exact role of extensive surgery and chemoradiation therapy is not well established. Furthermore, major surgery inevitably leads to large defects requiring reconstructive surgery. Rectus abdominis myocutaneous (RAM) and abdominal advancement flaps have an independent and constant blood supply, are (relatively) easily harvested, and provide substantial skin coverage and soft 
tissue. Chemoradiotherapy (CRT) is applied in squamous cell carcinoma from other organ sites, but its value has hardly been studied in penile cancer.

We retrospectively described the surgical and oncological outcomes in fifteen patients with LAPSCC undergoing surgical resection with RAM flaps or advancement flaps in chapter 7. Of fifteen patients, ten were treated with curative intent. Thirteen patients received induction chemotherapy. Thirteen patients (87\%) experienced wound complications, including five Clavien-Dindo grade III complications. In eleven of the fifteen patients (73\%), the disease recurred (median recurrence-free interval 106 days). The majority of recurrences (91\%) were locoregional, and in four cases the patient also had lesions in distant organs. Ten of the 15 patients (67\%) died of their disease. The overall median follow-up interval was 10.5 months. The results of this study show that large surgical procedures with reconstruction for LAPCC are associated with a risk of perioperative complications, including severe complications, and a cure rate of only $27 \%$. In fact these results indicate that surgery needs careful consideration, and that there is a need for alternative treatments. Lack of robust quality-of-lifedata is also a serious shortcoming in the decision process for this patient category. The study was limited by its retrospective design, the absence of quality-of-life measurements, and the cohort size.

In chapter $\mathbf{8}$ preliminary results are provided of a prospective cohort study aiming to evaluate the efficacy and toxicity of CRT for LAPSCC. We included patients fit for CRT with LRAPC with no evidence of distant metastases. Locally advanced was defined as a CT4, tumours with satellite lesions, tumours with a very large surface, tumours in the penile basis/bulb or tumours where radical resection was deemed unattainable. Regionally advanced tumour was defined as palpable nodes $>3 \mathrm{~cm}$ in diameter (cN2-3), fixed nodes or suspicion of extranodal extension (ENE) on imaging, or pelvic nodal involvement (cN3). The CRT treatment scheme was adapted from the protocol for anal SCC. consisting of 49.5 Gy in 33 daily fractions on affected inguinal and pelvic areas, combined with mitomycin C (intravenous injection on day one) and capecitabine (orally, twice daily) on radiation days. Primary tumours and PET/CT-positive tumour deposit received a higher dose of 59.5 in daily fractions of 1.8 Gy. Patients with incomplete responses were eligible for salvage surgery or palliative therapy.

Forty patients were included. One-year and two-year progression free survival (PFS) were both 32\%, overall survival (OS) was 70\% and 52\% respectively (median follow-up of 27 months). Upon first evaluation, responses were complete 
(35\%), partial (35\%) and progressive disease (30\%). At the end of follow-up, sixteen patients (40\%) are alive with no evidence of disease. In general, CRT was well-tolerated. Sixteen patients (40\%) experienced one or more therapy related severe toxicity (all grade 3) during therapy or follow-up. No therapy related grade 4 or 5 events occurred. Disease recurred or progressed in 26 patients. This study is limited by its small sample size and lack of direct comparison to treatment alternatives. With these acceptable survival and toxicity rates, CRT appears as a feasible therapy for locoregionally advanced penile cancer. It reduces the necessity of surgical resection and can result in long-term disease-free survival.

Chapter 9 provides a reflection on the findings of the research presented in this thesis and places our results in a larger perspective. 


\section{SAMENVATTING}

Peniskanker wordt in hoofdstuk 1 geïntroduceerd met een korte omschrijving van de epidemiologie, etiologie en risicofactoren, tumorimmunologie, beeldvorming en behandeling van de ziekte.

Hoofdstuk 2 en 3 behandelen immunologische aspecten van peniskanker. We vergeleken expressie van verscheidene immuunfactoren met ziekte-specifieke overleving (ZSO) en lymfekliermetastasen (LKM) bij diagnose. Daartoe gebruikten we gearchiveerd tumormateriaal. De rol van PD-L1 werd bestudeerd in hoofdstuk 2. PD-L1 is een zogenoemd "checkpoint" (controlepunt)-molecuul van het immuunsysteem dat tot expressie gebracht kan worden op tumorcellen of immuuncellen. Het remt de functie van T-cellen wanneer het zich bindt aan zijn receptor. Anti PD-L1/PD-1 immunotherapie kan dit mechanisme blokkeren en zo de aanval op de tumor door T-cellen versterken. We onderzochten PD-L1 expressie op verschillende plekken in de tumor-micro-omgeving (TMO): tumor, stroma en tumor-infiltrerende macrofagen (TIM). Ook noteerden we het patroon van PD-L1-expressie, zijnde diffuus of voornamelijk aan de tumor-stromarand.

Van de 200 tumoren waren er 96 (48\%) PD-L1+ (score 1\% of hoger). Van de PD-L1+ tumoren toonde er 59 (62\%) voornamelijk randexpressie en 79 (82\%) waren hoog-risico HPV (hrHPV) negatief, vergeleken met 75\% van het totale cohort $(p=0,03)$. In vergelijking met PD-L1-negatieve tumoren, hadden de expressiepatronen verschillende prognostische waarde, zowel in de hele groep als in de hrHPV-negatieve subgroep. In de multivariabele analyse bleek een randexpressiepatroon geassocieerd met afwezigheid van lymfekliermetastasen (odds ratio (OR) 0,4) terwijl diffuse expressie juist een associatie had met slechtere overleving (hazard ratio (HR) 2,58). Deze resultaten waren meer uitgesproken in de hrHPV'- subgroep (OR 0,25 en HR 3,92).

In hoofdstuk 3 werden meer immuunfactoren bestudeerd. Analyse omvatte eerder beschreven hrHPV-status, immunohistochemische scores van klassiek en niet-klassiek humaan leukocyt antigeen (HLA) klasse I, PD-L1, en nieuwe gegevens van TIM en cytotoxische en regulatoire T-cellen. Klinische en pathologische karakteristieken werden meegenomen, evenals uitgebreide opvolggegevens.

In de gehele groep ( $n=216$ ) werden diffuse PD-L1 tumorcelexpressie, CD163+ macrofaag-infiltratie, upregulatie van niet-klassiek HLA klasse I, en weinig infiltratie van stromale CD8 ${ }^{+}$T-cellen allen geassocieerd met LKM. In het 
multivariabele model bleef alleen PD-L1 expressie over als significante predictor voor LKM (OR 2,8, p = 0,05). Negatieve hrHPV status en diffuse PDL1 tumorexpressie werden significant geassocieerd met slechte overleving en bleven dat ook na correctie voor klinische parameters (HR 9,7, p < 0,01 en HR 2,8, $p=0,03)$. PD- L1 was de enige immuunfactor met verschillende expressie in HPV ${ }^{+}$ en $\mathrm{HPV}^{-}$tumoren, met meer expressie in de laatstgenoemde groep $(p=0,03)$.

In het HPV- cohort $(\mathrm{n}=158)$ werden LKM geassocieerd met diffuse tumorPD-L1-expressie, veel CD163+ macrofageninfiltratie, en weinig stromale CD8 ${ }^{+}$ T-celinfiltratie. De eerste twee parameters werden ook gelinkt aan ZSO. In het multivariabel regressiemodel bleef diffuse PD-L1 expressie significant ongunstig voor ZSO (HR 5,0, p < 0,01).

Deze resultaten benadrukken de complexiteit van de tumor micro-omgeving in peniskanker en wijzen richting meerdere mogelijke aangrijpingspunten voor immunotherapie. De hier beschreven immuunfactoren kunnen helpen bij risicostratificatie en moeten worden bestudeerd in klinisch onderzoek met immunotherapie om uiteindelijk naar geïndividualiseerde behandeling te leiden.

Hoofdstuk 4 geeft een overzicht van stadiëring en beeldvorming van peniskanker. Volgens de beschouwde literatuur is T-stadiëring gestoeld op lichamelijk onderzoek, maar kan MRI de sensitiviteit verhogen waar nodig. N-stadiëring is het meest complex voor kleine metastasen omdat die makkelijk te missen zijn. Voor de detectie van kleine metastasen heeft de dynamische schildwachtklierprocedure (SWKP) de voorkeur omdat het accurate pathologische stadiëring betreft zonder de bijwerkingen en complicaties van inguinale lymfeklierdissectie (ILKD). Voorafgaand aan de SWKP dient een echogeleide cytologische punctie gedaan te worden om onontdekte macrometastasen te voorkomen. De cytologische punctie is ook waardevol bij het aantonen van metastasen in verdachte liezen. Niettemin kunnen kleine metastasen gemist worden met elke niet- of minimaal invasieve stadiëringsmethode. Men moet blijven proberen de fout-negatievenratio daarvan verder te reduceren.

Zeer verdachte liezen verdienen een ILKD vanwege de grote therapeutische waarde. Voor M-stadiëring is conventionele anatomische beeldvorming aanbevolen. Van FDG-PET/CT is een hoge sensitiviteit beschreven. Diens waarde wordt verder geëvalueerd in hoofdstuk 5 en $\mathbf{6}$ voor zowel $\mathrm{N}$ - als M-stadiëring. 
Follow-up berust op lichamelijk onderzoek en echogeleide cytologische punctie. PET/CT heeft mogelijk een rol in lokaliseren van vermoedelijke recidieven maar is niet aanbevolen voor routinematige controle.

Hoofdstuk 6 is een uitgevoerde retrospectieve studie naar de PET/CT scan. In onze review vonden we aanwijzingen dat PET/CT vooral bruikbaar kan zijn bij de detectie van bekkenkliermetastasen en occulte afstandsmetastasen voorafgaand aan systemische chemotherapie en/of uitgebreide chirurgie. Om de patiënten die het meest waarschijnlijk profijt hebben van zulke therapieën beter te selecteren, onderzochten we PET/CT resultaten die waren gemaakt bij patiënten met klinisch evidente lymfekliermetastasering en/of grote primaire tumoren (grote T3 of T4). FDG-PET/CT had een hoge sensitiviteit en negatief voorspellende waarde (NVW) voor het stadiëren van bekkenklieren (sensitiviteit 85\%, specificiteit 75\%, NVW 90\%, positief voorspellende waarde (PVW) 65\%). FDG-PET/CT had ook een hoge PVW voor detectie van afstandsmetastasen (93\%) die werden gevonden in 23\% van de patiënten. Met deze testeigenschappen maakt PET/CT het mogelijk patiënten met bekkenkliermetastasen vroeg te selecteren voor multimodale behandeling en helpt PET/CT vergeefse behandelingen van patiënten met afstandsmetastasen te voorkomen. De bevindingen worden beperkt door de retrospectieve aard van de studie en het gebrek aan directe vergelijking met enkel een CT scan.

In hoofdstuk $\mathbf{7}$ en $\mathbf{8}$ bestuderen we patiënten die een uitvoerige behandeling behoeven. De behandeling vaneen locoregional gevorderd plaveiselcelcarcinoom van de penis (LGPCCP) is uitdagend. Omdat de ziekt erg zeldzaam is, en al helemaal gevorderde stadia, is de precieze rol van chirurgie en chemoradiotherapie daarvoor nog deels onduidelijk. Daarnaast leiden grote operaties onvermijdelijk tot grote defecten die op hun beurt reconstructieve chirurgie vereisen. Bij myocutane rectus abdominis (MRA) en abdominale opschuifplastieken is er een onafhankelijke en constante bloedtoevoer, de lappen zijn (relatief) gemakkelijk te oogsten, en voorzien in substantiële huidbedekking en weke delen massa. Chemoradiotherapie (CRT) wordt toegepast in plaveiselcelcarcinomen (PCC) van verschillende organen, maar de waarde ervan voor peniskanker is nog nauwelijks beschreven.

In hoofdstuk 7 beschreven we retrospectief de chirurgische en oncologische uitkomsten van vijftien patiënten met LGPCCP die behandeld werden met MRA- of opschuifplastieken. Van de vijftien werden er tien met curatieve intentie behandeld. Dertien patiënten kregen inductie chemotherapie. Dertien patiënten 
(87\%) kregen te maken met wondcomplicaties, waaronder vijf Clavien-Dindo graad III complicaties. Elf van de vijftien patiënten (73\%) kreeg een recidief (mediane ziektevrij interval 106 dagen). De meeste recidieven (91\%) was locoregionaal, in vier gevallen had de patiënt ook metastasen op afstand. Tien van de vijftien patiënten (67\%) stierven als gevolg van de ziekte. Het totale mediane follow-up-interval was 10,5 maand. De resultaten van deze studie laten zien dat grote chirurgische ingrepen met reconstructie voor LGPCCP geassocieerd zijn met een risico op complicaties, waaronder ook ernstige complicaties, alsmede een genezingspercentage van slechts $27 \%$. In feite wijzen deze resultaten erop dat chirurgisch ingrijpen zorgvuldig moet worden afgewogen en dat er behoefte is aan alternatieve behandelopties. Een gebrek aan robuuste kwaliteit-van-levendata is ook een ernstig tekortkomen bij besluitvorming met deze patiëntengroep. Deze studie werd beperkt door haar retrospectieve aard en het ontbreken van kwaliteit-van-leven-metingen en de cohortgrootte.

In hoofdstuk $\mathbf{8}$ geven we voorlopige resultaten van een prospectieve cohortstudie met als doel de effectiviteit en toxiciteit van chemoradiatie voor locoregionaal gevorderd peniscarcinoom te evalueren. We includeerden patiënten die fit genoeg waren voor CRT en definieerden LGPCCP zonder aanwijzingen voor afstandsmetastasen. Lokaal gevorderd werd gedefinieerd als cT4, tumoren met satellietlaesies, tumoren met een groot oppervlak, tumoren in de penisbasis of -bulbus, of tumoren waar radicale resectie anderszins onhaalbaar werd geacht. Regionaal gevorderd werd gedefinieerd als palpabele klieren met diameter $>3 \mathrm{~cm}$ (cN2/cN3), gefixeerde lymfeklieren of verdenking op extranodale groei (ENE) op beeldvorming, of bekkenkliermetastasering (N3).

Het CRT behandelschema was gebaseerd op het protocol voor anuscarcinomen, bestaande uit 49,5 Gy in 33 dagelijkse fracties op aangedane inguinale en iliacale gebieden, gecombineerd met mitomycine $\mathbf{C}$ (intraveneuze injectie op dag 1) en capecitabine (oraal, tweemaal daags) op bestralingsdagen. Primaire tumoren en PET/CT-positieve tumordeposities kregen een hogere dosis van 59,5 in dagelijkse fracties van 1,8 Gy. Patiënten met een incomplete respons kwamen in aanmerking voor aanvullende (salvage) chirurgie of palliatieve therapie.

Veertig patiënten werden geïncludeerd. 1-jaar en 2-jaar progressievrije overleving (PVO) waren beiden 32\%, totale overleving (TO) waren respectievelijk 70\% en 50\% (mediane follow-up 27 maanden). Bij de eerste evaluatie werden responses gemeten als compleet (35\%), partieel (35\%) en progressieve ziekte (30\%). Aan het einde van de follow-up waren zestien patiënten (40\%) in leven 
zonder tekenen van ziekte. Over het algemeen werd CRT goed verdragen. Zestien patiënten (40\%) kregen één of meer klachten van ernstige toxiciteit (allen graad 3) tijdens de behandeling of daarna. Er werden geen behandeling-gerelateerde graad 4 of 5 klachten gemeld. Die ziekte recidiveerde bij 26 patiënten (65\%). Deze studie werd beperkt door de kleine studiegroep en de afwezigheid van een tweede arm met alternatieve behandeling. Met deze acceptabele overlevingsen toxiciteitscijfers lijkt CRT een geschikte behandeling voor locoregionaal gevorderd peniscarcinoom. Het vermindert de noodzaak tot chirurgisch ingrijpen en kan resulteren in een langdurige ziektevrije overleving.

In hoofdstuk 9 reflecteren we op de bevindingen van het in dit proefschrift beschreven onderzoek. Daarnaast worden de resultaten in een bredere context geplaatst. 


$$
11
$$


Chapter 11

Appendices 


\section{LIST OF ABBREVIATIONS}

\begin{tabular}{|c|c|}
\hline$A E$ & adverse event \\
\hline ASA & American Society of Anesthesiologists \\
\hline$A \cup C$ & area under the curve \\
\hline AWD & alive with disease \\
\hline$\beta 2 \mathrm{M}$ & Beta-2-microglobulin \\
\hline BMI & body mass index \\
\hline$C D$ & cluster of differentiation \\
\hline $\mathrm{Cl}$ & confidence interval \\
\hline CRT & chemoradiotherapy \\
\hline CTCAE & Common Terminology Criteria for Adverse Events \\
\hline CT & computed tomography \\
\hline DD / DOD & died of disease \\
\hline DSS & disease specific survival \\
\hline DSM & disease specific mortality \\
\hline DSNB & dynamic sentinel node biopsy \\
\hline DVT & deep venous thrombosis. \\
\hline EAU & European Association of Urology \\
\hline EGFR & epithelial growth factor receptor \\
\hline ENE & extranodal extension \\
\hline$-f$ & free flap \\
\hline FDA & food and drug administration \\
\hline FDG & ${ }^{18} \mathrm{~F}$-fluorodeoxyglucose \\
\hline FFPE & formalin fixed and paraffin embedded \\
\hline FN & false negative \\
\hline FNAC & fine needle aspiration cytology \\
\hline FNR & false negative rate \\
\hline FP & false positive \\
\hline FU & follow-up \\
\hline Gy & gray \\
\hline HLA & human leukocyte antigen \\
\hline HNSCC & head and neck squamous cell carcinoma \\
\hline HPV & human papilloma virus \\
\hline$H R$ & hazard ratio \\
\hline hrHPV & high risk human papilloma virus (also oncogenic HPV) \\
\hline ICG & indocyanine green \\
\hline iChT & induction chemotherapy \\
\hline IFN- $\gamma$ & interferon gamma \\
\hline
\end{tabular}




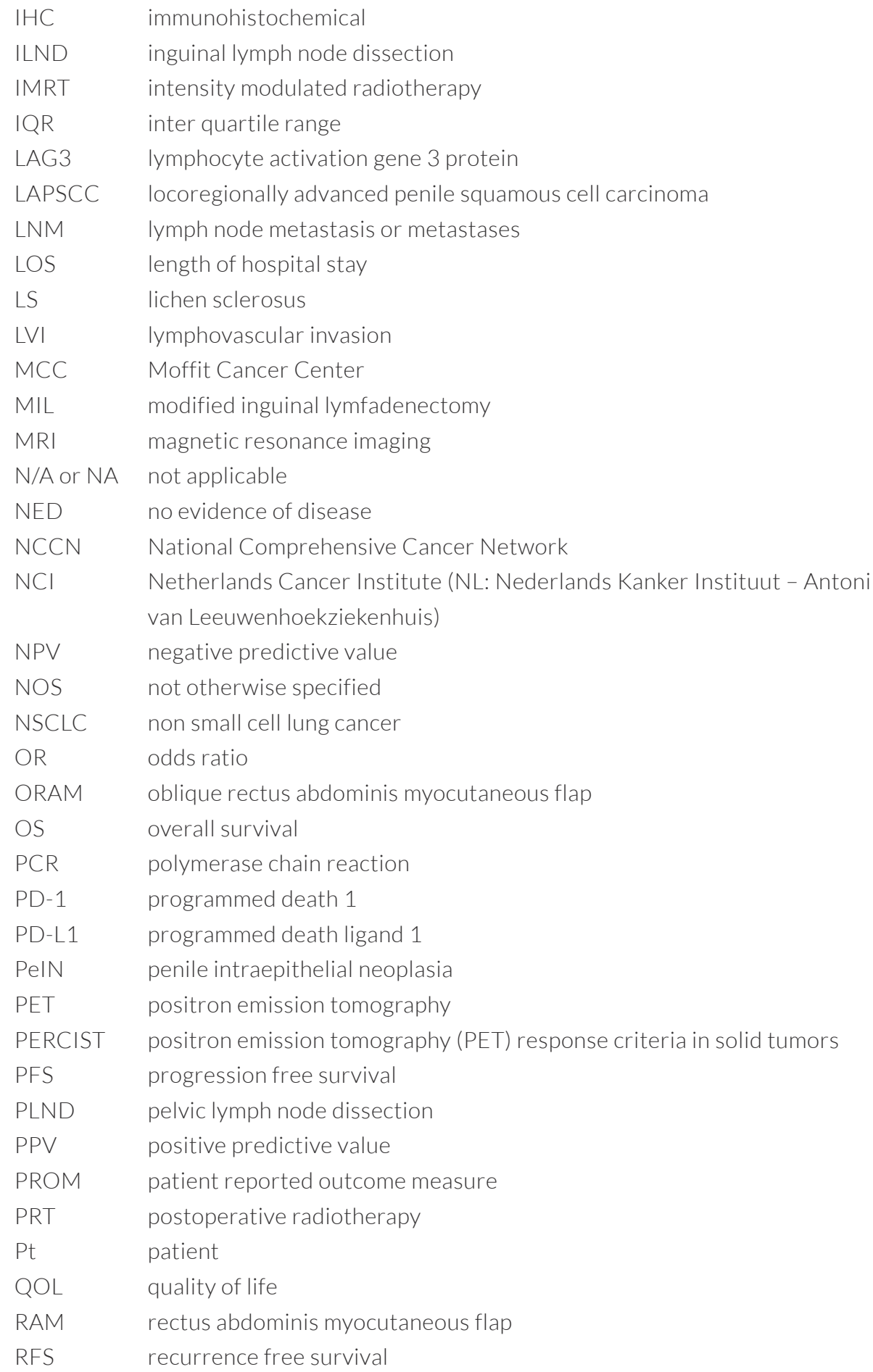




$\begin{array}{ll}\text { ROC } & \text { receiver operating characteristic } \\ \text { RS } & \text { recurrence site } \\ \text { SCC } & \text { squamous cell carcinoma } \\ \text { SIB } & \text { simultaneous integrated boost } \\ \text { SNB } & \text { sentinel node biopsy } \\ \text { SPECT } & \text { single photon emission computed tomography } \\ \text { TFL } & \text { tensor fasciae latae muscle flap } \\ \text { TFM } & \text { tumour-free margins } \\ \text { TIM } & \text { tumor infiltrating macrophage } \\ \text { TNM } & \text { Tumor Node Metastasis } \\ \text { TME } & \text { tumor microenvironment } \\ \text { TN } & \text { true negative } \\ \text { TP } & \text { true positive } \\ \text { TPF } & \text { docetaxel, cisplatin, fluorouracil } \\ \text { Treg } & \text { regulatory T-cell } \\ \text { UICC } & \text { Union for International Cancer Control } \\ \text { US } & \text { Ultrasound } \\ \text { USA } & \text { United States of America } \\ \text { UTI } & \text { urine tract infection } \\ \text {-V } & \text { vascularized } \\ \text { VAS } & \text { visual analogous scale } \\ \text { VRAM } & \text { vertical rectus abdominis myocutaneous flap } \\ \text { WHO } & \text { world health organization } \\ & \end{array}$




\section{REVIEW COMMITTEE}

Prof. dr. L.M.O. de Kort

Professor of Urology

Prof. dr. M.G.E.H. Lam

Professor of Nuclear Medicine

Prof. dr. M.R. van Dijk

Professor of Pathology

Prof. dr. T.D. de Gruijl

Professor Translational Tumor Immunology

Prof. dr. J.L.H.R. Bosch

Professor of Urology

Prof. dr. H.G. van der Poel

Professor of Urology 


\section{LIST OF COAUTHORS}

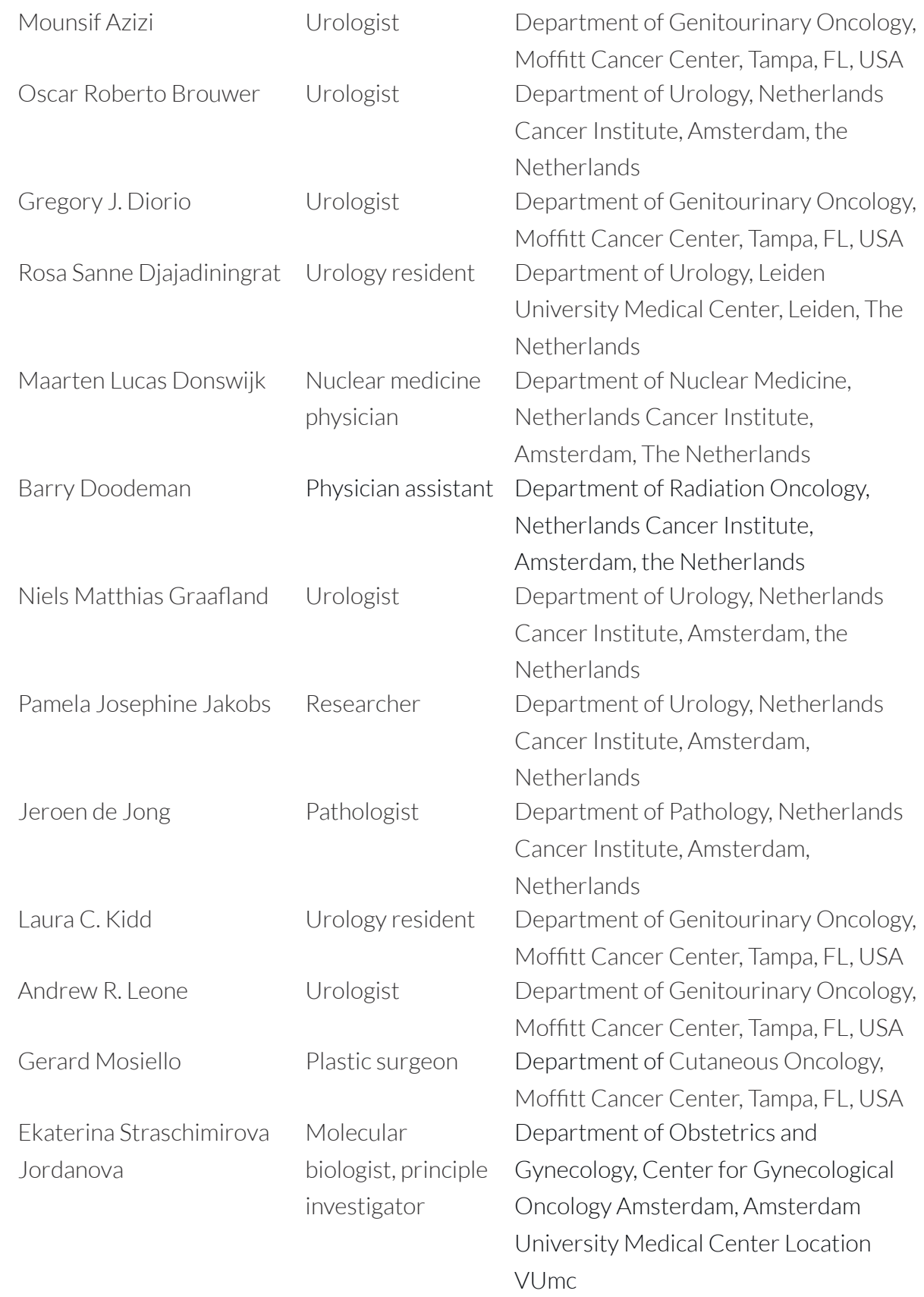




\begin{tabular}{|c|c|c|}
\hline Anne Marijne Heeren & $\begin{array}{l}\text { Biomedical } \\
\text { researcher }\end{array}$ & $\begin{array}{l}\text { Department of Obstetrics and } \\
\text { Gynecology, Center for Gynecological } \\
\text { Oncology Amsterdam, Amsterdam } \\
\text { University Medical Center Location } \\
\text { VUmc }\end{array}$ \\
\hline Michiel van der Heijden & Medical oncologist & $\begin{array}{l}\text { Department of Medical Oncology, } \\
\text { Netherlands Cancer Institute, } \\
\text { Amsterdam, the Netherlands }\end{array}$ \\
\hline Simon Horenblas & $\begin{array}{l}\text { Urologist, principle } \\
\text { investigator }\end{array}$ & $\begin{array}{l}\text { Department of Urology, Netherlands } \\
\text { Cancer Institute, Amsterdam, the } \\
\text { Netherlands }\end{array}$ \\
\hline Vincent van der Noort & Statistician & $\begin{array}{l}\text { Department of Biometrics, Netherlands } \\
\text { Cancer Institute, Amsterdam, the } \\
\text { Netherlands }\end{array}$ \\
\hline Floris Jan Pos & $\begin{array}{l}\text { Radiation } \\
\text { oncologist }\end{array}$ & $\begin{array}{l}\text { Department of Radiation Oncology, } \\
\text { Netherlands Cancer Institute, } \\
\text { Amsterdam, the Netherlands }\end{array}$ \\
\hline Joyce Sanders & Pathologist & $\begin{array}{l}\text { Department of Pathology, Netherlands } \\
\text { Cancer Institute, Amsterdam, } \\
\text { Netherlands }\end{array}$ \\
\hline Philippe Edouard Spiess & Urologist & $\begin{array}{l}\text { Department of Genitourinary Oncology, } \\
\text { Moffitt Cancer Center, Tampa, FL, USA }\end{array}$ \\
\hline $\begin{array}{l}\text { Helene Hoegsbro } \\
\text { Thygesen }\end{array}$ & $\begin{array}{l}\text { Statistician, } \\
\text { principle science } \\
\text { advisor }\end{array}$ & $\begin{array}{l}\text { Department of Conservation, Wellington, } \\
\text { New Zealand }\end{array}$ \\
\hline Erik Vegt & $\begin{array}{l}\text { Nuclear medicine } \\
\text { physician }\end{array}$ & $\begin{array}{l}\text { Department of Radiology and Nuclear } \\
\text { Medicine, Erasmus MC University } \\
\text { Medical Center, Rotterdam, The } \\
\text { Netherlands }\end{array}$ \\
\hline $\begin{array}{l}\text { Michelle Wilhelmina } \\
\text { Johanna Versleijen, }\end{array}$ & $\begin{array}{l}\text { Nuclear medicine } \\
\text { physician }\end{array}$ & $\begin{array}{l}\text { Department of Nuclear Medicine, } \\
\text { Netherlands Cancer Institute, } \\
\text { Amsterdam, The Netherlands }\end{array}$ \\
\hline $\begin{array}{l}\text { Gerrit Lambertus } \\
\text { Vrijenhoek }\end{array}$ & Physician assistant & $\begin{array}{l}\text { Department of Radiation Oncology, } \\
\text { Netherlands Cancer Institute, } \\
\text { Amsterdam, the Netherlands }\end{array}$ \\
\hline Kamran Zargar & Urologist & $\begin{array}{l}\text { Department of Genitourinary Oncology, } \\
\text { Moffitt Cancer Center, Tampa, FL, USA }\end{array}$ \\
\hline
\end{tabular}




\section{PUBLICATIONS \& PRESENTATIONS}

\section{Journal publications}

1. Rafael TS, de Vries HM, Ottenhof SR, Hofland I, Broeks A, de Jong J, Bekers E, Horenblas S, de Menezes RX, Jordanova ES, Brouwer OR. Distinct Patterns of Myeloid Cell Infiltration in Patients With hrHPV-Positive and hrHPV-Negative Penile Squamous Cell Carcinoma: The Importance of Assessing Myeloid Cell Densities Within the Spatial Context of the Tumor Front. Immunol. 2021 Jun 14. 12:682030. doi.org/10.3389/fimmu.2021.682030

2. Ottenhof SR, Djajadiningrat RS, Versleijen MWJ, Donswijk ML, van der Noort V, Brouwer OR, Graafland NM, Vegt E, Horenblas S. F-18 Fluorodeoxyglucose Positron Emission Tomography with Computed Tomography Has High Diagnostic Value for Pelvic and Distant Staging in Patients with High-risk Penile Carcinoma. Eur Urol Focus. 2021 Mar 5:S2405-4569(21)00055-9. doi: 10.1016/j. euf.2021.02.012. Online ahead of print.

3. De Vries HM, Ottenhof SR, van der Heijden MS, Pos FJ, Horenblas S, Brouwer OR. Management of the penile squamous cell carcinoma patient after node positive radical inguinal lymph node dissection: current evidence and future prospects. Curr Opin Urol. 2020 Mar;30(2):223-228. Review.

4. De Vries HM, Ottenhof SR, Horenblas S, van der Heijden MS, Jordanova ES. Defining the Tumor Microenvironment of Penile Cancer by Means of the Cancer Immunogram. Eur Urol Focus. 2019 Mar 9. Epub 2019 Mar 9. Review.

5. Johnstone PAS, Boulware D, Djajadiningrat RS, Ottenhof SR, Necchi A, Catanzaro M, Ye D, Zhu Y, Nicolai N, Horenblas S, Spiess PE. Primary Penile Cancer: The Role of Adjuvant Radiation Therapy in the Management of Extranodal Extention in Lymph Nodes. Eur Urol Focus. 2018 Oct 13. doi: 10.1016/j.euf.2018.10.07 Epub 2018 Oct 14.

6. Ottenhof SR, Djajadiningrat RS, Thygesen HH, Jakobs PJ, Jóźwiak K, Heeren AM, de Jong J, Sanders J, Horenblas S, Jordanova ES. The Prognostic Value of Immune Factors in the Tumor Microenvironment of Penile Squamous Cell Carcinoma. Front Immunol. 2018 Jun11. doi: 10.3389/fimmu.2018.01253.

7. Ottenhof SR, Leone A, Djajadiningrat RS, Azizi M, Zargar-Shoshtari K, Kidd LC, Diorio G, Mosiello G, Graafland NM, Spiess PE, Horenblas S. Surgical and Oncological Outcomes in patients after Vascularised Flap Reconstruction for Locoregionally Advanced Penile Cancer. Eur Urol Focus. 2018 Feb 9. doi: 10.1016/j.euf.2018.02.002. Epub 2018 Feb 9.

8. Ottenhof SR, Vegt E. The role of PET/CT imaging in penile cancer. Trans Androl Urol. 2017 Oct;6(5):833-838. Review. 
9. Baumgarten A, Chipollini J, Yan S, Ottenhof SR, Tang DH, Draeger D, Protzel C, Zhu Y, Ye DW, Hakenberg OW, Horenblas S, Watkin NA, Spiess PE. Penile sparing surgery for penile cancer: a multicenter international retrospective cohort. J Urol. 2018 May;199(5):1233-1237.

10. Tang DH, Yan S, Ottenhof SR, Draeger D, Baumgarten AS, Chipollini J, Protzel C, Zhu Y, Ye DW, Hakenberg OW, Horenblas S, Watkin NA, Spiess PE. Laser ablation as monotherapy for penile squamous cell carcinoma: A multi-center cohort analysis. Urol Oncol. 2018 Apr;36(4):147-152.

11. Chipollini J, Yan S, Ottenhof SR, Zhu Y, Draeger D, Baumgarten AS, Tang DH, Protzel C, Ye DW, Hakenberg OW, Horenblas S, Watkin NA, Spiess PE. Surigcal management of penile carcinoma in situ: results from an international collaborative study and review of the literature. BJU Int. 2018 Mar;121(3):393398.

12. Ottenhof SR, Leone AR, Horenblas S, Spiess PE, Vegt E. Advancements in staging and imaging for penile cancer. Curr Opin Urol. 2017 Nov;27(6):612-620.

13. Tang DH, Yan S, Ottenhof SR, Draeger D, Baumgarten AS, Chipollini J, Protzel C, Zhu Y, Ye DW, Hakenberg OW, Horenblas S, Watkin NA, Spiess PE. Glansectomy as primary management of penile squamous cell carcinoma: an International Study Collaboration. Urology. 2017 Nov;109:140-144.

14. Necchi A, Pond GR, Raggi D, Ottenhof SR, Djajadiningrat RS, et al. Clinical Outcomes of Perioperative Chemotherapy in Patients With Locally Advanced Penile Squamous Cell Carcinoma: Results of a Multicenter Analysis. Clin Genitourin Cancer. 2017 Oct;15(5):548-555.e3.

15. Ottenhof SR, Djajadiningrat RS, de Jong J, Thygesen HH, Horenblas S, Jordanova ES. Expression of Programmed Death Ligand 1 (PD-L1) in penile cancer is of prognostic value and associated with HPV status. J Urol. 2017 Mar;197(3 Pt 1):690-697. is Publication of the week, NKI-AVL Library

16. Ottenhof SR, de Graaf P, Soeterik TF, Neeter LM, Zilverschoon M, Spinder M, Bosch JL, Bleys RL, de Kort LM. Architectuur van het Corpus Spongiosum: een anatomische studie. Tijdschr Urol (2016). doi:10.1007/s13629-016-0159-7.

17. Ottenhof SR, de Graaf P, Soeterik TF, Neeter LM, Zilverschoon M, Spinder M, Bosch JL, Bleys RL, de Kort LM. Architecture of the Corpus Spongiosum: An Anatomical Study. J Urol. 2016 Sep;196(3):919-25.

18. Ottenhof SR / van Hulst AM / Kroon W / van der Linden ES / Nagtzaam L, Wegner I, Gunning AC, Grolman W, Braunius W. Grade of dysplasia and malignant transformation in adults with premalignant laryngeal lesions. Head \& Neck. 2016 Apr;38 Suppl 1:E2284-90. Review. 


\section{Book publications}

Textbook of Penile Cancer. Muneer, Horenblas (eds.) Springer (2016) $2^{\text {nd }}$ ed. ISBN 978-3-319-33220-8.

- Epidemiology of Penile Cancer. Sarah R. Ottenhof, Maaike C. G. Bleeker, Daniëlle A. M. Heideman, Peter J. F. Snijders, Chris J. L. M. Meijer, Simon Horenblas. Pages 1-9.

- Etiology of Penile Cancer. Sarah R. Ottenhof, Maaike C. G. Bleeker, Daniëlle A. M. Heideman, Peter J. F. Snijders, Chris J. L. M. Meijer, Simon Horenblas. Pages 11-15.

- Management of Lymph Nodes. Sarah R. Ottenhof, Niels M. Graafland, Simon Horenblas. Pages 167-1994.

- Follow-Up of Patients with Penile Cancer. Simon Horenblas, Sarah R. Ottenhof, Niels M. Graafland. Pages 303-309.

Penile Cancer. Spiess (ed.) Humana Press 2016, (2 ${ }^{\text {nd }}$ ed). ISBN 9781493966776.

- Dynamic Sentinel Node Biopsy and FDG-PET/CT for Lymph Node Staging in Penile Cancer. Niels M. Graafland, Sarah R. Ottenhof, Renato A. Valdés Olmos, Erik Vegt. Pages 45-53

\section{Web publications}

EAU Patient Information website, www.patients.uroweb.org

- Penis Cancer. S.R. Ottenhof and A. Parnham, 2018. Access via https:// patients.uroweb.org/library/penis-cancer/

- Penile Curvature / Peyronie's disease. M. Behrent, S.R. Ottenhof and G. Patruno. Access via https://patients.uroweb.org/library/penilecurvature/

\section{Presentations}

1. Externe Refereeravond Urologie, Breda. Peniscarcinoom, nieuwste inzichten. 10 nov 2020

2. Bijeenkomst Taskforce Nederland HPV kankervrij, Rotterdam. Urologie en HPV. 14 feb 2020

3. EAU Annual Congress (EAU18), Kopenhagen, Denemarken. Tumour immunology of penile cancer (poster) 16 mrt 2018

4. EAU Annual Congress (EAU18), Kopenhagen, Denemarken. Use of FDG-PET/CT for staging pelvic lymph nodes (poster) 16 mrt 2018 放 Best poster of the session 
5. NVU najaarsvergadering, Nieuwegein. Het gebruik van PET/CT-scans voor het stadiëren van bekkenklieren van peniscarcinoompatiënten met lieskliermetastasen. 3 nov 2017

6. Dutch Tumor Immunology Meeting, Breukelen. Tumor escape in the microenvironment of penile carcinoma. 22 juni 2017

7. American Urological Association Annual Meeting (AUA2017), Boston, USA. Tumor escape in the microenvironment of penile carcinoma (poster). 13 mei 2017

8. Refereeravond UMCU, Utrecht. Beeldvorming en stadiëring van peniscarcinomen. 18 apr 2017

9. EAU Section of Urological Research (ESUR16), Parma, Italy. Tumour escape in the microenvironment of penile carcinoma. 22 okt 2016

10. Onderzoeksschool Oncologie Amsterdam retreat 2016, Renesse. Tumour escape in the microenvironment of penile carcinoma. 5 okt 2016 is 2e prijs voor beste presentatie

11. NVU voorjaarsvergadering, Leiden. Architectuurvan het corpus spongiosum. 20 mei 2016

is Genomineerd voor de Vlietstraprijs

12. NVU voorjaarsvergadering, Leiden. Immunologie van het peniscarcinoom. 20 mei 2016

13. EAU Annual Congress (EAU16), München, Duitsland. Immunotherapy in Penile Carcinoma - Programmed Death Ligand 1 is a potential target (poster). 12 mrt 2016

is Best poster of the session

14. 28 Symposium voor Experimenteel Onderzoek Heelkundige Specialismen (SEOHS), Leiden. De architectuur van het corpus spongiosum. 11 dec 2015

15. NVU najaarsvergadering, Nieuwegein. Programmed Death Ligand 1 is een mogelijk aangrijpingspunt voor immunotherapie in peniscarcinoom. 6 nov 2015

16. OOA retreat 2015, Renesse. Immunotherapy in Penile Carcinoma - PD-L1 is a potential target (poster) 14 okt 2015

17. Refereeravond UMCU, Utrecht. De structuur van het corpus spongiosum urethrae, eerste resultaten van een anatomische studie. 10 feb 2015 


\section{ABOUT THE AUTHOR}

Sarah Rosanne Ottenhof was born to Britta Verboom and Ferdinand Ottenhof on the $8^{\text {th }}$ of July in Wageningen, the Netherlands. She grew up with her elder sister Eva and two elder brothers Anne and Maarten.

After graduating from secondary school (Karel de Grote College, Nijmegen) she travelled to Central America where she learned Spanish and participated in a cultural association in Honduras. In 2007 she started medical school at University Utrecht.

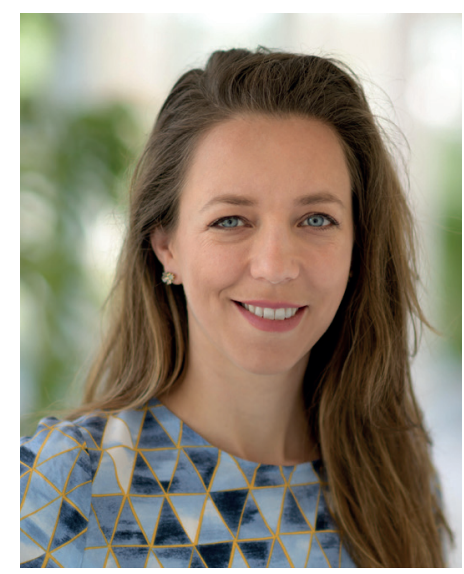

Her interest in urology was born during a surgical rotation and she continued with a combined clinical and research internship at the urology department of the University Medical Center Utrecht under the supervision of drs. MTWT Lock, prof. dr. LMO de Kort and prof. dr. RLAW Bleijs. The results of that anatomical study were published in the Journal of Urology. During her medical training Sarah also went abroad to Argentina (ENT medicine) and Ghana (anaesthesia/urology).

After receiving her medical degree she started her PHD training at the Netherlands Cancer Institute in 2015 under the supervision of prof. dr. S Horenblas and dr. ES Jordanova. Her research mainly focused on immunological aspects of penile cancer, staging and imaging of penile cancer, and the evaluation of old and new therapies for advanced stages of the disease. In addition to scientific journal papers Sarah contributed to books on penile cancer and wrote patient information leaflets as a member of the working group on patient information of the European Association of Urology (EAU).

In July 2018 Sarah started working as a medical officer (resident not in training, ANIOS). She worked at the urology departments of Tergooi hospital, Sophia Children's hospital and Amphia hospital. She is currently appointed as surgical resident in training at the IJsselland hospital in Capelle aan den IJssel as part of her urology training at the Erasmus Medical Center in Rotterdam.

She is happily together with Jannes ten Berge, they currently live in Rotterdam. 


\section{DANKWOORD}

Kort voordat ik afstudeerde solliciteerde ik voor dit onderzoek. In mijn brief schreef ik over een "ideale start van mijn loopbaan binnen de urologie". Dat bleek alleszins waar. De tijd in het Antoni van Leeuwenhoekziekenhuis koester ik zeer.

Mijn promotor Simon Horenblas. Wat ben ik je dankbaar. Het onderzoek paste goed bij mij, de begeleiding evenzeer. Je vertrouwen en geduld waren een basis voor goed gedijen. Ik voelde mij zowel vrij als verzekerd van steun. Een heel enkele keer was je streng (Zo mag je van mij niet fietsen) waardoor ik nu fietslampjes én een proefschrift heb.

Mijn copromotor Katja Jordanova. Jouw onbegrensde gedrevenheid voor je vak is inspirerend en aanstekelijk. Ik heb ontzettend veel van je geleerd en ben je zeer erkentelijk voor het geduld dat je daar soms voor moest opbrengen. Het is een voorrecht altijd op jou te mogen rekenen.

Leden van de promotiecommissie dank voor het beoordelen van dit proefschrift.

Stichting Lucendi Foundation en diegene die anoniem wil blijven, dank voor de financiële steun van dit onderzoek.

Alle coauteurs hartelijk dank voor jullie onmisbare bijdrage aan dit proefschrift. Many thanks to the international colleagues in the penile cancer research field for their direct or indirect contributions to this thesis.

De statistici Helene Thygesen, Vincent van der Noort en Katarzyna Jóźwiak, ik heb ervan genoten de uitdaging van weinig-patiënten-en-veel-vragen telkens samen aan te gaan. Tony "Query" van der Velde dank voor de hulp met de database. Core facility dank voor alle hulp en faciliteiten waar ik gebruik van mocht maken.

Urologen in het AVL dank voor alle data, hulp, interesse en aandacht bij het oefenen van presentaties. In het bijzonder Oscar Brouwer, sinds enkele jaren hoofd van het peniskankeronderzoek. De gedrevenheid waarmee jij je op dit werk hebt gestort is groot en heeft al snel vruchten afgeworpen. Dank voor je betrokkenheid bij de laatste fase van mijn onderzoek. Verpleegkundig specialisten Erik van Muilekom, Corinne Tillier en Eva Offringa dank voor het werk met peniskanker. 
Jong bier moet gisten en wat was het een feest. Collega onderzoekers uit het O-gebouw en de buitengewesten: Anna 2x, Daphne, Fleur, Hester, Joris, Jos, Klaske, Lianne, Lisanne, Linde, Lotte, Louisa, Luuk, Maartje, Marieke, Marnix, Martijn, Mathilde, Mette, Nikki, Pien, Rebecca 2x, Ruud, Sheima, Sophie, Vera en Willem. Dit promotietraject was niet half zo leuk geweest zonder jullie. Dank voor de vele borrels, lunches, koffiemomenten, tochtjes op de boot van Arthur, etc. Speciale dank voor de legendarische wintersportvakanties (amateurclub Rosanne, Ann-Jean, Marije en Rebecca). Hulde aan "Busje O" Marit, Max, Hanneke, Juliette, Sanne en de heerlijke huwelijksfeesten van Minke, Ravi en Rosa. Yoga met Tessa en Lisette, later met Simone (Release your eyeballs). Niet te vergeten Nick de stickerkoning. Derma queens Eva en Viola, we zien elkaar in het EMC.

Lieve Simone en Merijn, wat een geluk had ik met jullie als kamergenoten. De markt, café café, en de mooiste figuur uit mijn proefschrift, dank! Charlotte en Joost, de ontelbare lollige momenten hebben mijn werkplezier met meer dan een "trend naar significantie" doen stijgen.

Soumaya en Ruben, jullie zijn een absolute verrijking van mijn onderzoekstijd geweest. Dank daarvoor! Noëlle dank voor de prettige samenwerking. Het is helaas (nog) niet gekomen tot een gezamenlijke publicatie.

Dank Ivar Bleumer voor het wekken van mijn interesse in de urologie. Tycho Lock en Paul Veenboer voor een onvergetelijk leuke semi-artsstage. Laetitia de Kort en Petra de Graaf voor mijn wetenschapsstage en de kansen daarna.

Simon's kroost ofwel masters of urology: dank voor de dolle uitjes, het trouw bezoeken van de peniskankersessies en het vele voorwerk. Team penis in mijn hart. Rosa, ik had me geen betere voorganger kunnen wensen dan jij. Hielke-Martijn, dank voor je zorgvuldigheid en je steun bij de laatste loodjes. Laura jij staat altijd met raad en daad voor me klaar.

Mijn collega's van het klinische werk en de urologen in Tergooi, Sophia en Amphia: dank voor de leuke en leerzame tijd. Arnout, Kèren en buddy Kim, dank voor de aanmoedigingen. Fieke, Belle, Anne en Winesh: het is gelukt! Dank voor alles.

Mijn leven lang ben ik gezegend met een aantal trouwe vrienden en vriendinnen. Joas en Myrte wat zijn we groot geworden. Suzan wat een treffer dat jouw vriend een van de weinigen is die ook de inhoud van dit boek gaat lezen. Cris ik bof maar 
met jouw talent voor genieten. Dank aan de dokters, Chantal voor het successen vieren, Lisa dat ik na al die jaren nog steeds op je kan rekenen. Biaina voor je immer wijze raad. Annelinne zonder jou was het al heel vroeg mis gegaan met mijn artsencarrière. Je bent een engel.

Elies al snel nadat wij collega's waren, werden we dikke vriendinnen. Niets bleef onbesproken (Trouwens pikkie..) en we werden zelfs huisgenoten. Nog steeds kan ik altijd bij je terecht (Hee von P). Je bent een van de meest loyale mensen die ik ken en ik kijk uit naar een leven lang collega's en vriendinnen zijn.

Anne de oudste van mijn geniale Sibs. Ik denk dat onderzoek eigenlijk ook goed bij jou past, al denk jij (nog) van niet. Je bent een voorbeeld voor me, én een paranimf (klasse Saar!).

Mijn familie, Rudi, Malkanthi, Maarten, Jytte, Eva, en Jan Jaap, dank voor het warme thuis, de onvoorwaardelijke steun, goede adviezen en het vertrouwen. Mam, toen jij tijdens mijn artsenopleiding uitsprak dat je onderzoek wel bij mij vond passen, had ik nooit gedacht dat je gelijk had. Dank voor je liefde en steun. Mijn vader (overleden 2008) zou ik vooral willen laten zien hoe gelukkig ik ben, en dat ik Jannes heb. Vergeleken daarmee is deze prestatie onbelangrijk. Familie van Jan dank voor een immer warm onthaal en John, dank voor de prachtige omslag.

Lieve Jan, door jou heb ik me het meest gesteund gevoeld de afgelopen jaren. Je bent een ster in ontspannen en plezier maken. Jouw zorgen en troost waren een zegen op moeilijke momenten (Kom maar bij Jantje). Je bent superlief. Ik kan alleen maar hopen dat ik jou net zo gelukkig maak als jij mij. 


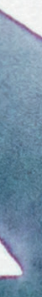

